\title{
Rethinking Dredging: A quantitative analysis of dam removal techniques
}

\author{
A Dissertation Presented to \\ The Faculty of the School of Engineering and Applied Science \\ University of Virginia \\ In Partial Fulfillment \\ Of the Requirements for the Degree \\ Doctor of Philosophy (Civil and Environmental Engineering)
}

By

Kristen M. Cannatelli

August 2013 


\section{APPROVAL SHEET}

The thesis submitted in partial fulfillment of the requirements for the degree of Doctor of Philosophy (Civil and Environmental Engineering)

Kristen M. Cannatelli, Author

This thesis has been read and approved by the examining committee:

Dr. Joanna C. Curran, Advisor

Dr. Teresa B. Culver, Chair

Dr. Patricia Wiberg

Dr. Richard Miksad

Dr. Winston Lung

Accepted for the School of Engineering and Applied Science:

Dean, School of Engineering And Applied Science

August 2013 
In memory of Leonard A. Cannatelli, Sr, who showed me what it means to work hard and Francis P. Cannatelli, who never let me quit. 


\begin{abstract}
The number of dams in the U.S. is estimated at over 2 million. Most are small dams, less than 4 meters high, built approximately 100 years ago. Many are structurally deficient, no longer in use, and are being removed with limited understanding of how the river system will be affected. A new approach to engineering dam deconstruction and managing the sediment impounded by small dams is needed that will reduce the ecological uncertainty about dam removal, address stake holder concerns, and reduce the economic expenditure of dredging that is associated with dam removal. Dredging sediment from behind a dam is common due to uncertainties associated with releasing it downstream. At the same time, the lack of sediment supply downstream leads to channel and back erosion and often necessitates expensive river and bank restoration projects.
\end{abstract}

This dissertation provides a direct comparison and analysis of five common methods of dam deconstruction: removal in horizontal stages from the top; removal in horizontal stages with portions of the side left in place; removal in vertical stages from the side; removal in vertical stages from the center; removal in a single-stage (also simulating dam failure), in combination with adjustments to the flow rate to simulate low flow and flood conditions as well as three sediment types scaled from typical dam removal scenarios. All of the experiments took place in a $9 \mathrm{~m}$ long flume in the Sustainable Rivers lab at the University of Virginia.

The flow rate had the greatest impact on downstream channel behavior following dam removal, with high flows resulting in increased quantities of sediment transported out of the systems and low flow rates corresponding to instream channel deposition. The addition of silt to the sediment mixture resulted in the downstream sediment wave moving more slowly through the downstream channel under low flows. The removal of the portion of the structure that brought the elevation of the dam below the elevation of the reservoir sediment had the largest impact on the downstream channel behavior, corresponding to the various deconstruction methods. The results of this research will make dam removal more accessible by reducing or eliminating the costs associated with unnecessary dredging of uncontaminated sediments prior to dam removal. 


\section{Acknowledgements}

\section{A river cuts through a rock, not because of its power, but its persistence}

Undertaking this $\mathrm{PhD}$ has been a truly life-changing experience for me and it would not have been possible without the support and encouragement that I received from many people, especially my immediate family: Mom, Troy, Colleen and Bocephus.

I also would like to thank my advisor, Dr. Joanna Curran. I appreciate all her contributions of time, ideas and funding to make my $\mathrm{PhD}$ experience possible. Her guidance and support have shaped my career and opened up opportunities that I never thought were possible.

My committee members: Dr. Patricia Wiberg, Dr. Teresa Culver, Dr. Wu-Seng Lung and Dr. Richard Miksad, for their time and advice in improving my dissertation work and overall educational experience at the University of Virginia.

I gratefully acknowledge the funding sources that made my $\mathrm{PhD}$ work possible, in particular the National Science Foundation (NSF) and the Graduate Assistance in Areas of National Need (GAANN) program of the U.S. Department of Education.

The members of the sustainable rivers lab group have contributed immensely to my experience at the University of Virginia, in particular Lu Tan, an original member and great resource in setting up the flume; Kevin Waters, a constant source of encouragement, buffer for ideas and high-five supplier; and honorary group member Jim Danberg, for his countless hours spent fixing equipment issues and helping me fabricate all of the necessary pieces for my experiments. I would also like to thank my most dedicated undergraduate summer students, Ellen Buckley and Mary Beth Brown, for their countless hours spent running sediment samples and putting up with "call me maybe" on repeat all summer long. Other grad students that I have had the pleasure with or alongside of are Amy Grady, Jenny Hansen, Stavros Carlos, Juan Ruiz and Alicia Nobles in addition to the numerous students that have come through the lab.

My time at the University of Virginia was made enjoyable in large part due to the many friends and groups that became a part of my life. I am grateful for the time spent with wonderful friends and all of the great memories that we've shared. My time at UVA was also enriched by my involvement with the St. Thomas Aquinas Catholic Church (Psalm 46:5); the Junior League of Charlottesville, the Boys and Girls Club of Charlottesville, and the UVA club water polo team. A special thank you to the sorority, Erin Kallman and Rachel Baker, for getting me through the first two years of grad school with tons of laughs and celebrations. As well as my extended Charlottesville family, especially Lauren Connor, Seth Berkowitz, and Adam and Laura Long.

Thank you.

Kristen M. Cannatelli University of Virginia 


\section{Table of Contents}

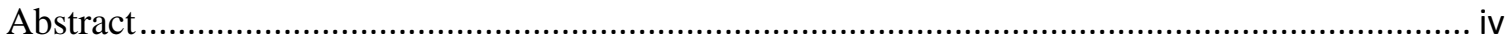



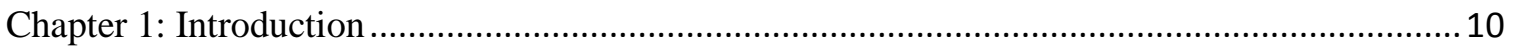

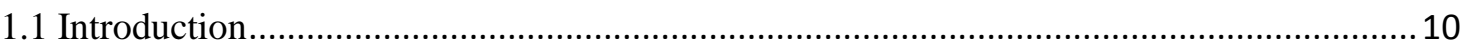



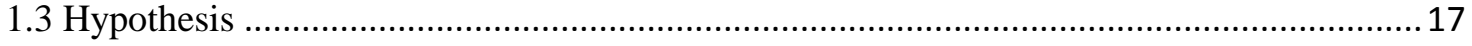

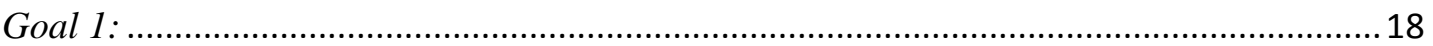

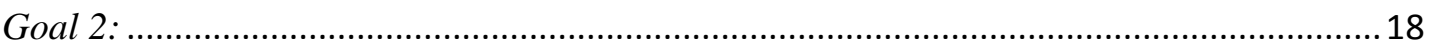

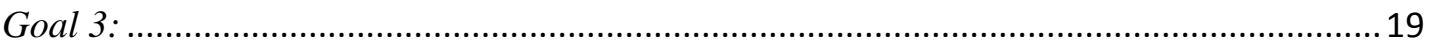

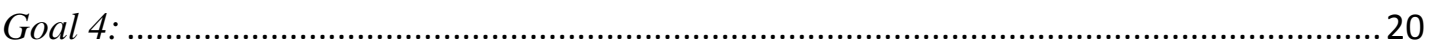

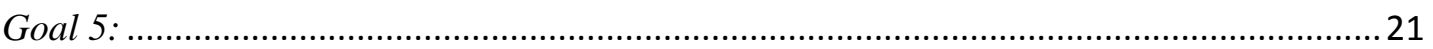

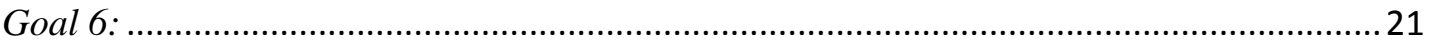



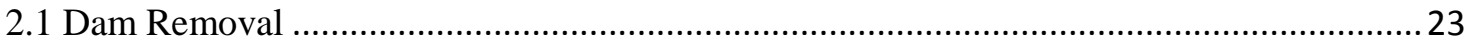



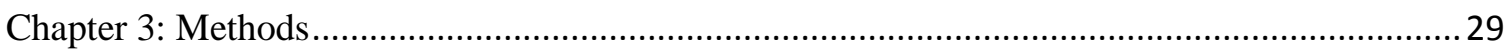

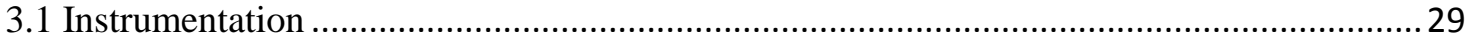

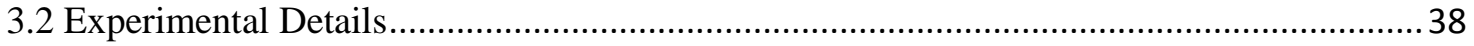



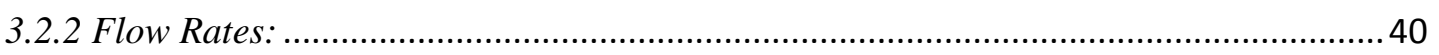

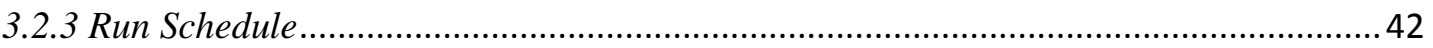

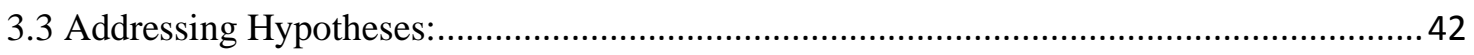

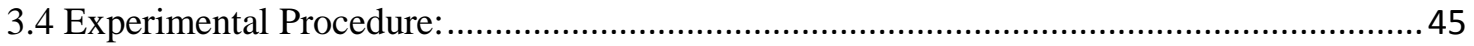

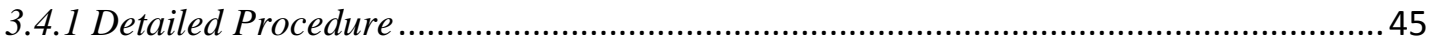

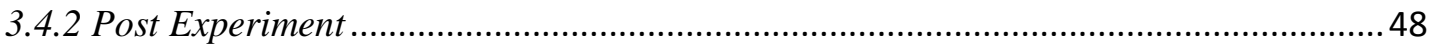

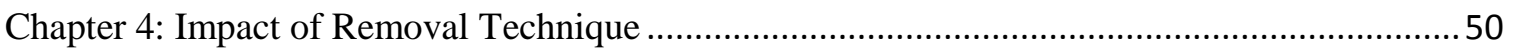




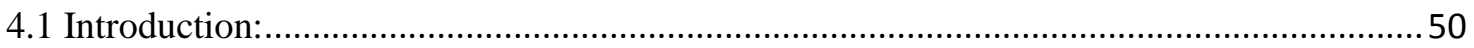

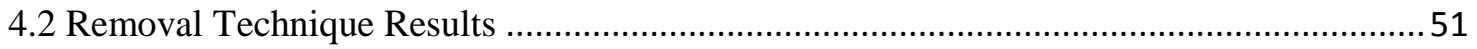

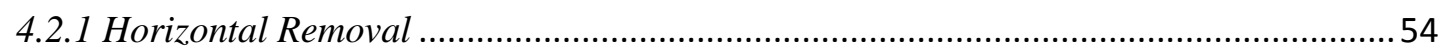

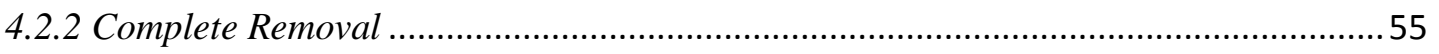

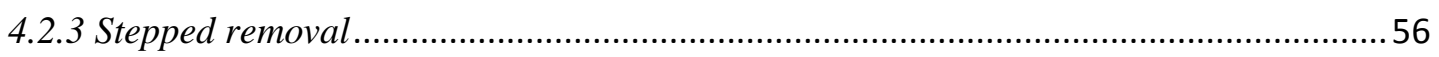

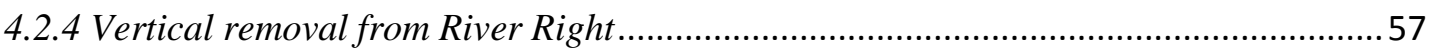

4.2.5: Vertical Removal from the Center ........................................................................ 58

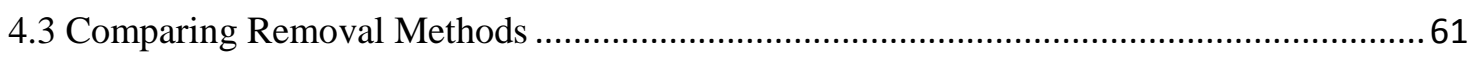

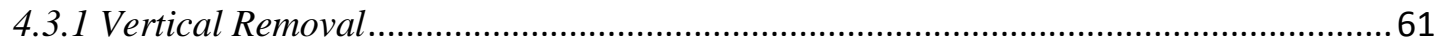

4.3.2 Horizontal and Stepped Removal .......................................................................6



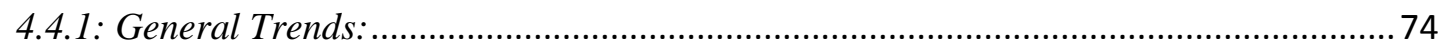

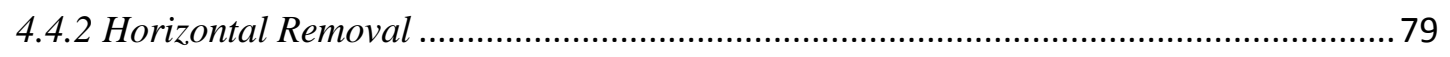





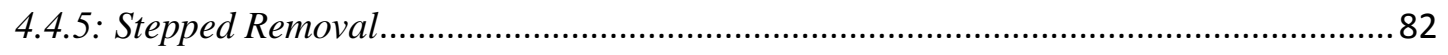

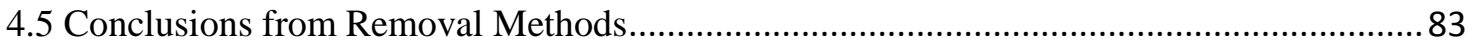

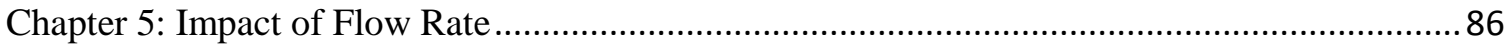

5.1 Introduction:



5.2.1 Changes in Downstream channel bathymetry following dam removal......................... 88

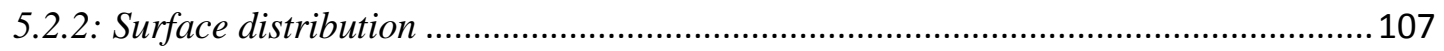

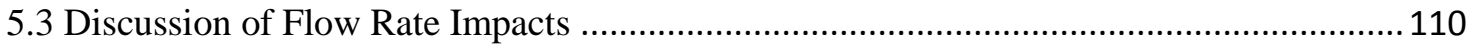



Chapter 6: Impact of sediment type on the downstream channel ............................................ 124



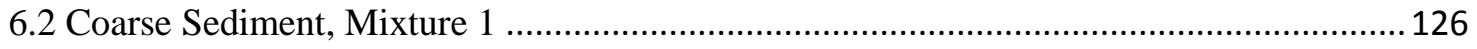

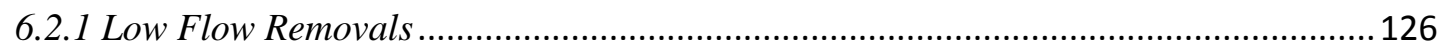




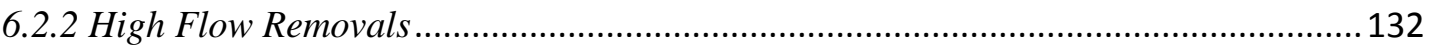

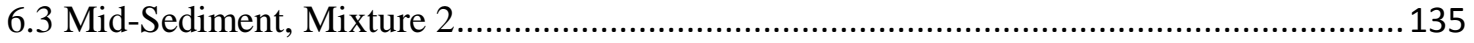

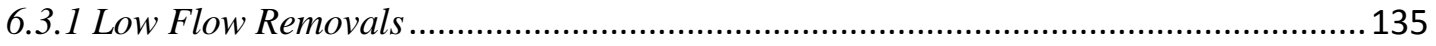

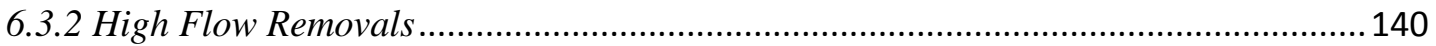



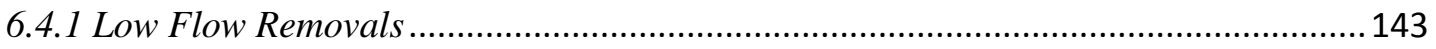

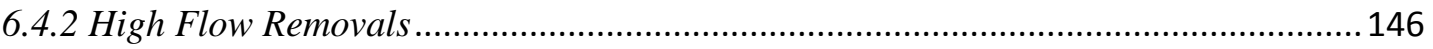

6.5 Combined Influence of Sediment Mixture and Dam Removal Method ........................... 148



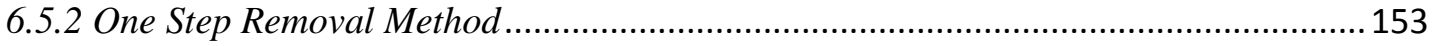

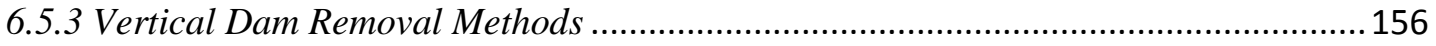

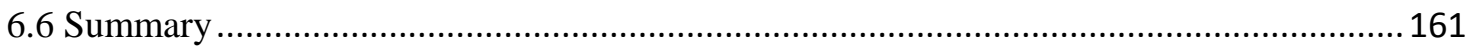

6.7 Conclusion from the sediment type impacts ............................................................ 169

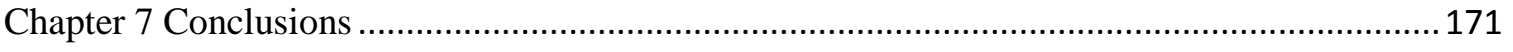

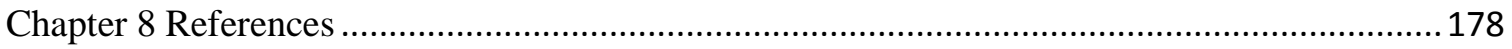

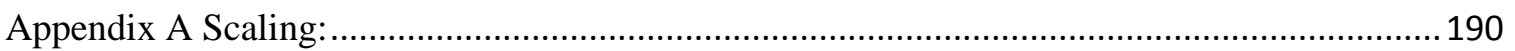

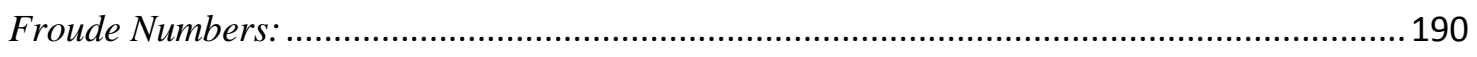

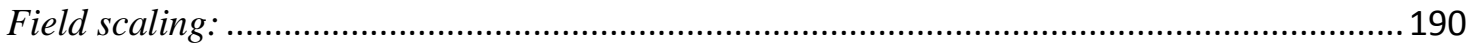





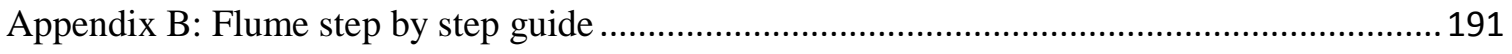

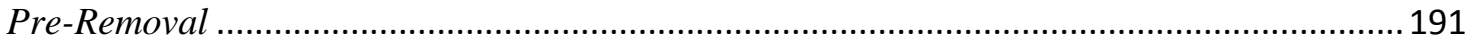



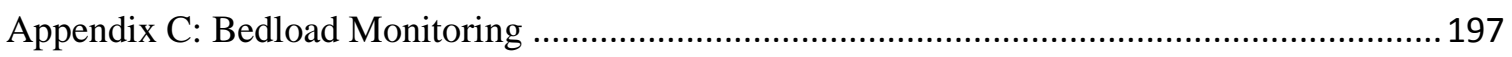

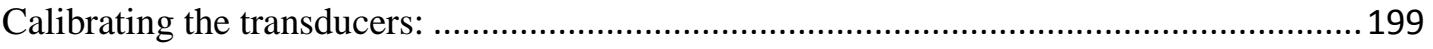

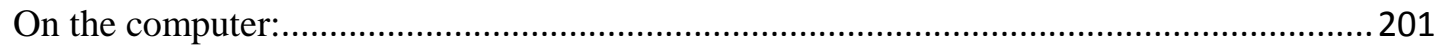

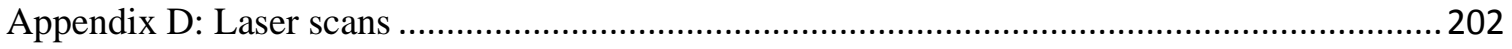

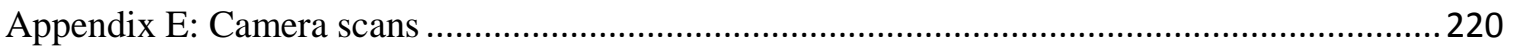

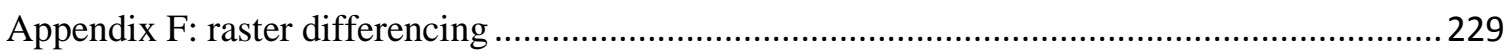




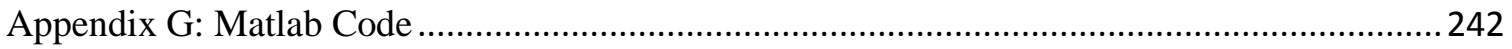

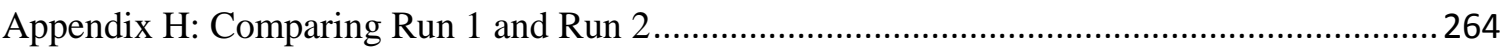




\section{Chapter 1: Introduction}

\subsection{Introduction}

Throughout the United States, over 76,000 dams (> 2 meters high) have been constructed on America's rivers (Pohl 2002). If all structures including those smaller than 2 meters high are counted, there may be as many as 2 million dams (Graf 1999). These small dams have been built for a myriad of reasons, including: water supply for domestic and industrial use, irrigation, flood control, sediment control, water power (i.e. mills), recreation, and enhanced groundwater recharge (Heinz Center 2002; Brandt 2000). The initial purpose of many small dams has long since passed, the reservoirs have filled with sediment, and the dams have been left to deteriorate in place, blocking miles of spawning and rearing habitat of anadromous fish (Hough-Shee, 2013). In 2012 alone, 65 dams were removed throughout 19 states with a majority occurring in Pennsylvania (13 dams removed), Massachusetts (9) and Oregon (8), bringing the total documented dam removals in the United States to nearly 1100 (Kober, 2013).

Dam safety inspection and re-licensing is occurring in a different regulatory and economic atmosphere than when dams were planned and built (Bartley and Rutherford 2005). In addition to the risk of structural failure (Fountain 2011), dams are being removed as a result of society's values and attitudes becoming more eco-friendly and concerned with ecosystem and riverine functions. Outdated dams are barriers to migrating fish and limit opportunities for river recreation, in addition to creating drowning hazards and threatening the safety of downstream communities (Kober, 2013). Government agencies at the state and local levels now must not only consider safety issues of aging dams, but also environmental issues (Pejchar and Warner 2001). Virginia law requires that all structures impounding more than 50 acre-feet of water be inspected for safety (Department of Conservation and Recreation 2010). Due to changes in land 
use and population growth, the hazard rating associated with many small dams has increased. There are 1455 dams in Virginia (Every Single Place 2011), and many are deemed to be deficient (American Society of Civil Engineering 2007). These dams must be removed or rehabilitated, and dam removal is often the least expensive option (Burroughs et al. 2009).

Dam removal is complicated by the bulk of sediment impounded behind the dam, as the erosion, transport, and deposition of the impounded sediments are typically the most important physical effects of dam removal (Heinz Center 2002). Questions arise due to a lack of predictive ability concerning what will happen to the sediment if it is released upon dam removal. Opinions on the fate of the sediment range between two extremes: the sediment will pass through the channel to a larger receiving water body somewhere downstream with minimal impact on the channel; or the sediment will deposit in the immediate reach downstream, smothering the channel bed and destroying aquatic habitat. Stakeholder concerns about dam removals often focus on the morphology of the channel post dam removal, which is a reflection of sediment transport and deposition processes (Leopold et al. 1964; Church 2006). For example, questions raised around a recent small dam removal in Charlottesville, Virginia, focused on both a fear of losing fish habitat (due to sediment deposition) and a fear of the formation of mosquito habitat (due to sediment immobility forming shallow pools) (Rosen 2007; McDaniel 2007). In a dam removal in Connecticut, a portion of the sediment stored behind the Union City dam on the Naugatuck River was excavated and relocated behind an old headrace structure on site to minimize sediment discharges, while additional sediment went to a landfill due to high levels of polycyclic aromatic hydrocarbon compounds (Wildman and MacBroom 2005). Because of these contaminant and stakeholder concerns, the bulk of impounded sediment is typically dredged prior to dam removal. Dredging and disposing of sediment is expensive and can make dam 
removal decisions dependent on the economic impact to the owner's (i.e. city, county, state) budget (Randle and Greimann 2006; Michigan DNR 2007). Ironically, starving the downstream river of sediment is one of the recognized negative impacts of dams. It is well established that rivers downstream of dams erode to become wider and/or deeper because flow energy that would have been expended transporting the sediment load from upstream instead erodes the channel bed and banks (Williams and Wolman 1984). The result of a dam without flood control is a downstream channel bed that is armored or degraded (Petts and Gurnell 2005). Releases of impounded sediment can reverse the sediment deficit and improve the downstream aquatic habitat by increasing natural channel complexity, including bed mobility and bedform development (Salant et al. 2006).

Dams alter two critical elements of a geomorphic system: the ability of a river to transport sediment and the amount of sediment available for transport (Kondolf 1997; Grant et al. 2003). Physical changes downstream of dams are dependent on the balance of sediment and hydrologic regimes and include channel degradation and narrowing, coarsening of channel bed texture, channel aggradation, sediment bar formation, channel widening, and no measurable change (Brandt 2000; Everitt 1993; Fassnacht et al. 2003; Gordon and Meentemeyer 2006; Graf 2006; Yang et al. 2006; Phillips 2003; Phillips et al. 2005). If a tributary inputs sediment to the channel downstream of the dam but the dam does not release flows with sufficient stream power to transport that sediment, the channel downstream will aggrade. In cases where there is no sediment input and flow rates are reduced to the extent that only the fine sediments are mobilized, the channel bed below the structure armors (Vericat et al. 2006). Where there is no sediment input and continued flow over the dam, the base level of the channel is reduced due to scour downstream of the dam. In a survey of the changes associated with 21 dams, Williams and 
Wolman (1984) documented channel bed degradation immediately downstream of each dam. Degradation of the Missouri River at Kansas City is thought to result in part from dams in the upstream watershed (Blank 2009). Bed and bank erosion becomes the only source of sediment, contributing to long-term degradation (Vericat and Batalla 2005) and threatens existing downstream infrastructure. For example, bed scour around bridge pylons effectively reduces the footing depth for a bridge which can lead to eventual bridge collapse.

The public perception of and attitudes towards dam removal have evolved over recent decades as the number of dam removals has increased. Dam removals were rare and consideration of migratory aquatic species as a reason for dam removal did not become common until years after Congress began requiring that dam licensing consider and mitigate the impact of the dam on fish and wildlife (Becker 2006). Stakeholder concerns and uncertainty regarding the consequences of dam removal on the surrounding landscape limited the number of dam removals per year. However, over the years, dams have continued to age and deteriorate. More than 400 U.S. dams failed between 1984 and 1995, and as of 2000, over $20 \%$ of surveyed dams needed maintenance at an estimated cost of \$543 million (Stanley and Doyle 2003). When the Edwards Dam in Maine was removed in 1999, the cost of removal was $\$ 2.7$ million but the cost for needed dam modifications to ensure fish passage was $\$ 10$ million. Similarly in 1986, structural repairs to a low head dam in Wisconsin to mitigate safety concerns was estimated to $\$ 3.3$ million while removing the structure ended up costing $\$ 80,000$. The Rife-Loth Dam in Waynesboro, Virginia was a hazard to the local community and was removed in the fall of 2011 largely because repairing the dam would cost $\$ 250,000$ and removing it entirely cost approximately $\$ 80,000$ (Slack 2011). The City of Danville, Illinois, has two dams recommended for removal based on safety, liability and lack of fish passage (Moss, 2013). The combined costs of restoring 
fish passage through completely removing both structures was $\$ 1.74 \mathrm{M}$ and partial removal was $\$ 2.03 \mathrm{M}$, while improving fish passage through the addition of a stepped spillway was estimated to cost $\$ 4.77 \mathrm{M}$ and constructing a rock ramp would cost $\$ 3.79 \mathrm{M}$, making complete removal the best option both for restoring the system and cost efficiency (Moss, 2013). The removal of the Elwha and Glines Canyon dams was motivated by the passing of the Elwha River Ecosystem and Fisheries Restoration Act and the removal of the structures has opened up 70 miles of the Elwha River and its tributaries to anadromous fish passage (National Park Service, 2013a). Data from 31 small dams that have been removed reveals that the lowest estimate of repair costs was three to five times higher than the cost of removal (Harris 2008). The rising costs of dam maintenance, including costs associated with mitigating the negative effects of a dam on fish and other species, and the often limited recognizable benefits from dams have combined to result in an increasing trend of dam removals. The number of dam removals per decade rose from fewer than 20 in the 1960 's and 1970 's, to 100 in the 1980 's, and over 500 in the last 20 years (Stanley and Doyle 2003). As more dams are removed and the economic benefits of dam removal realized, the public perception of dam removal has grown favorable.

Small dam removal is an integral component of many stream restoration projects (Parker 2004) as reconnecting the upstream and downstream channel can restore river health and clean water, revitalize fish and wildlife, improve public safety and recreation, and enhance local economies (Kober, 2013). Improved predictions of how removing dams will affect the surrounding river will enable communities to proceed with dam removal in a manner that promotes a sustainable river system and reduces expenditures and uncertainties concerning the impounded sediment. There remains a great deal of uncertainty in predictions of subsequent channel evolution and uncertainty concerning potential immediate damage to the ecosystem by 
sedimentation (Rosen 2007; Collins et al. 2005; Provence 2006). While the scientific community is beginning to understand some of the many ecological, societal, and economic benefits and drawbacks related to dam removal, questions remain pertaining to sediment issues and the morphodynamical response of the downstream channel upon removal of a dam partially or completely filled with sediment (Bromley et al. 2005; Bromley 2008). The possible impacts of erosion, transport, and deposition of reservoir sediment must be addressed in all dam removal studies (Randle 2003). Only recently have the sediment dynamics following dam removals been addressed through quantitative research. River restoration projects involving dam removal need a process by which to predict the changes in the downstream channel bed surface and in-channel morphology so that channel processes and are sustained and improved.

The magnitude and extent of sediment related impacts to the downstream channel morphology depend upon the characteristics of the impounded sediments, the morphology of the downstream channel, the method of dam removal, and flow rate (Hart et al. 2002; Poff and Hart 2002; Cannatelli and Curran 2012). The research presented here directly addresses three of these parameters: impounded sediment characteristics, the sequencing of dam deconstruction, and flow rates during dam removal, with sediment transport monitoring and bed scans to capture downstream morphology.

\subsection{Objectives}

The objective of this research was to quantify the impacts of dam deconstruction sequencing under a range of impounded sediment grain size distributions and flow rates so that the effect of sediment release on the downstream channel morphology could be predicted. To satisfy the overarching objective, several smaller objectives were defined through a series of experimental goals (which will be detailed in Chapter 3): 
1. Quantitatively measure the volume and size distribution of sediment transport following dam deconstruction:

a) In horizontal layers from the top of the dam (Goal 1; Figure 1.3.1a)

b) In vertical segments from the center of the channel (Goal 2; Figure 1.3.1b)

c) In vertical segments from the side of the channel (Goal 2; Figure 1.3.1c)

d) In horizontal layers of decreasing length (Goal 3; Figure 1.3.1d)

e) Completely removed in one step (Goal 4; Figure 1.3.1e).

2. Quantitatively measure the impact of sediment characteristics on the transport and deposition of impounded sediment (Goal 5)

3. Quantitatively measure the impact of flow rate on the transport and deposition of impounded sediment (Goal 6). 

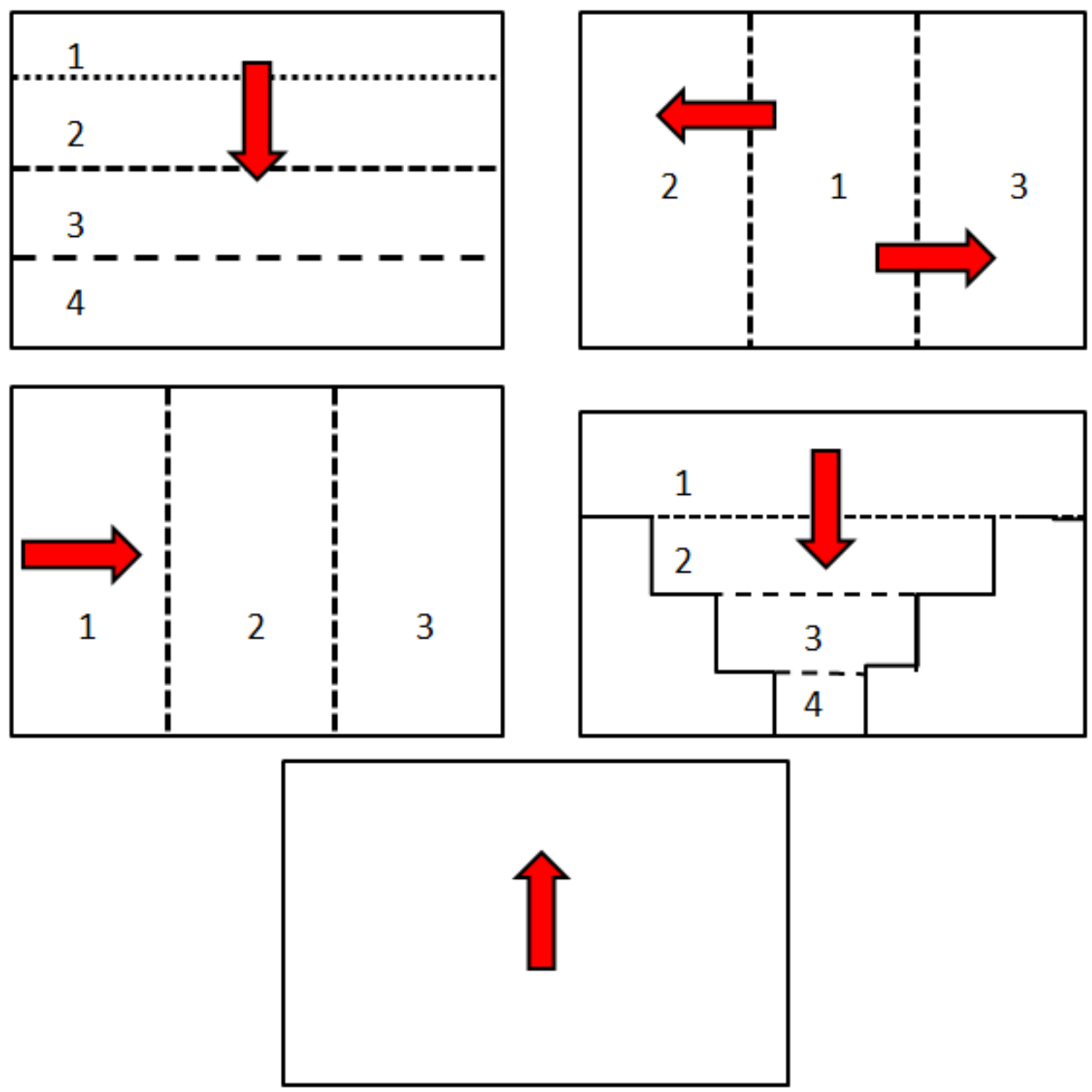

Figure 1.3.1: Dam removal schemas for the flume experiments. The dotted line signifies the plexiglass pieces and the numbers correspond to the removal order and part number. The red arrow denotes the direction of the removal: (a) horizontal removal schema; (b) vertical removal from the center; (c) vertical removal from the side; (d) stepped removal; (e) one-step removal

\subsection{Hypothesis}

The central research hypothesis is that for a given distribution of impounded sediments, small dam deconstruction can be sequenced such that impounded sediments released downstream will have a positive impact on the geomorphic character of the downstream reaches. To test the central hypothesis and accomplish the overall objectives of this research, 6 specific goals were pursued: 


\section{Goal 1:}

Quantitatively measure the rate and size distribution of sediment transported when a dam is removed in horizontal layers from the top of the dam (Figure 1a).

The hypothesis for the horizontal removal is that removal from the top down will have a similar effect as introducing a pulse of fine sediment to the channel. The sediment will enter the downstream channel in suspension. Sediment in the impounded area is expected to be released as the dam is deconstructed, so the sediment will move downstream as a series of unimodal waves. Previous flume experiments suggest that when a dam is removed in horizontal segments, there will be an initial pulse of sediment delivery that decreases during the removal process in a way similar to that of a removal that had the entire structure removed in one step (complete removal), but results in an overall smoother and more controllable release of stored sediment (Bromley 2008; Cantelli et al. 2004). A conflicting result was observed in the field during the Brewster Creek Dam removal near St. Charles, Illinois, where the dam was deconstructed in 5 horizontal stages and the sediment load during the first three notches was only 14 percent of the load that transported during the final two notches (Straub 2007). This method of deconstruction also mirrors the method used on the Stronach Dam on the Pine River in Michigan (Burroughs et al. 2009).

\section{Goal 2:}

Quantify the rate and size distribution of sediment transported when a dam is removed in vertical sections. Two removal sequences will be tested under this goal: removal of the middle panel as the first step (Figure 1b), and removal of a panel from the side as the first step (Figure 1c).

The hypothesis is that when the dam is removed in vertical sections the impact on the downstream channel will be focused on the area of river in line with the first section removed. 
Sediment flux will include all grain sizes and be higher with the first panel removed than any of the subsequent sections. Scour and deposition will be focused within the area of channel downstream of the first section removed which may limit the spatial extent of downstream channel change. The Secor Dam on the Ottawa River in Ohio was removed in vertical sections from the center over the course of three days, with channel incision acting as the dominant process and the initial breaching of the dam resulting in a downstream migration of a sediment wave (Harris 2008). The initial downstream sediment deposit was primarily focused on the right hand side of the channel immediately below the dam site (Harris 2008). Dam removal in vertical sections initiating at one side of the dam rather than the middle was the sequence used to remove St. John dam on the Sandusky River in Ohio (ICF Consulting and Woodlot Alternatives 2005). The Brownsville Dam on the Calapooia River in Oregon was also removed in vertical sections from the side and observed narrowing of the wetted channel and increases of areas of the bars within the first 450m downstream of the structure (Walter and Tullos 2010).

\section{Goal 3:}

Quantify the rate and size distribution of sediment transported when a dam is removed in a stepped fashion with horizontal segments of descending length removed from the top of the dam (Figure 1d).

A partial dam removal with a portion of the structure left in place, or stepped removal, is common to reduce construction costs as well as a form of historic preservation (Randle and Greimann, 2006). The amount of reservoir sediment eroded by river flows is dependent on the amount of the dam removed and the amount of reservoir drawdown with each piece (Randle and Greimann, 2006).The hypothesis for the stepped dam removal is that removing the structure in pieces descending in length, from the top down will have a similar affect as introducing a pulse 
of fine sediment to the channel. The sediment will enter the downstream channel in suspension and behave similarly to the horizontal removal. However, this method will result in less sediment being transported downstream. Leaving a portion of the structure in place will aid in stabilizing the reservoir sediment. This method was employed in the removal of a $2 \mathrm{~m}$ high dam on the lower Manatawny Creek in southeastern Pennsylvania, leaving behind $0.5 \mathrm{~m}$ of the structure to stabilize the sediment (Bushaw-Newton et al. 2002).

\section{Goal 4:}

Quantify the rate and size distribution of sediment transported when a dam is completely removed in a single step (Figure 1e).

The hypothesis for the complete dam removal is that this method will result in the sediment being transported downstream all at once. The sediment will enter the downstream channel through bedload transport as well as in suspension. This method will produce the highest rates of sediment in transport. Immediately after dam removal, we anticipate the sediment in the reservoir will undergo rapid channel incision that will eventually transition to slow incision and channel widening with time (Cantelli et al. 2004). This method of removal is observed in many planned removals as well as failure scenarios. The Lake Ha!Ha! earthen dam, Ste. Genevieve, Missouri, failed during a large storm, the channel downstream of the dam incised $7 \mathrm{~m}$ vertically, and erosion and large scale widening were observed (El Kadi Abderrezzak et al. 2008). The Laville and Rockdale dams in Wisconsin were removed in a single step and illustrated the dependence of downstream sedimentation on the rate and magnitude of channel development and evolution within the reservoir (Doyle et al. 2003). The Elwha dam removal began June 2011 with the construction of a temporary diversion channel, allowing the reservoir material, as well as the dam structure, to be removed under "dry" conditions (National Park Service, 2013b). This 
method is most similar to a modified complete removal with the reservoir sediment emptied before the dam removal takes place.

\section{Goal 5:}

Quantify the impact of sediment characteristics on the transport and deposition of impounded sediment under the range of dam removal scenarios.

The hypothesis for the impact that sediment characteristics have on the transport and deposition is that sediment released will transport downstream at a rate dependent on the gravel:sand:silt content. Sediment pulses will move as waves through a combination of dispersion and advection, depending on the grain size composition of the wave. Gravels are expected to move primarily as bed load, while the fine sediment sizes will move as both bed load and in suspension. In addition to the method of sediment movement, the rate of transport is expected to vary with sediment composition. Doyle (2003) found that channel development following dam failure was strongly controlled by the composition of the reservoir sediment. Sand has the potential to disturb the bed downstream and break an armor layer, if one exists, and sand content over approximately $30 \%$ will cause an overall increase in sediment transport downstream (Wilcock and Crowe 2003; Curran 2007).

\section{Goal 6:}

Quantify the impact of the flow rate on the transport and deposition of impounded sediment under the range of dam removal scenarios.

The hypothesis for the impact that flow rate will have on the transport and deposition of the sediment is that the higher flow rates will mobilize a larger amount of sediment than the lower flow rates, resulting in sediment evacuating the reservoir more quickly and downstream deposition will be a function of distance downstream from the reservoir, discharge magnitude, 
and time since the original sediment release (Wohl and Cenderelli 2000). Cannatelli and Curran (2012) found that the timing of the local hydrology around the removal played a large role in the sediment transport patterns and in turn in the overall evolution of the channel. When the structures were removed during low flows, the channel was able to quickly stabilize, whereas when the dam was removed during high flows the channel was highly unstable and experienced high rates of sediment aggradation and degradation. Through the experiments outlined here, I was able to quantify the impact of the flow rate on the distance downstream where deposition occurs. 


\section{Chapter 2: Background}

\subsection{Dam Removal}

In addition to the impact that in-place dams have on local hydrology and sediment transport regimes, removing them creates additional complications. Dam removal has the potential to affect the physical, biological, and geomorphic components of a river ecosystem, and often the component responses are intertwined (Bushaw-Newton et al. 2002). For example, the sudden release of impounded sediments can affect fish habitat as pools are in-filled with fine sediments (Rathburn and Wohl 2003; Wohl and Cenderelli 2000), alter water chemistry via sudden influxes of nutrients, affecting both flora and fauna (Stanley and Doyle 2003; Stanley and Doyle 2002); and change channel morphology through bed aggradation, bar formation, or channel migration (Pizzuto 2002). The majority of dam removals, and the focus of this research, are small dams. Small dams are defined here to agree with the definition used in the American Association of State Highway and Transportation Officials (AASHTO) report: a small dam is a constructed barrier in a river with a structural height not exceeding 15.2 meters (50 feet) (ICF Consulting and Woodlot Alternatives 2005). Although the removal of a large dam typically is a significant event, smaller dam removals can have a cumulatively greater impact on river ecosystem health (ICF Consulting and Woodlot Alternatives 2005; Landers 2004). Small dams are much more common than large dams, and the release of sediment behind any dam affects both downstream and upstream channel processes. New large dams may not be built within the United States, but small dams will continue to be built (Herald-Zeitung 2006; NRCS 2006) and removed into the future. How small dams and the sediment impounded by them are managed is an important component to sustaining riverine ecosystem health. Shifts in sediment transport rates and patterns are a prominent and significant response to dam removal (Hart et al. 2002). However, few dam removals have been studied with respect to downstream sediment transport 
and deposition (Rathburn and Wohl 2003; Wohl and Cenderelli 2000; Kondolf and Wilcock 1996, Doyle 2003, Stewart 2006, Harris 2008).

Much of the negative effects of releasing impounded sediment are drawn from speculation that the sediment will smother the downstream bed surface as excessive deposition of fine sediments has a destructive effect on benthic macroinvertebrate populations (Wood and Armitage 1997), however less than 5\% of all dam removals in the U.S. have published ecological studies (Thomson et al. 2005). The ecological effects of releasing a full impoundment on the downstream channel morphology remain unclear, however it is known that the sediment will affect the downstream channel in a way that reflects the characteristics of the impounded sediments. While fine sediment transports and deposits far distances from the dam site, it is easily suspended and remobilized with each flood event such that its impact is spatially extensive but short-lived (Wohl and Cenderelli 2000; Cenderelli and Cluer 1998; Stampfli, 2012). The ease with which fines are transported out of a river reach limits the impact on the bulk of the channel bed. For example, sampling results 10 months after a dam removal in Ohio showed the bulk of the fine material passed through the downstream channel reach without interacting with the bed (Cheng and Granata 2007). In the few studies where sediment transport rates have been measured or estimated following dam removal, the time frame for evacuation of impounded sediment from the downstream reach ranges from days to decades. While sediment usually mobilizes immediately upon dam removal, in the case of a Manatawny Creek Dam the impounded sediment was primarily gravel and did not mobilize for a number of months, highlighting the dependence of deposition patterns on the grain size distributions present (Hart et al. 2002). 
Channel morphologic field measurements after dam removal are limited and often show conflicting results. The result is a database of useful information about an individual dam removal, but not a robust suite of information from which the uncertainties surrounding the effect of releasing reservoir sediment can be reduced. For example, following the removal of the Woolen Mills dam (WI), sediment flushing through the system took only six months. In contrast, sediment released with the removal of the Newaygo Dam (MI) is expected to take 50-80 years to transport completely (Bednarek 2001). After removal of a 2-meter high dam along the Manatawny Creek (PA) in 2000, increased sediment transport quickly led to major changes in channel form in the former impoundment and downstream reaches (Bushaw-Newton et al. 2002). When the Embry Dam (VA) was removed, the amount of sediment released downstream with dam removal exceeded predictions, and excessive silt deposits necessitated dredging by the Department of Public Works (Boorstein 2005). Only very recently have changes in sediment transport rates and bed surface sediments been measured following dam removal. At the Milltown Dam in Montana, changes in the bed surface grain size distribution are being monitored (Wilcox et al. 2008; Epstein and Wilcox 2008). The Marmot Dam removal (OR) included a team of researchers considering sediment as well as macroinvertebrate and fish populations (Pacific Gas and Electric 2007). Data showed a peak in suspended sediment transport upon dam removal that lowered quickly and deposition of a gravel wedge in the immediate reach downstream of the dam (Major et al. 2008; Podolak et al. 2008; Wallick et al. 2008). The cases of Marmot and Milltown Dams present specific case studies where the channels were high gradient. The results may not easily transfer to small dam removals in other areas of the US where streams have low gradients and transport more fine sediments than gravels (Walter and Merritts 2008). 
Laboratory experiments have provided some insight concerning the behavior of sediment pulses and the evacuation of impounded sediments with dam removal. Over gravel beds, the mobility of sediment pulses is dependent on the sediments in the pulse. When the pulse sediment is primarily coarse grained, transport is dominated by dispersion, and when the pulse is composed of fine sediments, both diffusion and dispersion are significant (Lisle et al. 2001; Lisle et al. 1997). Flume experiments at the National Center for Earth-surface Dynamics (NCED) focused on the evolution of the former reservoir area as sediment evacuated following dam removal. A sequence of three experiments evaluated the effects of basin geometry, sediment grain size, hydrology, and the rate of base level change on the morphodynamic response of the reservoir (Cantelli et al. 2004). Their findings showed that after the sudden removal of a dam, flow incision into the reservoir deposit induced erosion of reservoir sediment followed by a period of bank collapse and channel widening. A physical model of the Glines Canyon Dam showed that the location of the initial incision affected the location and rate of reservoir erosion when the dam was removed in sections (Bromley et al. 2005; Bromley 2008). Laboratory studies are very useful, however many common removal scenarios have not been analyzed. Woolen Mills Dam (VA) was removed in horizontal layers so that the height of the dam was slowly lowered. A low head dam on the Ottawa River (Ohio) was removed in vertical sections over the course of three days (Harris 2008). Neither situation mirrors what has previously been modeled in a flume.

\subsection{Environmental Impacts}

Sediment transport processes and ecological attributes of the biota in the downstream aquatic ecosystem will determine how the sediment affects downstream ecology following dam removal. Sediment deposition is unlikely to be a linear stressor of aquatic ecosystems. It is more likely to have a non-linear effect meaning that there can be some quantity of fines deposited on 
the bed surface before negatively affecting the ecosystem. There are potential benefits to the downstream aquatic ecosystem following the release of impounded sediments (Slagel and Griggs 2008). With the reconnection of flow and sediment transport processes, the channel morphology will increase in complexity (Bartley and Rutherford 2005). The availability of ecosystem habitat is enhanced by increasing the complexity of channel form (Tomsic et al. 2007). Dam removal will eliminate an existing downstream sediment deficit (ICF Consulting and Woodlot Alternatives 2005) and re-establishing sediment supply to the downstream channel can replenish channel banks and reduce channel widening (Francisco 2004). Many river restoration projects have a goal of stabilizing channel banks. Thus, sediment releases can reduce the need for hardened engineering devices during channel restoration projects. An ecological engineering benefit of this research is a better informed and more natural channel restoration practice.

In addition to the sediment composition, the magnitude, duration and sequence of flows are all important controls on bedload transport and the impact that a removal will have on the downstream channel (Wohl and Cenderelli 2000). Cannatelli and Curran (2012) found that channel evolution following dam removal was not unidirectional and the rates and stages of channel evolution depended on local hydrology, specifically that dams removed during high flows had the channel reach a state of dynamic equilibrium faster than those removed during the low flow season, however the high flows were also associated with larger amounts of degradation.

The magnitude and extent of sediment related impact to downstream channel morphology depend upon the characteristics of the impounded sediments, the morphology of the downstream channel, and the method of dam removal (Hart et al. 2002; Poff and Hart 2002). This research evaluates a range of dam deconstruction sequences, flow rates, and impounded sediment 
characteristics, directly addressing and reducing uncertainties associated with the impact of small dam removal on the downstream channel. 


\section{Chapter 3: Methods}

\subsection{Instrumentation}

The specific goals and hypotheses of this project were tested through 23 completed flume experiments (31 proposed and 25 tested) at the University of Virginia's (UVA) Sustainable Rivers Lab. While it is not possible to recreate the three-dimensional nature of a natural channel, this fact is outweighed by the capacity to obtain detailed measurements of the flow field and sediment transport rates with controlled physical models of dam removal. The flume represented a mid-section of a channel (Sharp 1981; Peakall et al. 1996), so that the influence of impounded sediment and dam deconstruction on the downstream reaches was measured directly. This is a commonly employed approach in both engineering (Davies 1980; Canovaro et al. 2007) and river geomorphology (Wilcock et al. 2001; Curran and Wilcock 2005).

The flume has an experimental channel that is 9 meters long, 0.6 meters wide, and 0.5 meters deep (Figure 3.1.1). The dams were installed $2 \mathrm{~m}$ downstream from the flume inlet, and there was a 1-meter long sediment trap at the downstream end of the flume. This provides 8 meters of active channel length for these experiments. The working length of flume downstream of the dam is equal to $6 \mathrm{~m}$ or 10 channel widths. The water reservoir has a capacity of $4.5 \mathrm{~m}^{3}$. The channel slope was adjustable up to a $5 \%$ grade, however was kept at $0.00 \%$ for the Runs and the bed was allowed to adjust naturally. Flow discharge was controlled by a variable frequency motor capable of flows up to $0.11 \mathrm{~m}^{3} / \mathrm{s}$. For this series of experiments, water was recirculated, but sediment was not recirculated. 


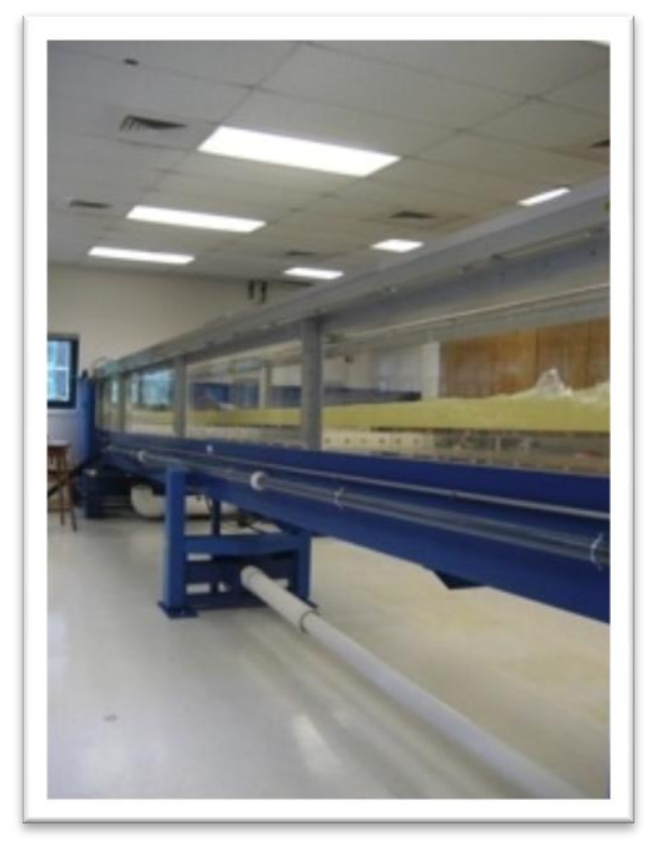

Figure 3.1.1: A profile view of the flume in the Sustainable Rivers Lab at the University of Virginia

The use of digital elevation models (DEMs) in the analysis of alluvial channel beds has become increasingly common (Nikora et al.1998; Lane 2005; Michael and Gerhard 2006). Fine resolution Digital Elevation Models (DEMs) of the bed surface were created from the data collected by a Micro-Epsilon scanCONTROL laser profiler (Figure 3.1.3). This profilometer was attached to a carriage that traversed the width and length of the flume and used laser triangulation to determine the distance to the channel bed. Five individual laser scans were preformed over the length of the flume for each channel surface, varying laterally across the channel, to ensure the highest level of accuracy of data that was possible using this method. The three dimensional data that was collected with the laser scanner was run through a Matlab script to compile the five individual scans of the channel into one master data set for input into GIS. In the areas where overlap of the data occurred, the maximum elevation of the two values was chosen as the elevation at that location. Once the data set was properly formatted, the information formed a database file in GIS that was then converted into terrains to create accurate 
three-dimensional models of the channel bed (Appendix D). The terrains were converted to rasters and overlaid with the previous part of the run to create a raster difference file with visual and quantifiable information on the channel changes in between each part (Appendix F). The raster differences were created for each part of the run in succession as well as for Pre-Removal to Final bed. The profiler was able to measure the bed surface topography to an accuracy of 0.5 $\mathrm{mm}$, making detailed measurements of bed elevations above a reference datum possible through the DEM. The profilometer was not capable of collecting accurate data through the water column, so it was necessary to drain the flume prior to scanning. To minimize disturbance to the experiments, scans were conducted of the initial and final channel beds and after each part of the dam was removed. Quantifying the downstream deposition patterns in this manner allowed for the identification of where the sediment eroded and deposited at each meter in the downstream channel extending 10 channel widths below the dam removal location.

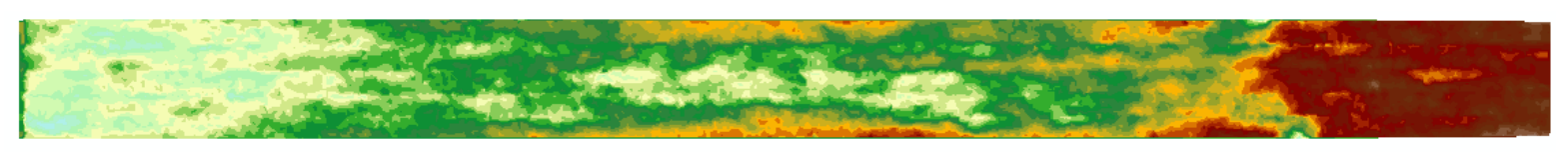

Figure 3.1.2: An example of a high resolution DEM from Run 15 final bed (flow is from right to left, see Appendix D for all additional figures and scale). 


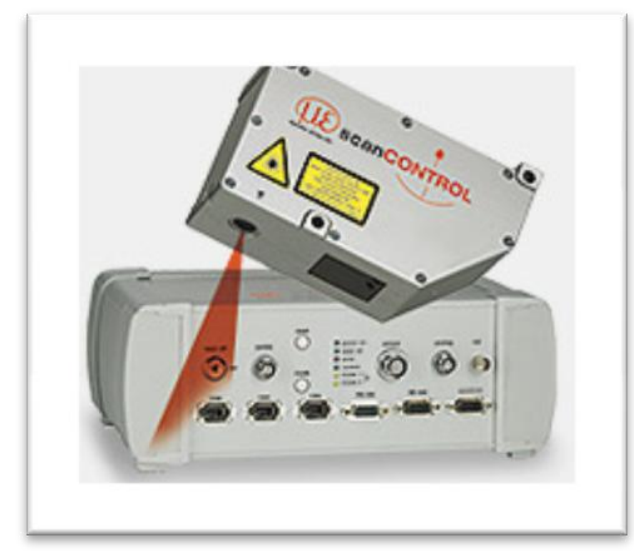

Figure 3.1.3: A stock photo of the Micro-Epsilon laser profiler

In addition to quantifying the channel change downstream of a dam removal under high and low flow scenarios, it was also necessary to quantify the amount of sediment leaving the active downstream channel section. A trap was constructed at the end of the artificial stream channel with $10 \mathrm{~cm}$ sides that were flush with the upstream channel bed to prevent the bed sediment from entering the trap and $10 \mathrm{~cm}$ high on the opposite side of the trap to keep sediment from evacuating trap and entering the flume reservoir. The amount of sediment deposited in the sediment trap at the end of the channel was collected, weighed and a grain size distribution was completed following each Part of the Run. If the trap was filled before the Run was complete, the time was noted, the Run was stopped and the trap was emptied and weighed before resuming the Run. There was some sediment that entered the flume reservoir downstream, most of which was traveling as wash load, but the sediment trap was effective at capturing the majority of sediment traveling as suspended load and bedload. Following dam removal, a majority of the concerns about the downstream impact are centered around sediment deposition in the downstream channel and the amount evacuating farther downstream. The sediment traveling as wash load in these experiments was not a critical component in identifying that trend. Continuous still photos 
were taken at 10 second intervals in the sediment trap to monitor the accumulation in a time sensitive manner, but only the total loads are analyzed in the following sections.

In addition to using the laser bed scans, a series of photos was completed to allow for a visual representation of the bed. A series of approximately 150 pictures were taken at $5 \mathrm{~cm}$ increments along the length of the flume using a 6 megapixel digital camera. The images were stitched together using the computer program PTGui that utilizes automatically identified match points to create a panoramic from individual images (Figure 3.1.4). These panoramics were used to calculate the percent sand on the surface of the bed following each experiment.

Figure 3.1.4: An example of a camera scan from Run 15 (see Appendix E for all camera scans).

The temporal patterns of bedload transport following dam removal are very important to the results of this project. The laser scans can only be performed while the flume is drained, limiting data collection to in-between removal parts after the water has drained. Continuous load monitoring is necessary for time sensitive quantitative analysis of sediment deposition and redistribution patterns following the dam break when water clarity was diminished due to suspended sediment.

While there have been several reported case studies that involve the use of various bed load monitoring techniques in the field (Kuhnle, 1991, Kuhnle, 1992), there has not been any publications that suggests modifying these techniques for use in flume experiments. After investigating bed load transport monitoring methods that have been used in the past (Reid 1980, Harris and Richards 1995, Sear 2000, Laronne, Alexabdrov, Bergman, Cohen, Garicia Laroon, 
Sala, 2000, Lewis 1991, Kuhnle 1991), a modified system was developed for use in the Sustainable Rivers Lab.

A false bottom was created in the flume by installing a series of eight 1-m long segments of $3 / 4$ " thick plexi-glass, with a set of pressure pillows attached to transducers below the false bottom (Figure 3.1.5). The transducers logged the total pressure at each gage in analog signals. The data was converted from analog to digital signals through the data acquisition system and recorded using National Instruments Signal Express. Meters 2 through 7 continuously monitored pressure in the water-filled pillows to estimate the sediment load over the downstream channel (Figure 3.1.7). An additional transducer in the sediment trap at the end of the flume provided a measure of water pressure The water depth was continuously monitored using a 0.1 bar gauge while the 1 bar gauges were used to monitor the sediment weight (Figure 3.1.8). After the signals were saved, data that was collected before and after each Run was manually extracted and the files converted using pressure to load calibration curves, in Matlab (see calibration data in Appendix C). The load of the water was subtracted from the total load, resulting in a measure of amount of sediment over each 1-meter section, providing accurate time sensitive data on changes in areas of sediment deposition and erosion throughout the experiments (Figure 3.1.6). This information is used in identifying areas of deposition and erosion occurring during each run segment sediment exiting the flume was collected in the sediment trap and was weighted following each stage of a dam removal. This information, in combination with the DEMs, allows for quantification of the sediment in transport in a way that has never been done before. 


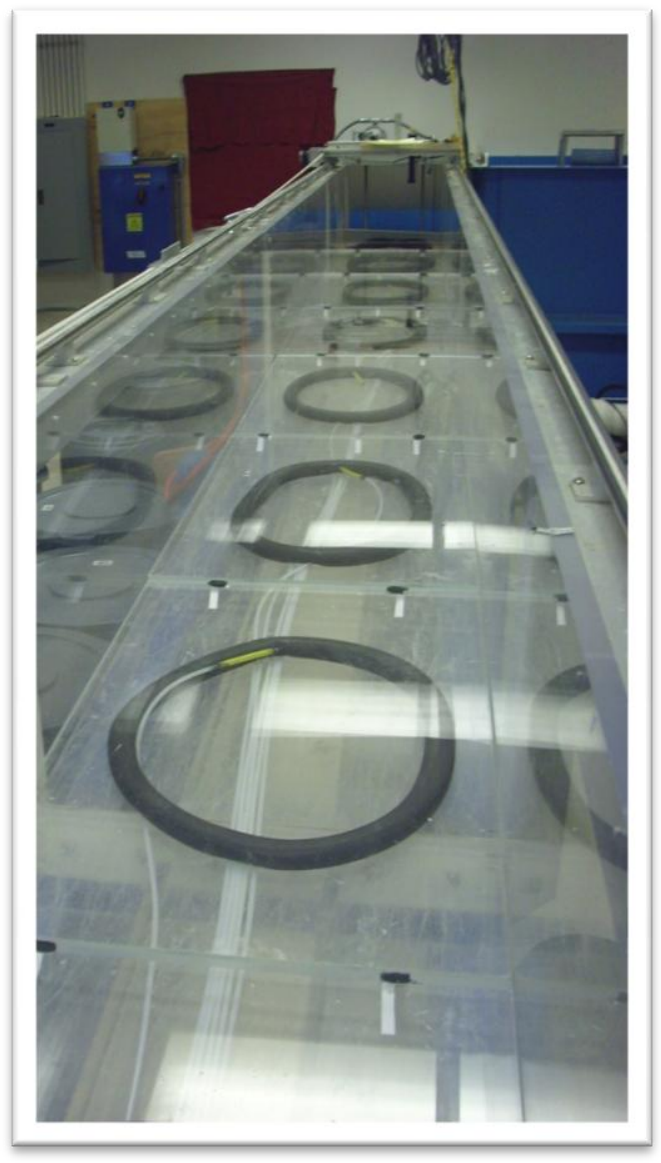

Figure 3.1.5: Photo of the of the pressure tubes installed in the flume in the Sustainable Rivers Lab. In this image, the plastic tubing from the pressure pillows is visible under the false bottom; pressure transducers are connected to each tube at the upstream end of the flume. 


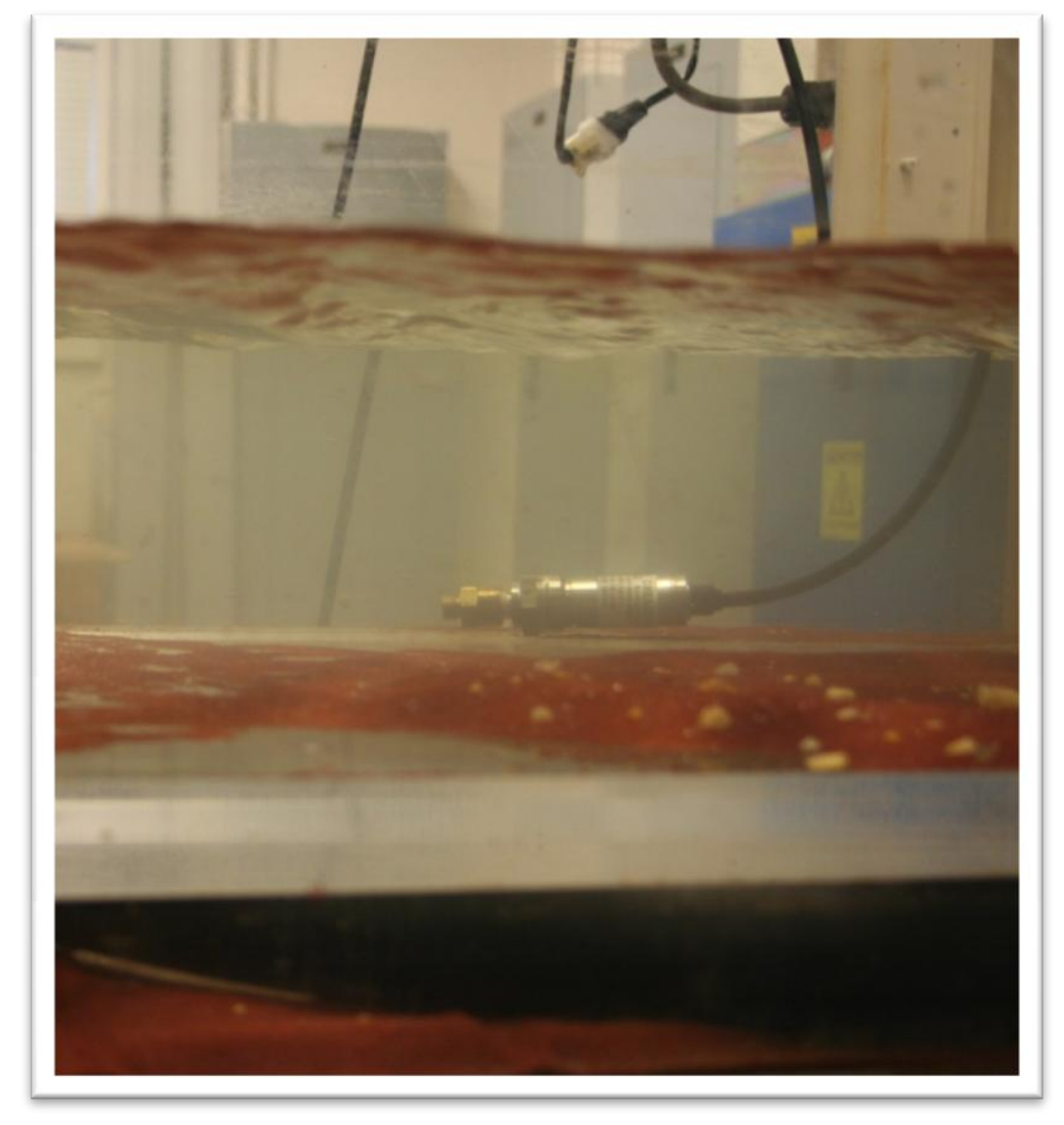

Figure 3.1.6: The water level 0.1bar gauge pressure transducer is open to the water column located in the sediment trap

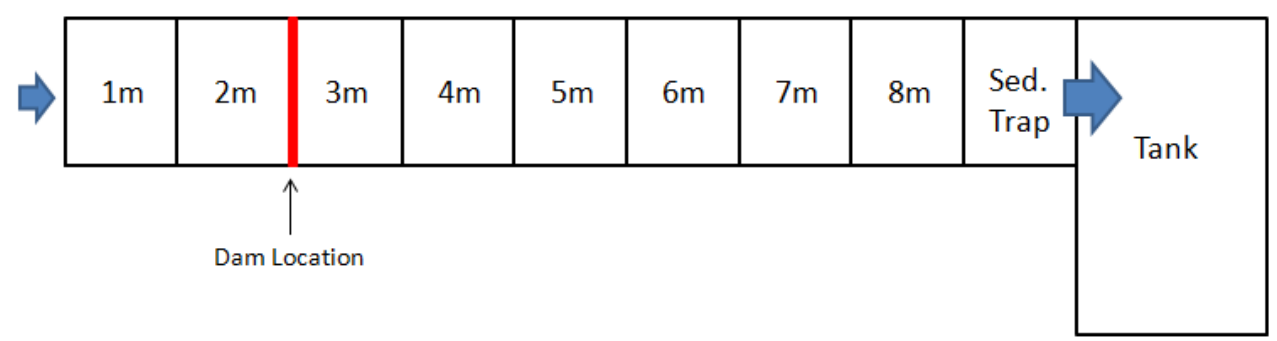

Figure 3.1.7: Aerial view of the flume schema with meters labeled, flow direction shown with blue arrows, and the dam location labeled in red 


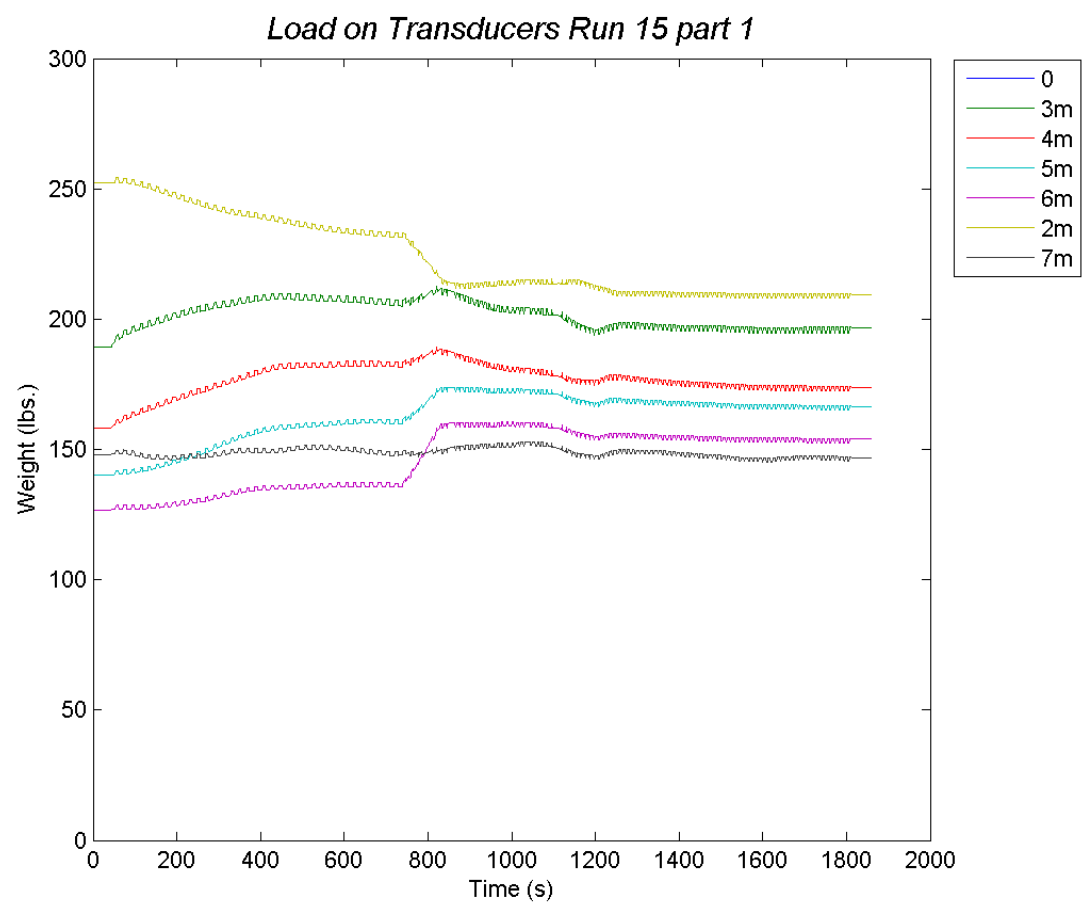

Figure 3.1.8: An example of transducer data converted from analog signals to $\mathrm{kg}$. 


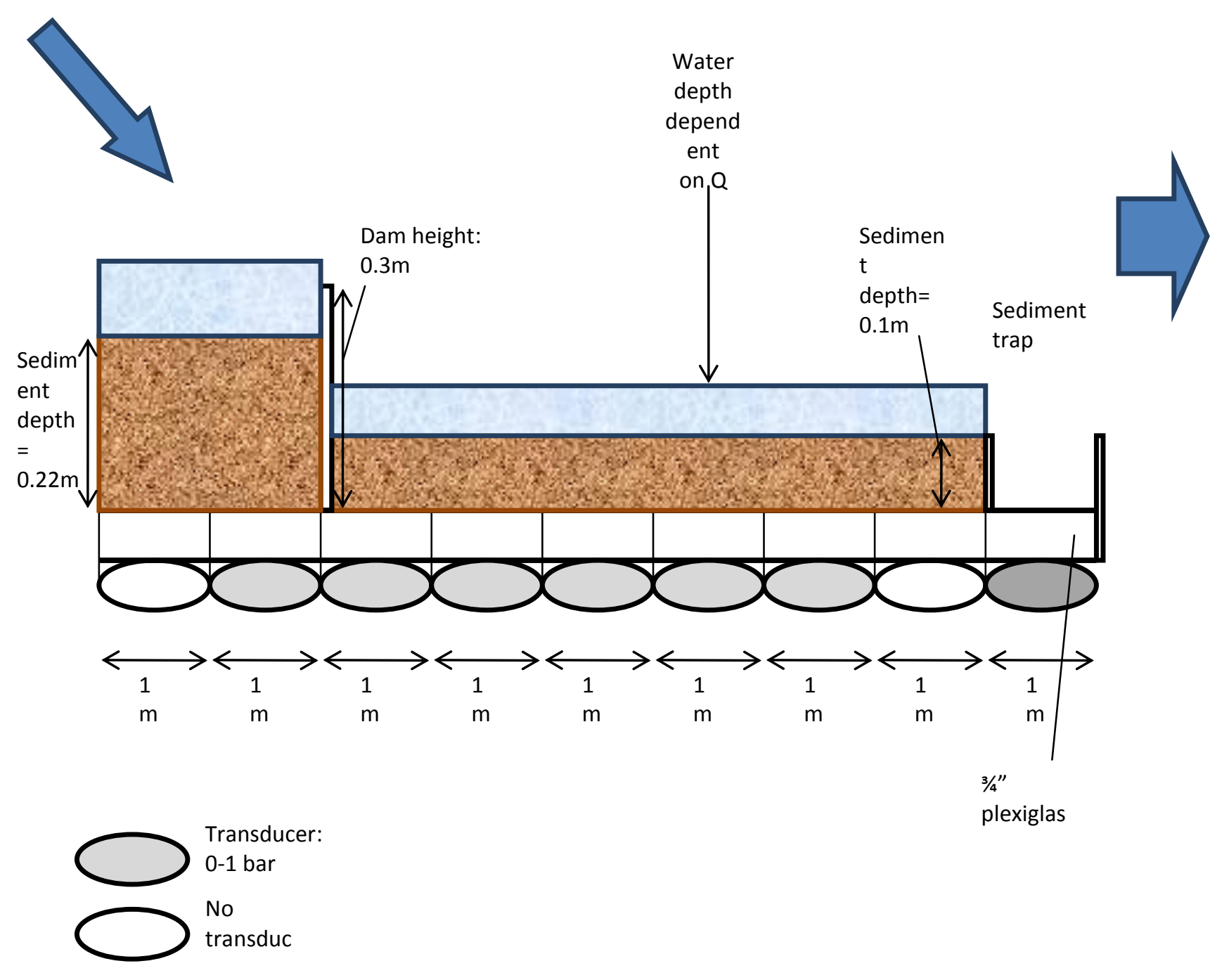

Figure 3.1.9: A profile view of the bed load monitoring schema installed in the Sustainable Rivers Lab at the University of Virginia with arrows denoting flow directions.

\subsection{Experimental Details}

\subsubsection{Scaling:}

The dams created in the flume are geometrically scaled using details on low head dam removal (ICF Consulting and Woodlot Alternatives 2005). The average ratio of dam height to dam length in the United States is 0.10 . Ideally, each simulated dam will extend across the flume width and the ratio applied to scale dam height. However, given the width constraints of the flume, the dam height would be $0.06 \mathrm{~m}$ and the sediment behind it would be $0.045 \mathrm{~m}$. Thus, the vertical scale has been exaggerated 5 fold and the dams are all $0.30 \mathrm{~m}$ high. 
The flow in the experiments is dynamically scaled using the Froude number (Fr), which is the ratio of inertial forces to gravitational forces acting on the flow.

$$
F r=\frac{U}{\sqrt{g H}}
$$

Where $\mathrm{U}=$ mean flow velocity $(\mathrm{m} / \mathrm{s}) ; \mathrm{g}=$ gravitational acceleration $\left(\mathrm{m} / \mathrm{s}^{2}\right) ;$ and $\mathrm{H}=$ flow depth (m). The Froude number scales the dynamic forces in the experiments and enables the results of flume results to be expanded to field scenarios.

The Reynolds number $(\mathrm{Re})$ is the ratio of inertial forces to viscous forces acting on the flow. It provides a dimensionless fluid scaling ratio between flume experiments and field situation and is commonly used to scale very low Reynolds number experiments. The ratio of inertial to viscous forces controls how velocity varies as a function of distance from channel boundaries

$R e=\frac{4 U R}{v} \quad$ Equation (2)

$\mathrm{R}=$ hydraulic radius $(\mathrm{m})$ and $v=$ kinematic viscosity $\left(\mathrm{m}^{2} / \mathrm{s}\right)$. Similitude of both the Reynolds and the Froude numbers can only be achieved if the fluid viscosity of the model is less than that of the prototype. Because this study focuses on open channel flows that are fully turbulent and have very large Reynolds numbers, adherence to Reynolds number scaling is relaxed and instead the flow rates in the flume were chosen to ensure a fully turbulent flow, which agrees with field conditions (see Appendix A).

The sediment used in the experiments was a mixture of sand, silt, and gravel. The sediment is not scaled. The dam size and flow hydraulics are scaled but the sediment interactions 
are not. This process has been used in past research experiments and been successful in modeling transport and channel changes (Davies 1980; Canovaro et al. 2007).

\subsubsection{Flow Rates:}

All of the flume experiments were tested under two removal flow rates. The rates were determined with the shear stress needed to mobilize the sediments in mind. The Shields number $\left(\tau_{\mathrm{c}}{ }^{*}\right)$ is the relationship between the fluid drag force acting on a sediment particle and the force resisting motion that determines whether sediment transport will occur.

$$
\tau_{c}^{*}=\frac{\tau_{c}}{(s-1) \rho g D} \quad \text { Equation (3) }
$$

where $\rho=$ fluid density $\left(\mathrm{kg} / \mathrm{m}^{3}\right) ; \tau=\rho \mathrm{U}_{*}{ }^{2} ; \mathrm{U}_{*}=$ shear velocity of uniform flow $(\mathrm{m} / \mathrm{s})=(\mathrm{gRS})^{0.5} ; \mathrm{g}=$ gravitational acceleration $\left(\mathrm{m} / \mathrm{s}^{2}\right) ; \mathrm{R}=$ hydraulic Radius or flow area/wetted perimeter; $\mathrm{s}=$ submerged specific gravity of sediment $=\rho_{\mathrm{s}} / \rho ; \rho_{\mathrm{s}}=$ sediment density $\left(\mathrm{kg} / \mathrm{m}^{3}\right) ; \mathrm{D}=$ particle diameter (m).

The discharge prior to dam removal was set to $\mathrm{Q} 1=0.0116 \mathrm{cms}$. This flow was calculated to create a subcritical flow and depth that was constant at $0.1 \mathrm{~m}$ above the dam. Depth downstream of the dam was allowed to adjust. Utilizing the flume tailgate to set water depth would have compromised the goal of simulating downstream channel changes following dam removal. The associated shear stress was expected to mobilize only the smallest sediment sizes and simulated winnowing flows downstream of dams, allowing the sediments to achieve a more natural bed surface (Figure 3.2.1). 




Figure 3.2.1: The ratio of pre-removal shear stress to the critical shear stress for the three sediment types used in these experiments

When the dam was deconstructed, the discharge was either maintained at Q1 to simulate removal during a low channel flow, or Q2 to simulate removal during a high channel flow. Q1 $=0.0116 \mathrm{cms}$ is scaled from planned dam removals and has a Froude Number of 0.195 (Burroughs et al. 2009; Wildman and MacBroom 2005; Harris 2008; Bushaw-Newton et al. 2002; Wohl and Cenderelli 2000; Doyle et al. 2003; Cheng and Granata 2007; Walter and Tullos 2010; Skalak et al. 2009; Lorang and Aggett 2005; Pohl 2004). The flow rate Q2 was $0.036 \mathrm{cms}$ with a corresponding Froude number of 0.6 (Doyle et al. 2003; Cheng and Granata 2007). Each experiment was run to completion as outlined in Section 3.4, and with the sediment composition and the dam removal sequencing held constant. The flume slope was held constant at 0.00 and the sediment bed was free to adjust its slope. At the beginning of each experiment, the area upstream of the dam was filled to $75 \%$ of the structure height $(30 \mathrm{~cm})$ with the same sediment mixture used downstream of the dam to create a channel bed $0.10 \mathrm{~m}$ thick. The result was a sediment impoundment with depth $22.5 \mathrm{~cm}$ that spanned the flume width and extended $2 \mathrm{~m}$ upstream. The volume of sediment behind the simulated dam was $0.15 \mathrm{~m}^{3}$. 


\subsubsection{Run Schedule}

Table 3.2.1: Flume Run schedule (asterisk denotes Runs that were stopped prior to completion due to excessive erosion):

\begin{tabular}{|c|c|c|c|c|c|c|}
\hline Run & $\begin{array}{l}\text { Flow } \\
\text { Rate }\end{array}$ & $\begin{array}{l}\text { Removal } \\
\text { Technique }\end{array}$ & Part 1 & Part 2 & Part 3 & Part 4 \\
\hline 2 & low & horizontal & $4 / 25 / 2012$ & $5 / 2 / 2012$ & $5 / 4 / 2012$ & $5 / 9 / 2012$ \\
\hline 3 & high & horizontal & $5 / 14 / 2012$ & $5 / 15 / 2012$ & $5 / 16 / 2012$ & $5 / 17 / 2012$ \\
\hline 4 & low & complete & $5 / 21 / 2012$ & & & \\
\hline 5 & high & complete & $5 / 24 / 2012$ & & & \\
\hline 6 & low & stepped & $5 / 28 / 2012$ & $5 / 29 / 2012$ & $5 / 30 / 2012$ & $5 / 31 / 2012$ \\
\hline 7 & high & stepped & $6 / 4 / 2012$ & $6 / 5 / 2012$ & $6 / 6 / 2012$ & $6 / 7 / 2012$ \\
\hline 8 & low & vertical from side & $6 / 11 / 2012$ & $6 / 12 / 2012$ & $6 / 13 / 2012$ & \\
\hline 9 & high & vertical from side & $6 / 15 / 2012$ & $6 / 17 / 2012$ & $6 / 18 / 2012$ & \\
\hline 10 & low & $\begin{array}{l}\text { vertical from } \\
\text { center }\end{array}$ & $6 / 20 / 2012$ & $6 / 21 / 2012$ & $6 / 22 / 2012$ & \\
\hline 11 & high & $\begin{array}{l}\text { vertical from } \\
\text { center }\end{array}$ & $6 / 26 / 2012$ & $6 / 27 / 2012$ & $6 / 28 / 2012$ & \\
\hline 12 & low & horizontal & $7 / 31 / 2012$ & $8 / 2 / 2012$ & $8 / 3 / 2012$ & $8 / 6 / 2012$ \\
\hline 13 & high & horizontal* & $8 / 8 / 2012$ & $8 / 9 / 2012$ & $8 / 10 / 2012$ & \\
\hline 14 & low & complete & $8 / 13 / 2012$ & & & \\
\hline 15 & high & complete & $8 / 15 / 2012$ & & & \\
\hline 16 & low & stepped & $8 / 20 / 2012$ & $8 / 21 / 2012$ & $8 / 22 / 2012$ & $8 / 23 / 2012$ \\
\hline 17 & high & stepped* & $8 / 27 / 2012$ & $8 / 28 / 2012$ & & \\
\hline 18 & low & vertical from side & $8 / 30 / 2012$ & $9 / 4 / 2012$ & $9 / 5 / 2012$ & \\
\hline 19 & high & vertical from side & $9 / 8 / 2012$ & $9 / 10 / 2012$ & $9 / 11 / 2012$ & \\
\hline 20 & low & $\begin{array}{l}\text { vertical from } \\
\text { center }\end{array}$ & $9 / 14 / 2012$ & $9 / 17 / 2012$ & 9/18/2012 & \\
\hline 21 & high & $\begin{array}{l}\text { vertical from } \\
\text { center }\end{array}$ & $9 / 21 / 2012$ & $9 / 24 / 2012$ & $9 / 26 / 2012$ & \\
\hline 22 & low & horizontal & $10 / 23 / 2012$ & $10 / 24 / 2012$ & $10 / 25 / 2012$ & $10 / 30 / 2012$ \\
\hline 24 & low & complete & $11 / 2 / 2012$ & & & \\
\hline 25 & high & complete & $11 / 7 / 2012$ & & & \\
\hline 30 & low & $\begin{array}{l}\text { vertical from } \\
\text { center }\end{array}$ & $11 / 9 / 2012$ & $11 / 11 / 2012$ & $11 / 12 / 2012$ & \\
\hline 31 & high & $\begin{array}{l}\text { vertical from } \\
\text { center }\end{array}$ & $11 / 14 / 2012$ & $11 / 15 / 2012$ & $11 / 16 / 2012$ & \\
\hline
\end{tabular}

\subsection{Addressing Hypotheses:}

To address goals 1 through 4, Quantify the rate and size distribution of sediment transport under different dam removal sequencing: Flume Runs tested combinations of sediment mixtures and 
dam deconstruction phasing. Five dam deconstruction sequencing scenarios were simulated in the Runs: removal in horizontal layers from the top down (Figure 1.3.1a); removal in vertical sections with the first section removed from the center of the dam (Figure 1.3.1b); removal in vertical sections with the first section removed from the right of the thalweg (Figure 1.3.1c); removal in a stepped formation from the top down with portions of the structure remaining (Figure 1.3.1d); and a complete removal (Figure 1.3.1e).

To address goal 5, Quantify the impact of sediment characteristics on the transport and deposition of impounded sediment under the range of dam removal scenarios: Three sediment mixtures were created from gravel $\left(D_{50}=8.0 \mathrm{~mm}\right)$, sand $\left(D_{50}=1.0 \mathrm{~mm}\right)$, and silt $\left.\left(\mathrm{D}_{50}=0.06 \mathrm{~mm}\right): \mathrm{a}\right)$ $70 \%$ sand $+30 \%$ gravel, b) $1 \%$ silt $+64 \%$ sand $+35 \%$ gravel and c) $2.5 \%$ silt $+85 \%$ sand $+12.5 \%$ gravel. The first sediment mixture had a $\mathrm{D}_{50}=0.65 \mathrm{~mm} \mathrm{D}_{16}=0.397 \mathrm{~mm} \mathrm{D}_{84}=4.62 \mathrm{~mm}$ with an average of $68 \%$ of the bed finer than $2 \mathrm{~mm}$. The first sediment mixture was chosen to reflect the grain size distributions of Icicle Creek Dam Removal (WA) and the Ottawa River Dam Removal $(\mathrm{OH})$ (Lorang 2005; Harris 2008). The second sediment mixture had a $\mathrm{D}_{50}=0.61 \mathrm{~mm} \mathrm{D}_{16}=0.24$ $\mathrm{mm} \mathrm{D}_{84}=4.74 \mathrm{~mm}$ with an average of $64 \%$ of the bed finer than $2 \mathrm{~mm}$. The second sediment mixture is chosen to reflect the sediment dredged prior to the Embry and Woolen Mills dam removals in Virginia as well as the Merrimack Village Dam (NH) (Pearson 2011). The third sediment mixture had a $\mathrm{D}_{50}=0.38 \mathrm{~mm} \mathrm{D}_{16}=0.15 \mathrm{~mm} \mathrm{D}_{84}=2.08 \mathrm{~mm}$ with an average of $85 \%$ of the bed finer than $2 \mathrm{~mm}$. In all three cases, the impounded sediments were primarily sand with limited quantities of gravels and silts. The third sediment, with the highest silt and sand content, was included to broaden the results of this research to dams impounding primarily fine-grained sediments on low gradient channels. Channel bed and impoundment sediment were comprised of 
the same mixture because a river is expected to have impounded sediment that has the same size distribution as the channel bed.

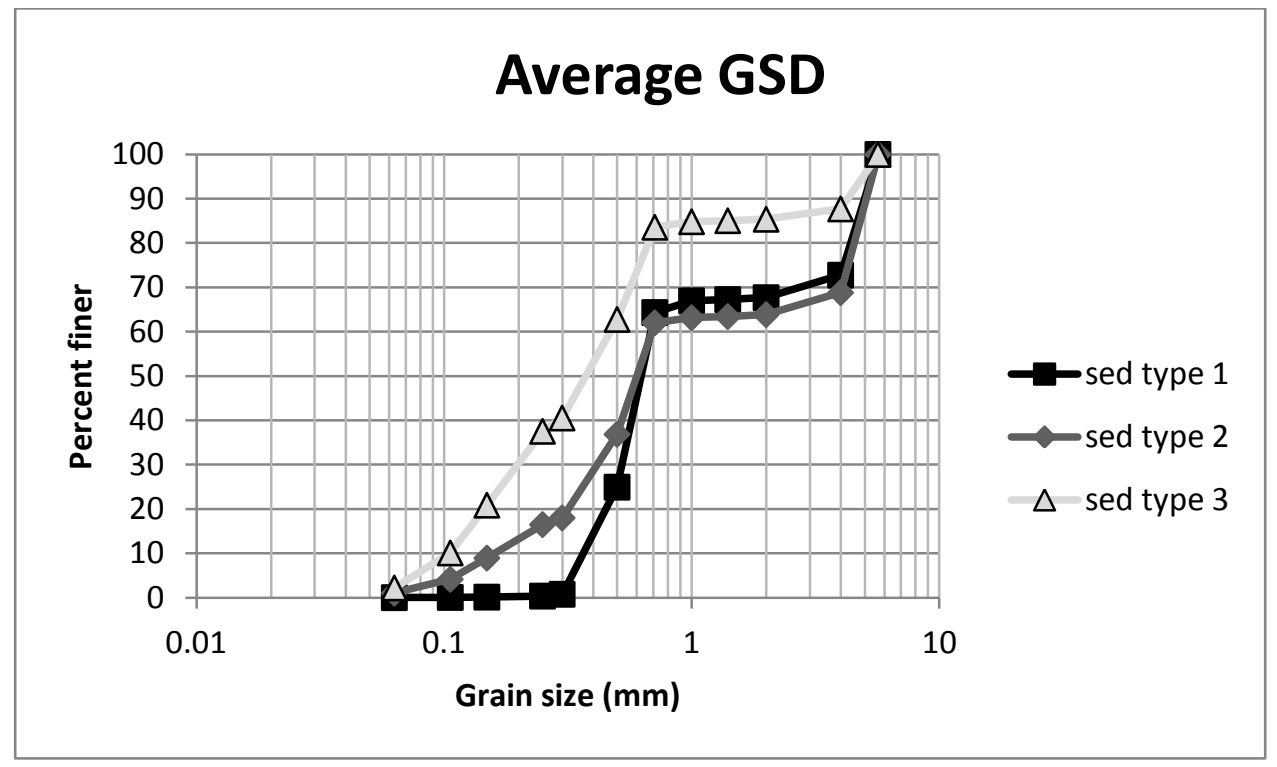

Figure 3.3.1: Average grain size distribution for the three sediment types used in the experiments

To address goal 6, Quantify the impact of the flow rate on the transport and deposition of impounded sediment under the range of dam removal scenarios. Two flow rate scenarios were tested. The first was scaled to replicate the low flow conditions, as many dam removals are planned for low flows. Removing the dams during low flows allows the downstream channel time to adjust to the increased flow rates and incoming reservoir sediment before large storms arrive. The second testing scenario was scaled to high flow rates typical in an unplanned removal, such as dam failure, and a few planned dam removals. This scenario allowed us to quantify the channel response under flood conditions and provide decision makers with information to evaluate the risk of dam failure in comparison with planned removals. 


\subsection{Experimental Procedure:}

Flume experiments were initially slated to be performed for each of the 3 sediment mixtures ( $\mathrm{a}, \mathrm{b}$ and $\mathrm{c}$ ), each of the 5 dam removal scenarios (top down, vertical from middle, vertical from the side, stepped, and complete removal), and each of the flow rate scenarios (low flow: Q2 and high flow: Q3). Two Runs, horizontal and stepped high flow for sediment type 2, were not run to completion due to excessive erosion immediately downstream of the dam piece that exposed the plexiglass below the sediment. Continuing the experiments under these conditions would have resulted in underestimating the sediment transport that would take place without the artificial datum present. The third sediment type was run under three removal techniques, with stepped removal and vertical removal from the side not repeated due to similarities with previous Runs. Vertical removal from the center was run under both flow conditions in the third sediment type, and horizontal removal was executed under low flow conditions. Thus, there were 10 flume experiments for each simulated dam for the first sediment type, 8 completed experiments for the second sediment type and 5 completed experiments for the third sediment type, There were 23 complete flume experiments in total, with a duplicate of the first Run to verify the precision of the equipment and methodology (Table 1).

\subsubsection{Detailed Procedure}

The procedure for each experiment was held constant throughout all of the Runs to ensure that the changes observed were entirely based on the parameters that were being investigated.

Step 1: Create Bed. The channel bed was well mixed following the previous Run and grab samples of the sediment were taken at $2 \mathrm{~m}$ increments throughout the flume to identify the initial grain size distribution prior to removal. The bed was screeded level at $0.1 \mathrm{~m}$ throughout the length of the flume. 
Step 2: Prepare Bed. A low flow (Q1) was run for a minimum 10 hours over the sediment bed to allow for the winnowing of fines from the bed surface and to better represent the state of a river downstream of a dam. The sediment did not fully mobilize under this flow for the first two sediment types investigated, but there was sediment in transport under the third sediment type prior to removal (Figure 3.2.1).

Step 3: Place Dam. The dam piece or series of pieces were inserted at the upstream end of the flume, $2 \mathrm{~m}$ downstream of where the water enters the system. The dam pieces were constructed from a series of plexi-glass pieces abutted against two L-brackets permanently attached to the edges of the flume, as shown in Figure 1.

Step 4: Form Impoundment. The area above the dam was filled with the same sediment mix that was used to create the channel bed. Sediment was filled to $75 \%$ of the maximum dam height which corresponded to a $22.5 \mathrm{~cm}$ reservoir sediment depth, representing a dam that has been in existence for a long time and filled with sediment.

Step 5: Pre-Removal Flow. A constant flow rate of Q1 was run through the channel to allow the reservoir sediment to adjust to the flow rate, emulating a channel where the dam had been in place for years prior to removal.

Step 6: Bed Surface Measurements. Measurements made prior to disturbance included grain size distribution and geomorphic variability of the bed topography. The sediment was three different colors to facilitate grain size identification by color: the pea gravels were light brown, the sand was a chocolate brown and the fine sand/silt blend was white. A fine resolution DEM of the initial bed surface was created from a digital scan of the bed surface using the profiler. A camera scan was also performed that allowed for the percent sand on the bed surface to be quantified. 
Step 7: Initialize flow: Slowly increase the flow entering the flume channel to minimize disturbance to the bed. Set the flow rate to the desired testing rate (Q1 or Q2).

Step 8: Part One. The first part of dam removal occurred, with the first section being removed, releasing the impounded sediment. Suspended sediment was sampled at 2-minute intervals at the downstream end of the flume to create a continuous record of the suspended sediment concentration leaving the system throughout each experiment. Samples were taken as grab samples from the flow column. Although sediment was not recirculated, there was the possibility that the finest size fractions could enter the water recirculation system and discharge into the upstream end of the flume. To account for this possibility, suspended sediment samples were taken from the incoming flow upstream of the dam once every 5 minutes following each phase of dam removal. Bedload transport into the sediment trap was captured in images at 10-second intervals with a stationary camera operated through LabView to create a continuous transport record for each experiment. In addition to monitoring the bed load exiting the flume, continuous load monitoring took place throughout the flume with the use of the pressure sensors described in Chapter 3.1. A still camera and a video camera were used to visually capture the changing bed surface. The video camera was critical for capturing the immediate and time sensitive changes that occurred as the dam was being removed. The still photos were taken to document notable changes at my discretion. Sediment elevation and water level were manually collected every 2 minutes at $0.5 \mathrm{~m}, 1.5 \mathrm{~m}, 2.1 \mathrm{~m}, 2.5 \mathrm{~m}, 3.5 \mathrm{~m}, 4.5 \mathrm{~m}, 5.5 \mathrm{~m}, 6.5 \mathrm{~m}$ and $7.5 \mathrm{~m}$. The cameras, transducers, manual bed elevation data and sediment trap data allowed me to record time sensitive data in between the digital elevation scans, as scanning the bed required the flume to be drained prior to data collection. The combination of photographs, DEMs, and continuous bed load measurements provides a combination of qualitative and quantitative data. 
Step 9: Bed Surface Measurements. When the sediment transport had reduced to less than $10 \%$ of its initial (or peak) transport rate, which in most cases was 30 minutes after the removal of the dam piece, the flume was stopped and the bed surface downstream of the dam recorded through still photos, and a DEM was created, as detailed in step 6. The sediment trap was emptied, weighed, and the sediment sieved for grain size composition. The suspended sediment samples were filtered, dried, and weighed prior to the removal of the next step.

Step 10: Part Two. Following the second phase of dam removal. Bed load and suspended sediment were measured as in step 8 . Once sediment transport rates had reduced to less than $10 \%$ of the peak rate following the second deconstruction phase, the flume was stopped and bed surface measurements conducted, similar to steps 6 and 9. This step was repeated until all phases of dam deconstruction were complete and a final set of bed surface measurements recorded.

Step 11: Bed Removal and Analysis. Following the final bed surface evaluation, sediment samples of the subsurface were collected, dried, and sieved to measure any differences in the grain size distributions between the bed load, bed surface, active layer, and subsurface.

\subsubsection{Post Experiment}

At the end of each Run, a data set existed that described the bed surface in detail and total transport rates prior to removal, following each phase of dam deconstruction, including post dam removal. Flow parameters in each data set included: flow rate, flow velocity, Froude number, bed slope, water slope, and flow depth. Sediment parameters in each data set included: total transport rate, suspended sediment transport rate, and the volumes of sediment exported from the downstream reach, deposited in the downstream reach, and remaining stationary. The composition of sediment in the downstream channel was documented in each data set through: the grain size distribution of the bed surface, percent of bed surface covered by sand, and the 
distribution of sand, silt, and gravel in the sediment bed following dam removal. The following are calculated for each data set: shear velocity (eqn. 1), friction factor (eqn. 2), Manning's n (eqn. 3), and shear stress (eqn. 4).

$U_{*}=\sqrt{g R S_{e}}$ equation (3.1)

$f f=\frac{8 U_{*}}{U}$

equation (3.2)

$n=\frac{A R^{2 / 3} \sqrt{S_{e}}}{Q}$

equation (3.3)

$\tau=\rho g R S_{e}$

equation (3.4)

where $U_{*}$ is shear velocity, $U$ is velocity $(\mathrm{m} / \mathrm{s}), \mathrm{g}$ is gravity $\left(\mathrm{m}^{2} / \mathrm{s}\right), \mathrm{S}_{\mathrm{e}}$ is energy slope, $\mathrm{R}$ is hydraulic radius $(\mathrm{m}), f f$ is friction factor, $\rho$ is water density $\left(\mathrm{g} / \mathrm{m}^{3}\right), \mathrm{A}$ is flow area $\left(\mathrm{m}^{2}\right)$, and $\mathrm{Q}$ is total discharge $\left(\mathrm{m}^{3} / \mathrm{s}\right)$. These variables were used in testing the hypotheses and to meet the overall objectives of this work. 


\section{Chapter 4: Impact of Removal Technique}

\subsection{Introduction:}

With the increased prevalence of dam removal, it is important to understand the impact that various methods of structural removal has on the downstream channel. While flow rate and sediment type are site dependent parameters, removal technique is a factor that decision makers can often control, and this study may provide insight into technique selection based on desired downstream impacts. Five common methods for removing low head dams (complete, vertical from the center, vertical from the side, partial with the sides remaining, and horizontal removal) were tested under two flow conditions and three sediment types to quantify changes in the downstream channel bed topography associated with each removal method.

The removal methodologies investigated in this series of experiments were aimed at identifying sediment deposition patterns as a result of the size and location of the portion of the dam removed. The two vertical removal techniques tested had the same size openings following the removal of each section, but the removal location varied. The location of the first section removed has long been speculated in the field to influence the impact to the downstream channel, but removal location was often dictated by constructability and site access issues. This is the first study where the multiple removal mechanisms have been directly analyzed under the same conditions. Similarly, this is the first time where the benefits of leaving the sides and base of the structure in place, which has been used to minimize downstream sediment transport and mark historical landmarks, can be directly compared to the downstream impacts of completely removing the structure. The goal of that comparison is to learn if leaving a portion of the structure aids in stabilizing the reservoir sediments and preventing them from transporting downstream. 

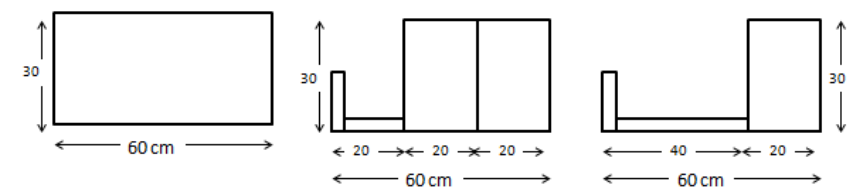

Figure 4.1.1a Vertical Removal from the Side
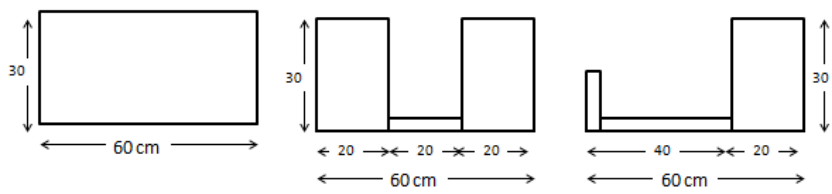

Figure 4.1.1b Vertical Removal from the Center
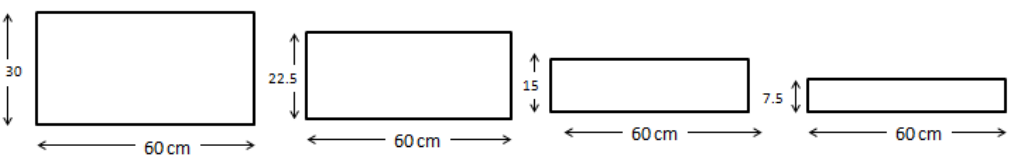

Figure 4.1.1c Horizontal Removal
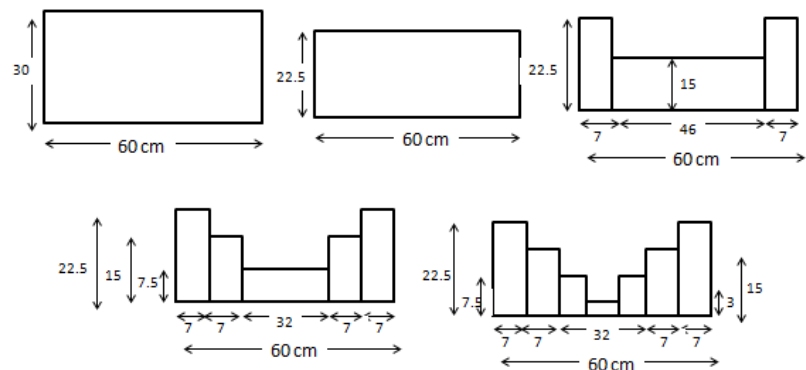

Figure 4.1.1d Stepped Removal

\subsection{Removal Technique Results}

Sediment deposition and erosion patterns downstream of the dam location were identified using the Digital Elevation Models (DEMs) created from the Micro-Epsilon laser scans of the bed. The digital elevation databases were converted from terrains to rasters in GIS and a raster difference was completed to identify and quantify the areas of deposition and erosion as each piece of the dam was removed, as well as from the Preremoval to Final bed (Table 4.2.1; Table 4.2.2; Appendix F). The total sediment transported out of the reach following each 
deconstruction step was also monitored to quantify the amount of sediment traveling further downstream than the first 10 channel widths below the removal location.

Table 4.2.1: Summary of the change in total sediment (in $\mathrm{kg}$ ) over the downstream channel length from the dam expressed as the sediment weight found from the raster difference of the bed scans from Preremoval to Final bed (negative values denote erosion and positive values deposition)

\begin{tabular}{|r|r|r|r|r|r|r|r|r|}
\hline Run & $2 \mathrm{~m}$ & $3 \mathrm{~m}$ & $4 \mathrm{~m}$ & $5 \mathrm{~m}$ & $6 \mathrm{~m}$ & $7 \mathrm{~m}$ & $8 \mathrm{~m}$ & $3 \mathrm{~m}-8 \mathrm{~m}$ \\
\hline 2 & -52.25 & -5.96 & -1.19 & -5.61 & -2.64 & 10.26 & 21.1 & 15.96 \\
\hline 3 & -120.95 & -52.63 & 9.10 & 18.3 & 7.791 & -6.17 & -3.22 & -26.8 \\
\hline 4 & -64.45 & 11.44 & 15.44 & 15.56 & 17.06 & 16.82 & 7.72 & 84.04 \\
\hline 5 & -54.88 & -0.61 & -1.02 & -2.01 & -8.79 & -10.24 & -6.49 & -29.2 \\
\hline 6 & -50.42 & 8.92 & 21.56 & 4.83 & -4.36 & 4.71 & -2.66 & 32.99 \\
\hline 7 & -117.12 & -51.96 & -9.96 & 2.55 & -4.4 & 6.99 & 11.61 & -45.2 \\
\hline 8 & -75.93 & 18.33 & 19.53 & 19.59 & 6.47 & 7.85 & 9.52 & 81.29 \\
\hline 9 & -79.40 & -11.27 & 8.639 & 13.71 & 7.82 & 0.54 & -2.94 & 16.5 \\
\hline 10 & -42.00 & 0.04 & 2.57 & 1.44 & 0.14 & 3.30 & 0.59 & 8.07 \\
\hline 11 & -96.89 & 10.91 & 23.05 & 20.58 & 12.41 & 5.78 & 0.97 & 73.7 \\
\hline 12 & -62.2 & 49.44 & 18.78 & 8 & 7.01 & 1.71 & 6.23 & 91.16 \\
\hline 13 & -9.82 & -78.02 & 7.20 & 0.20 & 2.37 & 3.13 & -1.81 & -66.9 \\
\hline 14 & -49.58 & 29.88 & 25.79 & 11.82 & 16.61 & 9.70 & 12.18 & 106 \\
\hline 15 & -91.45 & 15.88 & 8.29 & -2.30 & -8.22 & -11.51 & -7.97 & -5.84 \\
\hline 16 & -5.30 & 6.84 & 1.11 & 0.32 & -0.21 & -0.34 & -0.45 & 7.28 \\
\hline 17 & 24.24 & -48.21 & 5.33 & 5.15 & 1.10 & -2.82 & -2.37 & -41.8 \\
\hline 18 & -49.58 & 39.89 & 12.03 & 3.35 & 4.58 & 4.05 & 15.08 & 78.98 \\
\hline 19 & -135.32 & -66.52 & 11.63 & 4.44 & 9.68 & 2.72 & -0.64 & -38.7 \\
\hline 20 & -53.78 & 63.87 & 11.34 & 6.08 & 1.30 & 6.43 & 8.53 & 97.55 \\
\hline 21 & -129.55 & -65.09 & 14.53 & 19.46 & 3.55 & -4.50 & -9.95 & -42 \\
\hline 22 & -44.16 & 31.85 & 32.97 & 49.17 & 7.62 & 2.17 & 8.25 & 132 \\
\hline 24 & -52.74 & 12.81 & 15.76 & 24.77 & 17.48 & 0.27 & 0.01 & 71.11 \\
\hline 25 & -85.33 & -7.08 & -24.4 & -17.97 & -6.34 & -2.71 & -13.1 & -71.6 \\
\hline 30 & -26.83 & 12.15 & 14.18 & 10.91 & 8.60 & 0.73 & -1.81 & 44.75 \\
\hline 31 & -96.62 & -93.74 & -5.25 & -22.25 & -17.46 & -40.59 & -25.9 & -205 \\
\hline
\end{tabular}


Table 4.2.2: Summary of the change in total sediment (in $\mathrm{kg}$ ) over the downstream channel length expressed as the sediment weight found from the raster difference of the bed scans by part (negative values denote erosion and positive values deposition)

\begin{tabular}{|c|c|c|c|c|c|c|c|c|c|}
\hline & & 2 & 3 & 4 & 5 & 6 & 7 & 8 & $3-8$ net \\
\hline \multirow[t]{4}{*}{ run2 } & prepart1 & -6.06 & 0.71 & 9.34 & -2.22 & -2.30 & 2.54 & 0.31 & 8.38 \\
\hline & part1part2 & -7.56 & 8.36 & 3.31 & 7.34 & -0.62 & 6.90 & 0.74 & 26.03 \\
\hline & part2part3 & -34.30 & -11.52 & -11.02 & -7.09 & 2.88 & 3.51 & 23.76 & 0.52 \\
\hline & part 3 part 4 & -4.47 & -3.51 & -2.81 & -3.71 & -2.67 & -2.69 & -3.73 & -19.11 \\
\hline \multirow[t]{4}{*}{ run3 } & prepart1 & -46.19 & -117.62 & 10.87 & 21.82 & 12.10 & -2.06 & 1.26 & -73.63 \\
\hline & part1part2 & -49.73 & 33.52 & -0.77 & -1.44 & -3.20 & -3.21 & -2.94 & 21.98 \\
\hline & part2part3 & -16.81 & 20.80 & -0.43 & -1.70 & -1.17 & -0.94 & -0.99 & 15.57 \\
\hline & part 3 part 4 & -8.41 & 10.67 & -0.62 & -0.44 & 0.05 & 0.02 & -0.60 & 9.08 \\
\hline run4 & prepart1 & -64.46 & 11.44 & 15.44 & 15.56 & 17.07 & 16.82 & 7.72 & 84.06 \\
\hline run5 & prepart1 & -54.89 & -0.61 & -1.02 & -2.01 & -8.80 & -10.24 & -6.49 & -29.17 \\
\hline \multirow[t]{4}{*}{ run6 } & prepart1 & -54.89 & -0.61 & -1.02 & -2.01 & -8.80 & -10.24 & -6.49 & -29.17 \\
\hline & part1part2 & -30.65 & -10.83 & 13.08 & 0.54 & -5.93 & 3.22 & -7.19 & -7.10 \\
\hline & part2part3 & -15.84 & 20.59 & 6.88 & 3.65 & 3.13 & 2.24 & 3.10 & 39.58 \\
\hline & part 3 part 4 & -0.16 & -13.08 & -4.21 & -4.12 & -4.04 & -7.50 & -7.24 & -40.19 \\
\hline \multirow[t]{4}{*}{ run7 } & prepart1 & -10.46 & -49.86 & 14.94 & 18.42 & 3.71 & 13.54 & 11.50 & 12.24 \\
\hline & part1part2 & -51.47 & -15.40 & 5.51 & 5.17 & 4.57 & 2.84 & 4.03 & 6.73 \\
\hline & part2part3 & -54.08 & 17.26 & -30.91 & -21.01 & -13.50 & -9.62 & -2.82 & -60.61 \\
\hline & part3part4 & 3.64 & -3.96 & 0.57 & 0.02 & 0.84 & 0.25 & -1.26 & -3.54 \\
\hline \multirow[t]{3}{*}{ run8 } & prepart1 & -69.47 & 23.56 & 19.27 & 26.13 & 11.82 & 10.74 & 2.32 & 93.84 \\
\hline & part1part2 & -6.17 & 1.43 & 2.75 & -2.01 & -2.01 & -1.50 & 7.97 & 6.64 \\
\hline & part2part3 & -0.31 & -6.66 & -2.48 & -4.57 & -3.38 & -1.46 & -0.80 & -19.34 \\
\hline \multirow[t]{3}{*}{ run9 } & prepart1 & -66.44 & -7.06 & 13.10 & 19.11 & 12.89 & 3.28 & 0.13 & 41.46 \\
\hline & part1part2 & -10.80 & 3.63 & -2.97 & -5.20 & -5.26 & -2.92 & -3.20 & -15.93 \\
\hline & part2part3 & -2.26 & -7.87 & -1.56 & -0.23 & 0.18 & 0.20 & 0.06 & -9.22 \\
\hline \multirow[t]{3}{*}{ run10 } & prepart1 & -41.55 & 11.13 & 9.11 & 8.86 & 7.66 & 9.49 & 3.43 & 49.67 \\
\hline & part1part2 & -7.60 & 1.18 & -5.80 & -8.12 & -7.63 & -5.59 & -2.08 & -28.04 \\
\hline & part 2 part 3 & 7.12 & -12.27 & -0.76 & 0.71 & 0.11 & -0.61 & -0.78 & -13.60 \\
\hline \multirow[t]{3}{*}{ run11 } & prepart1 & -94.24 & 10.22 & 31.67 & 28.70 & 23.35 & 14.87 & 7.64 & 116.44 \\
\hline & part1part2 & -5.37 & -1.24 & -7.54 & -7.34 & -9.16 & -6.90 & -6.22 & -38.40 \\
\hline & part2part3 & 2.67 & 1.94 & -1.13 & -0.82 & -1.78 & -2.21 & -0.48 & -4.48 \\
\hline \multirow[t]{4}{*}{ run12 } & prepart1 & -1.54 & 3.45 & 2.50 & 2.10 & 1.93 & 2.70 & 2.13 & 14.80 \\
\hline & part1part2 & -50.05 & 45.62 & 20.32 & 11.52 & 9.91 & 0.80 & 1.15 & 89.33 \\
\hline & part2part3 & -11.12 & 1.84 & -1.50 & -2.97 & -2.50 & -0.23 & 5.44 & 0.07 \\
\hline & part 3 part 4 & 0.45 & -1.54 & -2.57 & -2.65 & -2.33 & -1.54 & -2.48 & -13.11 \\
\hline run13 & prepart1 & -9.82 & -78.04 & 7.20 & 0.20 & 2.37 & 3.13 & -1.81 & -66.94 \\
\hline
\end{tabular}




\begin{tabular}{|c|c|c|c|c|c|c|c|c|c|}
\hline run14 & prepart1 & -49.59 & 29.88 & 25.79 & 11.82 & 16.62 & 9.71 & 12.19 & 106.01 \\
\hline run15 & prepart1 & -91.46 & 15.88 & 8.29 & -2.30 & -8.22 & -11.51 & -7.98 & -5.84 \\
\hline \multirow[t]{4}{*}{ run16 } & prepart1 & -5.30 & 6.84 & 1.11 & 0.32 & -0.21 & -0.34 & -0.45 & 7.28 \\
\hline & part1part2 & -34.49 & 13.15 & 20.48 & 15.82 & 16.15 & 14.62 & 11.85 & 92.07 \\
\hline & part2part3 & -24.06 & -3.27 & -7.51 & -6.33 & -4.72 & -2.44 & -1.95 & -26.22 \\
\hline & part3part4 & -5.89 & 1.81 & -0.28 & -2.57 & -4.33 & -4.74 & -2.61 & -12.72 \\
\hline run17 & prepart1 & 24.25 & -48.22 & 5.33 & 5.15 & 1.10 & -2.82 & -2.37 & -41.82 \\
\hline \multirow[t]{3}{*}{ run18 } & prepart1 & -56.49 & 35.90 & 19.91 & 8.83 & 6.42 & -2.30 & -1.12 & 67.63 \\
\hline & part1part2 & 4.46 & 1.44 & -5.26 & -4.17 & -0.79 & 4.93 & 7.78 & 3.93 \\
\hline & part2part3 & 2.36 & 2.57 & -2.65 & -1.31 & -1.03 & 1.42 & 8.43 & 7.43 \\
\hline \multirow[t]{3}{*}{ run19 } & prepart1 & -133.96 & -82.48 & 14.20 & 6.86 & 11.05 & 2.33 & 0.13 & -47.92 \\
\hline & part1part2 & 2.59 & 10.91 & -2.61 & 0.27 & 0.60 & 2.36 & -0.21 & 11.33 \\
\hline & part2part3 & -3.97 & 5.04 & 0.05 & -2.69 & -1.97 & -1.97 & -0.55 & -2.10 \\
\hline \multirow[t]{3}{*}{ run20 } & prepart1 & -33.81 & 68.61 & 23.42 & 2.82 & 1.92 & 1.98 & 2.88 & 101.63 \\
\hline & part1part2 & -11.44 & 4.16 & -3.90 & 5.75 & 0.70 & 4.18 & 3.84 & 14.74 \\
\hline & part2part3 & -8.59 & -8.89 & -8.20 & -2.47 & -1.33 & 0.25 & 1.84 & -18.79 \\
\hline \multirow[t]{3}{*}{ run21 } & prepart1 & -105.82 & -73.98 & 20.47 & 25.74 & 9.83 & 2.59 & -1.53 & -16.88 \\
\hline & part1part2 & -23.23 & -65.10 & 14.54 & 19.46 & 3.55 & -4.50 & -9.95 & -42.01 \\
\hline & part2part3 & -0.52 & 73.98 & -20.47 & -25.74 & -9.83 & -2.59 & 1.53 & 16.88 \\
\hline \multirow[t]{4}{*}{ run22 } & prepart1 & -22.14 & 10.08 & -0.11 & -0.05 & -1.06 & -2.78 & -0.65 & 5.43 \\
\hline & part1part2 & -4.55 & 12.92 & 26.12 & 3.16 & 0.44 & -1.45 & 0.69 & 41.87 \\
\hline & part2part3 & -20.61 & 4.30 & 2.11 & 35.37 & -1.48 & -1.15 & 0.67 & 39.82 \\
\hline & part3part4 & 3.10 & 7.54 & 4.87 & 10.72 & 9.71 & 7.54 & 7.53 & 47.91 \\
\hline run24 & prepart1 & -52.75 & 12.81 & 15.76 & 24.78 & 17.49 & 0.27 & 0.01 & 71.12 \\
\hline run25 & prepart1 & -85.35 & -7.08 & -24.38 & -17.97 & -6.34 & -2.71 & -13.11 & -71.59 \\
\hline \multirow[t]{3}{*}{ run30 } & prepart1 & -21.69 & 16.49 & 18.74 & 12.12 & 2.13 & 1.60 & 1.93 & 53.01 \\
\hline & part1part2 & -2.39 & -3.56 & -2.79 & -0.08 & 3.34 & -2.33 & -2.87 & -8.29 \\
\hline & part2part3 & -2.86 & -0.80 & -1.80 & -1.14 & 3.13 & 1.45 & -0.87 & -0.03 \\
\hline \multirow[t]{3}{*}{ run31 } & prepart1 & -107.99 & -95.35 & 10.99 & -8.42 & 4.61 & -16.39 & -9.26 & -113.81 \\
\hline & part1part2 & -9.04 & 12.58 & -10.93 & -12.23 & -18.42 & -18.01 & -13.39 & -60.40 \\
\hline & part2part3 & 20.40 & -10.98 & -5.36 & -1.64 & -3.68 & -6.21 & -3.23 & -31.10 \\
\hline
\end{tabular}

\subsubsection{Horizontal Removal}

Horizontal removal corresponds to Runs 10, 20 and 30 under low flows and Runs 11, 21 and 31 under high flows. The first portion of the structure was removed, bringing the height of the remaining dam to $22.5 \mathrm{~cm}$ or level with the reservoir sediment, and minimal change in the 
downstream channel was observed. The majority of the downstream deposition following horizontal removal occurred following the removal of the second dam piece (Run 2: $26 \mathrm{~kg}$, Run 12: $89 \mathrm{~kg}$, and Run 22: $42 \mathrm{~kg}$, Figure 4.2.1), which coincided with the reservoir sediment height becoming higher than the remaining dam height. Downstream erosion was observed following low flow horizontal removal in the first two sediment types after the fourth dam piece was removed and was deposited in the downstream sediment trap. However, the amount of erosion was less than the total amount of deposition for the run, resulting in a net amount of deposition Pre to Final bed of $16 \mathrm{~kg}$ for sediment type $1,91 \mathrm{~kg}$ for sediment type 2 , and $132 \mathrm{~kg}$ for sediment type 3.

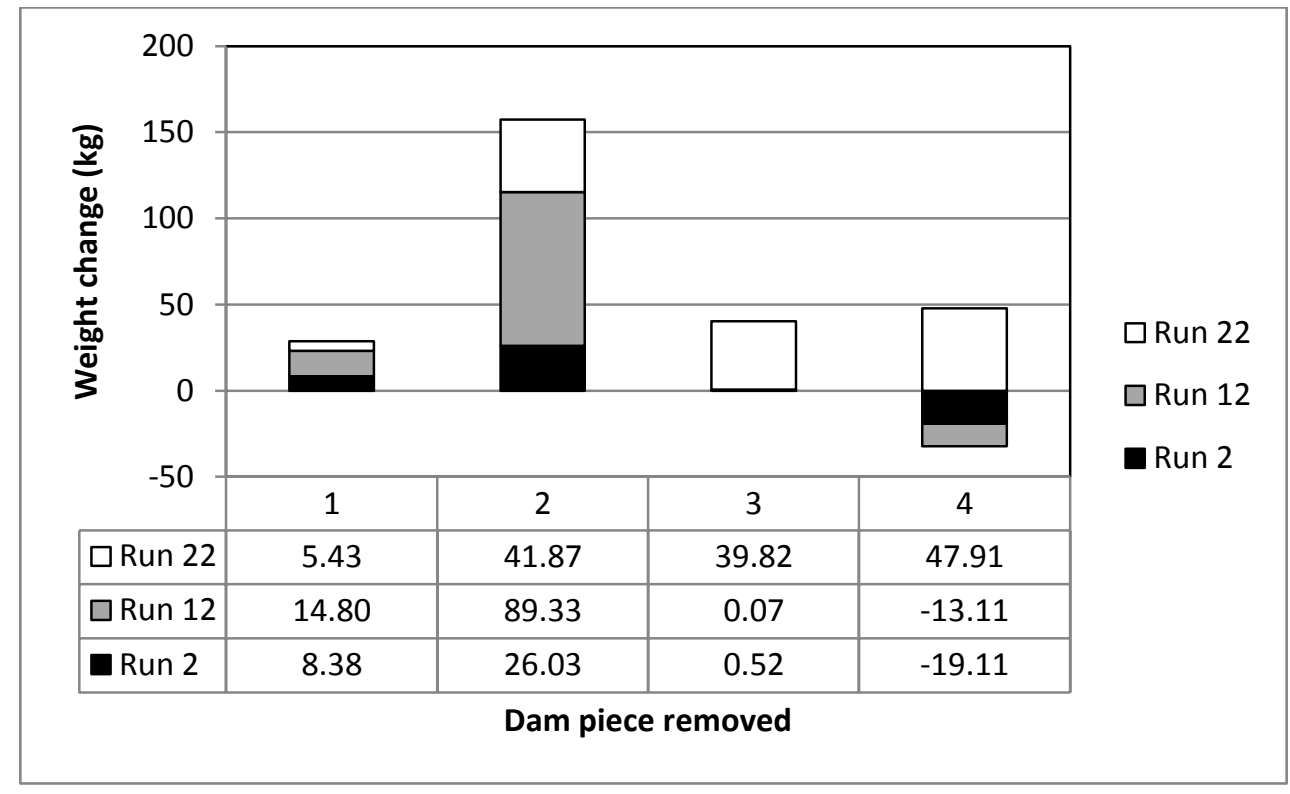

Figure 4.2.1: The change in total sediment over the downstream channel length from the dam expressed as the sediment weight found from the raster difference of the bed scans following the removal of each part following horizontal removal $\left(1 \mathrm{~m}^{3}=2650 \mathrm{~kg}\right)$

\subsubsection{Complete Removal}

Removing the structure in a single step is referred to here as complete removal. Complete removal under low flow conditions corresponds to Runs 4, 14 and 24 while Runs 5, 15 and 25 were complete removals under high flows. The behavior of the bed following low flow complete 
removal followed a general trend of reservoir erosion and downstream channel deposition. Following complete removal under low flow conditions, $84 \mathrm{~kg}$ deposited within the 10 channel widths downstream during the first sediment type tested (Run 4), $147 \mathrm{~kg}$ deposited in that reach with the second sediment type (Run 14) and $71 \mathrm{~kg}$ deposited during the third sediment type (Run 24; Table 4.2.1). All low flow complete removal runs exhibited deposition throughout the downstream channel regardless of sediment type. The percentage of the total downstream deposition that occurred decreased with distance downstream. Following Run 4; only 9\% of the total downstream deposition occurred at 8m and following Run 14 9\% of total deposition occurred at $7 \mathrm{~m}$ and $11.5 \%$ at $8 \mathrm{~m}$ which are among the lowest percentages for the run. The remainder of deposition occurred closer to the location of the removal. The higher silt content of the third sediment type resulted in a sediment slug which deposited between 3 to $6 \mathrm{~m}$ with $15 \%$, $22.2 \%, 34.8 \%$ and $24.6 \%$ of the deposition occurring at $3,4,5$, and $6 \mathrm{~m}$ respectively, and only $0.3 \%$ and $0.002 \%$ of the deposition occurring at 7 and $8 \mathrm{~m}$.

\subsubsection{Stepped removal}

Leaving the sides of the structure in place is a mechanism often employed for historical reasons or to minimize reservoir erosion. Stepped removal under low flows corresponds to Runs 6 and 16 and to Runs 7 and 17 under high flows. Overall, there was deposition on the downstream bed regardless of low or high flow rate and sediment type, but the pattern was variable within the individual deconstruction steps. During low flow stepped removal without silt present (Run 6), the removal of the first and third pieces resulted in the most sediment deposition in the downstream channel (41 kg following the removal of Part 1 and $39 \mathrm{~kg}$ following Part 3), with net erosion after removal of Part $2(7 \mathrm{~kg})$ and Part $4(40 \mathrm{~kg})$. When silt was present in the sediment mixture during the low flow stepped removal scenario (Run 16), the overall trend was also net downstream deposition from Preremoval to Final bed, but the majority of the 
downstream deposition occurred following the removal of the second piece $(92 \mathrm{~kg})$. Downstream erosion followed the removal of the third and fourth pieces (26 and $13 \mathrm{~kg}$ respectively), but there was a net deposition of $60 \mathrm{~kg}$ in the downstream channel for the run (Table 4.2.1 and Table 4.2.2).

\subsubsection{Vertical removal from River Right}

Vertical removal from the side is a common method of removal when there are constructability issues at the site and it is more convenient to leave the equipment on the bank and remove from the side. Vertical removal from the right hand side was completed under the first two sediment conditions, with (Run 18 and 19) and without silt present (Run 8 and 9) and under high (Run 9 and 19) and low flows (Run 8 and 18). In both of the tested scenarios the reservoir preferentially eroded from the right hand side and deposited throughout the downstream channel following removal of the first dam piece (net $94 \mathrm{~kg}$ and $68 \mathrm{~kg}$ for sediment type 1 and 2 respectively). Erosion occurred locally after the removal of the second piece at 5, 6 and $7 \mathrm{~m}$ for sediment type 1 and at 4,5 and $6 \mathrm{~m}$ for sediment type 2 , however the downstream channel had an overall trend of net deposition (7 and $4 \mathrm{~kg}$ respectively; Figure 4.2.2). Similarly, after the removal of Part 3, erosion occurred throughout the downstream channel with sediment type 1 , resulting in net erosion of $20 \mathrm{~kg}$, and at 4, 5 and $6 \mathrm{~m}$ for sediment type 2, with an overall trend of $7 \mathrm{~kg}$ of net deposition (Table 4.2.2). Vertical removal from the side exhibited an overall trend of deposition from the Preremoval surface to the final bed with localized erosion in-line with the dam pieces being removed. High flow vertical removal from the side had similar patterns of erosion in-line with of the dam piece removed and with sediment deposition further downstream from 4 to $8 \mathrm{~m}$ with and without silt present (Run 9 and Run 19). Overall, a majority of the deposition throughout the downstream channel following vertical removal from the side 
occurred following the removal of the first piece with localized erosion downstream of the portion of the structure removed (67\% of the structure remained).



Figure 4.2.2: Digital elevation models for all parts for vertical removal from the side during low flow under sediment types 1 and 2 (Run 8 and Run 18). The flow is from right to left. The scale is in $\mathrm{mm}$

\subsection{5: Vertical Removal from the Center}

Vertical removal starting from the center of the channel and working outward is also a common method of dam removal. In contrast to the removal from the side, low flow vertical removal from the center resulted in patches of erosion and deposition in the downstream channel and overall net downstream deposition for all 3 sediment types (Run 10, 20, and 30). All three 
runs exhibited downstream deposition following the removal of Sections 2 and 3 (Run 10:50 kg, Run 20: $102 \mathrm{~kg}$ and Run 30: $53 \mathrm{~kg}$ ) and localized deposition at 3m following the removal of Part 1 (Figure 4.2.3). After the removal of the second dam piece with the first sediment type, the downstream channel underwent erosion at all downstream sections, with the exception of $1 \mathrm{~kg}$ of deposition at $3 \mathrm{~m}$ (Run 10.2; $1 \mathrm{~kg}$ of deposition), with net erosion of $28 \mathrm{~kg}$ throughout the downstream channel. The second sediment type (Run 20.2) had net downstream deposition of 15 $\mathrm{kg}$ across the downstream channel with localized erosion occurring at $4 \mathrm{~m}$. Following the removal of the second piece, the third sediment (Run 30.2) had erosion at every downstream section except for $6 \mathrm{~m}$ ( $3 \mathrm{~kg}$ deposited) for total net erosion of $8 \mathrm{~kg}$ in the entire downstream section. The removal of the third piece resulted in net erosion in all 3 runs (14, 19 and $0.05 \mathrm{~kg}$ respectively). The first sediment type (Run 10) had deposition at 5 and $6 \mathrm{~m}$ (42 and $0.1 \mathrm{~kg}$ ), the second sediment type (Run 20) had deposition at 7 and $8 \mathrm{~m}(0.3 \mathrm{~kg}$ and $2 \mathrm{~kg})$, and the third sediment (Run 30) had deposition at 6 and $7 \mathrm{~m} \mathrm{(3} \mathrm{and} 1 \mathrm{~kg}$ ), but the sum of the deposited sediment was not large enough to offset the trend of net erosion for the channel. 


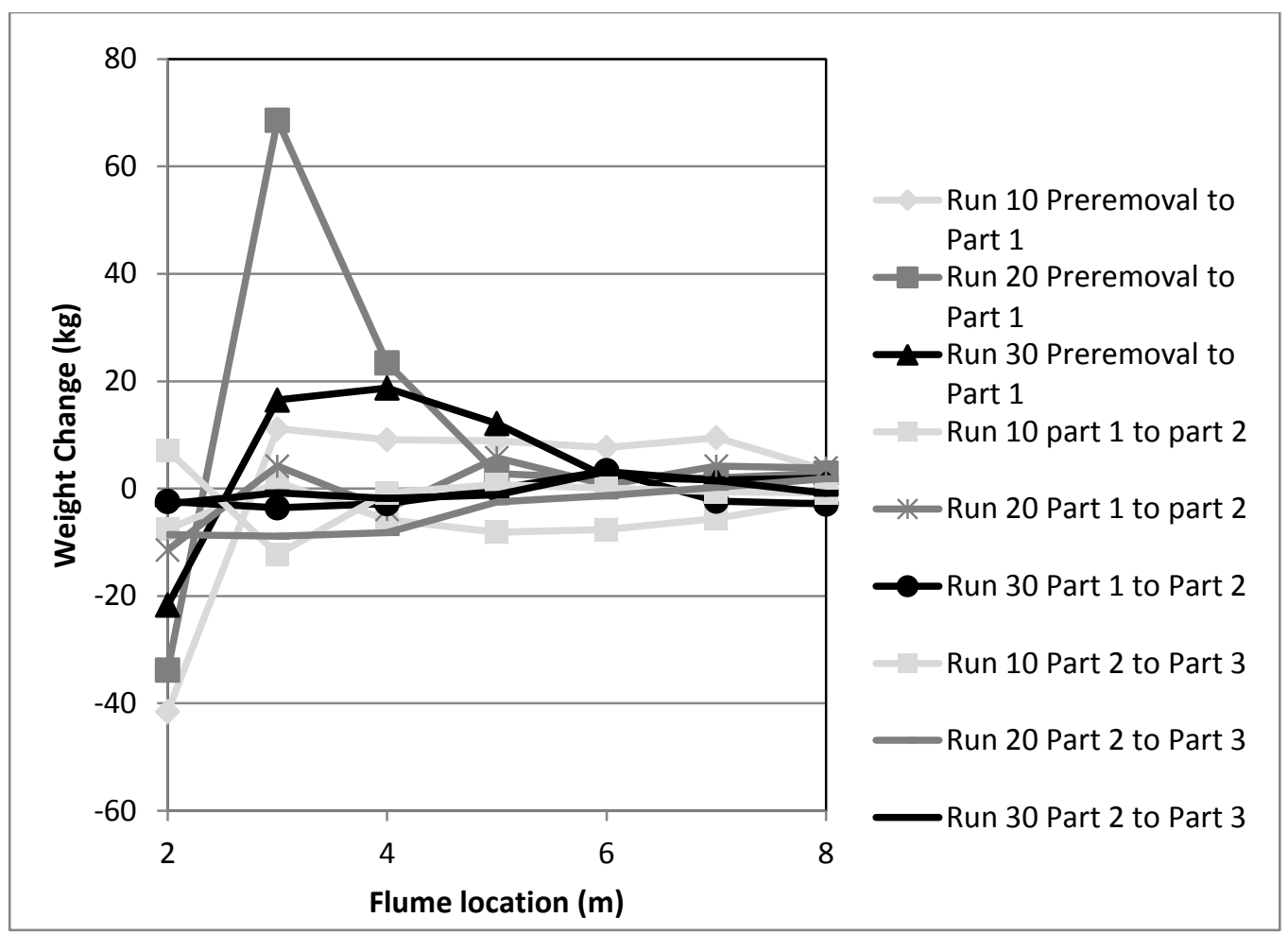

Figure 4.2.3: Summary of the change in total sediment (in $\mathrm{kg}$ ) in the flume expressed as the sediment weight found from the raster difference of the bed scans in between each part of the removal process for low flow vertical removal from the center. 


\subsection{Comparing Removal Methods}

In addition to identifying the trends that were observed under each removal condition, it is important to compare the impact that similar removal types have on the channel downstream of the removed structure. The two most similar pairs of removal types tested were vertical removal from the side and from the center, and horizontal and stepped removal under the same sediment type and flow conditions.

\subsubsection{Vertical Removal}

Low flow vertical removal with the first portion of the structure removed from either the side or the center of the channel under the first sediment type highlighted the impact that removal location had on downstream sediment deposition patterns. While identical in the size of pieces removed, the downstream channel experienced twice as much deposition following vertical removal with the first portion removed from the side than from the center. Following the removal of the first dam piece for Runs 8 and 10 (67\% of the structure remained; Table 4.2.2), there was nearly 10 times more deposition in the Preremoval to Final bed scans when the first piece removed came from the side than the center under the first sediment (Table 4.2.1). There was greater similarity in the downstream deposition amounts for the second sediment type, with total net deposition between the Preremoval to Final bed of $79 \mathrm{~kg}$ for vertical removal from the side and $98 \mathrm{~kg}$ of deposition for vertical removal from the center (Table 4.2.1). The downstream channel experienced a majority of the overall deposition after the first piece was removed in both scenarios $(68 \mathrm{~kg}$ vertical from the side and $102 \mathrm{~kg}$ for vertical removal from the center; Table 4.2.2) and net deposition after the second dam piece was removed (33\% of structure remained). The removal of the third piece using sediment type $2(0 \%$ of the structure remained) resulted in net erosion at all downstream sections with the exception of 7 and $8 \mathrm{~m}$ for vertical removal from 
the center and 3, 7 and 8m for vertical removal from the side. However, the overall trend remained net deposition across the downstream channel for these experiments (Figure 4.3.1).

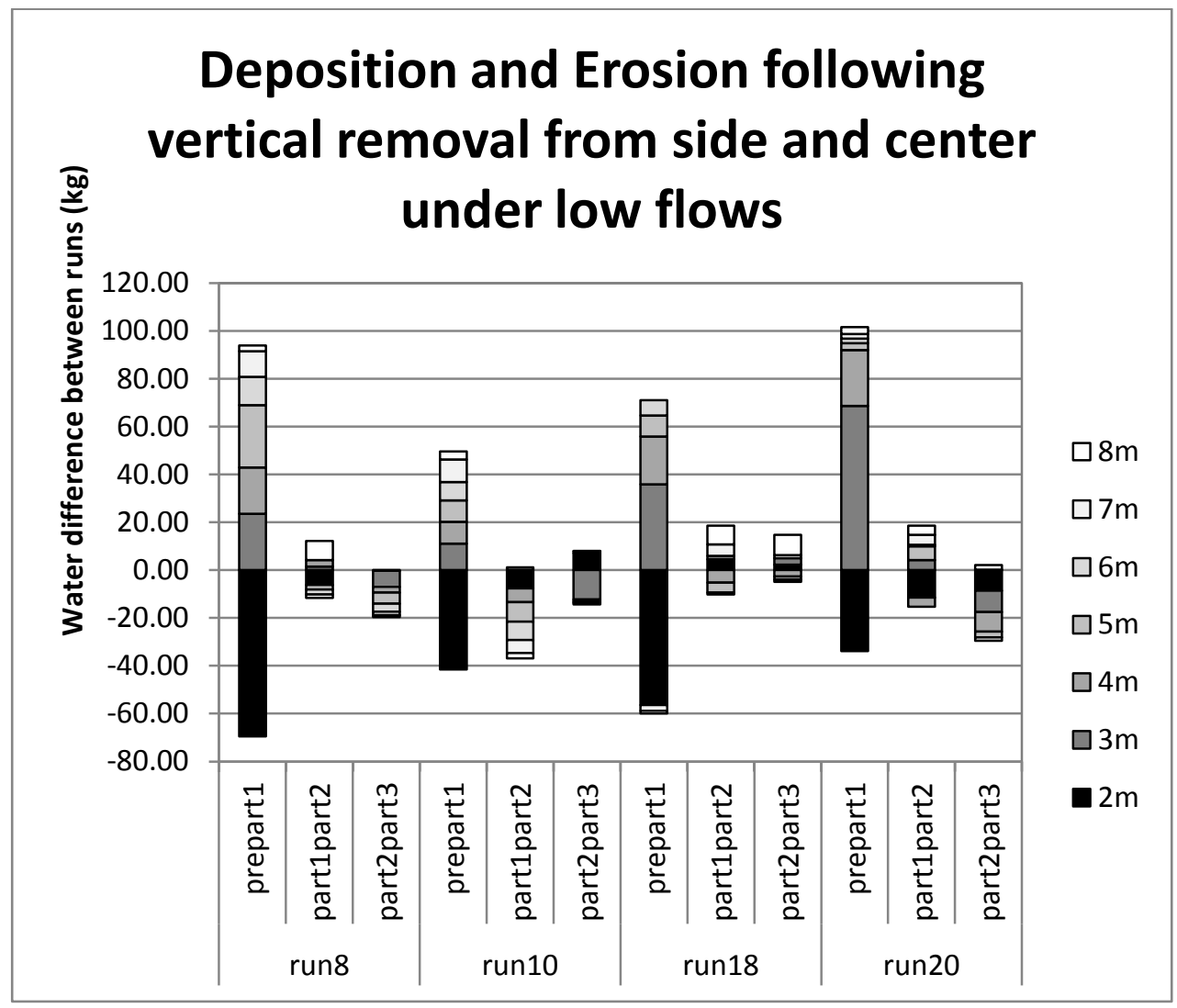

Figure 4.3.1: Summary of the change in total sediment (in $\mathrm{kg}$ ) over the channel as the sediment weight calculated from the raster difference of the bed scans following each portion of the removal process for vertical removal from the side and center under low flows.

The deposition and erosion patterns within each meter, or each 1.7 channel widths, were calculated from the raster differences created from the laser scans and DEMs. Vertical removal from the side during the first sediment type under low flow conditions (Run 8) resulted in erosion in the $0.5 \mathrm{~m}$ immediately below the dam on the left hand side where the structure remained in place. Erosion in the center of the channel occurred over the first half meter downstream of the dam after the second piece was removed, which had been across the center of the channel. The removal of the third and final piece resulted in erosion from the right side of the channel (Figure 4.3.2a). The erosion patterns corresponded to the location of the pieces removed 
during vertical removal both from the center of the channel and from the side of the channel under the same flow and sediment conditions (Run 10 and Run 8). Downstream erosion within the half meter below the dam took place following the removal of the center piece of the structure during Part 1 . The removal of the second piece, which had been situated to the side of center, resulted in erosion downstream of that location and deposition downstream of the location where the first piece was removed. The removal of the third and final piece resulted in downstream erosion with a majority of the erosion on river left, in-line with the location of the final dam piece removed (Figure 4.3.2b). However, the total erosion was not enough to remove the previously deposited sediment.

The direct impact of removal location on the downstream channel under low flows with no silt present was localized to the first meter downstream of the dam removal location in both center and side removal scenarios for sediment 1 . 




Figure 4.3.2: Raster difference scans showing the change in bed elevation for the first sediment type during vertical removal from a) the side (Run 8) and b) the center (Run 10) under low flows. Flow is from right to left. The scale is in $\mathrm{mm}$.

During the second sediment type under low flows, the impact of the vertical removal deconstruction was primarily over the $2 \mathrm{~m}$ ( 3.3 channel widths) downstream of the removal location (Figure 4.3.3). Following the first stage of vertical removal from the side under low flow conditions (Run 18) erosion was observed within the first meter downstream of the new opening, with deposition downstream on the left hand side of the channel where the structure remained intact. The downstream channel experienced erosion over the first 3 meters (or 5 
channel widths) below the location of the second dam section removed. At the same time there was deposition on the right hand side where the first section was removed and had previously exhibited erosion. Following the removal of the third and final piece, deposition was limited to the area downstream and directly in-line with the new opening in the dam, where waster and sediment was now free to transport, with erosion throughout the right hand side and the center of the channel.

During vertical removal from the center of the channel (Run 20), deposition occurred within the 2 meters (3.33 channel widths) downstream of the site of the removal of the first dam piece and immediately downstream of the removal location of the second piece. Concurrent with this deposition, there was erosion downstream of the remaining piece on the left hand side. Upon removal of the third and final dam piece, there was erosion throughout the 2 meters (or 3.33 channel widths) downstream of the dam location on the right hand side but deposition in the center of the channel.

Comparing vertical removal methods from runs using the same flows and sediment type (Run 18 and Run 20) allows the influence of the deconstruction location laterally across the dam to become apparent. Following Part 1, channel deposition occurred over the first 4 meters downstream of the dam following removal from the side, while the removal from the center had deposition only though the first $2 \mathrm{~m}$ downstream of the dam (Table 4.2.2). Following the removal of Part 2, removal from the side resulted in erosion on the right hand side (where the first piece was removed) while removal from the center experienced erosion over the first meter downstream on the left hand side (where the dam portion remained). After Part 3 was removed, there was erosion on the right hand side of the channel during vertical removal from both the center and the side with a greater amount of erosion occurring with center removal; (Figure 
4.3.3). The overall net result was more sediment deposition over the first meter immediately downstream of the dam when deconstruction began from the center of the dam (Table 4.2.1).
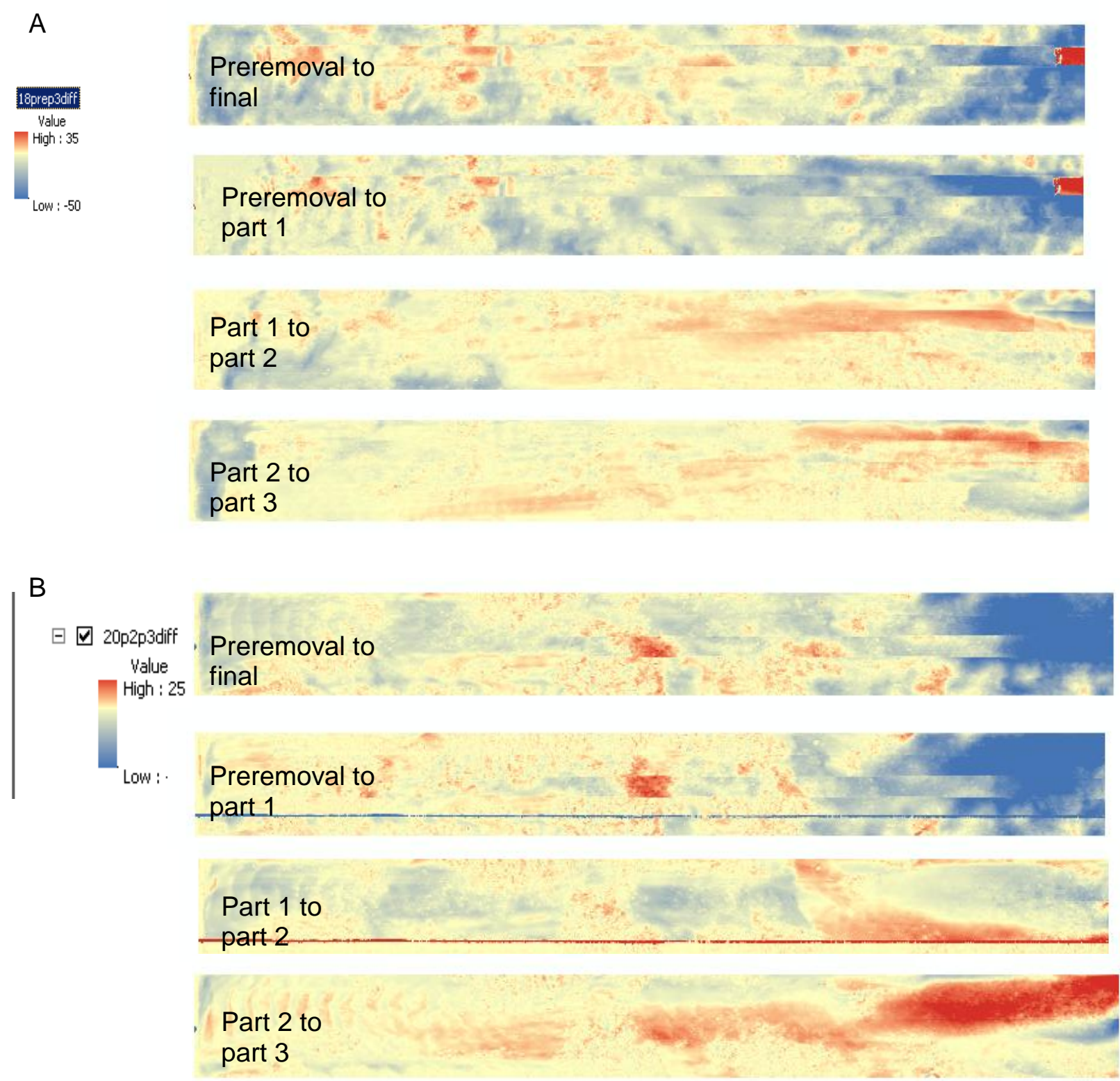

Figure 4.3.3: Raster differences showing the change in bed elevation for the second sediment type under low flow conditions for vertical removal from the side (Run 18; A) and from the center (Run 20; B). Flow is from right to left.

In addition to identifying where the sediment deposits within the 10 channel widths downstream of a removal, the amount of sediment exiting the reach was also quantified through 
the accumulation in the downstream sediment trap, which acted as an analog for sediment traveling further downstream in the field. Following vertical removal from the center the downstream channel had four times more total sediment deposit in the trap under both sediment types 1 and 2 when compared to vertical removal from the side. Vertical removal from the side under low flow conditions and sediment type 1 (Run 8) resulted in $27 \mathrm{~kg}$ of sediment accumulation in the trap, while vertical removal from the center (Run 10) resulted in $93 \mathrm{~kg}$ total accumulation in the trap. Under the second sediment type tested under low flow conditions, $5 \mathrm{~kg}$ of sediment deposited in the sediment trap following vertical removal from the side (Run 18) and $24 \mathrm{~kg}$ following vertical removal from the center (Run 20). The majority of the deposition in the sediment trap occurred after Part 3 was removed in vertical removal from the side under sediment type 1(Run 8) and vertical side and center under sediment type 2 (Run 18 and 20; Figure 4.3.4). 


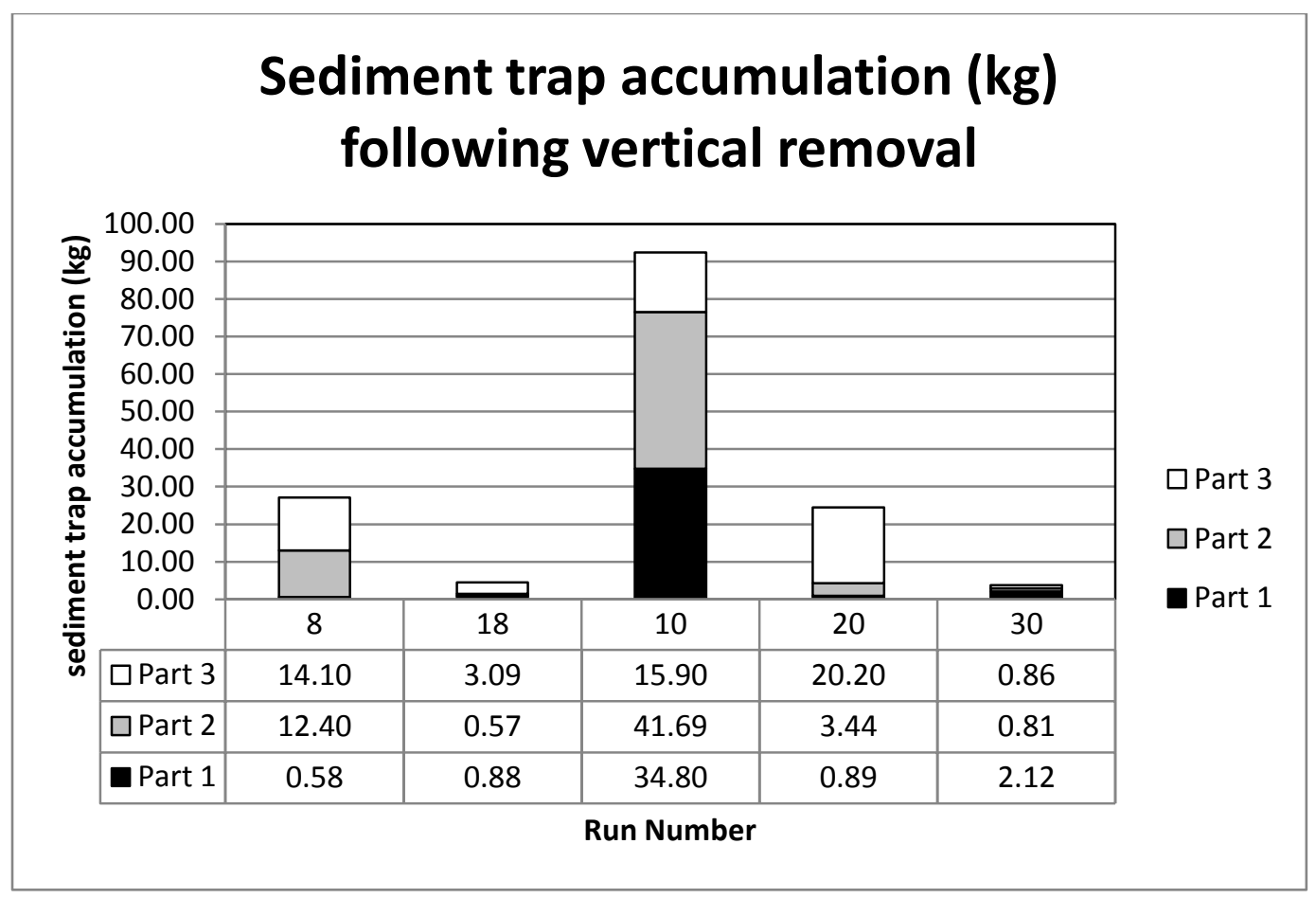

Figure 4.3.4: Sediment accumulation in the sediment trap downstream of the active channel (in $\mathrm{kg}$ ) for vertical removal (side and center) under the first two sediment compositions and the low flow scenario.

\subsubsection{Horizontal and Stepped Removal}

Comparing horizontal and stepped removals allows for the quantification of the impact of leaving a portion of the structure in place on the downstream sediment deposition patterns. Following the removal of the first 2 parts of dam types, there were similar amounts of the structure left behind (50\% for horizontal and $56 \%$ for stepped removal), but when the third and fourth pieces were removed a larger percentage of the structure remaining for stepped removal: $25 \%$ and $0 \%$ remained for horizontal removal after steps 3 and $4 ; 42.5 \%$ and $38 \%$ remained for stepped removal after steps 3 and 4; Table 4.3.1. When comparing the Preremoval to Final bed conditions, the sediment deposition extended further downstream under low flow stepped deconstruction than under low flow horizontal removal both with and without silt in the channel sediment. Both removal methods resulted in net deposition from the Preremoval to Final bed for 
all sediment types tested (Table 4.2.2). Under the horizontal removal method, the downstream channel exhibited net deposition following the first 3 removal stages, and net erosion following the removal of the fourth and final piece. Under the stepped removal method, the downstream channel experienced net deposition following the first removal stage (Table 4.3.1). Net deposition over the downstream channel was also measured following the removal of Parts 3 and 4 with sediment 1 (Run 6) and Part 2 with sediment 2 (Run 16). The removal of the final remaining dam pieces caused net erosion of the downstream channel bed (Table 4.3.1).

Table 4.3.1: Horizontal and Stepped removal net deposition (positive) and erosion (negative) values in the 10 channel widths downstream of the dam removal location. The values are calculated from the raster weight differences for low flow scenarios under the first 2 sediment types

\begin{tabular}{|c|c|c|c|c|c|}
\hline \multicolumn{3}{|c|}{ Horizontal } & \multicolumn{3}{c|}{ Stepped } \\
\hline $\begin{array}{c}\text { \% of } \\
\text { structure } \\
\text { remaining }\end{array}$ & $\begin{array}{c}\text { Sediment } \\
1\end{array}$ & $\begin{array}{c}\text { Sediment } \\
2\end{array}$ & $\begin{array}{c}\text { \% of } \\
\text { structure } \\
(\mathrm{kg})\end{array}$ & $\begin{array}{c}\text { Sediment } \\
1\end{array}$ & $\begin{array}{c}\text { Sediment } \\
2 \\
(\mathrm{~kg})\end{array}$ \\
\hline 75 & 8.38 & 14.80 & 75 & -29.17 & 7.28 \\
\hline 50 & 26.03 & 89.33 & 56 & -7.10 & 92.07 \\
\hline 25 & 0.52 & 0.07 & 42.5 & 39.58 & -26.22 \\
\hline 0 & -19.11 & -13.11 & 38 & -40.19 & -12.72 \\
\hline
\end{tabular}

Horizontal and stepped dam deconstruction methods led to net deposition over the downstream channel for all of the sediment types tested under low flows (Runs 2, 6, 12, 16 and 22). Within the downstream channel, deposition was observed at all locations between the Preremoval to Final bed under low flow stepped removal for the first sediment type except for 6 and $8 \mathrm{~m}$, which had erosion. Horizontal dam removal under the same conditions resulted in net deposition for the channel as a whole, but there was localized erosion at 3, 4, 5 and $6 \mathrm{~m}$ (Table 4.2.1). Following the removal of Part 1 during the low flow scenario with sediment type 1 (75\% of the structure remained in both removal methods), deposition occurred at $3 \mathrm{~m}(12 \mathrm{~kg}), 4 \mathrm{~m}(6 \mathrm{~kg})$, $5 \mathrm{~m}(5 \mathrm{~kg}), 6 \mathrm{~m}(2 \mathrm{~kg}), 7 \mathrm{~m}(7 \mathrm{~kg})$ and $8 \mathrm{~m}(9 \mathrm{~kg})$ following stepped removal (Run 6), and the 
horizontal removal (Run 2) had net deposition at $3 \mathrm{~m}(0.7 \mathrm{~kg}), 4 \mathrm{~m}(10 \mathrm{~kg}), 7 \mathrm{~m}(2.5 \mathrm{~kg})$, and $8 \mathrm{~m}$ $(0.5 \mathrm{~kg})$ but net erosion at 5 and $6 \mathrm{~m}$ ( 2.2 and $2.3 \mathrm{~kg}$ respectively; Table 4.2.2). After Part 2 of the stepped dam deconstruction method was removed (56\% remained), there was net erosion in the downstream channel and localized areas of deposition at 4,5 and $7 \mathrm{~m}$. Following step 2 of the horizontal dam removal method (50\% of the structure remained), localized erosion occurred at $6 \mathrm{~m}$ while there was deposition elsewhere in the channel. Channel net deposition occurred following the removal of the third piece in both removal types, but with localized differences in pattern. Stepped removal resulted in deposition throughout the channel (42.5\% of structure remained) while the horizontal removal method led to limited, localized bed erosion at 3, 4, and $5 \mathrm{~m}$ ( $25 \%$ of the structure remained). The result of the downstream channel following removal of the fourth piece of the stepped (38\% of the structure remained) and horizontal ( $0 \%$ of the structure remained) removal methods was erosion (Table 4.2.2).

When silt was present in the channel sediment (sediment type 2), removal under low flow conditions resulted in net downstream sediment deposition on the channel bed following the removal of the first two pieces for both dam removal methods (12 and 16) and net channel bed erosion following the removal of the fourth and final piece. Following the removal of Part 1, which left $75 \%$ of the structure remaining in place in both deconstruction methods, net downstream deposition was observed, with twice as much sediment deposition following horizontal removal (15 vs. $7 \mathrm{~kg}$ ). Downstream channel deposition following the removal of Part 2 was near equal between the stepped and horizontal deconstruction methods (92 and $89 \mathrm{~kg}$ respectively; Table 4.3.2). The removal of Part 3 of the stepped dam deconstruction resulted in bed erosion at every meter and net erosion of $26 \mathrm{~kg}$ from the downstream channel. When the third piece of the horizontal dam was removed, there was almost no net change in the 
downstream channel despite deposition at 3 and $8 \mathrm{~m}$ and erosion at 4, 5,6 and $7 \mathrm{~m}$. The removal of the fourth and final piece left $38 \%$ of the structure in place in the stepped removal scenario but no structure in the horizontal removal method. Upon complete dam removal through horizontal steps, the channel bed had eroded $13.1 \mathrm{~kg}$. Because there was part of the original dam structure remaining in place following completion of a staged dam removal, there was a greater amount of overall bed erosion for a total net erosion of $12.7 \mathrm{~kg}$ (Table 4.2.2). Thus, under low flow removal for sediment type 2, there was a comparable amount of erosion throughout the downstream channel when the entire structure was removed in horizontal layers and 38\% of the structure left in place due to a stepped removal.

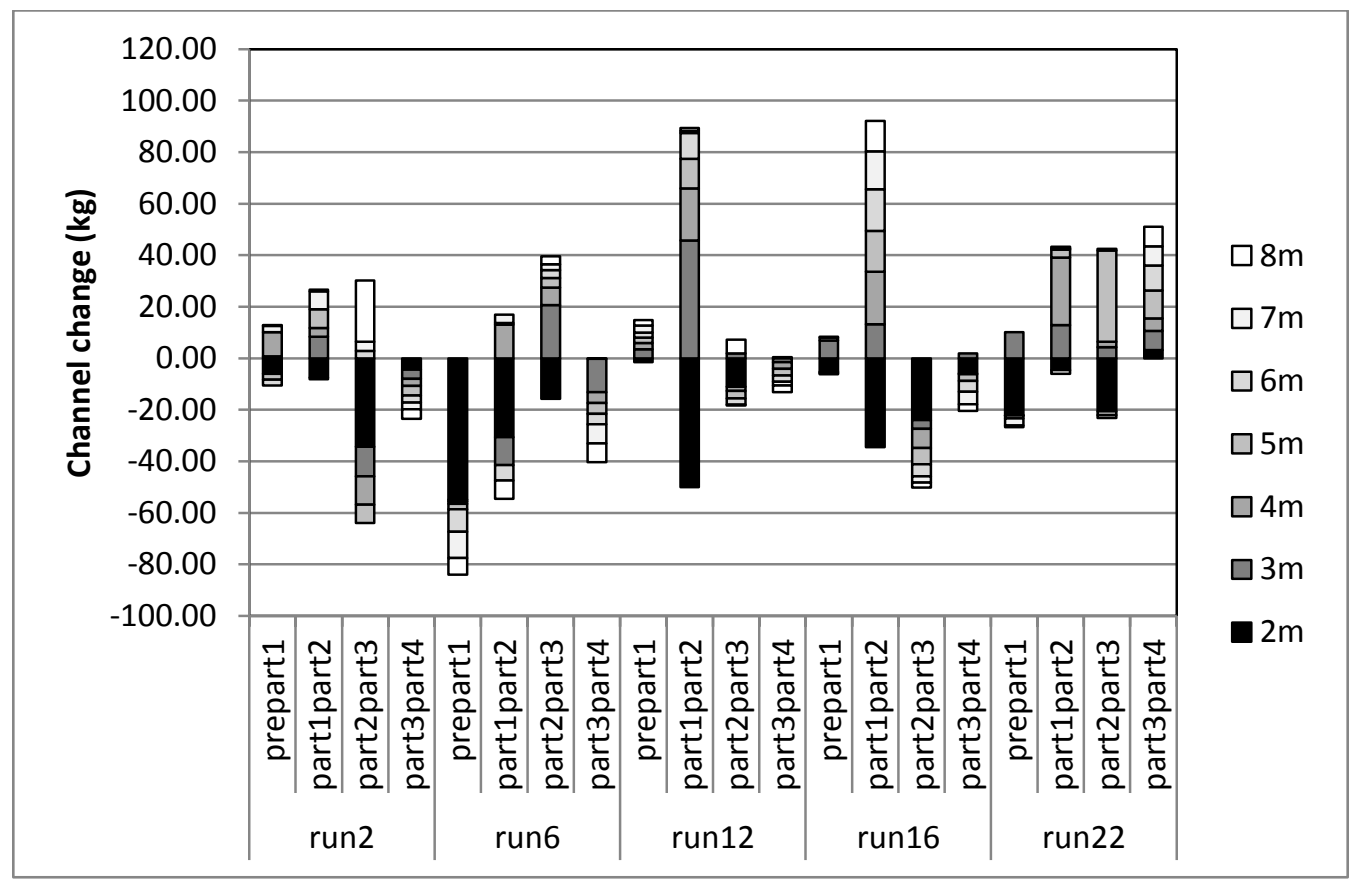

Figure 4.3.5: Summary of the deposition and erosion over the downstream channel length following each portion of the removal process for horizontal and stepped removal under low flows. The values were calculated though raster difference of the bed scans.

Overall, similar trends of deposition and erosion were observed following the removal of the dam pieces in both a horizontal and stepped removal scenario. After the removal of the first piece, there was net deposition on the channel downstream of the dam. Following the removal of 
the second piece, sediment deposition occurred throughout the downstream channel for stepped removal and over the upstream half of the downstream channel following horizontal removal. Horizontal and stepped removal methods resulted in similar trends of bed erosion following the removal of Parts 3 and 4.

It is relevant to quantify the amount of sediment that accumulated in the sediment trap downstream of the active channel as a measurement of the amount of sediment transported further than 10 channel widths downstream of the dam removal site. The largest amounts of sediment removed from in the trap occurred following low flow horizontal removal under the first sediment type (Run 2), while the least amount of sediment transported to the trap during the stepped and horizontal removals with the second sediment type (Run 12; Figure 4.3.6). In all runs, with the exception of Run 12, stepped and horizontal removal methods resulted in the largest amount of sediment transported to the trap following the removal of Part 3 . The removal of Part 3 caused the elevation of the dam to be below the height of the sediment in the reservoir. The lowest sediment accumulation in the trap occurred following the removal of Part 1, where $75 \%$ of the structure remained in place and the dam height was approximately equal to the at a height of $22.5 \mathrm{~cm}$ in both scenarios, with the exception of Run 2. 


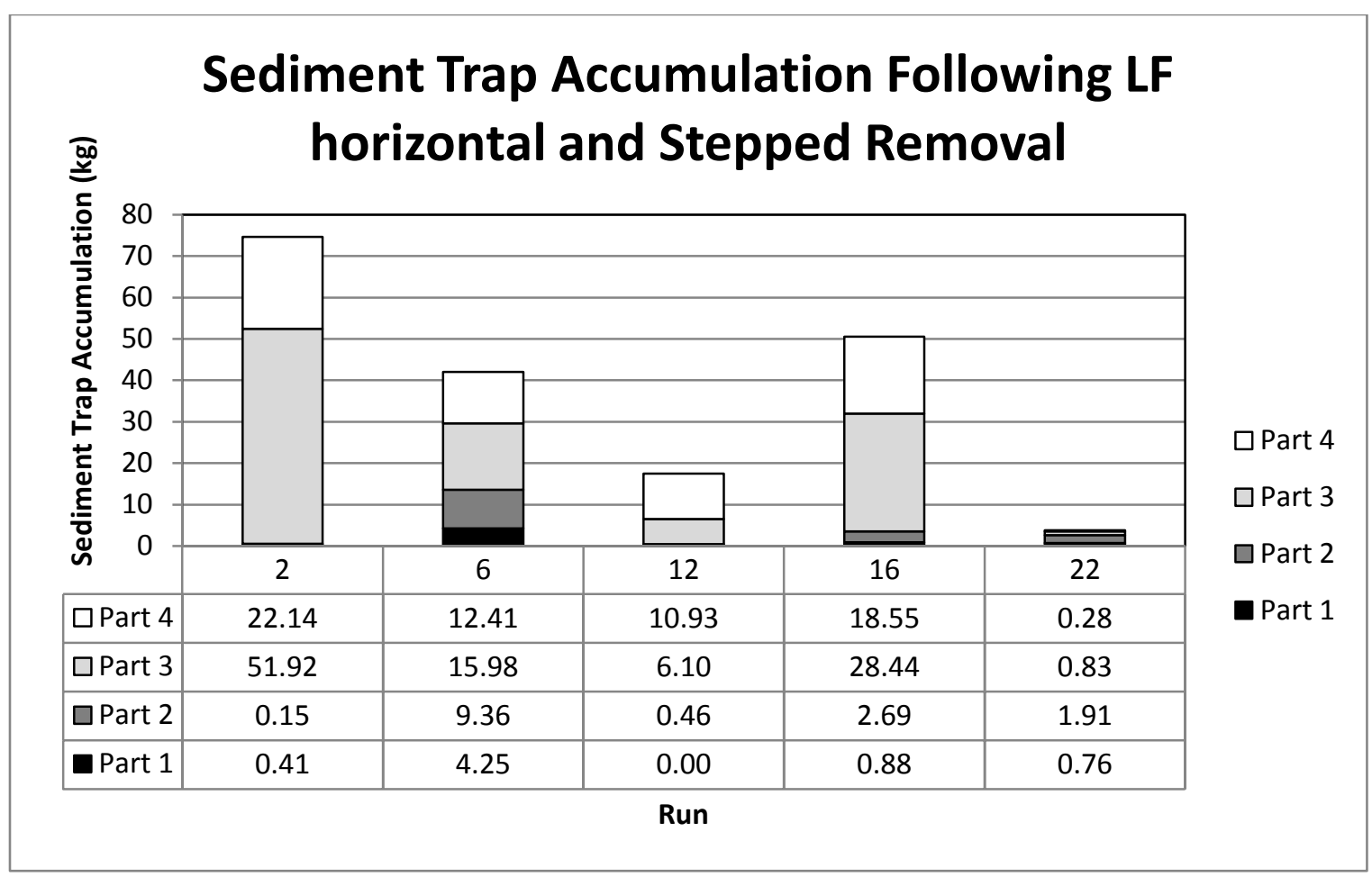

Figure 4.3.6: Downstream sediment trap accumulation in $\mathrm{kg}$ following low flow horizontal and stepped removal 


\subsection{Discussion of Removal Methods}

\subsection{1: General Trends:}

There was net deposition in the downstream channel for all runs conducted under low flow conditions (Table 4.4.1). Although all dam deconstruction sequences resulted in net deposition on the downstream channel, removal sequencing influenced the magnitude and pattern of deposition and also created localized areas of bed erosion. The largest amount of total downstream deposition when using either of the first two sediment types occurred upon single stage dam deconstruction. Under sediment type 3, which had the largest silt content, dam deconstruction in horizontal layers resulted in the largest amount of downstream channel deposition. The least amount of downstream channel aggradation occurred under dam deconstruction sequencing in vertical sections starting from the center of the dam (Table 4.4.1). Spatial variability in channel deposition patterns corresponded to dam removal methods. Under sediment types 1 and 2, the stepped removal method resulted in the lowest total deposition in the region immediately downstream of the dam. Excess deposition can negatively impact the downstream channel following removal by burying spawning grounds or eradicating biohabitiats (Hickey, 2013) and using a stepped removal technique in these situations may mitigate some of the negative impacts of removing the dam structure. Conversely, additional sediment may be beneficial to a downstream channel in areas where the banks are scouring and bed erosion is prevalent. In this situation a complete removal during low flows would aid in replenishing the sediment immediately downstream of the dam. 
Table 4.4.1: Net deposition for all 5 dam removal methods and sediment types run under low flow conditions. These quantities were calculated using raster differencing and then converting the volume to a sediment weight.

\begin{tabular}{|c|c|c|c|}
\hline & $\begin{array}{c}\text { Deposition } \\
\text { under Sed } \\
1(\mathrm{~kg})\end{array}$ & $\begin{array}{c}\text { Deposition } \\
\text { under Sed } \\
2(\mathrm{~kg})\end{array}$ & $\begin{array}{c}\text { Deposition } \\
\text { under Sed 3 } \\
(\mathrm{kg})\end{array}$ \\
\hline Horizontal & 16 & 91 & 132 \\
\hline Complete & 84 & 106 & 71 \\
\hline Stepped & 33 & 7 & \\
\hline Vertical Side & 81 & 79 & \\
\hline Vertical Center & 8 & 98 & 45 \\
\hline
\end{tabular}

Following removal under low flows, the largest amount of sediment accumulated in the downstream trap under sediment types 1 and 3 and the second largest accumulation under sediment 2 occurred following vertical dam removal beginning in the center of the dam (Table 4.4.2). This removal sequence also resulted in the least sedimentation over the 10 channel widths downstream of the removal location for sediments 1 and 3 . These results indicate that sequencing dam deconstruction in vertical sections starting from the dam center will transport the largest amount of sediment furthest downstream under low flows. Complete removal resulted in the lowest amount of sediment accumulation in the trap for sediment types 2 (Run 14) and 3 (Run 24), which also corresponded to the greatest amount of sedimentation on the downstream channel.

If sediment traveling past the area immediately downstream of the removal location is a concern, as was the case on the Elwha River in Washington, then performing a complete removal may be the preferred removal technique. Following the Elwha dam removal, which is most comparable to the complete removal experiments, a large sediment plume traveled downstream to form a fan at the river mouth. Researchers expect that suspended sediment concentrations are large enough to develop a slurry that will sink as it enters the Pacific Ocean (Hickey, 2013). It is speculated that this process will help reduce erosion along the Olympic Coast, aiding in restoring 
natural beaches on the bluffs near Port Angeles (Hickey, 2013). While the Elwha dam removal is a much larger scale than the study presented here, the same principles can be applied. Of the removal methods tested, removing the dam in vertical sections starting from the center would be the most likely to result in additional sediment inputs further downstream of the removal location (i.e. for beach replenishment).

Table 4.4.2: Sediment trap accumulation (in $\mathrm{kg}$ ) for all 5 dam removal methods and sediment types run under low flow conditions

\begin{tabular}{|c|c|c|c|}
\hline & $\begin{array}{c}\text { Deposition } \\
\text { under Sed } \\
1\end{array}$ & $\begin{array}{c}\text { Deposition } \\
\text { under Sed } \\
2\end{array}$ & $\begin{array}{c}\text { Deposition } \\
\text { under Sed } \\
3\end{array}$ \\
\hline Horizontal & 74.6 & 17.5 & 3.8 \\
\hline Complete & 54.7 & 0.5 & 0.8 \\
\hline Stepped & 42 & 50.6 & \\
\hline Vertical Side & 27.1 & 4.5 & \\
\hline $\begin{array}{c}\text { Vertical } \\
\text { Center }\end{array}$ & 92.4 & 54.5 & 3.8 \\
\hline
\end{tabular}

When using the second sediment type, a majority of the downstream deposition was observed following the removal of Part 1 under the following combinations of flow rate and removal sequencings: complete high flow, complete low flow, vertical removal from the side and center during low flows, and vertical removal from the center during high flows (Table 4.4.3). This was the removal step that reduced the dam height to below the reservoir sediment height, making the reservoir sediment readily available to transport. The removal of Part 2 resulted in the largest amount of downstream sedimentation when the dam was removed following the horizontal and stepped deconstruction sequences (Table 4.4.3). The removal of Part 2 was the step in these methods when the dam structure elevation dropped below the elevation of the reservoir sediment. If a dam removal were to take place where the structure is removed horizontally through constant decreases in elevation, with or without the sides remaining in place, a majority of the movement of sediment from reservoir to the downstream channel would 
occur when the elevation of the structure was less than the elevation of the reservoir sediment. When removal occurs under low flows and the deconstruction proceeds vertically from either the side or center or the dam is removed in one step, the majority of the impact to the downstream channel occurs following the removal of the first piece, when the elevation of the structure is reduced to below the reservoir sediment height. The ability to predict at what point during a dam deconstruction the majority of the reservoir sediment will transport downstream and how much of that sediment will deposit on the downstream channel bed can be useful in areas of sensitive aquatic habitat. Similar trends of deposition and erosion were observed during runs conducted with (as discussed above) and without silt present. Following vertical removal from the side and center, as well as complete removal, a majority of the bed deposition occurred following the removal of the first piece without silt present. Unlike the scenarios where silt was present, a majority of the downstream channel change followed the removal of the third piece during removal in both horizontal segments from the top down and with the sides remaining in place (horizontal and stepped removal). The flow rate in these experiments remained same; indicating that the larger shear stresses required to mobilize the larger grain sizes may be the culprit for this inconsistency. The impact of sediment type on downstream sediment transport is discussed in more detail in Chapter 6.

Table 4.4.3: Net sediment eroded or deposited over the channel downstream of each stage of each dam removal. Sediment weights were calculated through raster differencing and the volumes converted to weights. All values are in $\mathrm{kg}$.

\begin{tabular}{|c|c|c|c|c|c|c|c|c|c|}
\hline Run & PreP1 & P1P2 & P2P3 & P3P4 & Total & $\begin{array}{c}\% \\
\text { PreP1 }\end{array}$ & $\begin{array}{c}\% \\
\text { P1P2 }\end{array}$ & $\begin{array}{c}\% \\
\text { P2P3 }\end{array}$ & $\begin{array}{c}\% \\
\text { P3P4 }\end{array}$ \\
\hline 2 & 8.38 & 26.03 & 0.52 & -19.11 & 15.96 & 52.9 & 164.6 & 3.3 & -120.8 \\
\hline
\end{tabular}




\begin{tabular}{|c|c|c|c|c|c|c|c|c|c|}
\hline 3 & -73.63 & 21.98 & 15.57 & 9.08 & -26.8 & 272.6 & 138.9 & 98.5 & 57.4 \\
\hline 4 & 84.06 & N/A & N/A & N/A & 84.04 & 100.0 & N/A & N/A & N/A \\
\hline 5 & -29.17 & N/A & N/A & N/A & -29.2 & 100.0 & N/A & N/A & N/A \\
\hline 6 & -29.17 & -7.10 & 39.58 & -40.19 & 32.99 & 79.1 & -44.9 & 250.3 & -254.1 \\
\hline 7 & 12.24 & 6.73 & -60.61 & -3.54 & -45.2 & -27.1 & 42.5 & -383.2 & -22.4 \\
\hline 8 & 93.84 & 6.64 & -19.34 & N/A & 81.29 & 115.7 & 42.0 & -122.3 & N/A \\
\hline 9 & 41.46 & -15.93 & -9.22 & N/A & 16.5 & 254.2 & -100.7 & -58.3 & N/A \\
\hline 10 & 49.67 & -28.04 & -13.60 & N/A & 8.065 & 618.6 & -177.3 & -86.0 & N/A \\
\hline 11 & 116.44 & -38.40 & -4.48 & N/A & 73.7 & 158.3 & -242.8 & -28.3 & N/A \\
\hline 12 & 14.80 & 89.33 & 0.07 & -13.11 & 91.16 & 16.2 & 564.8 & 0.4 & -82.9 \\
\hline 13 & -66.94 & N/A & N/A & N/A & -66.9 & 100.0 & N/A & N/A & N/A \\
\hline 14 & 106.01 & N/A & N/A & N/A & 106 & 100.0 & N/A & N/A & N/A \\
\hline 15 & -5.84 & N/A & N/A & N/A & -5.84 & 100.0 & N/A & N/A & N/A \\
\hline 16 & 7.28 & 92.07 & -26.22 & -12.72 & 7.278 & 12.1 & 582.1 & -165.8 & -80.4 \\
\hline 17 & -41.82 & N/A & N/A & N/A & -41.8 & 100.0 & N/A & N/A & N/A \\
\hline 18 & 67.63 & 3.93 & 7.43 & N/A & 78.98 & 85.6 & 24.9 & 47.0 & N/A \\
\hline 19 & -47.92 & 11.33 & -2.10 & N/A & -38.7 & 123.8 & 71.6 & -13.3 & N/A \\
\hline 20 & 101.63 & 14.74 & -18.79 & N/A & 97.55 & 104.2 & 93.2 & -118.8 & N/A \\
\hline 21 & -16.88 & -42.01 & 16.88 & N/A & -42 & 40.2 & -265.6 & 106.7 & N/A \\
\hline 22 & 5.43 & 41.87 & 39.82 & 47.91 & 132 & 4.0 & 264.7 & 251.8 & 302.9 \\
\hline 24 & 71.12 & N/A & N/A & N/A & 71.11 & 100.0 & N/A & N/A & N/A \\
\hline 25 & -71.59 & N/A & N/A & N/A & -71.6 & 100.0 & N/A & N/A & N/A \\
\hline 30 & 53.01 & -8.29 & -0.03 & N/A & 44.75 & 118.6 & -52.4 & -0.2 & N/A \\
\hline 31 & -113.81 & -60.40 & -31.10 & N/A & -205 & 55.4 & -381.9 & -196.7 & N/A \\
\hline
\end{tabular}

Table 4.4.4: Sediment deposition in the downstream trap (in $\mathrm{kg}$ ) for all runs by part, total and that percent of the total sediment deposited in the trap for each dam removal method. All values are in $\mathrm{kg}$.

\begin{tabular}{|c|c|c|c|c|c|c|c|c|c|}
\hline Run & Part 1 & Part 2 & Part 3 & Part 4 & Total & $\begin{array}{c}\% \text { Part } \\
1\end{array}$ & $\begin{array}{c}\% \\
\text { Part } \\
2\end{array}$ & $\begin{array}{c}\% \\
\text { Part } \\
3\end{array}$ & $\begin{array}{c}\% \\
\text { Part } \\
4\end{array}$ \\
\hline 2 & 0.41 & 0.15 & 51.92 & 22.14 & 74.62 & 0.5 & 0.2 & 69.6 & 29.7 \\
\hline
\end{tabular}




\begin{tabular}{|c|c|c|c|c|c|c|c|c|c|}
3 & 84.32 & 70.85 & 9.54 & 4.01 & 168.72 & 50.0 & 42.0 & 5.7 & 2.4 \\
\hline 4 & 54.69 & N/A & N/A & N/A & 54.69 & 100.0 & N/A & N/A & N/A \\
\hline 5 & 143.78 & N/A & N/A & N/A & 143.78 & 100.0 & N/A & N/A & N/A \\
\hline 6 & 4.25 & 9.36 & 15.98 & 12.41 & 42.00 & 10.1 & 22.3 & 38.0 & 29.6 \\
\hline 7 & 1.59 & 66.35 & 142.20 & 2.67 & 212.81 & 0.7 & 31.2 & 66.8 & 1.3 \\
\hline 8 & 0.58 & 12.40 & 14.10 & N/A & 27.08 & 2.1 & 45.8 & 52.1 & N/A \\
\hline 9 & 79.78 & 30.60 & 10.30 & N/A & 120.68 & 66.1 & 25.4 & 8.5 & N/A \\
\hline 10 & 34.80 & 41.69 & 15.90 & N/A & 92.38 & 37.7 & 45.1 & 17.2 & N/A \\
\hline 11 & 28.35 & 50.91 & 11.42 & N/A & 90.68 & 31.3 & 56.1 & 12.6 & N/A \\
\hline 12 & 0.00 & 0.46 & 6.10 & 10.93 & 17.49 & 0.0 & 2.6 & 34.9 & 62.5 \\
\hline 13 & 88.07 & N/A & N/A & N/A & 88.07 & 100.0 & N/A & N/A & N/A \\
\hline 14 & 0.46 & N/A & N/A & N/A & 0.46 & 100.0 & N/A & N/A & N/A \\
\hline 15 & 129.10 & N/A & N/A & N/A & 129.10 & 100.0 & N/A & N/A & N/A \\
\hline 16 & 0.88 & 2.69 & 28.44 & 18.55 & 50.55 & 1.7 & 5.3 & 56.3 & 36.7 \\
\hline 17 & 69.75 & N/A & N/A & N/A & 69.75 & 100.0 & N/A & N/A & N/A \\
\hline 18 & 0.88 & 0.57 & 3.09 & N/A & 4.54 & 19.5 & 12.5 & 68.0 & N/A \\
\hline 19 & 148.31 & 17.62 & 6.03 & N/A & 171.96 & 86.2 & 10.2 & 3.5 & N/A \\
\hline 20 & 0.89 & 3.44 & 20.20 & N/A & 24.53 & 3.6 & 14.0 & 82.4 & N/A \\
\hline 21 & 146.01 & 14.73 & 6.12 & N/A & 166.86 & 87.5 & 8.8 & 3.7 & N/A \\
\hline 22 & 0.76 & 1.91 & 0.83 & 0.28 & 3.78 & 20.1 & 50.5 & 21.9 & 7.4 \\
\hline 24 & 0.81 & N/A & N/A & N/A & 0.81 & 100.0 & N/A & N/A & N/A \\
\hline 25 & 101.27 & N/A & N/A & N/A & 101.27 & 100.0 & N/A & N/A & N/A \\
\hline 30 & 2.12 & 0.81 & 0.86 & N/A & 3.79 & 56.0 & 21.4 & 22.6 & N/A \\
\hline 31 & 152.52 & 44.48 & 13.05 & N/A & 210.05 & 72.6 & 21.2 & 6.2 & N/A \\
\hline
\end{tabular}

\subsubsection{Horizontal Removal}

The process of removing a dam in horizontal layers is analogous to a controlled reservoir drawdown, which is a process used to transport sediment from a reservoir over time and reduce potentially unwanted effects of releasing a large volume of reservoir sediment to the downstream channel (Randle and Greimann, 2006). The Condit dam in Southwestern Washington state was removed in horizontal segments over 26 months, from October 2010 through December 2012. The structure was removed through the use of hydraulic excavators with jackhammer heads, instead of using drilling and blasting methods (similar to complete removal) in order to contain the broken concrete on site and minimize the impact to the downstream water quality and aquatic life (Stampfli, 2012). A year after dam removal began, turbidity levels and the general 
topography of the channel immediately downstream of the dam had returned to conditions similar to what was observed prior to deconstruction, while the lower river channel was still adjusting to the high sediment load (Stampfli, 2012). Horizontal removal during sediment type 1 under low flows (Run 2) exhibited the same behavior of low rates of sediment accumulation in the channel immediately downstream of the dam, with high rates of sediment accumulation in the downstream sediment trap.

Low amounts of long term sediment accumulation were observed immediately downstream of the Stronach Dam on the Pine River, Michigan, which was removed in a series of horizontal layers. The structure was removed using a horizontal deconstruction sequence over the course of 6 years to minimize the risk of environmental impacts while maintaining a low cost (Battige et al, 1997). Relatively small amounts of reservoir sediment eroded during the first two years of removal, but as removal progressed, erosion from the reservoir increased, with the highest rates of reservoir erosion following the final step in the removal (Borroughs et al 2009). After the entire structure was removed, approximately $15 \%$ of the eroded reservoir sediment had deposited within the 21 channel widths immediately downstream of the dam structure with the remaining sediment having traveling downstream or depositing onto the floodplain (Burroughs et al 2009). While the focus of this research is on changes to the downstream channel, a similar trend in reservoir erosion was measured during horizontal removal in Run 2, with a majority of the reservoir erosion occurring following the removal of the third piece $(25 \%$ of the structure remained).

\subsubsection{Vertical Removal:}

The Brownsville dam on the Calapooia River, Oregon was removed in two stages (Walter and Tullos, 2010), comparable to the process of vertical dam removal starting from the side. A majority of the downstream channel change occurred within the 13.4 channel widths downstream 
of the dam (Walter and Tullos, 2010). In the experiments presented here, high rates of deposition were measured in the 10 channel widths downstream of the dam and low rates of sediment transport were measured downstream of the study reach (Runs 8 and 18), which is similar to the field case.

Dam deconstruction in vertical sections from both the channel side and the channel center resulted in erosion in the reach immediately downstream and in-line with the removal location and deposition downstream and in-line with those areas where the structure remained intact. This trend was also observed when the Anaconda Dam on the Naugatuck River, CT was partially breached during a high flow storm event prior to the dam's scheduled removal. The break concentrated the flow towards the downstream bank on river left, mimicking the flume experiments testing the process of vertical dam removal starting from the side under high flow conditions (Wildman and Macbroom, 2005). Sediment deposition occurred along the right bank throughout the first year following the dam's failure, which was in-line with the remaining dam pieces (Wildman and MacBroom, 2005).

\subsection{4: Complete Removal}

The Marmot dam on the Sandy River in Oregon, was removed using a temporary cofferdam, simulating a complete removal scenario (Major et al 2010). Immediately following removal, bedload transport was primarily comprised of sand (>90\%) and transitioned to the transport and deposition of a predominately gravel material 18-20 hours after breaching occurred (Major et al 2010). The downstream fluvial response to the abrupt sediment loading included enhanced sediment transport under modest discharge rates and substantial (4m thick) deposition of sand and gravel in the few $\mathrm{km}$ (40 channel widths) downstream of the dam site (Major et al 2010). The sand and gravel mixture comprising the Sandy River bed has a similar composition to sediment type 1 used in these experiments. Complete removal under low flows with sediment 
type 1 (Run 4) also resulted in large amounts of sediment accumulation in the 10 channel widths immediately downstream of the removal location.

The Union City Dam was a complete removal that took place on the Naugatuck River (CT) although a portion of the reservoir sediment was mechanically evacuated prior to the removal of the structure to allow for anadromous and resident fish passage and to increase public safety (Wildman and MacBroom, 2005). Upon dam removal, there was minimal sediment accumulation immediately downstream of the dam site and thus no significant changes in the downstream bed topography (Wildman and MacBroom, 2005). The inconsistency of the sediment transport behavior in this case study in comparison to Marmot Dam and the flume results is likely a result of dredging a portion of the reservoir sediment prior to removal.

\subsection{5: Stepped Removal}

A partial dam removal with a portion of the structure left in place, or stepped removal, is common to reduce construction costs and a form of historic preservation (Randle and Greimann, 2006). The removal of the Glines Canyon Dam began as a horizontal removal for the first 17 feet of deconstruction in September 2011, bringing the structure height down to the water level, but the remainder of the 173 foot structure was removed in a vertical notched method, alternating sides (National Park Service, 2013b). By October 2012, 50 vertical feet of the structure remained in place (Dunagan, 2013). While this case study is complicated and utilizes several of the removal methods discussed, it is most similar to stepped removal. Sediment transport patterns documented in the downstream channel include the sudden appearance and disappearance of gravel bars along much of the riverbed, as well as a new sandy beach at the mouth of the Elwha, increasing the available habitat for shellfish (Dunagan, 2013). This pattern of sediment transport and deposition was observed in the flume, as large amounts of sediment accumulated in the downstream sediment trap following experiments testing dam removal using the stepped process 
under low flow conditions, analogous to the large amounts of reservoir sediment that traveled downstream to the mouth of the Elwha River. However, the flume experiments (Runs 6 and 16) resulted in very low rates of sediment deposition in the channel immediately downstream of the dam while the reservoir material from Glines Canyon Dam filled in the previous step-like gradient as well as former pools on the site to create a smooth continuous channel slope (Dunagan, 2013). The inconsistent downstream sediment deposition patterns may be a result of the combination of several removal methods employed at Glines Canyon. While the first stage of the removal utilized a staged removal process with a portion of the sides remaining in place, the majority of the dam was deconstructed using a process of vertical notches that allowed the reservoir sediment to erode into the downstream channel in large quantities. The discrepancy could also be due in part to the steep slope of the Elwha channel which enabled a large sediment transport capacity.

\subsection{Conclusions from Removal Methods}

The method of dam deconstruction sequencing has been shown to influence the downstream patterns of deposition and erosion. Five dam removal methods were investigated during this project: horizontal removal, where the dam decreased in height at the same rate in the vertical direction; complete removal, where the dam was removed in one instantaneous step; stepped removal, which was a modification of the horizontal removal method with the sides and base of the structure left in place; vertical removal, where one third of the structure was removed and exposed a portion of the reservoir sediment (the first piece was removed from the side and from the center). The results from this research can be used to choose a deconstruction method based on the desired changes in downstream channel bathymetry as well as amount of sediment that evacuates out of the reservoir and the downstream channel. 
The general trends observed following horizontal and stepped methods of dam removal were low amounts of sediment deposition within the 10 channel widths immediately downstream of the dam and high amounts of sediment transport out of the reach. This finding is directly transferrable from the flume to field case studies, with sediment expected to be transported downstream of the channel immediately below the dam location. A large amount of sediment accumulation in the downstream channel occurred following the methods of vertical dam removal starting from either the side or center of the dam, as well as complete removal. There were lower rates of sediment deposition following the methods of horizontal and stepped dam removal. The vertical removal location, from the side or center, only impacted the 1.67 channel widths immediately downstream of the structure, with erosion occurring downstream of the removal location and deposition behind the remaining structure. Following field application of these dam removal methods, sediment deposition immediately below the dam would be expected, with minimal amounts of sediment transporting further downstream.

When planning a dam removal during the low flow season or when low flows are anticipated, it would be advised to use horizontal or stepped removal in scenarios where additional sediment in the downstream channel would be detrimental to the system. The least amount of downstream sediment deposition occurred following the stepped dam removal method. Therefore, if a removal is being planned during the low flow season, it would be recommended to use a stepped removal process with a portion of the structure remaining in place to minimize the amount of total downstream deposition. However, if under these same flow conditions, downstream sediment deposition is not a concern or the downstream channel would benefit from channel aggradation, vertical or complete removal would be the preferential dam deconstruction method. Complete dam removal as a single step resulted in the highest amount of 
downstream sediment deposition that was observed under low flows, with vertical removal also resulting in large amounts of deposition on the downstream channel.

A majority of the sediment deposition following horizontal dam removal where the dam was deconstructed in a sequence of constant decreases in elevation is expected to occur when the elevation of the structure becomes less than the elevation of the reservoir sediment. Similarly, when removal takes place under low flows and involves vertical removal from either location or complete removal, the majority of the impact to the downstream channel will occur following the removal of the first portion of the structure, when the reservoir sediment is exposed. 


\section{Chapter 5: Impact of Flow Rate}

\subsection{Introduction:}

There are many reasons to remove a dam, some of which are time sensitive and the structure must be removed immediately, such as structural failure, but a majority of planned removals can be arranged to take place around the local hydrologic regime. Information about the local hydrology can influence project scheduling and may help support decisions concerning the long-term liability with respect to dam breaching (Hotchkiss, Barber and Wohl, 2001). Downstream fish kills, the in-filling of riffle-pool habitat, degradation of aquatic and riparian habitat, increased deposition and/or scour at bridge crossings, and destabilization of stream banks and streambeds are all potential impacts of dam removal that are influenced by the hydrologic and hydraulic regime (Hotchkiss, Barber and Wohl, 2001). Cannatelli and Curran (2012) found that the timing of the dam removal with respect to local hydrology played a large role in the sediment transport patterns following dam removal and in turn, the overall evolution of the channel within the reservoir after removal. During low flows, the channel was able to quickly stabilize, while during high flows the channel exhibited much higher rates of sediment aggradation and degradation (Cannatelli and Curran, 2012). The timing relative to the high flow season may also result in a temporal lag between dam removal and the movement of reservoir sediments (Kibler, 2011), as observed during the Marmot dam removal. The structure was removed from the Sandy River in Oregon in July with the aid of a coffer dam, during the baseflow season, and substantial evacuation of the reservoir sediment did not occur until October when the coffer dam failed following the first storm of the year (Grant, 2008).

It has been hypothesized that following dam removals during high flows, a larger amount of sediment will be mobilized and evacuated from the reservoir with subsequent amounts of 
downstream sediment deposition a function of distance downstream from the reservoir, discharge magnitude, and time since the dam removal (Wohl and Cenderelli 2000). The results presented in this chapter will illustrate the importance of considering flow season during dam removals. Results may be used to justify removing a dam during a certain season based on the desired downstream deposition patterns. These experiments applied high and low flow rates to three sediment types and five removal techniques to identify how the downstream sediment deposition patterns were influenced by the timing of a dam removal during high or low flow seasons.

\subsection{Flow Rate Results}

A discharge of $0.0116 \mathrm{cms}(\mathrm{Q} 1)$ was run for a minimum of 10 hours prior to all runs to allow a preremoval surface to form that was representative of what would be observed in the field after a river has been water worked for many years. When the dam was deconstructed, the discharge was either maintained at Q1 to simulate removal during a low channel flow, or Q2 to simulate removal during a high channel flow. The Q1 flow rate of $0.0116 \mathrm{cms}$ was scaled from planned dam removals in the field and had a Froude Number of 0.195 (Burroughs et al. 2009; Wildman and MacBroom 2005; Harris 2008; Bushaw-Newton et al. 2002; Wohl and Cenderelli 2000; Doyle et al. 2003; Cheng and Granata 2007; Walter and Tullos 2010; Skalak et al. 2009; Lorang and Aggett 2005; Pohl 2004). The flow rate Q2 was $0.036 \mathrm{cms}$ with a corresponding Froude number of 0.6 , and was chosen to reflect unplanned dam breaks and the few dam removals documented during high flow conditions (Doyle et al. 2003; Cheng and Granata 2007). Each experiment was conducted as outlined in Section 3.4, and with the sediment composition and the dam removal sequencing held constant. The flume slope was held constant at 0.00 and the sediment bed was free to adjust its slope. 


\subsubsection{Changes in Downstream channel bathymetry following dam removal}

\subsection{1a: Complete removal}

Complete removal is a method of planned deconstruction as well as a proxy for unplanned structural failure. Directly comparing the sediment deposition patterns of the downstream channel under different flow rates provides quantifiable data about the behavior of the reservoir sediment following a planned removal under low flows and failure under high flows. The downstream channel behavior following complete removal was tested under three

sediment types with varying quantities of silt present for both high and low flow rates (Runs 4, 5, 14, 15, 24 and 25). After complete removal, under low flows without silt in the sediment mixture (Run 4), deposition occurred at every meter within the downstream channel, with the most deposition from 4 to7 $\mathrm{m}$ (Figure 5.2.1). In contrast, high flows applied to the same sediment mixture (Run 5) resulted in erosion throughout the downstream channel with a majority occurring from 6 to $8 \mathrm{~m}$ (Figure 5.2.1). When comparing the reservoir area for these two runs, the low flow removal resulted in an additional $9.5 \mathrm{~kg}$ of sediment evacuating the reservoir immediately upstream of the dam piece $(2 \mathrm{~m})$ than was calculated under high flows. Deposition over the downstream channel under low flows (Run 4) was 110.9kg greater than under high flows (Run 5), which transported an additional $88.9 \mathrm{~kg}$ of sediment out of the channel to the sediment trap. High and low flow rate removals were repeated under the second sediment mixture, which had a small addition of silt. The meter above the dam experienced an additional $42.2 \mathrm{~kg}$ of erosion during high flows (Run 15; $91.6 \mathrm{~kg}$ ) than during low flows (Run 14; $49.4 \mathrm{~kg}$ ). Despite the additional sediment entering the channel during high flows, the downstream channel experienced net erosion $(5.9 \mathrm{~kg})$. The low flow removal resulted in net deposition in the downstream channel following removal $(106 \mathrm{~kg})$. Net deposition was calculated at every meter 
downstream of the dam, with a majority occurring at 3 and $4 m$ (Run 14; Figure 5.2.1).

Deposition was also observed at 3 and $4 \mathrm{~m}$ following removal under high flow, but erosion throughout the remainder of the channel resulted in an overall net erosion (5-8m; Figure 5.2.1).

Complete removal under the third sediment type, which had the highest silt content, also resulted in net deposition in the downstream channel bed following removal during low flows (Run $24 ; 71.1 \mathrm{~kg}$ ) and net erosion following high flows (Run $25 ;-71.6 \mathrm{~kg}$ ). However, there was a similar pattern of maximum bed change in the middle reach. Maximum aggradation under low flows occurred from 4 to $6 \mathrm{~m}$ in the channel (Run 24; Figure 5.2.1), and following high flows, maximum erosion was calculated at 4 and $5 \mathrm{~m}$ in the downstream channel (Run 25; Figure 5.2.1). 




Figure 5.2.1: Erosion and deposition patterns downstream of the dam site following complete removal under all flows and sediment conditions (negative denotes erosion, positive deposition; location in channel noted by meter number on left hand side of the table). Weights were calculated from GIS rasters created from DEMs of the channel bed.

Sediment deposited downstream of a dam removal can be used to minimize erosion furthur downstream and aid in coastal replenishment, as is predicted to occur along the Olympic Coast following the Elwha and Glines Canyon dam removals through sediment accumulation and restoration of the natural beaches on the bluffs near Port Angeles (Hickey, 2013). Total sediment accumulation in the trap at the end of the active channel of the flume was used to quantify the amount of sediment that was transported out of the system following each Part of the removal process in this series of experiments. 
During complete removal, the entire structure was removed in a single step. When silt was not present (Run 4 and 5), this technique resulted in approximately three times more sediment accumulation in the trap under high flows (Run 5; 143.8kg deposited) than during low flows (Run 4; 54.9kg deposited; Figure 5.2.2). The addition of silt to the mixture resulted in $0.5 \mathrm{~kg}$ accumulated in the trap under low flows (Run 14), while high flows resulted in $129.1 \mathrm{~kg}$ of deposition (Run 15; Figure 5.2.2). Similarly under the third sediment type, $0.8 \mathrm{~kg}$ of sediment deposited in the trap during low flows (Run 24) and 101.3kg of sediment deposition occurred following high flows (Run 25; Figure 5.2.2). Regardless of sediment type, there was a significant increase in the amount of sediment deposited in the downstream trap during high flows when compared to the low flow scenario following complete removal (Figure 5.2.2).

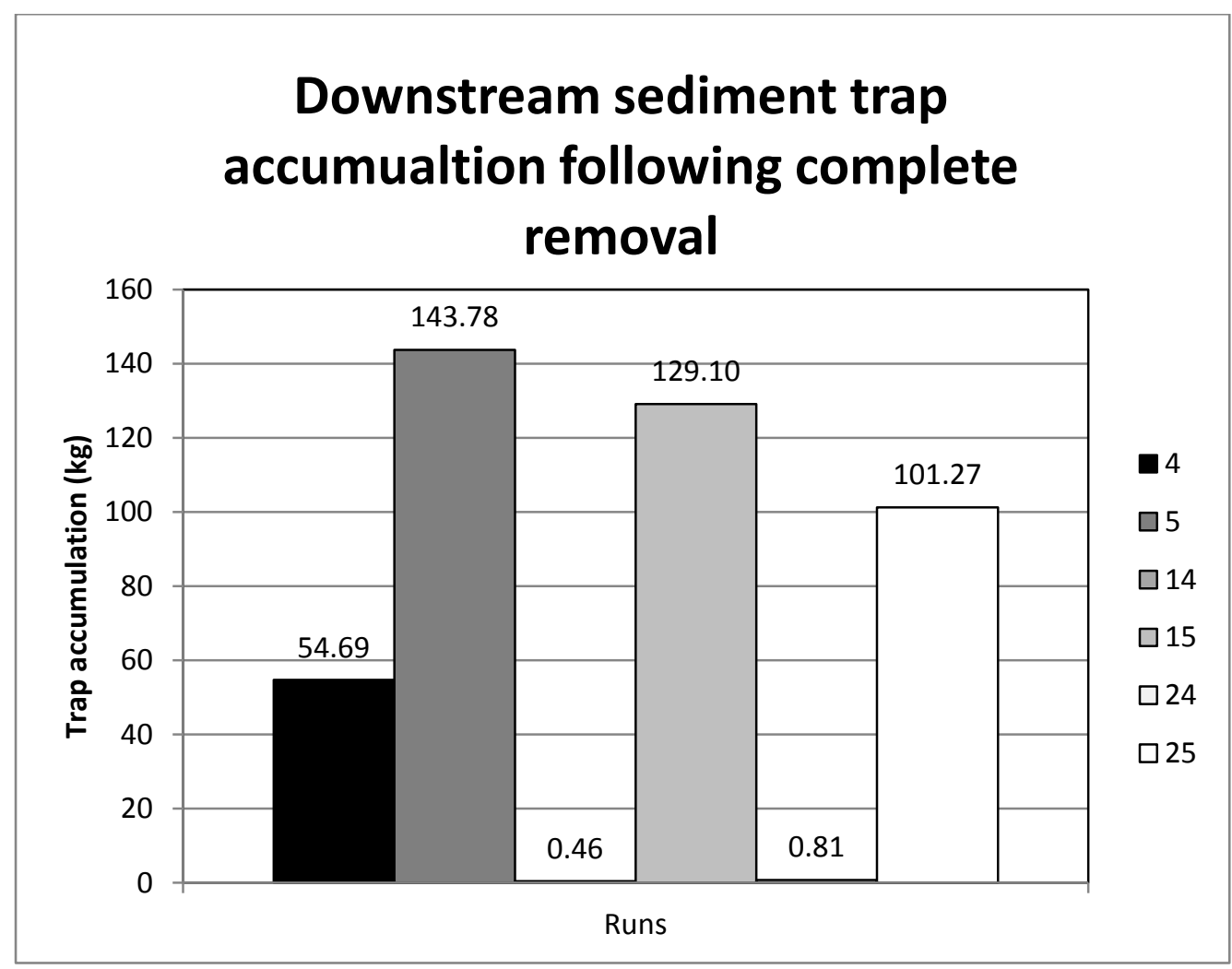

Figure 5.2.2: Sediment trap loads in kg for complete removal under high and low flows for all 3 sediment types. 


\subsection{1b: Horizontal and Stepped Removal}

Often a portion of the structure will be left in place to mark historical locations and aid sediment stability during flood events. The impacts of this methodology have not been compared previously to the downstream channel patterns that would occur without any of the structure left in place under the same conditions. Directly comparing the results of leaving a portion of the structure in place (stepped removal) to removing the entire structure in stages (horizontal removal), provides a data set that can be used to justify one deconstruction method over another based on sediment deposition patterns under high and low flows.

Similar to complete removal, the downstream channel following stepped and horizontal removal exhibited net deposition from Pre-Removal to Final bed following low flow removal and net erosion in the downstream channel following removal during high flows (Table 5.2.1). The high flow rate Runs with silt present in the sediment mixture (Run 13 and Run 17) were not run to completion due to excessive erosion of the channel immediately below the dam removal location $(3 \mathrm{~m})$ following the removal of the first part of the structure. Once the erosion reached the plexi-glass channel bottom, an artificial datum on the amount of erosion that could occur was imposed on the results. Comparing the downstream channel bed elevations from Pre-Removal to Final bed under high flows without silt present (Runs 3 and 7) and Pre-Removal to Part 1 under high flows when silt was present (Run 13 and 17), shows that the highest amounts of erosion occurred in the first meter downstream of the dam removal location (Table 4.2.1).

Changes in the amount of sediment in the downstream channel were measured following each removal step of the dam removals. The largest amount of downstream channel deposition during horizontal dam removal under low channel flows followed the removal of Part 2. At this point, $50 \%$ of the dam structure was removed and the corresponding increase in downstream 
channel volume was $48.2 \%$ for the coarse sediment mixture (Run 2 ) and $76.2 \%$ for the second sediment mixture which contained fines (Run 12; Figure 5.2.3). The most net erosion in the channel occurred following the removal of final dam piece, Part 4. Of all the fluctuations in the channel bed elevation, the removal of Part 4 caused $35.4 \%$ of the total changes under the first sediment mixture (Run 2) and $11.1 \%$ of the change for the second sediment mixture (Run 12). Run 13 was not fully executed due to excessive erosion at $3 \mathrm{~m}$, therefore conclusions about high flow horizontal removal were made exclusively from Run 3, which was the high flow removal under coarse sediment mixture. The majority of the erosion during Run 3 occurred following the removal of Part 1, with net deposition in the downstream channel following the removal of the remaining three pieces (Figure 5.2.3; Table 4.2.2).

The downstream channel following horizontal removal under low flows experienced high amounts of net deposition after the removal of Part 2 and net erosion following the removal of Part 4, resulting in an overall trend of net deposition. The downstream channel experienced a large amount of net erosion following the removal of the first dam piece under the method of horizontal dam deconstruction under a high flow rate, and although there was net deposition upon the removal of the remainder of the dam, the overall trend was net erosion over the downstream channel (Figure 5.2.3; Table 4.2.2). 
Table 5.2.1: Horizontal and Stepped removal net deposition (positive) and erosion (negative) values in the 10 channel widths downstream of the dam removal location $\mathrm{kg}$ from the raster weight differences of the Pre-Removal to Final beds for high and low flows. Runs 13 and 17 were not run to completion

\begin{tabular}{|c|c|c|c|}
\hline \multicolumn{2}{|c|}{ Low Flow } & \multicolumn{2}{c|}{ High Flow } \\
\hline Run & $\begin{array}{c}\text { Net Change } \\
(\mathrm{kg})\end{array}$ & Run & $\begin{array}{c}\text { Net Change } \\
(\mathrm{kg})\end{array}$ \\
\hline 2 & 15.97 & 3 & -26.83 \\
\hline 6 & 33.02 & 7 & -45.17 \\
\hline 12 & 91.17 & $13^{*}$ & -66.95 \\
\hline 16 & 7.26 & $17^{*}$ & -41.82 \\
\hline 22 & 132.05 & & \\
\hline
\end{tabular}




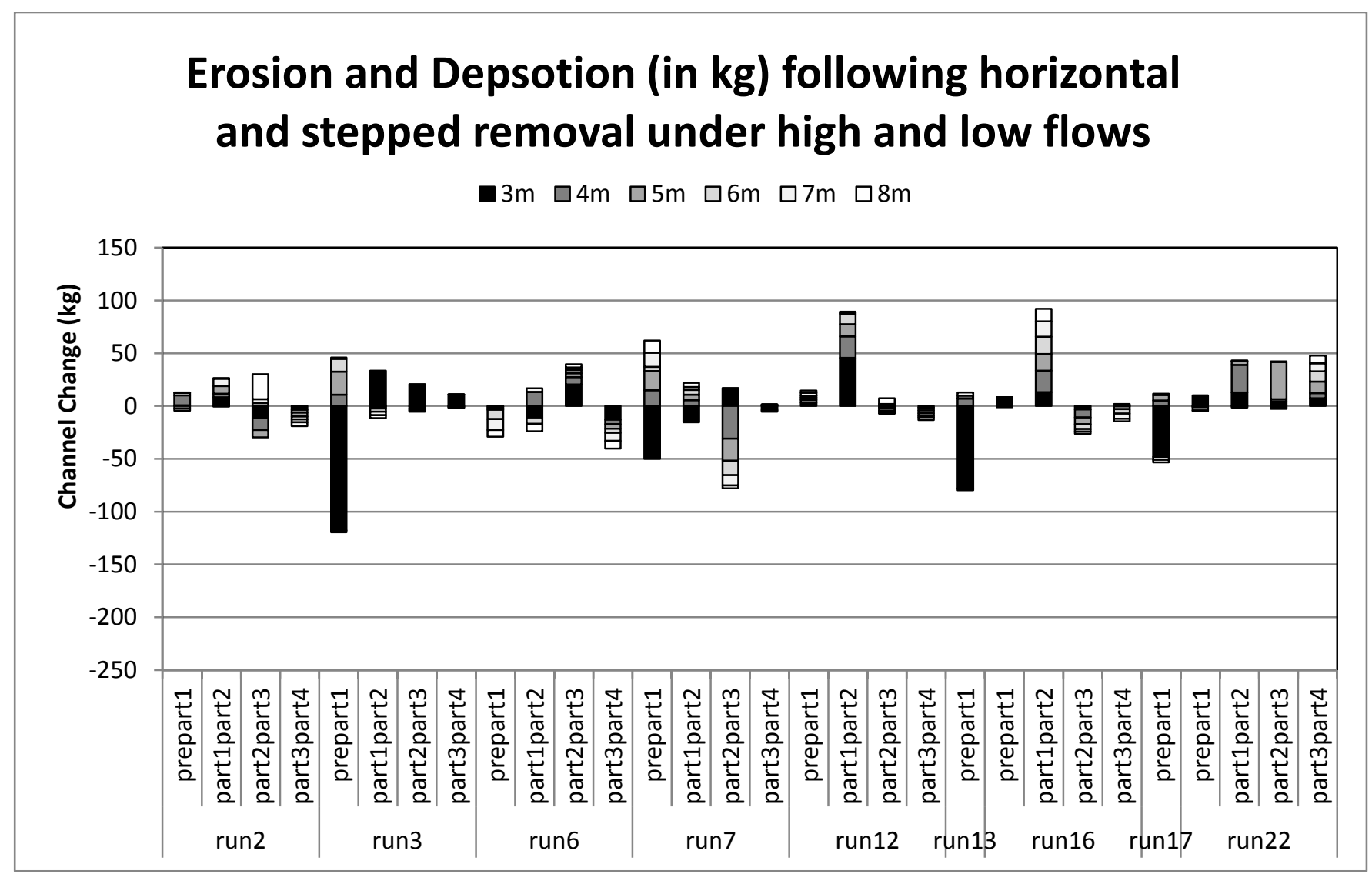

Figure 5.2.3: Erosion and deposition patterns downstream of the dam site following horizontal and stepped removals under all flows and sediment conditions (negative denotes erosion, positive deposition; location in channel noted by meter number on left hand side of the table). Runs 13 and 17 were cut short due to excessive erosion at $3 \mathrm{~m}$ (see Table 4.2.2 for numerical values). Weights were calculated from GIS rasters created from DEMs of the channel bed. 
The total amount of sediment that accumulated in the downstream sediment trap following horizontal removal under high flows (Run 3) was twice the amount that accumulated following low flows (Run 2; Figure 5.2.4). A majority of the accumulation in the trap occurred following the removal of the first 2 portions of the structure during high flows (50\% of the total trap accumulation following removal of Part 1 and $42 \%$ following the removal of Part 2 in Run 3). During low flows (Run 2), the majority of the sediment trap accumulation occurred following the removal of Parts 3 and 4(70\% and 30\% of the total trap accumulation, Table 5.2.2). For the same dam removal method but under a low flow rate and in a channel composed of a sediment mixture containing silt (Run 12), the majority of the sediment accumulation in the trap downstream of the reach occurred following the removal of Parts $3(34 \%)$ and $4(63 \%)$. When the high flow condition was used (Run 13), a large amount of sediment was transported to the downstream trap following the removal of the first piece of the structure (Figure 5.2.4). Run 13 was discontinued after Part 1 was removed. I speculate that due to the similarities following the removal of the first portion of both high flow scenarios (Run 3 and 13), that the sediment trap accumulation under both sediment types would be similar. 


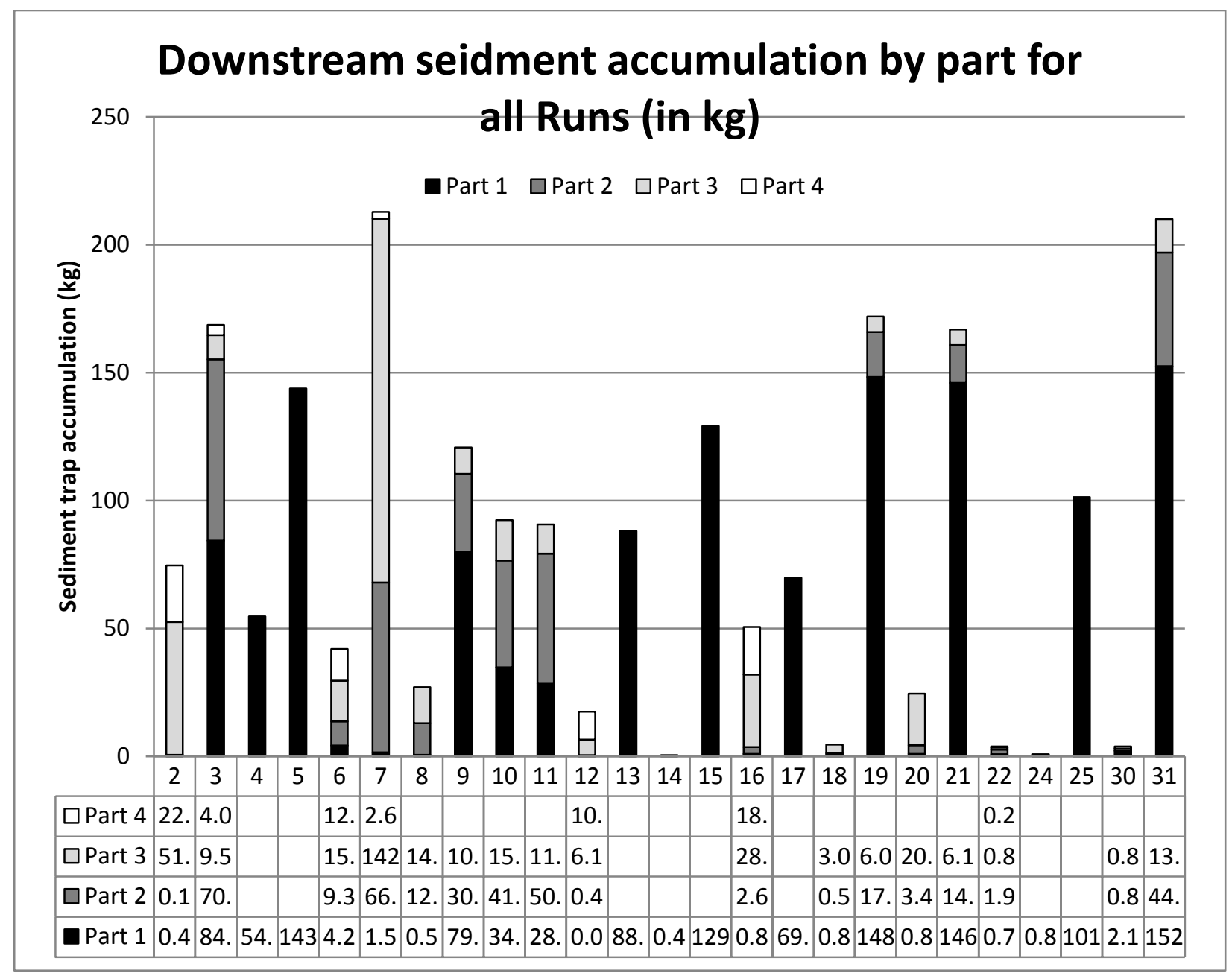

Figure 5.2.4: Sediment accumulation in the downstream trap following all removal scenarios. Results are in $\mathrm{kg}$ for all Runs 
Table 5.2.2: Sediment trap load in $\mathrm{kg}$ for the first sediment type by Part and percentage of the total load accumulation that occurred at each step.

\begin{tabular}{|c|c|c|c|c|c|c|c|c|c|}
\hline & $\begin{array}{c}\text { Part } \\
1\end{array}$ & $\begin{array}{c}\text { Part } \\
2\end{array}$ & $\begin{array}{c}\text { Part } \\
3\end{array}$ & $\begin{array}{c}\text { Part } \\
4\end{array}$ & Total & $\begin{array}{c}\text { Part } \\
1\end{array}$ & $\begin{array}{c}\% \\
\text { Part } \\
2\end{array}$ & $\begin{array}{c}\% \\
\text { Part } \\
3\end{array}$ & $\begin{array}{c}\% \\
\text { Part } \\
4\end{array}$ \\
\hline Run 2 & 0.4 & 0.1 & 51.7 & 22.1 & 74.6 & 0.5 & 0.2 & 69.6 & 29.7 \\
\hline Run 3 & 84.4 & 70.8 & 9.5 & 4.0 & 168.7 & 50.0 & 42.0 & 5.7 & 2.4 \\
\hline Run 4 & 54.9 & & & & 54.7 & 100.0 & & & \\
\hline Run 5 & 143.8 & & & & 143.8 & 100.0 & & & \\
\hline Run 6 & 4.3 & 9.5 & 15.9 & 12.4 & 42.0 & 10.1 & 22.3 & 38.0 & 29.6 \\
\hline Run 7 & 1.6 & 66.2 & 142.4 & 2.7 & 212.8 & 0.7 & 31.2 & 66.8 & 1.3 \\
\hline Run 8 & 0.6 & 12.2 & 14.1 & & 27.1 & 2.1 & 45.8 & 52.1 & \\
\hline Run 9 & 79.8 & 30.4 & 10.4 & & 120.7 & 66.1 & 25.4 & 8.5 & \\
\hline Run 10 & 34.9 & 41.7 & 15.9 & & 92.4 & 37.7 & 45.1 & 17.2 & \\
\hline Run 11 & 28.6 & 50.8 & 11.3 & & 90.7 & 31.3 & 56.1 & 12.6 & \\
\hline
\end{tabular}

When measured over the entire dam removal using the stepped removal method, the downstream channel exhibited net deposition when deconstruction occurred during low flows and net erosion during high flows (Table 5.2.1). Stepped removal with and without silt present under low flows (Run 6 and Run 16) resulted in net deposition over the downstream channel from Pre-Removal to Final bed (33.1 and $7.3 \mathrm{~kg}$ respectively; Table 5.2.1). Following the removal of Part 1, stepped removal with no silt present under low flow conditions (Run 6),there was $40.8 \mathrm{~kg}$ of net deposition throughout the downstream channel, with $30 \%$ of the change occurring at $3 \mathrm{~m}$ (Table 4.2.2). Upon removal of the second dam piece, the remaining dam structure was below the reservoir sediment height, and the downstream channel experienced net erosion of $7.1 \mathrm{~kg}, 26.6 \%$ of which occurred at $3 \mathrm{~m}$, but localized net deposition at 4,5 and $7 \mathrm{~m}$. Following the removal of Part 3, net deposition was measured $(7.3 \mathrm{~kg})$ throughout the downstream channel with $52 \%$ of the total downstream sediment accumulation occurring at $3 \mathrm{~m}$, similar to what was measured following removal of Part 1 (Table 4.2.2). The channel bed following removal of the fourth portion of the stepped removal structure under low flows 
experienced net erosion at every meter with the largest amount $(32.6 \%)$ occurring at 3m, similar to what was measured after the removal of Part 2 (Table 4.2.2).

Severe channel erosion in the meter below the dam occurred following stepped removal during the high flow condition (Run 7 and 17) and, Run 17 was not completed due to the erosion at $3 \mathrm{~m}$ following the removal of Part 1. Following the completion of dam removal under the stepped removal method, a channel sediment without silt, and high channel flow rate, channel bed erosion was measured at 3,4 and $6 \mathrm{~m}$ and net deposition at 5, 7 and $8 \mathrm{~m}$, such that the result was net erosion of the downstream channel (Run 7; Table 4.2.1). Following the removal of Part 1, there was $12.2 \mathrm{~kg}$ of net deposition over the channel bed despite $49.9 \mathrm{~kg}$ of erosion in the meter segment below the structure (3m), (Table 4.2.2). A similar pattern occurred following the removal of Part 2. There was erosion at $3 \mathrm{~m}(15.4 \mathrm{~kg})$ but deposition throughout the remainder of the downstream channel for net deposition across the reach. Net erosion over the downstream reach was calculated following the removal of the remainder of the dam (Parts 3 and 4) so that only the permanent dam edges remained in the channel. The largest amount of net erosion to the channel occurred following the removal of Part 3, where although there was $17.2 \mathrm{~kg}$ of sediment deposition at $3 \mathrm{~m}$, the remainder of the channel eroded in decreasing quantities downstream (30.8kg from $4 \mathrm{~m}, 20.9 \mathrm{~kg}$ from $5 \mathrm{~m}, 13.6 \mathrm{~kg}$ from $6 \mathrm{~m}, 9.5 \mathrm{~kg}$ from $7 \mathrm{~m}$ and $2.7 \mathrm{~kg}$ from $8 \mathrm{~m}$; Figure 5.2.3 and Table 4.2.2). After the removal of Part 4, the bed had net erosion at 3 and 8 meters with net deposition from $4 \mathrm{~m}$ to $7 \mathrm{~m}$, resulting in net erosion of $3.6 \mathrm{~kg}$ for the downstream channel (Table 4.2.2).

The downstream impact of stepped removal without silt present in the sediment mixture depended on the removal flow rate. Removal during high flows resulted in net erosion of the downstream channel (Run 7) while removal during low flows resulted in net deposition (Run 6). 
The dam removal stages were analyzed separately for the intermediary impacts on the downstream channel bed. The reach experienced net deposition following the removal of Part 1 and net erosion after the removal of Part 4 during both the low and high flow experiments. In both Runs, the meter immediately downstream of the dam structure $(3 \mathrm{~m})$ exhibited the largest amount of sediment fluctuations of the downstream channel. During Run 6 there was a total sediment flux of $56.7 \mathrm{~kg}$ at $3 \mathrm{~m}$ and aggradation of $8.9 \mathrm{~kg}$; during Run 7 a total flux of $86.5 \mathrm{~kg}$ occurred with degradation of $78.0 \mathrm{~kg}$. Regardless of flow rate, a majority of the channel adjustments occurred immediately downstream of the dam with net deposition throughout the downstream channel following the removal of Part 1 and erosion following the removal of Part 4.

The sediment trap following stepped deconstruction under sediment type 1 had five times more sediment accumulation during high flows (Run 7; 212.9kg) than low flows (Run 6; 41.9kg; Table 5.2.2). Both flow rates had the least amount of sediment accumulation following the removal of Part 1 (4.3kg and 1.6kg respectively; Figure 5.2.4). Following the removal of Part 2, the height of the remaining structure was below the initial height of the reservoir sediment. This step resulted in $31 \%$ of the total sediment trap deposition under high flows (Run 7) and 22\% during low flows (Run 6; Table 5.2.2). The largest amount of deposition in the sediment trap occurred following the removal of Part 3, with $38 \%$ of the total deposition during low flows and $67 \%$ during high flows (Table 5.2.2). After Part 4 was removed, $30 \%$ of the total low flow sediment trap deposition occurred, with minimal additional deposition at this step during high flows (Table 5.2.2). A similar trend was measured when the same removal method was followed but silt was present in the sediment mixture (Run 16). The majority of sediment accumulation in the trap occurred following the removal of Parts 3 and 4 (Figure 5.2.4). 
The general trend during stepped removal for high flows without silt present (Run 7) was sediment trap deposition following the removal of Part 2 with a majority occurring after the removal of Part 3. Sediment volumes measured from the trap were more similar to one another during the low flow rate stepped removal. Deposition following Parts 2, 3, and 4 of the dam removal were $22 \%, 38 \%$ and $30 \%$ of the total amount deposited in the trap (Table 5.2.2).

The high flow scenario with silt present was discontinued after the removal of Part 1 after 69.9kg of sediment had accumulated in the trap. This differs from Run 7 for which there was little accumulation in the sediment trap after the removal of the first dam piece. In summary, there was a larger amount of sediment transported out of the channel reach and deposited in the sediment trap during stepped dam removals during high flows than low flows, with the majority of the transport following the removal of Parts 3 and 4 in low flows.

\subsection{1c: Vertical Removal from the side and center}

Under both the high and low flow scenarios the downstream channel following vertical dam removals starting from the side without silt in the sediment mixture exhibited net deposition when the Pre-Removal channel bed was compared to the Final channel bed $(81.2 \mathrm{~kg}$ during Run 8 and 16.5kg during Run 9; Table 4.2.1). Results were similar when silt was present in the sediment mixture and the flow rate was low (Run 18). The entire downstream reach aggraded and net deposition was 78.9kg over the Final channel bed (Table 4.2.1). Following the dam removal under high channel flow and a sediment mixture containing silt (Run 19), there was a pattern of alternating deposition and erosion over the downstream reach. Net deposition occurred throughout the middle portion of the channel reach but erosion occurred at meters 3 and 8m. The channel erosion was extensive enough to create a net condition of channel degradation following the dam removal (Table 4.2.1). 
A net trend of downstream channel aggradation was measured following the removal of Part 1 of the vertical dam removal method beginning from the side of the dam under both high and low flow scenarios (Run 9 and 8). Following the removal of the first piece, downstream sediment deposition occurred at all meter segments under low flows (Run 8), and at all but 3m under high flows (Table 4.2.2). Following the removal of the second piece during low flows, net deposition occurred throughout the channel with localized areas of erosion at 5, 6 and 7m (Run 8). When the flows were high there was net erosion over the downstream channel with localized areas of deposition at 3m (Run 9). Under both flow scenarios (Runs 8 and 9), net channel erosion was calculated following the removal of the final vertical piece (19.3 and $9.2 \mathrm{~kg}$ respectively), with erosion throughout the downstream channel during low flows but only at meters 3, 4 and 5m during high flows. Regardless of flow rate, deposition was measured in the channel following the removal of Part 1 and erosion following the removal of Part 3 (Figure 5.2.5). The flow rate did, however, impact the amount of net deposition in the downstream channel with 5 times more deposition following removals during low flows than high flows without silt present and 117.7 additional $\mathrm{kg}$ of deposition during low flows with silt present than during the corresponding high flow Run (Table 4.2.1).

The quantity of sediment that transported out of the channel reach and accumulated in the trap after vertical dam removal starting from the dam side without silt present was four times larger following high flows (Run 9; 120.7kg) than low flows (Run 8; 27.2kg; Table 5.2.2). 46\% of the total amount of sediment deposited in the trap accumulated following the removal of Part 2 during low flows and 52\% of the total accumulation occurred following the removal of Part 3 (Table 5.2.2). Under high flows, the downstream trap had $66 \%$ of the total sediment accumulation following the removal of Part 1 and $25 \%$ of the total accumulation occurred 
following the removal of Part 2 (Table 5.2.2). When silt was present in the sediment mixture, the total amount of sediment accumulation in the trap was $4.6 \mathrm{~kg}$ following low flows (Run 18), with a majority of the deposition occurring after the removal of Part 3 (67\%). Following high flows, a total of $171.9 \mathrm{~kg}$ of sediment was deposited in the sediment trap, $86 \%$ of which deposited following the removal of Part 1 (Figure 5.2.4). A majority of the sediment moving further than 10 channel widths downstream of the removal location followed the removal of Part 1 for high flows and Part 3 for low flows during the vertical removal from the side deconstruction (Figure 5.2.4). For both sediment mixtures, the total amount of sediment accumulation in the trap following high flows was larger than the accumulation following low flows.

Vertical removal experiments were also run with the first piece removed from the center of the channel to identify the impact of the removal location on downstream sediment deposition and erosion under high and low flow rates. Vertical removal from the center with silt present in the sediment mixture resulted in net downstream deposition when the removal occurred under a low flow (Runs 20 and 30) but net downstream erosion when removal was during a high flow (Runs 21 and 31). Following the removal of the first piece under a low flow (Runs 20 and 30), deposition was measured over the downstream channel $(101.6 \mathrm{~kg}$ and $53.0 \mathrm{~kg})$ with the larger amount of deposition corresponding to the sediment with a lower silt content. The downstream channel (Runs 21 and 31) exhibited net erosion (16.9 and 113.8kg) following the removal of the center piece of the dam during high flow conditions, with localized deposition at 4, 5, 6 and $7 \mathrm{~m}$ for Run 21 and at 3 and $5 \mathrm{~m}$ for Run 31 (Table 4.2.2). Following the removal of the second piece under low flows the downstream channel exhibited net deposition for Run 20 (14.7kg) and net erosion for Run 30 (8.3kg). Following the removal of the second piece during high flows, the trend in the downstream channel bed was net erosion at 3, 7 and $8 \mathrm{~m}$ for Run 21 and 4,5,6,7 and 
$8 \mathrm{~m}$ for Run 31, resulting in net erosion for the downstream channel for both sediment mixtures during high flow dam removals (42 and 51.3kg; Figure 5.2.5). The removal of the third piece resulted in net erosion for horizontal removal under low flows for the second and third sediment types and also under high flows for the third sediment type (Runs 20, 30 and 31; Figure 5.2.5). Following dam removal during low flows, $18.8 \mathrm{~kg}$ of erosion was measured over the channel bed in Run 20, with net deposition at 7 and $8 \mathrm{~m}$, and net erosion of $0.03 \mathrm{~kg}$ in Run 30, with deposition at 6 and $7 \mathrm{~m}$ (Table 4.2.2). The downstream channel experienced net deposition following the third part of the dam removal under the second sediment type and a high channel flow rate (Run 21), largely a result of to $73.9 \mathrm{~kg}$ of deposition at 3 meters. There was erosion over the middle reach, from 4 to $7 \mathrm{~m}$, resulting in a net deposition of $16.9 \mathrm{~kg}$ for the downstream channel (Table 4.2.2). Erosion occurred throughout the downstream channel in Run 31 for a total $31.1 \mathrm{~kg}$ evacuated from the channel bed following removal of the final portion of the dam (Table 4.2.2). 


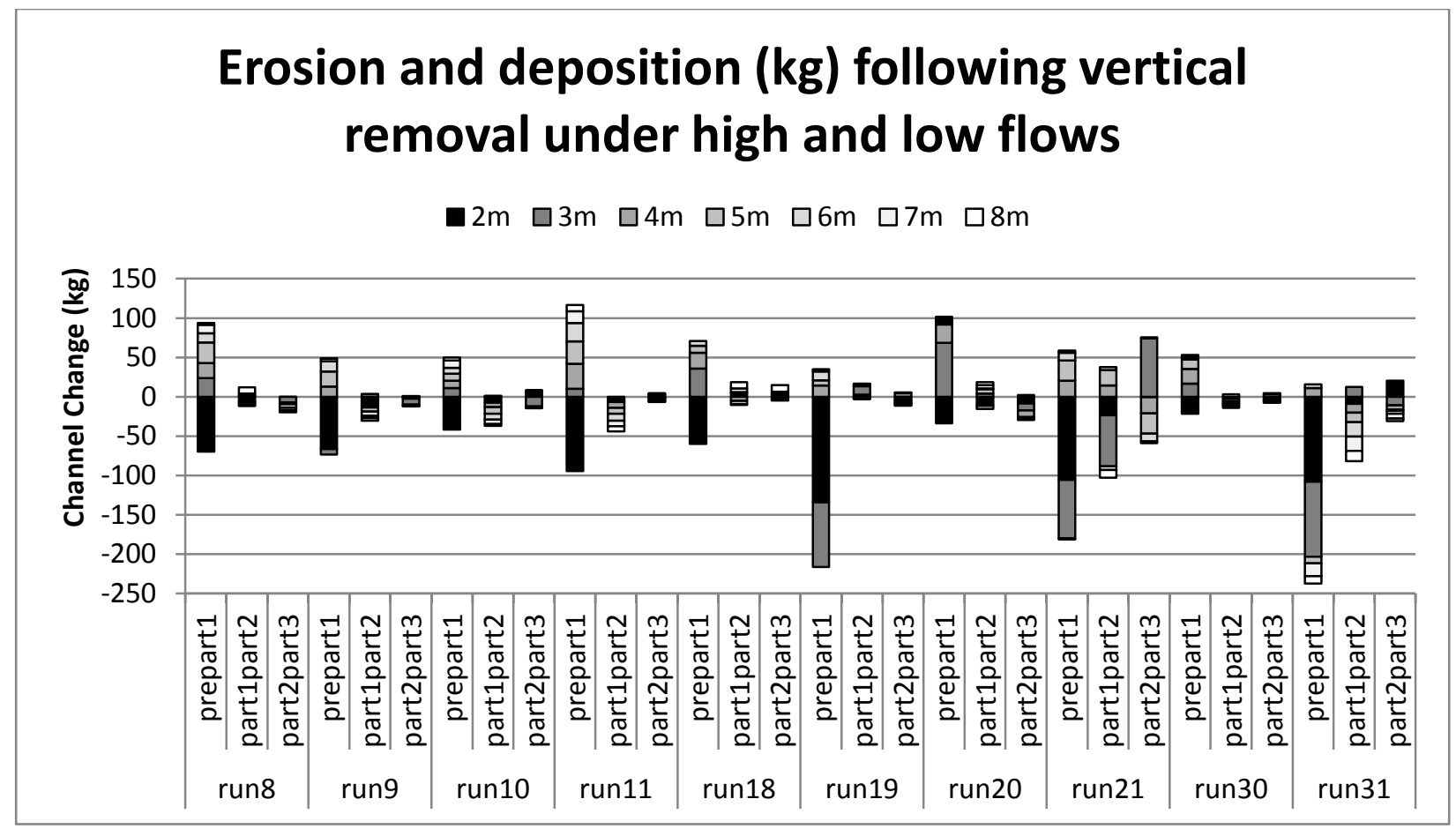

Figure 5.2.5: Erosion and deposition patterns downstream of the dam site following vertical removal under all flows and sediment conditions (negative denotes erosion, positive deposition; location in channel noted by meter number on left hand side of the table). Weights were calculated from GIS rasters created from DEMs of the channel bed.

When there was no silt in the sediment mixture, Runs 10 and 11, the downstream channel had net deposition under both high and low flow regimes following vertical dam removal starting from the channel center, with the removal during a high flow rate resulting in 9 times more deposition than for the low flow rate $(73.7 \mathrm{~kg}$ following high flows and $8.1 \mathrm{~kg}$ following low flows; Figure 5.2.5). With the exception of the quantity of sediment deposited, the channel bed after Runs without silt exhibited the same patterns of channel bed changes following the deconstruction sequencing for both flow rates. The downstream channel experienced deposition at every meter below the dam following the removal of the first piece of the structure under both flow rates (49.7 and $116.4 \mathrm{~kg}$ respectively; Table 4.2.2), and net erosion following the removal of the second dam piece (Run 10: $28 \mathrm{~kg}$ and Run 11: $38.4 \mathrm{~kg}$ ). Upon removal of the third piece, the 
downstream channel experienced net deposition at 3, 4, 7 and $8 \mathrm{~m}$ during low flows (net $13.6 \mathrm{~kg}$ ) and at 4, 5, 6, 7 and 8m during high flows (net 4.5kg; Table 4.2.2).

Deposition volumes in the sediment trap following vertical dam removal starting from the center did not follow the same trends observed following vertical removal from the side without silt present. The total amount of sediment accumulation in the downstream trap over the course of the Run was nearly identical under high (Run $11 ; 90.7 \mathrm{~kg}$ ) and low (Run $10 ; 92.5 \mathrm{~kg}$ ) flows (Table 5.2.2). The percent of the total weight accumulated in the trap after each Part was also similar regardless of flow rate. $38 \%$ of the total sediment trap accumulation occurred following the removal of Part 1 under low flows and $31 \%$ of the accumulation occurred following high flows. Similarly, following the removal of Part 2, 45\% of the total trap accumulation occurred during low flows and $56 \%$ during high flows. $17 \%$ of the total sediment deposited in the trap occurred following the removal of the final portion of the structure under low flows and $13 \%$ following high flows.

The addition of silt to the sediment mixture impacted the amount of sediment accumulation in the downstream trap following vertical dam removal beginning from the dam center. Larger quantities of sediment accumulation occurred following high flows than low flows, which is consistent with the patterns observed in vertical removal from the side. Following dam removals under high flows using the second sediment mixture, nearly seven times more sediment deposited in the trap over the course of the Run (Run $21 ; 166.9 \mathrm{~kg}$ ) when compared to the volume accumulated during low flow dam removals (Run 20; 24.8kg; Figure 5.2.4). Under the third sediment composite, the sediment trap had a total of $3.8 \mathrm{~kg}$ of sediment accumulation during low flows (Run 30) and 210kg of deposition in the trap during high flows (Run 31). The largest amount of deposition in the trap during high flows with silt present in the 
mixture occurred following the removal of the first portion of the dam (146.1 kg for Run 21 and $152.4 \mathrm{~kg}$ for Run 31). For dam removals during low flows, $82 \%$ of the total sediment trap accumulation occurred following the removal of the third piece in Run 20 and $56 \%$ following the removal of the first in Run 30 (Figure 5.2.4).

The impact of the flow rate on the total quantity of sediment that accumulated in the trap following vertical dam removal starting from the center of the dam was dependent on the presence of silt in the soil mixture. Without silt present, the amount of the sediment deposition in the trap was very similar in quantity and timing for both flow rates. When silt was present however, sediment accumulation in the trap was lower under low flows than high flows and a majority of the sediment trap accumulation during high flows took place following the removal of the first portion of the structure.

\subsection{2: Surface distribution}

Prior to the removal of any portion of the dam structure, a camera scan was completed to document the Pre-Removal conditions of the bed surface. The individual images were stitched together using PTGUI image software to create a panorama of the channel bed (Appendix E). Four 100-point grids were overlaid on the master image, one above the dam and three equally spaced downstream, from which the pebble counts were performed. The three downstream values of the percent of sand on the surface were averaged together to provide an estimate of the composition of the surface of the channel bed. 
Table 5.2.3: Average Percent sand on the surface of the bed for Pre-Removal and Final bed, with the $\%$ difference in the amount of sand on the bed surface from the high and low flow scenarios under both Pre-Removal and Final beds, negative values note a higher percent sand on the surface during low flows and the difference from the Final bed and the Pre-Removal bed with negative values indicative of a larger amount of sand on the Pre-Removal surface than Final bed or coarsening.

\begin{tabular}{|c|c|c|c|c|c|}
\hline Run & $\begin{array}{c}\text { Pre- } \\
\text { removal } \\
\text { average }\end{array}$ & $\begin{array}{c}\text { \% diff } \\
\text { low } \\
\text { pre- } \\
\text { removal }\end{array}$ & $\begin{array}{c}\text { Final } \\
\text { bed } \\
\text { average }\end{array}$ & $\begin{array}{c}\text { F diff } \\
\text { high to } \\
\text { low }\end{array}$ & $\begin{array}{c}\text { Difference } \\
\text { of Final } \\
\text { and Pre- } \\
\text { Removal } \\
\text { bed }\end{array}$ \\
\hline 2 & 65.01 & & 16.53 & & -48.48 \\
\hline 3 & 58.95 & -9.32 & 17.91 & 8.35 & -41.04 \\
\hline 4 & 53.17 & & 79.89 & & 26.72 \\
\hline 5 & 45.45 & -14.51 & 26.44 & -66.9 & -19.01 \\
\hline 6 & 47.66 & & 41.32 & & -6.34 \\
\hline 7 & 61.43 & 28.9 & 15.43 & -62.67 & -46 \\
\hline 8 & 46 & & 39.39 & & -6.61 \\
\hline 9 & 37.19 & -19.15 & 22.86 & -41.96 & -14.33 \\
\hline 10 & 44.08 & & 40.22 & & -3.86 \\
\hline 11 & 49.04 & 11.25 & 28.65 & -28.78 & -20.39 \\
\hline 12 & 36.91 & & 32.5 & & -4.41 \\
\hline 13 & 63.09 & 70.9 & 24.24 & -25.42 & -38.85 \\
\hline 14 & 75.48 & & 70.25 & & -5.23 \\
\hline 15 & 68.6 & -9.12 & 34.43 & -50.98 & -34.17 \\
\hline 16 & 58.26 & & 58.13 & & -0.13 \\
\hline 17 & 59.5 & 2.13 & 14.33 & -75.36 & -45.17 \\
\hline 18 & 66.67 & & 55.1 & & -11.57 \\
\hline 19 & 73 & 9.5 & 7.71 & -86 & -65.29 \\
\hline 20 & 44.14 & & 61.43 & & 17.29 \\
\hline 21 & 59.5 & 34.8 & 7.44 & -87.89 & -52.06 \\
\hline 22 & 91.18 & & 89.81 & & -1.37 \\
\hline 24 & 96.69 & & 93.66 & & -3.03 \\
\hline 25 & 96.97 & 0.28 & 85.95 & -8.23 & -11.02 \\
\hline 30 & 86.5 & & 80.99 & & -5.51 \\
\hline 31 & 98.9 & 14.33 & 36.36 & -55.11 & -62.54 \\
\hline
\end{tabular}


The percent of sand on the surface of the Final bed decreased when dams were removed during a high flow rate for all removal methods except for horizontal removal when using the first, coarser sediment type (Runs 3), resulting in an overall trend of increased bed surfaces coarsening during those dam removals occurring under high flows. The largest increase in the percentage of sand on the bed surface from pre-removal to the final bed occurred following complete, or single-step, dam removals under low flow conditions for each of the three sediment types tested. Stepped and vertical dam removals where the first piece was removed from the center resulting in the lowest percentage of sand on the Final bed surface when these dams were removed during high flows (Figure 5.2.6).

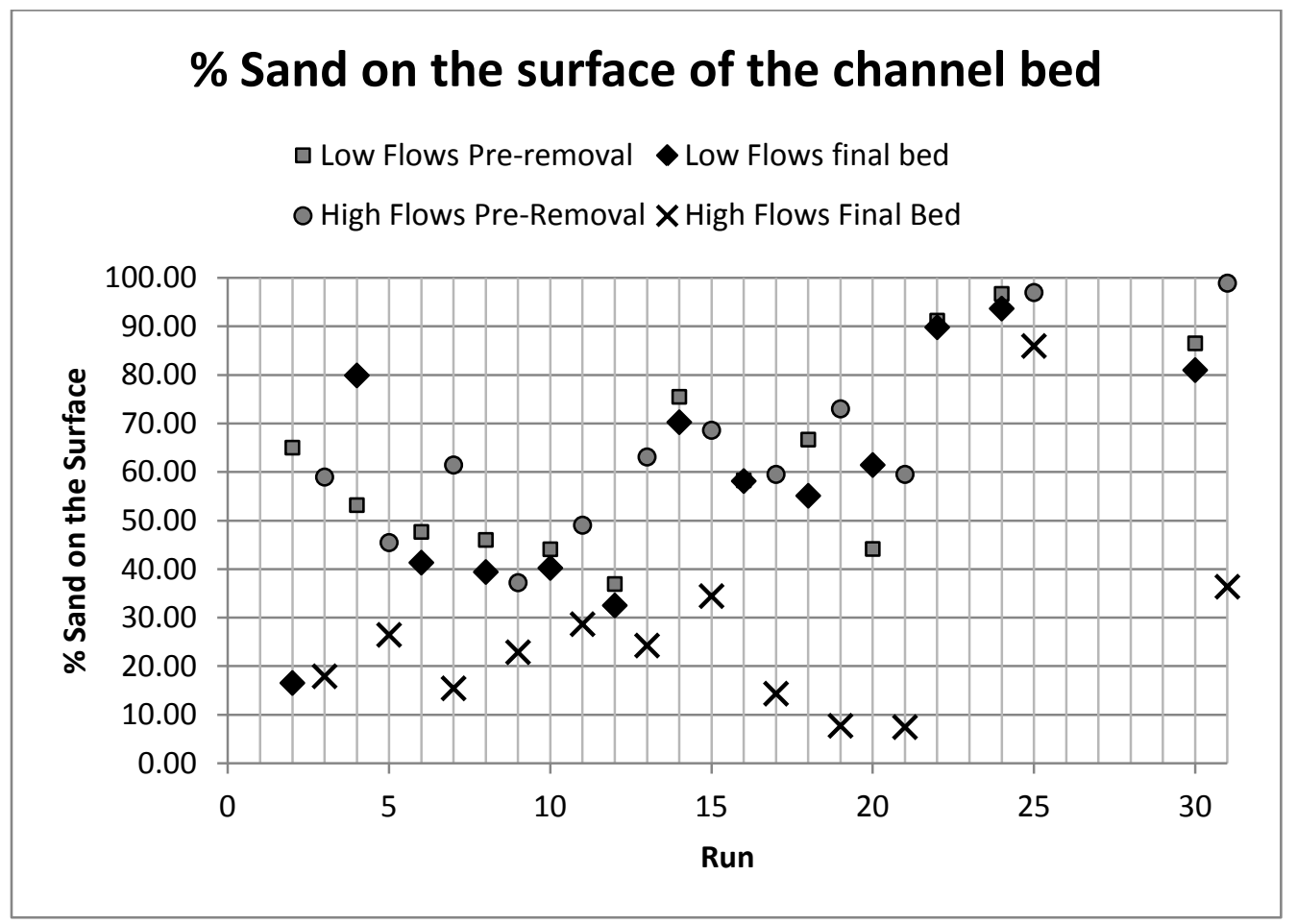

Figure 5.2.6: The percent sand on the surface of the channel bed from the Pre-Removal and Final bed camera scans under both high and low flow rates 


\subsection{Discussion of Flow Rate Impacts}

Changes to the bed surface following a dam removal were expected to be a function of distance downstream from the reservoir and the discharge magnitude (Wohl and Cenderelli, 2000). The impact of flow rate on the downstream channel following a dam removal was quantified through surface differencing, sediment trap accumulation, and the percent sand on the surface of the bed following the removal of a dam structure under two flow rates, three sediment types and five removal techniques. Identifying the general relationships associated with dam removal under high and low flows of varying deconstruction methods and silt content in the sediment provides for more informed decision-making when deciding on the timing of a dam removal. An increase in the amount of sand on a gravel channel bed can lead to a future increase in bed mobility (Curran and Wilcock, 2005; Skalak, 2002), which may have important impacts on riverine organisms (Minshall, 1984; Waters, 1995; Peterson, 1996; Bond and Downes, 2003). In some removals, it may be more desirable to have the negative downstream impacts be a higher magnitude over a shorter period of time which may affect 1 to 2 year classes of fish, than over a longer duration of which may affect multiple year classes of fish (Randle and Greimann, 2006).

Critical shear stress is the threshold for when sediment transport will begin. It is calculated using Equation 5.1.

$$
\tau_{\mathrm{c}}=\Theta^{*}(\mathrm{~s}-1) \operatorname{\rho g} \mathrm{d}_{50}
$$

$\tau_{\mathrm{c}}:$ Critical bed shear stress $\left(\mathrm{N} / \mathrm{m}^{2}\right)$

$\Theta^{*}=$ shields parameter for given particle size

$\mathrm{s}=$ specific gravity of the particles and is calculated as the ratio of specific weight of sediment $(\gamma \mathrm{s})$ to the specific weight of water $(\gamma)$ dimensionless

$\rho=$ density of water $\left(\mathrm{kg} / \mathrm{m}^{3}\right)$ 


$$
\begin{aligned}
& \mathrm{g}=\text { constant for acceleration of gravity }\left(\mathrm{m} / \mathrm{s}^{2}\right) \\
& \mathrm{d}_{50}=\text { subsurface median particle size }(\mathrm{m})
\end{aligned}
$$

The ratio of calculated shear stress to critical shear stress for this series of experiments was larger during high flows than low flows for all Runs except for the complete removal scenarios (Runs 4, 5, 24 and 25; Figure 5.3.2). The water depth measured for the high flow, complete dam removal scenarios was higher than that for the corresponding low flows, leading to the corresponding larger shear stress ratios for these dam removals. A value above one for the ratio of observed shear stress to calculated critical shear stress quantifiably describes the shear stress acting on the channel as larger than the minimum amount of shear stress required to mobilize the $\mathrm{D}_{50}$ grain size in the sediment mixture. All of the Runs had a value larger than one with the exception of Run 25, which had a ratio of 0.95 , which was attributed to a the very low bed slope measured following the dam removal (Figure 5.3.2). 


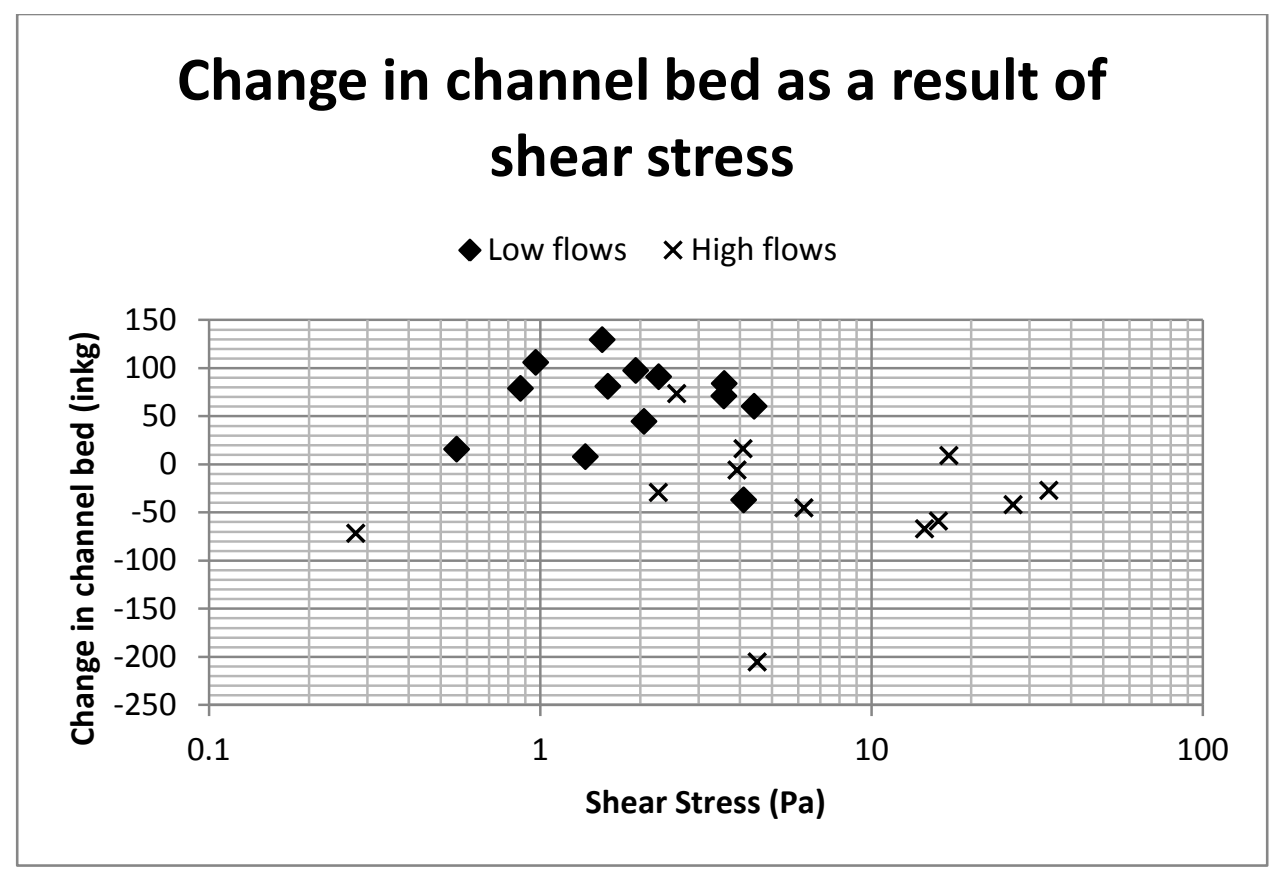

Figure 5.3.1: Shear stress and the corresponding change in the channel bed $(\mathrm{kg})$ found through the use of raster differencing for low and high flows using the raster differencing from Preremoval to Final beds for each Run



Figure 5.3.2: The ratio of the post removal shear stress to critical shear stress of the sediment for each of the flume Runs

For all dam deconstructions tested under high flow conditions, the downstream channel experienced a net erosion when silt was present in the sediment mixture. Net erosion also 
occurred when the dam was removed through the horizontal, staged, and complete removals methods without silt in the sediment mixture (Figure 5.3.1). Downstream channel erosion following complete dam removal during high flows was also observed following the Elwha dam removal, with up to a half million cubic yards of sediment erosion during a single wet winter week and continued erosion following spring rains (National Park Service, 2013a). My results showed the most erosion in the downstream channel during the dam removals tested under high flow rates occurred within the 1.67 channel widths directly downstream of the dam structure in all of the scenarios tested with the exception of complete removal. Of the high flow Runs where deposition occurred within the channel, it was localized to five channel widths downstream of the dam removal, with the exception of Run 7. When erosion was observed during low flow removal scenarios, a majority occurred in the five channel widths at the end of the active channel (6-8m). Thus, the most active portion of the downstream channel was within five channel widths immediately below the dam structure with sediment erosion and deposition during high flows and sediment deposition during low flows (with the exception of Runs 2, 4 and 10).

The amount of sediment that eroded from the reservoir was dependent on the flow rate during the dam removal. Following complete dam removal under low flow conditions, the reservoir eroded until the bed elevation was in line with the downstream channel bed for the first sediment type tested (Run 4), but with a portion of the sediment remaining in the reservoir when silt was present (Runs 14 and 24). The reservoir area following the removal of St. Johns dam on the Sandusky River also had minimal export of sediment and the dam was removed during under low flow rates (Cheng and Granata, 2007). Under high flow conditions and a complete dam removal however, my results showed no notable deposition in the downstream channel for any of the Runs $(5,15$ or 25$)$, but there was erosion and transport of reservoir sediment through the 
downstream channel to accumulate in the sediment trap further downstream. The removal of the Marmot dam on the Sandy River, Oregon involved the use of a cofferdam, The high flow events the year after the structural dam was removal eroded $245,000 \mathrm{~m}^{3}$ of sediment from the reservoir reach, but deposited only an additional $45,000 \mathrm{~m}^{3}$ in the downstream channel, resulting in a total of $111,000 \mathrm{~m}^{3}$ deposited in the downstream reach (including the sediment deposited following removal, but prior to high flows), or approximately $30 \%$ of the total sediment volume evacuated from the reservoir was deposited in the reach below the dam (Major et al, 2010). The dam removal method and sediment deposition patterns with respect to the reservoir evacuation upon removal of the Marmot dam were similar to the results presented here for the complete dam removal during high flow and demonstrate how the downstream reach quickly evolved from an accumulation zone to a transport reach during high channel flow rates. Sediment excavated from the reservoir during a complete dam removal under high flows transported through the system without depositing in the downstream channel in the first (Run 5) and third (Run 25) sediment types with deposition at 3 and $4 \mathrm{~m}$ in the second sediment mixture (Run 15). This result indicates that the method of complete dam removal timed to occur during high flow conditions would minimize the potential for burying any downstream biota or spawning grounds located in the channel immediately downstream of the removal location. In contrast, complete dam removal timed to occur during low channel flow conditions would resulted in sediment deposition throughout the entire downstream channel reach. This deposition could be useful when the downstream channel is sediment starved and additional sediment from the reservoir would help the downstream ecosystem and aid in minimizing downstream erosion.

The shear stress is a useful metric to predict downstream sediment transport patterns. When the shear stress is divided by the corresponding critical shear stress, the ability of the 
imposed flow rate to mobilize the different sediment sizes can be evaluated. The portion of the removal with the highest shear stress was expected to have the largest amount of erosion/ least amount of deposition in the downstream channel, as well as the largest amounts of deposition in the sediment trap. This expectation was met for only two runs, horizontal dam removal under sediment type 2 during a low flow rate (Run 12) and vertical dam removal with the first piece removed from the side for sediment type 2 and during a high flow rate (Run 19). The highest shear stresses during the stepped dam removal method under a low flow condition when there was silt present (Run 16) occurred following the removal of parts 3 and 4 and as a result there was erosion throughout the channel, and a large volume of sediment deposited in the sediment trap (Table 5.3.1). The portion of dam deconstruction with the lowest shear stresses was expected to have the highest amounts of deposition within the channel and the lowest amounts of deposition in the sediment trap. This occurred when the dam removal followed a horizontal removal process under low flows for sediment types 1 and 3 (Runs 2 and 22), and vertical dam removal starting from the center under the second sediment type during high flows (Run 21; Table 5.3.1). 
Table 5.3.1: Table of Runs by Part and the corresponding shear stress and sediment deposition in the channel and sediment trap.

\begin{tabular}{|c|c|c|c|c|}
\hline Run & $\tau-b$ & Ratio $\tau / \tau c$ & $\begin{array}{l}\text { Sediment } \\
\text { deposited in } \\
\text { channel }(\mathrm{kg})\end{array}$ & $\begin{array}{l}\text { Sediment } \\
\text { trap } \\
\text { accumulation } \\
(\mathrm{kg})\end{array}$ \\
\hline 2.1 & 3.43 & 6.72 & 8.37 & 0.41 \\
\hline 2.2 & 0.04 & 0.08 & 26.03 & 0.15 \\
\hline 2.3 & 2.43 & 4.77 & 0.52 & 51.91 \\
\hline 2.4 & 0.18 & 0.35 & -19.11 & 22.13 \\
\hline 3.1 & 2.69 & 5.13 & -73.62 & 84.30 \\
\hline 3.2 & 123.52 & 235.53 & 21.97 & 70.84 \\
\hline 3.3 & 11.14 & 21.24 & 15.57 & 9.54 \\
\hline 3.4 & 5.25 & 10.01 & 9.07 & 4.01 \\
\hline 4.1 & 3.59 & 7.05 & 84.04 & 54.67 \\
\hline 5.1 & 2.27 & 5.03 & -29.17 & 143.75 \\
\hline 6.1 & 8.24 & 17.40 & -29.17 & 4.25 \\
\hline 6.2 & 5.03 & 10.61 & -7.10 & 9.36 \\
\hline 6.3 & 3.81 & 8.04 & 39.58 & 15.97 \\
\hline 6.4 & 0.81 & 1.71 & -40.18 & 12.41 \\
\hline 7.1 & 16.67 & 35.22 & 12.24 & 1.59 \\
\hline 7.2 & 8.81 & 18.61 & 6.72 & 66.33 \\
\hline 7.3 & 1.20 & 2.54 & -60.60 & 142.17 \\
\hline 7.4 & 1.67 & 3.52 & -3.54 & 2.67 \\
\hline 8.1 & 2.77 & 6.34 & 93.82 & 0.58 \\
\hline 8.2 & 1.51 & 3.46 & 6.64 & 12.40 \\
\hline 8.3 & 0.55 & 1.25 & -19.34 & 14.10 \\
\hline 9.1 & 9.39 & 20.78 & 41.45 & 79.77 \\
\hline 9.2 & 2.24 & 4.96 & -15.92 & 30.59 \\
\hline 9.3 & 0.98 & 2.16 & -9.22 & 10.30 \\
\hline 10.1 & 0.63 & 1.39 & 49.66 & 34.79 \\
\hline 10.2 & 0.43 & 0.96 & -28.03 & 41.68 \\
\hline 10.3 & 4.59 & 10.17 & -13.60 & 15.90 \\
\hline 11.1 & 0.64 & 1.43 & 116.42 & 28.35 \\
\hline 11.2 & 1.96 & 4.42 & -38.39 & 50.90 \\
\hline 11.3 & 7.08 & 15.94 & -4.48 & 11.41 \\
\hline 12.1 & 0.85 & 1.94 & 14.80 & 0 \\
\hline 12.2 & 3.04 & 6.95 & 89.31 & 0.46 \\
\hline 12.3 & 1.42 & 3.24 & 0.07 & 6.10 \\
\hline 12.4 & 4.00 & 9.16 & -13.11 & 10.93 \\
\hline 13.1 & 14.47 & 33.10 & -66.93 & 88.05 \\
\hline 14.1 & 0.97 & 2.22 & 105.99 & 0.46 \\
\hline
\end{tabular}




\begin{tabular}{|c|c|c|c|c|}
\hline 15.1 & 3.93 & 8.99 & -5.84 & 129.07 \\
\hline 16.1 & 0.59 & 1.36 & 7.28 & 0.88 \\
\hline 16.2 & 0.54 & 1.23 & 92.05 & 2.68 \\
\hline 16.3 & 1.61 & 3.68 & -26.21 & 28.43 \\
\hline 16.4 & 16.68 & 38.17 & -12.72 & 18.55 \\
\hline 17.1 & 26.77 & 61.25 & -41.81 & 69.73 \\
\hline 18.1 & 2.13 & 4.87 & 67.61 & 0.88 \\
\hline 18.2 & 1.82 & 4.17 & 3.93 & 0.57 \\
\hline 18.3 & 1.10 & 2.53 & 7.43 & 3.09 \\
\hline 19.1 & 22.95 & 52.51 & 0.00 & 148.28 \\
\hline 19.2 & 18.51 & 42.35 & 11.32 & 17.62 \\
\hline 19.3 & 9.39 & 21.48 & -2.10 & 6.03 \\
\hline 20.1 & 3.58 & 8.18 & 101.61 & 0.89 \\
\hline 20.2 & 0.47 & 1.08 & 14.73 & 3.44 \\
\hline 20.3 & 1.64 & 3.75 & -18.79 & 20.20 \\
\hline 21.1 & 15.28 & 32.27 & -16.88 & 145.98 \\
\hline 21.2 & 17.41 & 36.78 & -42.00 & 14.73 \\
\hline 21.3 & 15.13 & 31.95 & 0.00 & 6.12 \\
\hline 22.1 & 4.68 & 18.36 & 5.43 & 0.76 \\
\hline 22.2 & 0.32 & 1.27 & 41.87 & 1.91 \\
\hline 22.3 & 1.25 & 4.89 & 39.82 & 0.83 \\
\hline 22.4 & 0.27 & 1.07 & 47.90 & 0.28 \\
\hline 24.1 & 3.58 & 12.95 & 71.11 & 0.81 \\
\hline 25.1 & 0.28 & 0.95 & -71.58 & 101.25 \\
\hline 30.1 & 2.06 & 7.24 & 53.00 & 2.12 \\
\hline 30.2 & 1.32 & 0.28 & -8.29 & 0.81 \\
\hline 30.3 & 1.55 & 0.28 & -0.03 & 0.86 \\
\hline 31.1 & 0.16 & 0.58 & -113.78 & 152.49 \\
\hline 31.2 & 7.65 & 27.63 & -60.39 & 44.47 \\
\hline 31.3 & 6.30 & 22.76 & -31.10 & 13.04 \\
\hline
\end{tabular}

Shear stress was not a reliable predictor of downstream channel deposition and erosion patterns. The removal of Part 1 during vertical dam removal with the removal starting from the side with sediment type 1 under low flows (Run 8) had the largest shear stress of the dam removal but also the largest amount of in-channel deposition and the least sediment trap deposition, attributed to the large amount of sediment available for transport to the downstream channel with the removal of the first part of the dam. The supply of sediment was much larger 
than the transport capacity of the flow to transport the sediment. Conversely, the removal of Part 3 had the lowest shear stress, the most erosion in the downstream channel, and the most sediment trap deposition (Table 5.3.3). In addition to the impact of shear stresses not resulting in the consistent downstream deposition patterns, the trend of deposition after the removal of Part 1 and erosion following the removal of Part 3 was not dependent on flow rate indicating that the portion of the structure removed was more critical than shear stress or flow rate in determining the downstream channel behavior.

The downstream channel flow following vertical dam removal beginning from the center of the dam had the lowest shear stresses following the removal of Part 2, which resulted in the largest amount of erosion in the downstream channel as well as the largest amount of sediment trap accumulation (Run 10, Figure 5.3.3). While the removal of Part 2 during high flows under the same conditions did not have the lowest observed shear stresses, it also had the largest amount of erosion in the downstream channel as well as the largest amount of sediment deposition in the trap, supporting the hypothesis that the portion of the structure removed determines the downstream channel behavior following vertical removal, regardless of the location of the first piece of the structure removed.

During horizontal dam removal conducted under high flows (Run 3), the largest shear stresses were calculated in the channel following the removal of Part 2. This part created the situation where the structure height was below the initial sediment height. Reservoir sediment was freely available to transport and the result was the largest amount of downstream sediment deposition of all of the stages of deconstruction and $70.8 \mathrm{~kg}$ of sediment accumulation in the trap (Table 5.3.1). The channel under the same removal sequence but low channel flows (Run 2) experienced the lowest shear stress values following the removal of Part 2 but the largest amount 
of sediment accumulation on the downstream channel and the lowest amount of sediment in the trap. The largest amount of downstream sediment deposition occurred following the removal of Part 2 when there was silt in the sediment mixture, but the second largest amount of shear stress in the downstream channel and $0.5 \mathrm{~kg}$ of sediment accumulation in the trap (Run 13; Table 5.3.1). The amount of sediment that accumulated in the downstream trap following the removal of Part 2 during dam removal through the horizontal deconstruction method was dependent on flow rate and shear stress. The high flow conditions and associated shear stresses resulted in larger amounts of sediment trap accumulation (Figure 5.3.3). However the amount of sediment that accumulated within the downstream channel was less dependent on shear stresses. Large amounts of sediment deposition in the downstream channel was dependent on the height of the remaining structure and when it was below the initial sediment height in the reservoir, regardless of flow rate or shear stress. 


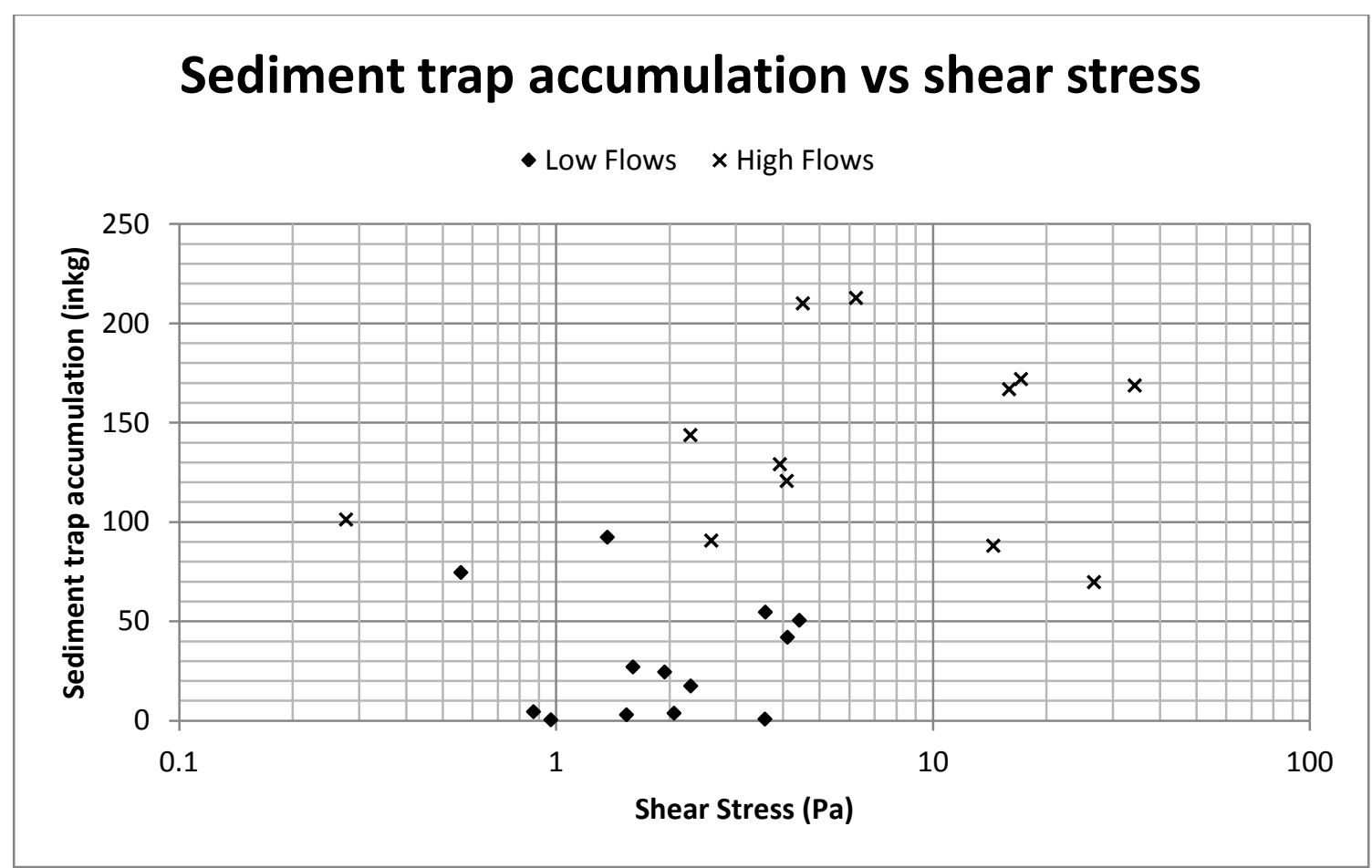

Figure 5.3.3: Total sediment trap accumulation for each run in $\mathrm{kg}$ plotted against the average calculated shear stress $(\mathrm{Pa})$ for the same Run.

Regardless of sediment type, the dam removals during high flow rates resulted in larger quantities of sediment accumulation in the downstream trap than the removals during low flows under the same conditions (Figure 5.3.4). With the exception of the process of vertical dam removal from the side under sediment type 1 (Runs 8 and 9), which resulted in similar amounts of deposition under high (90.7kg) and low (92.5kg) flows, all Runs exhibited at least twice as much deposition in the sediment trap under high flows than during low flows (under the same sediment and deconstruction techniques) for all runs that were executed to completion. 


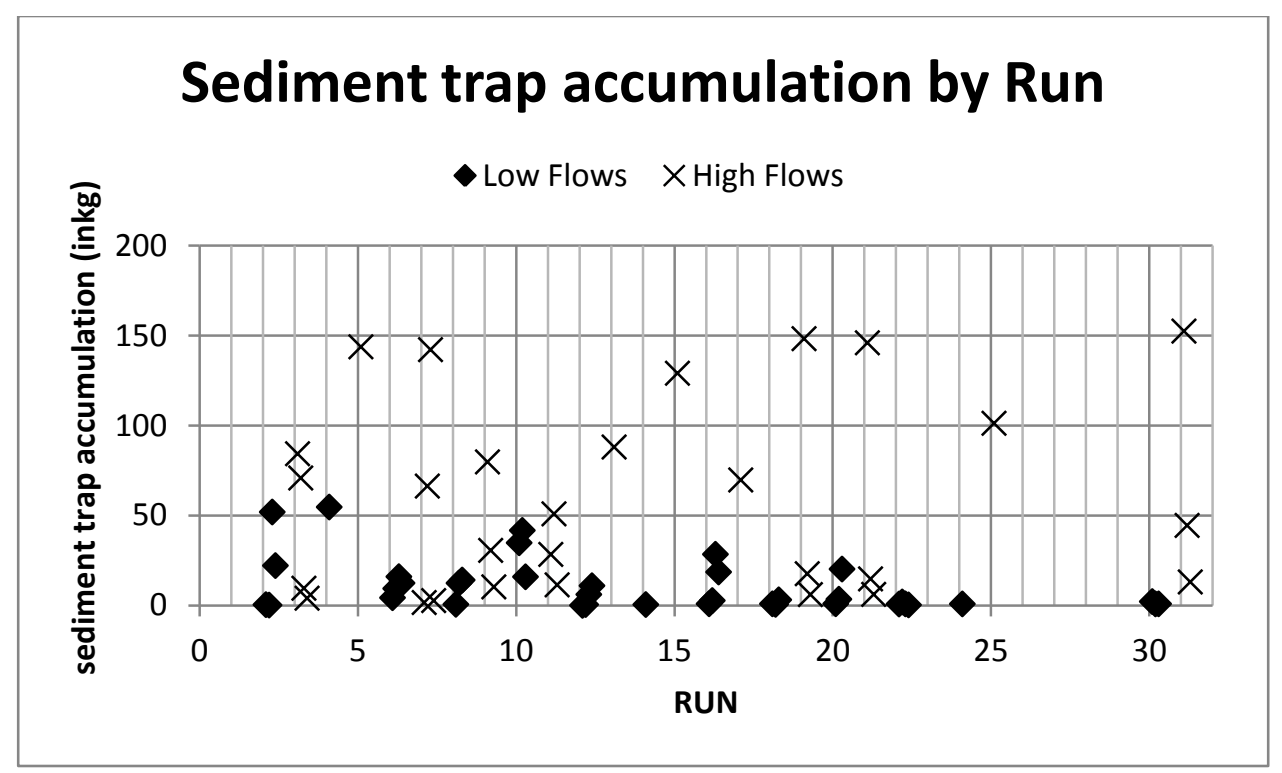

Figure 5.3.4: Total amount of sediment that accumulated in the downstream sediment trap in $\mathrm{kg}$ by Run

Flow rate influenced not only the quantity of sediment that accumulated in the trap but also the impact that each stage of the deconstruction process had on the sediment accumulation in the downstream trap. A majority of the sediment accumulation in the trap occurred following the removal of the first piece of the dam structure for all Runs and sediment types conducted under high flows, with the exception of stepped dam removal process (Runs 6 and 7) and vertical dam removal starting from the center (Runs 10 and 11). Similarly, all Runs conducted under a low channel flow rate had a majority of the sediment trap deposition occur following the removal of the second (Runs 10 and 22), the third (Runs 2, 6, 8, 16, 18 and 20) and the fourth portions of the structure (Run 12), with the exception of the process of vertical dam removal starting from the center (Run 30) when a majority of the sediment trap accumulation occurred following the removal of the first portion of the dam.

Discharge rates during dam removal were expected to govern the volume and grain size distribution in the channel in a transport limited system (Wohl and Cenderelli, 2000), exerting a dominant role over the amount of downstream channel bed aggradation (Hotchkiss, Barber and 
Wohl, 2001). Bed aggradation was speculated to occur concurrent with bed surface fining (Montgomery et al. 1999), pool in-filling (Lisle, 1982; Wohl and Cenderelli, 2000; James, 1989; Madej and Ozaki, 1996). These experiments measured downstream deposition and general bed surface fining following dam removals during a low flow condition. Bed surface coarsening occurred when the same dams were removed during high flow conditions, with the greatest amount of surface coarsening following stepped and vertical dam removal from the center. The flow rate was held constant at either Q1 or Q2 for all of the runs; therefore the variation in the amounts of sand on the bed surface was a result of the location of the flow entering the downstream channel as additional pieces of the structure were removed. Vertical dam removal and stepped dam removal processes involved smaller vertical openings than either the horizontal or complete dam removals, causing the same amount of flow entering the downstream channel through a smaller vertical orifice. If coarsening of the downstream channel is desirable, it would be ideal to not only plan a removal during high flows, but also to deconstruct the dam in a way that forces a majority of the flow to be directed through a small vertical opening that is laterally constrained. This methodology would have been ideal for the Halligan reservoir along the North Fork Poudre River in northern Colorado, where the release of $7,000 \mathrm{~m}^{3}$ of sediment resulted in the decimation of a self sustaining trout run and filled in pools throughout the $10 \mathrm{~km}$ downstream (Wohl and Cenderelli, 2000).

\subsection{Impact of Flow Rate Conclusions}

The results presented above can be used to aid in the prediction of the impact of regional flow patterns on sediment transport, deposition, and erosion during a low head dam removal. During low flow conditions, deposition was measured in the 10 channel widths below the dam removal location when comparing the Pre-Removal to Final bed conditions, regardless of the 
removal methodology and sediment type. Erosion was measured over the same downstream reach when the flow was higher and had a Fr=0.6 during the dam removal. The Final bed surface also developed a coarser bed surface during dam removals under High flows than low flows under the same conditions; however, in-between the stages of dam removal, the portion of the structure that was removed was the controlling parameter. The removal of the first portion of the dam in the vertical removal scenarios and the removal of the second portion of the dam in horizontal dam removals resulted in the largest amount of deposition in the downstream channel, regardless of flow rate or shear stress.

Local hydrology may inform project scheduling and help support decisions concerning the long-term liability with respect to dam breaching (Hotchkiss, Barber and Wohl, 2001). Complete dam removal and vertical dam removal from the side under a high flow condition were the experiments comparable to dam failure during a storm event and resulted in the least amount of downstream erosion. This was also documented in the single stage removal of Marmot dam, where a high flow at the time of breaching was used to reduce the risk of blocking fish passage as a result of insufficient reservoir incision (Major, 2008). The greatest amounts of erosion in the downstream channel occurred during dam removal through both the stepped and vertical dam removals from the center of the channel when silt was present in the sediment mixture and the flow rate was high. Thus, dam removal during low flow conditions using the Stepped dam removal or vertical dam removal from the center sequencing were shown to be the best method of deconstruction to minimize the amount of deposition, with complete and horizontal dam removals resulting in the highest amounts of downstream deposition. 


\section{Chapter 6: Impact of sediment type on the downstream channel 6.1 Introduction of Sediment Mixtures}

Previous dam removal flume experiments were primarily focused on the impacts of a sudden, large supply of uniform sediments to a channel (Park and Jain, 1986; Schumm et al., 1987), a scenario that does not adequately represent grain-size distributions likely to be involved in real world dam removals (Hotchkiss, Barber and Wohl, 2001). Field studies have found channel development following dam failure to be strongly controlled by the composition of the reservoir sediment (Doyle, 2003), which varies from site to site.

The experiments presented here tested the impacts of three different sediment grain size distributions that were designed to bracket the sediment distributions common in low head dam removals. Three sediment mixtures were created from gravel $\left(2.0 \mathrm{~mm}\right.$ to $\left.64.0 \mathrm{~mm} ; \mathrm{D}_{50}=8.0 \mathrm{~mm}\right)$, sand $\left(0.63 \mathrm{~mm}\right.$ to $\left.2.0 \mathrm{~mm} ; \mathrm{D}_{50}=1.0 \mathrm{~mm}\right)$, and silt $\left(0.004 \mathrm{~mm}\right.$ to $\left.0.63 \mathrm{~mm} ; \mathrm{D}_{50}=0.06 \mathrm{~mm}\right)$ : a) $70 \%$ sand $+30 \%$ gravel, b) $1 \%$ silt $+64 \%$ sand $+35 \%$ gravel and c) $2.5 \%$ silt $+85 \%$ sand $+12.5 \%$ gravel (Figure 3.3.1). The first sediment mixture had a $\mathrm{D}_{50}=0.65 \mathrm{~mm}, \mathrm{D}_{16}=0.397 \mathrm{~mm}$, and $\mathrm{D}_{84}=4.62 \mathrm{~mm}$ with an average sand content of $68 \%$ of the mixture. The first sediment mixture was designed to replicate the median grain size of the impounded and channel sediment from the Icicle Creek Dam Removal (WA) and the Ottawa River Dam Removal (OH) (Lorang 2005; Harris 2008). The second sediment mixture had a $\mathrm{D}_{50}=0.61 \mathrm{~mm}, \mathrm{D}_{16}=0.24 \mathrm{~mm}$, and $\mathrm{D}_{84}=4.74 \mathrm{~mm}$ with an average sand and silt content of $64 \%$. The second sediment mixture was designed to reproduce the median grain size and percent sand and silt content documented from the sediment dredged prior to the Embry and Woolen Mills dam removals in Virginia as well as the Merrimack Village Dam (NH) (Pearson 2011). The third sediment mixture had a $\mathrm{D}_{50}=0.38 \mathrm{~mm}$, $\mathrm{D}_{16}=0.15 \mathrm{~mm}$, and $\mathrm{D}_{84}=2.08 \mathrm{~mm}$ with an average sand and silt content that was $85 \%$ of the bed. 
The third sediment, with the highest silt and sand content, was included to broaden the results of this research to dams impounding primarily fine-grained sediments on low gradient channels. One of the large concerns with the mobilization of silt following dam removals is that it will be moved through the downstream channel as washload. Sediment mobilized into the water column can increase downstream turbidity, creating conditions that make it difficult for salmon to lay eggs and block light from reaching algae and other life on the channel bottom (Hickey, 2013). Channel bed and impoundment sediment were comprised of the same mixture because a river is expected to have impounded sediment transported downstream and therefore of the same size distribution as the channel bed.

The hypothesis for the impact of sediment characteristics on the transport and deposition was that sediment released will transport downstream at a rate dependent on the relative amounts of gravel, sand, and silt in the sediment mixture. Sediment sorting was also expected with dam removal and sediment pulses were expected to move downstream as a series of sediment waves through a combination of dispersion and advection, depending on the specific grain size composition of the wave. The impacts of sediment pulses comprised of coarse material, sediment type 1 in these experiments, were predicted to be localized to the reach directly downstream of the dam measurable from the beginning of the removal of the structure, and with impact magnitude diminishing over the downstream distance and time since the initial stage of dam removal (Kibler, 2011). Sediment erosion and deposition patterns in the downstream channel were visually qualitated after each stage of the dam removals using the camera scan panoramas (Appendix E) and numerically quantified from the laser surface scans using a GIS raster differencing, the processes for which were described in Chapter 3 (Appendix F). The 
combination of these 2 methods allowed me to identify sediment movement through the downstream reach.

Sediment that traveled beyond the 10 channel widths immediately below the dam location was captured in the sediment trap and represents the amount of sediment transported out of the downstream reach, defined as 10 channel widths in length. The amounts of sediment deposited in the downstream trap under each of the sediment mixtures were compared for each dam removal method and removal flow rate in order to isolate the impact of the sediment composition on downstream sediment transport.

\subsection{Coarse Sediment, Mixture 1}

\subsubsection{Low Flow Removals}

Five deconstruction methods were tested with a low flow $(\mathrm{Q}=0.0116 \mathrm{cms} ; \mathrm{Fr}=0.2)$ with the first sediment mixture in place. The sediment waves that formed with each removal were composed primarily of the sand sediments that were colored brown, making the progress of the wave visible in the panoramic photos. The largest of these waves developed during the Horizontal dam deconstruction method and was visible in the panoramic photos (Figure 6.2.1). The front of the sediment wave deposited first at $4 \mathrm{~m}$ downstream of the dam site, then moved to $5 \mathrm{~m}$ following the removal of Part 2, and down to $8 \mathrm{~m}$ after Part 3 was removed. The removal of Part 4 did not result in any aggradation within the 10 channel widths below the dam removal location. 


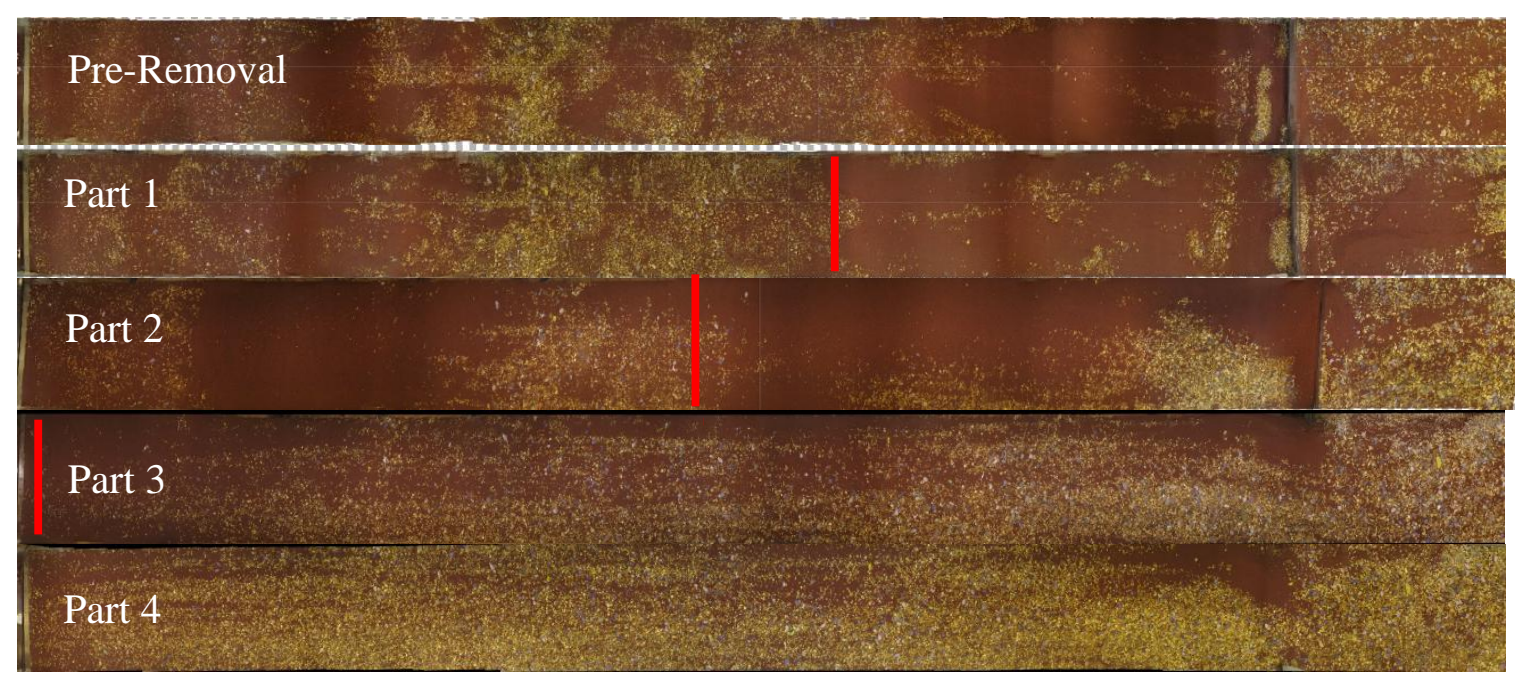

Figute 6.2.1: The camera panoramas of the channel bed following each part of the horizontal dam removal process under low flows and sediment type 1 (Run 2). Flow was from right to left.

The sediment slug is also identifiable from the longitudinal profile of the channel bed elevations that identify changes in the bulk sediment in the channel by meter for each portion of the Run (Figure 6.2.2). Following the removal of Part 1 sediment deposited over the first 4 meters downstream, and after the removal of Part 2 deposition extended from 3 and $5 \mathrm{~m}$ in the downstream channel. Upon the removal of Part 3, the sediment slug migrated downstream to cover the entire 8 meter reach downstream of the dam site, and the downstream channel did not have any additional sediment deposition following the removal of Part 4 (Figure 6.2.2). 


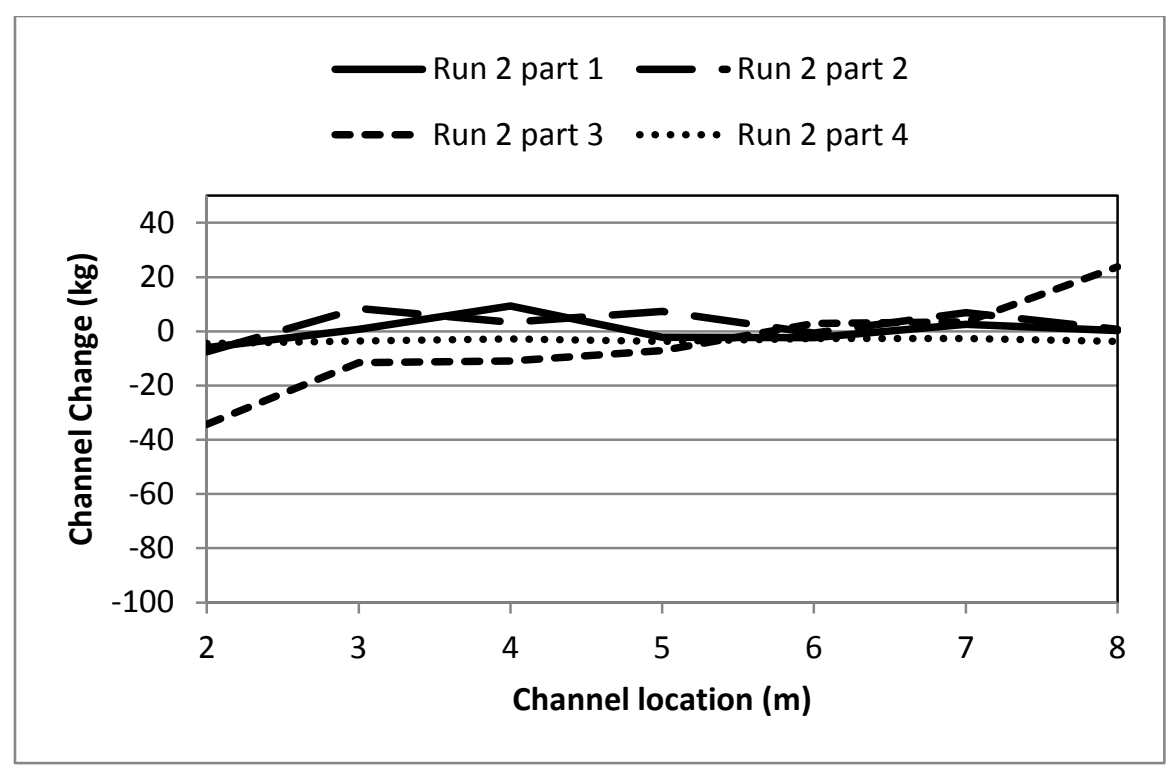

Figure 6.2.2: Longitudinal profiles of the sediment difference in the downstream channel (y-axis in $\mathrm{kg}$ ) between each part of the dam removal process for horizontal removal under low flows. Channel changes were measured as the difference between each sequential step of the removal (for example part 3 illustrates changes in bed weight as a result of the removal of that portion of the structure).

Sediment deposited across the downstream channel reach following dam removal using the complete removal method (Run 4). Deposition thickness was consistent over the downstream reach with a total bed aggradation of $84 \mathrm{~kg}$. The only measured erosion occurred in the area of the former reservoir as almost $60 \mathrm{~kg}$ of sediment was evacuated and transported downstream (Figure 6.2.3). 




Figure 6.2.3: Change in total sediment (in $\mathrm{kg}$ ) over the downstream channel length from the dam expressed as the sediment weight. The graph illustrates the difference from the initial to the final bed for complete removal under low flows and the first sediment mixture as calculated using the raster difference of the bed laser scans

Sediment transport during dam removal using a stepped deconstruction sequence alternated between deposition and erosion. There was erosion from the reservoir area and at the downstream end of the channel reach, from 6 to $8 \mathrm{~m}$, following the removal of the first portion of the structure but little change elsewhere in the reach. Upon removal of the second piece of the dam, which was the point at which the dam height was below the elevation of the reservoir sediment, aggradation occurred at $4 \mathrm{~m}$ and the erosion previously measured over 6-8 $\mathrm{m}$ was filled in. The entire downstream reach aggraded and a large sediment deposit formed at $3 \mathrm{~m}$ following the removal of the third piece. The deposited sediment as well as some of the original bed sediment eroded upon the removal of the fourth and final piece. The channel bed was degraded across the reach following completion of the dam removal (Figure 6.2.4). 


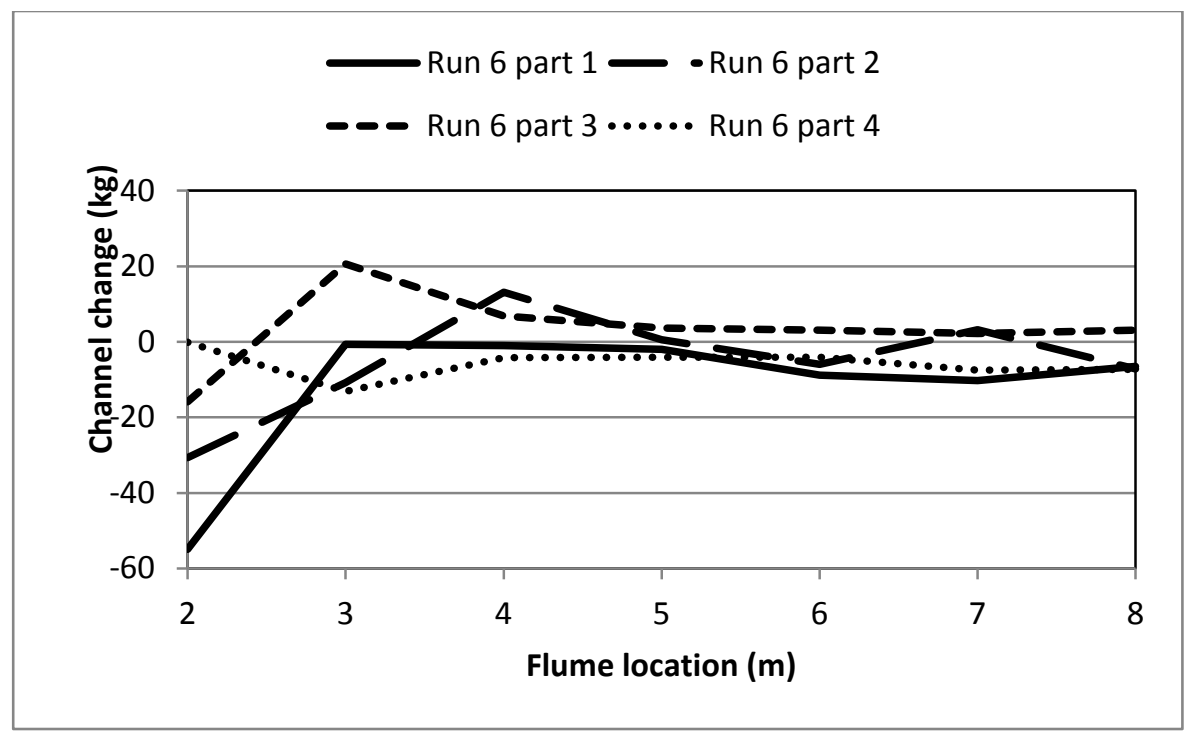

Figure 6.2.4: Longtitudinal profile of channel change (in $\mathrm{kg}$ ) following each part of the stepped removal under low flows for the first sediment mixture (Run 6). Positive denotes aggradation and negative denotes erosion bewteen each removal stage.

Although there was erosion and deposition during the intermediary stages of vertical dam removal from the side (Run 8), the elevation of the final bed surface was changed very little from the bed surface measured following the first step of the removal. Sediment deposited across the channel reach following removal of the first dam piece although there was an area of localized erosion on river left immediately downstream of the portion of the structure that was removed. The deposited sediment remained in place after the second and third pieces of the dam were removed, maintaining the bed elevation at what it was following the first stage of the removal. The exception was the persistent area of was localized channel erosion on the right hand side of the channel immediately downstream of the dam site. 


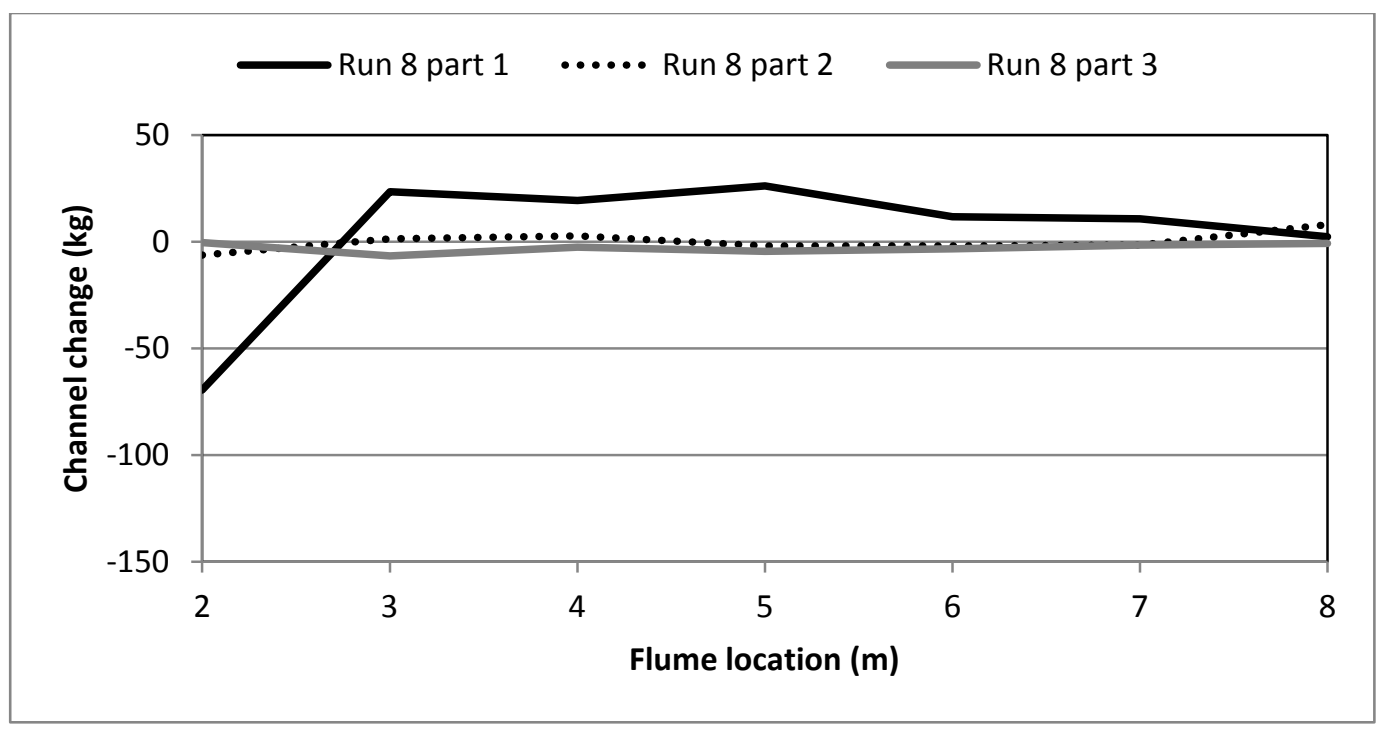

Figure 6.2.5: Longitudinal profiles of the sediment difference (y-axis in $\mathrm{kg}$ ) following each part of the dam removal process for vertical removal from the side under low flows (Run 8). Positive denotes aggradation and negative denotes erosion between each removal stage.

A similar pattern of initial deposition followed by minimal channel elevation change was measured for the Vertical dam removal method when the first part was removed from the center (Run 10). There was a limited amount of deposition and channel aggradation following the removal of Part 1. Erosion of the deposited sediment occurred upon the removal of Part 2, but there was nearly no change following the removal of Part 3 (Figure 6.2.6). 


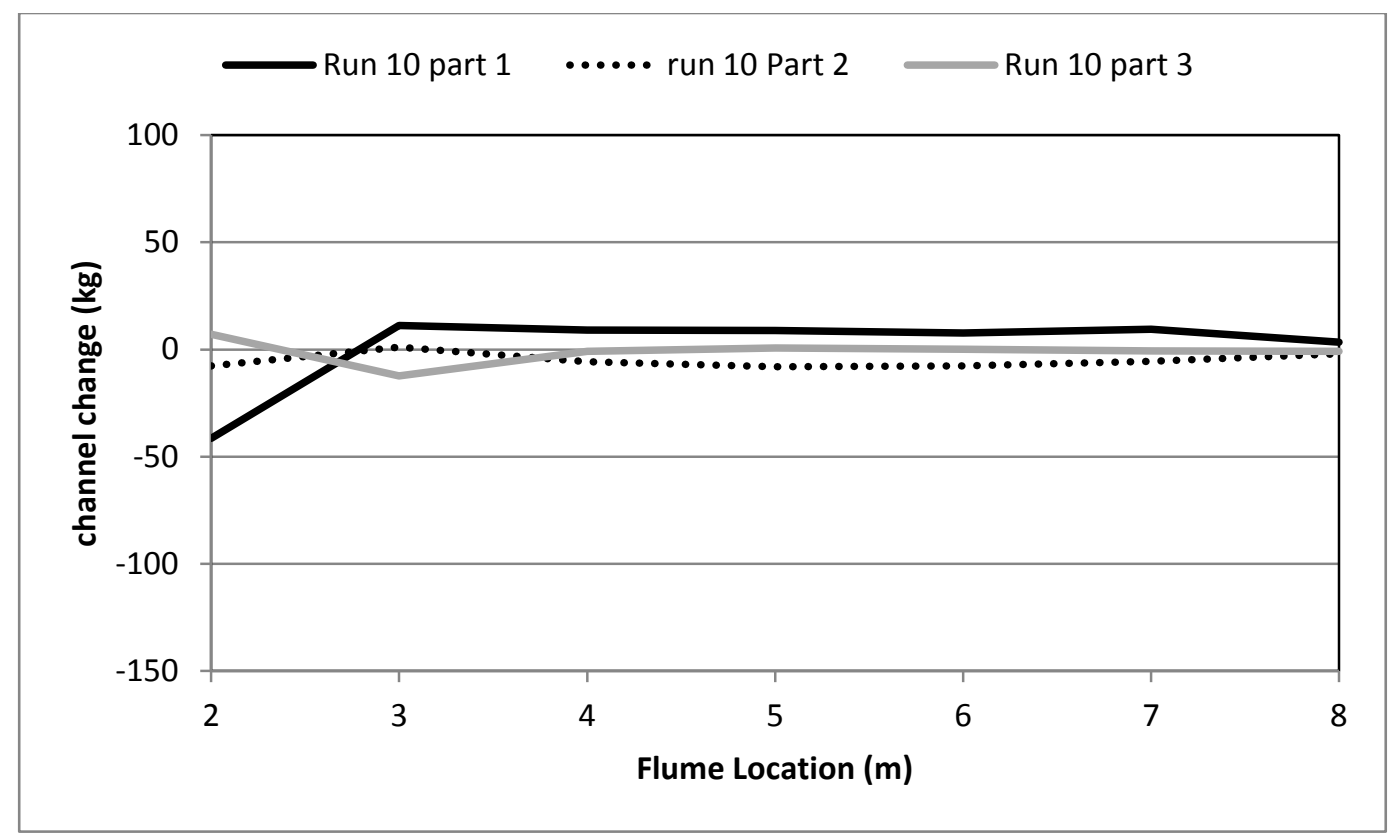

6.2.6: Longitudinal profiles of the sediment difference (y axis in $\mathrm{kg}$ ) following each part of the dam removal process for vertical removal from the center under low flows. Positive denotes aggradation and negative denotes erosion bewteen each removal stage.

\subsubsection{High Flow Removals}

Five deconstruction methods were tested with a high flow $(\mathrm{Q}=0.036 \mathrm{cms} ; \mathrm{Fr}=0.6)$ with the first sediment mixture in place. There was erosion of the bed immediately downstream of the dam site for each dam removal method tested. The amount of erosion and downstream sediment redistribution varied between the dam deconstruction methods and the individual stages within each method.

Erosion occurred during the horizontal dam deconstruction (Run 3). Erosion of the reservoir and the one meter segment below the removal location began following the removal of the first piece of the structure with the eroded sediment depositing over the following 3 meters of channel reach. The eroded area below the dam began to fill with sediment upon removal of the second dam piece, which also lowered the height of the remaining dam structure to below the reservoir sediment. The downstream reach that had experienced aggradation remained stable. 
Upon removal of the remainder of the dam pieces, the sediment continued to deposit in the previously eroded area immediately downstream of the dam while the downstream channel remained unchanged (Figure 6.2.7).

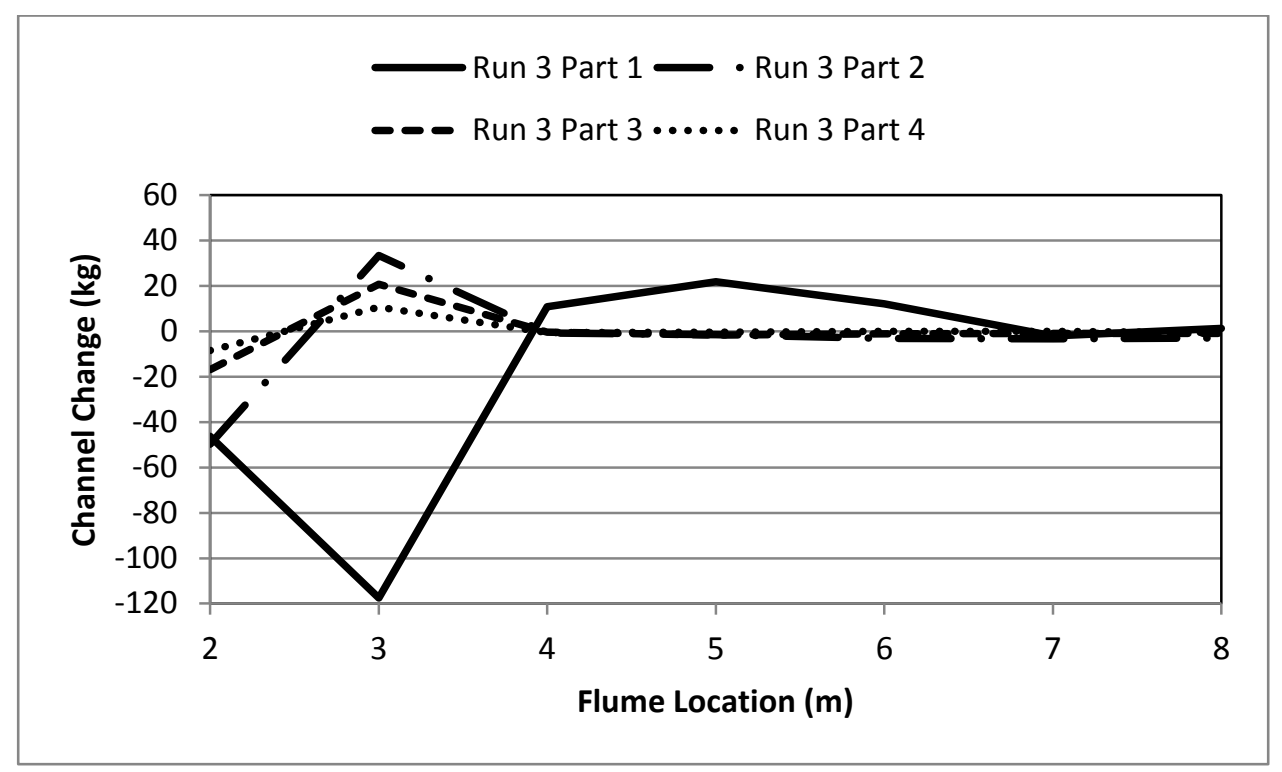

Figure 6.2.7: Longitudinal profiles of the sediment difference (y axis in $\mathrm{kg}$ ) following each part of the horizontal dam removal process from the center under high flows (Run 3). Positive denotes aggradation and negative denotes erosion bewteen each removal stage.

Channel erosion immediately downstream of the dam removed through the stepped removal method (Run 7) was primarily located along the center of the channel. Erosion began upon the removal of Part 1 and there was deposition throughout the remainder of the channel (Figure 6.2.8). Erosion of the area immediately downstream of the dam continued following the removal of Part 2 and sediment deposited from 4 to $8 \mathrm{~m}$. In contrast, the removal of Part 3 resulted in a deposition of sediment immediately below the dam and a large amount of erosion in the downstream channel. The final bed profile showed little change following removal of the Part 4 of the dam, and the bed profile remained similar to the profile following the removal of Part 3. 


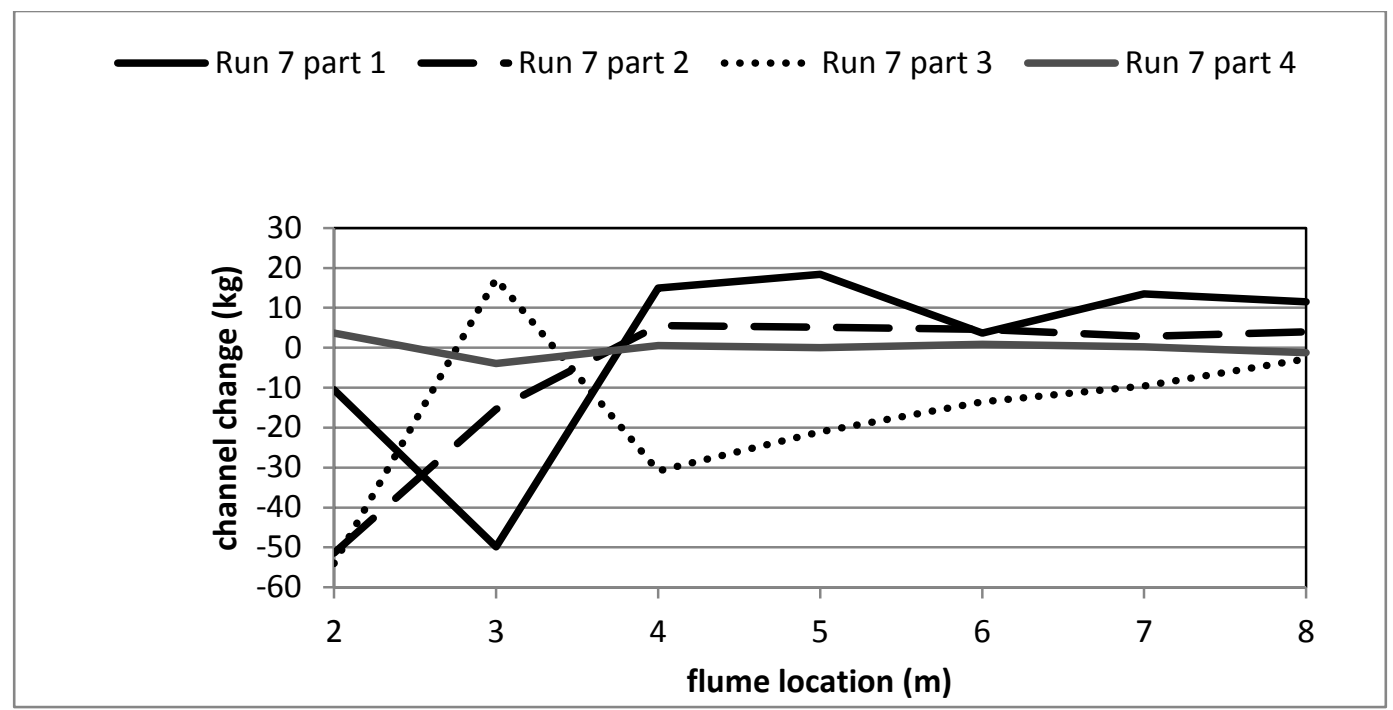

Figure 6.2.8: Longtitudinal profile of channel change (in $\mathrm{kg}$ ) following each part of the stepped removal under high flows. Positive denotes aggradation and negative denotes erosion.

Erosion was measured immediately downstream of the dam removal location following the first part of removal using the process of vertical dam removal beginning from the side (Run 9) with deposition in the remainder of the downstream channel. A majority of the observed channel change occurred with the removal of Part 1 and the bed experienced minimal deposition or erosion during the remainder of the dam removal (Figure 6.2.9).

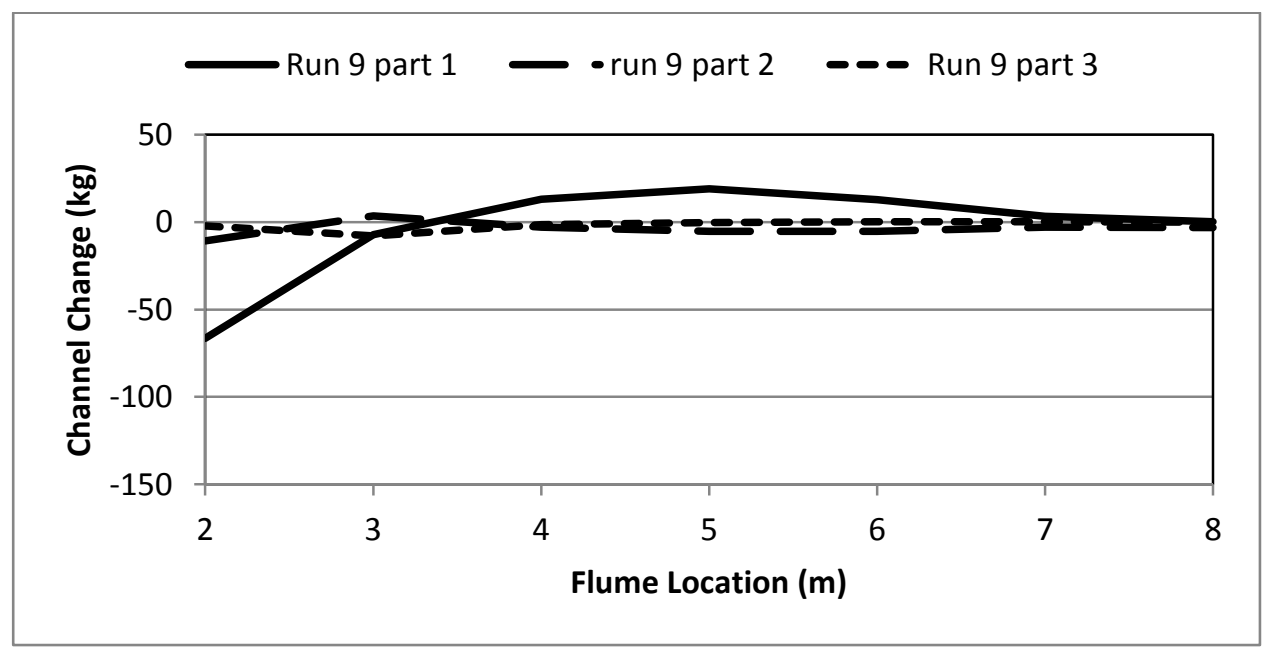

Figure 6.2.9: Longitudinal profiles of the sediment difference (y-axis in $\mathrm{kg}$ ) following each part of the dam removal process for vertical dam removal from the side under high flows for sediment type 1 (Run 9). Positive denotes aggradation and negative denotes erosion. 
Erosion was also immediate upon the first stage of the vertical dam removal when the piece was taken from the center (Run 11). The removal of the first portion of the dam resulted in erosion downstream of the remaining dam pieces, on the left hand side of the channel and throughout the downstream channel. Upon the removal of the second section of the dam the only change in the downstream bed was localized aggradation downstream of the only remaining dam piece. Minimal downstream channel change was measured following the removal of the third portion of the structure (Figure 6.2.10).



6.2.10: Longitudinal profiles of the sediment difference (y axis in $\mathrm{kg}$ ) following each part of the dam removal process for vertical removal from the center under high flows (Run 11). Positive denotes aggradation and negative denotes erosion bewteen each removal stage.

\subsection{Mid-Sediment, Mixture 2}

\subsubsection{Low Flow Removals}

The sediment wave generated during the Horizontal dam deconstruction method was the largest and most visible in the panoramic photos (Figure 6.3.1). The second sediment mix had a $\mathrm{D}_{50}$ of $0.61 \mathrm{~mm}$ and once the reservoir sediment height was above the dam, a large amount of sediment evacuated from the reservoir and deposited in the 3 meters below the dam. The recently deposited sediment was mobilized following the removal of the third piece and erosion 
continued throughout the downstream bed after the fourth piece was removed. The sediment slug migrated downstream as additional portions of the dam were removed.

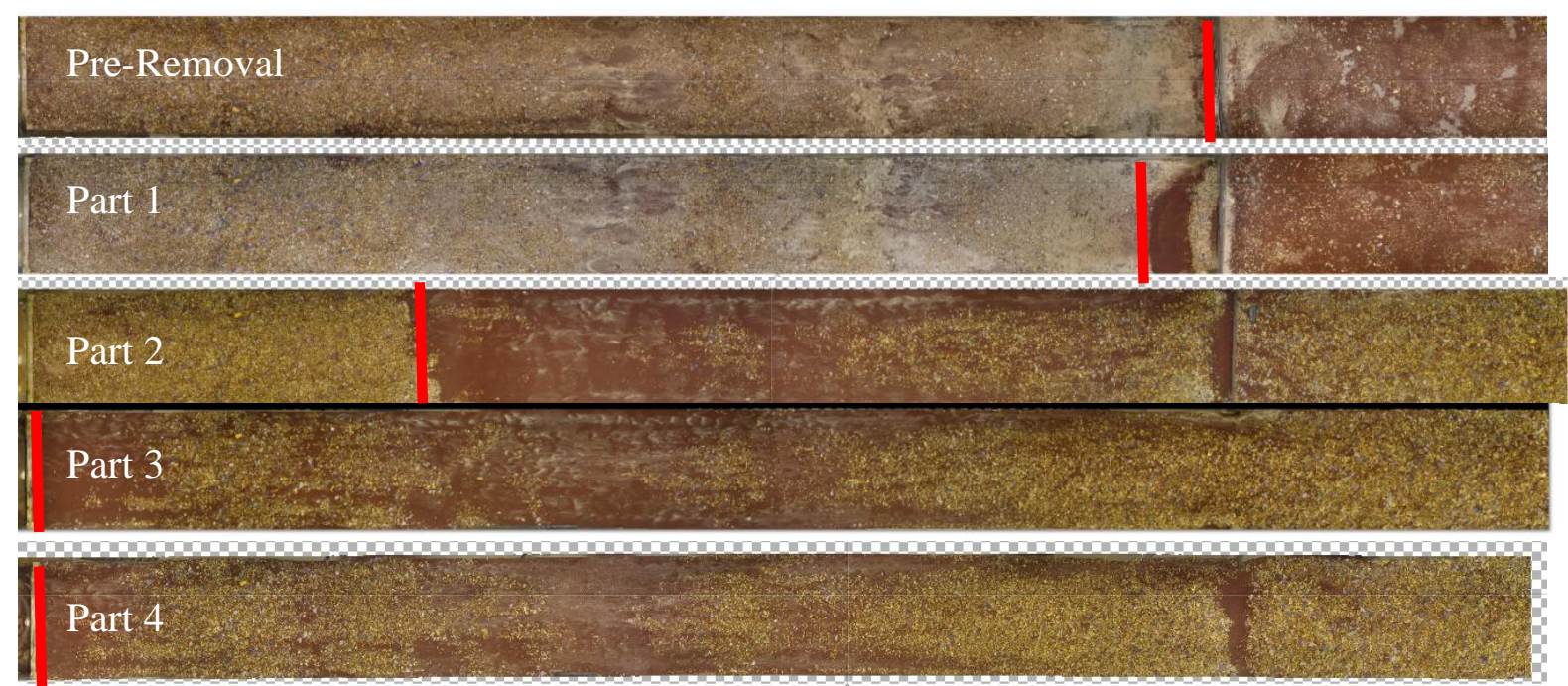

Figure 6.3.1: Panoramic photos of the channel bed following each part of the horizontal dam removal process for Run 12. The red line identifies the extent of the visible sediment slug. Flow was from right to left.

The sediment slug is also visible in the longitudinal profile of the change in the channel bed elevations in between each stage of dam removal that identify sediment deposition by meter for each portion of the Run (Figure 6.3.2). The downstream channel had the largest amount of sediment deposit following the removal of the second portion of the structure (Run 12 Part 2), with the majority of the sediment deposition occurring at $3 \mathrm{~m}$ and decreasing with distance downstream (Figure 6.3.2). The sediment slug migrated downstream of the active channel following the removal of Part 3 and was no longer noticeable following the removal of the fourth piece of the dam. 


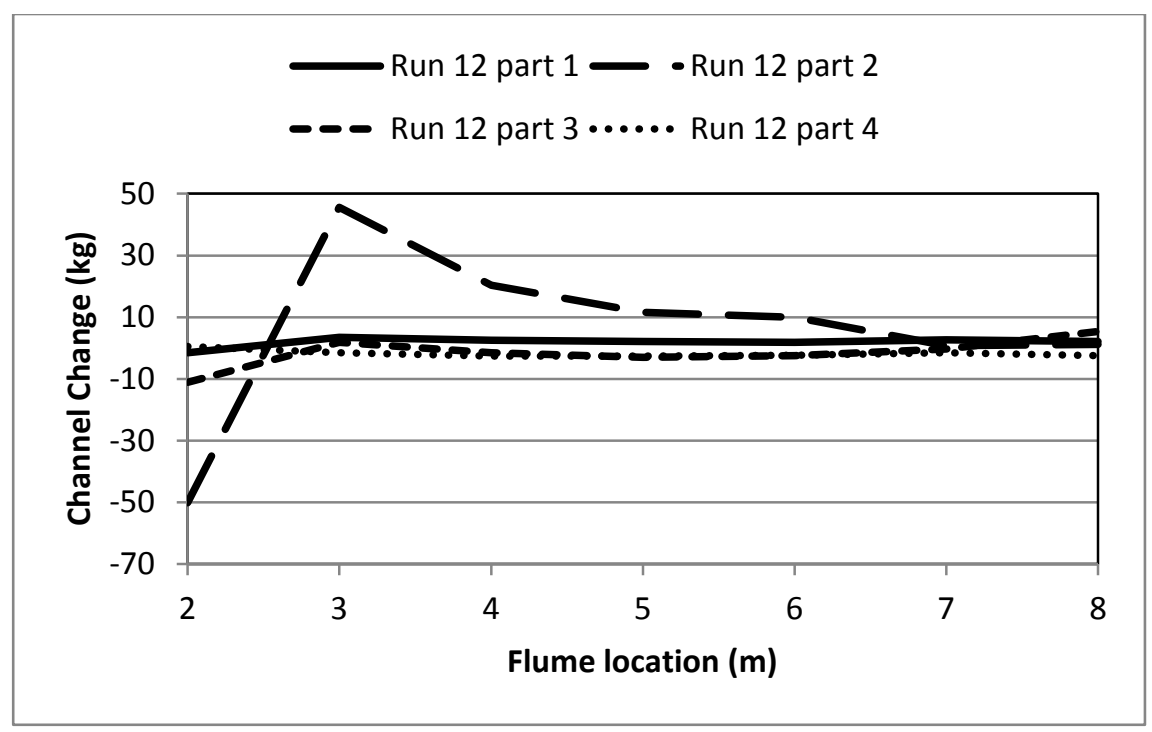

Figure 6.3.2: Longitudinal profiles of the change in sediment volume in the downstream channel (y-axis in $\mathrm{kg}$ ) following each part of the dam removal process for horizontal removal under low flows and sediment type 2 (Run 12). Positive denotes aggradation and negative denotes erosion bewteen each removal stage.

The downstream channel following complete removal under low flow conditions exhibited the sediment wave migrating downstream more slowly as the sediment mixture became finer. A majority of the sediment deposition was localized in the 2 meters below the dam structure (Run $14 ; 3$ and $4 \mathrm{~m}$ ). 


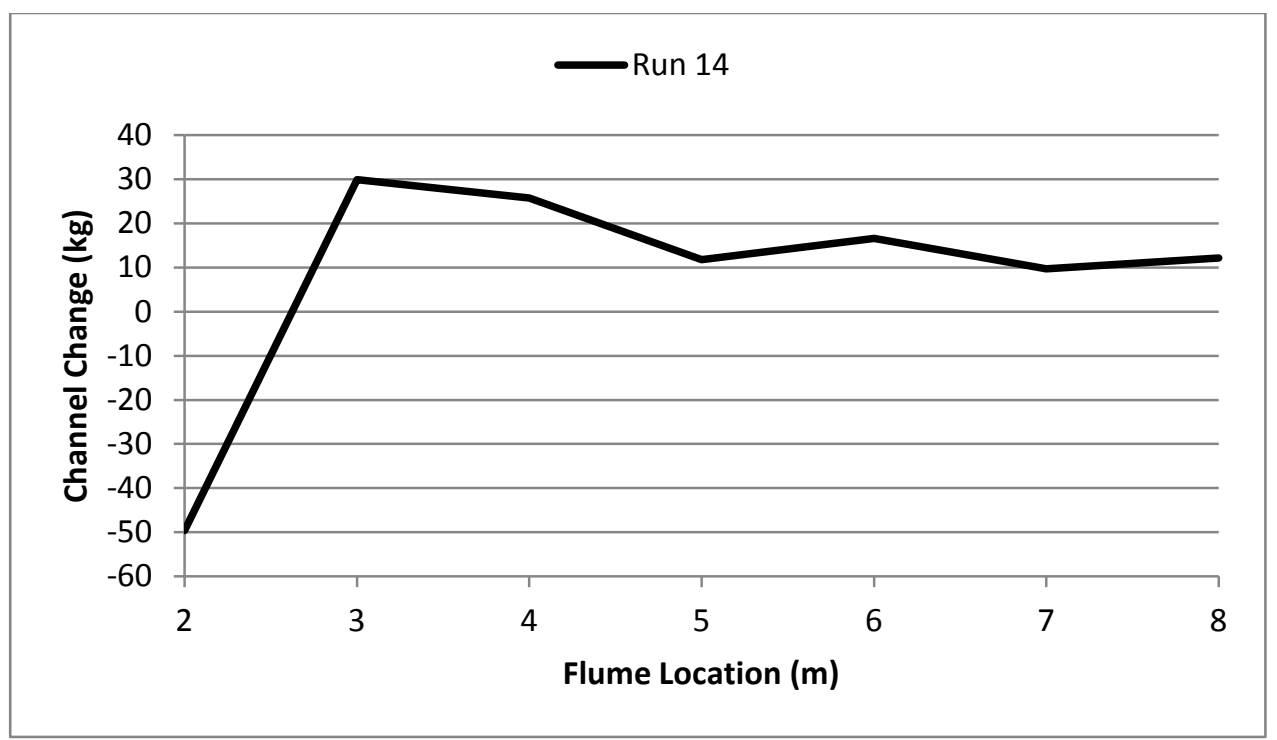

Figure 6.3.3: Longtitudinal profile of channel change (in $\mathrm{kg}$ ) following complete removal under low flows (Run 14) positive denotes aggradation and negative denotes erosion.

Following stepped removal, the channel had a noticeable sediment slug migrate downstream (Run 16). There was minimal deposition at $3 \mathrm{~m}$ following the removal of Part 1 and after Part 2 was removed deposition was observed throughout the downstream channel, decreasing with distance from the dam location (Figure 6.3.4). Following the removal of Part 3 and Part 4, there was minimal downstream deposition and no evidence of downstream sediment slug migration (Figure 6.3.4). The channel bed aggraded following the removal of Part 2 in both sediment mixtures, with more deposition observed in the finer sediment mixture (Run 16) than the coarser mixture (Run 6). 


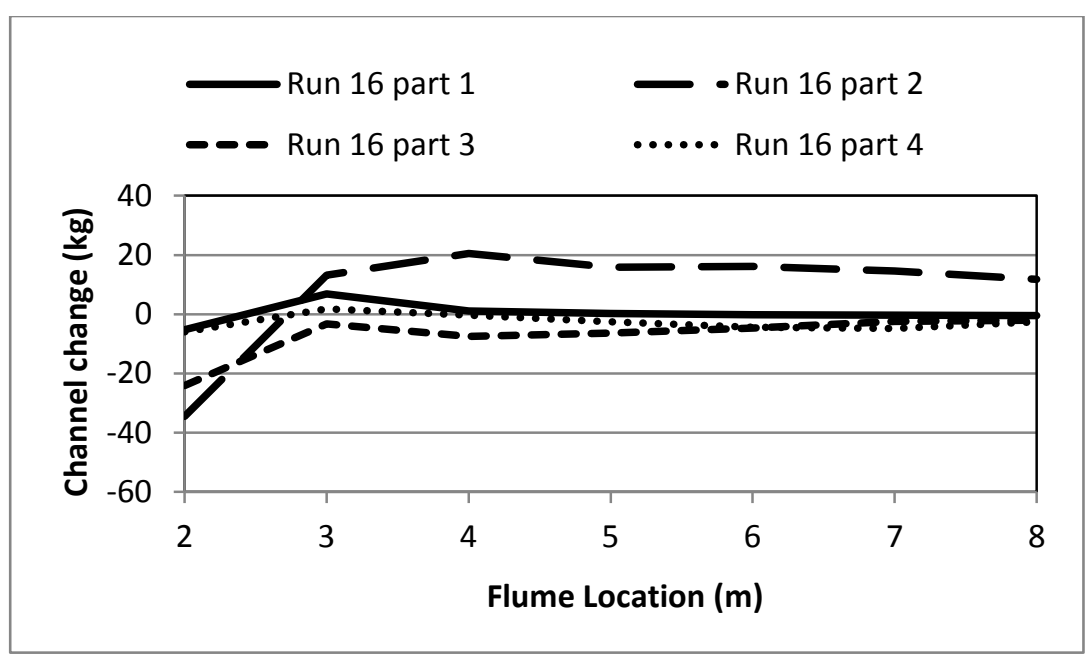

Figure 6.3.4: Longtitudinal profile of channel change (in $\mathrm{kg}$ ) following each part of the stepped removal under low flows positive denotes aggradation and negative denotes erosion.

The overall trend in the downstream channel following vertical dam removal from the side with the second sediment mixture (Run 18) was deposition throughout the channel from PreRemoval to Final bed. The downstream channel following this run (Run 18) behaved similarly to the first (Run 8) with deposition throughout a majority of the channel after the first piece was removed and minimal net change to the downstream channel after Part 2 and Part 3 (Figure 6.3.5).



Figure 6.3.5: Longitudinal profiles of the sediment difference (y-axis in $\mathrm{kg}$ ) following each part of the dam removal process for vertical dam removal from the side under low flows (Run 18). Positive denotes aggradation and negative denotes erosion. 
The downstream channel following vertical dam removal from the center (Run 20) exhibited deposition in the downstream channel following the removal of the first portion of the structure and erosion following the removal of the second piece, with minimal changes following the removal of the third piece (Figure 6.3.6).

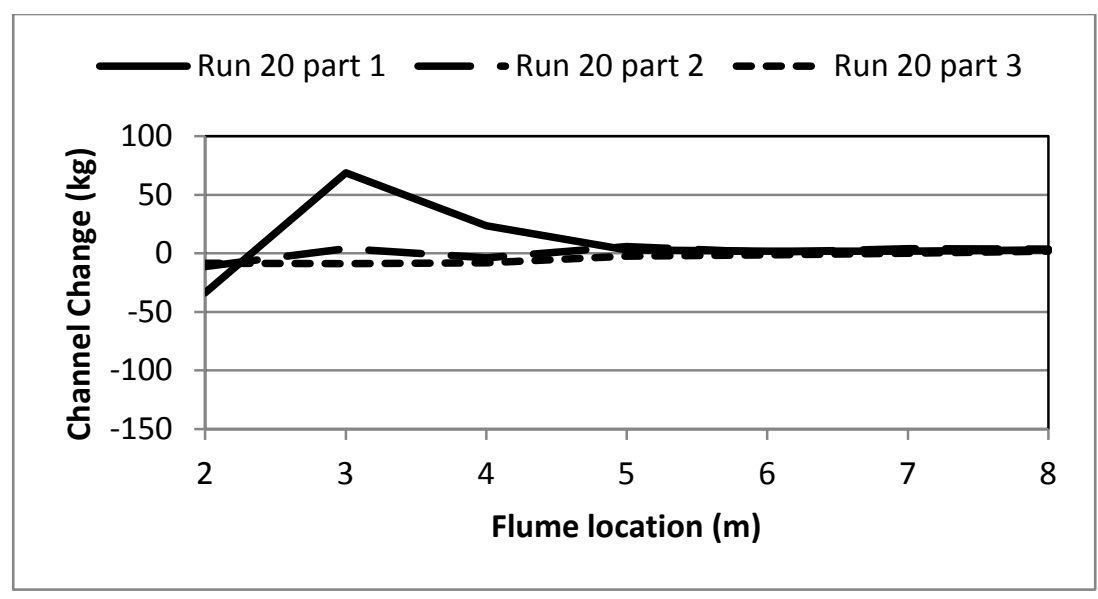

6.3.6: Longitudinal profiles of the sediment difference (y axis in $\mathrm{kg}$ ) following each part of the dam removal process for vertical dam removal from the center under low flows.

\subsubsection{High Flow Removals}

The removal of the first piece of the structure using a horizontal dam deconstruction method resulted in the downstream channel exhibiting erosion immediately below the dam piece with deposition further downstream (Run 13; Figure 6.3.7). The erosion at $3 \mathrm{~m}$ was so severe that the run was not completed. 


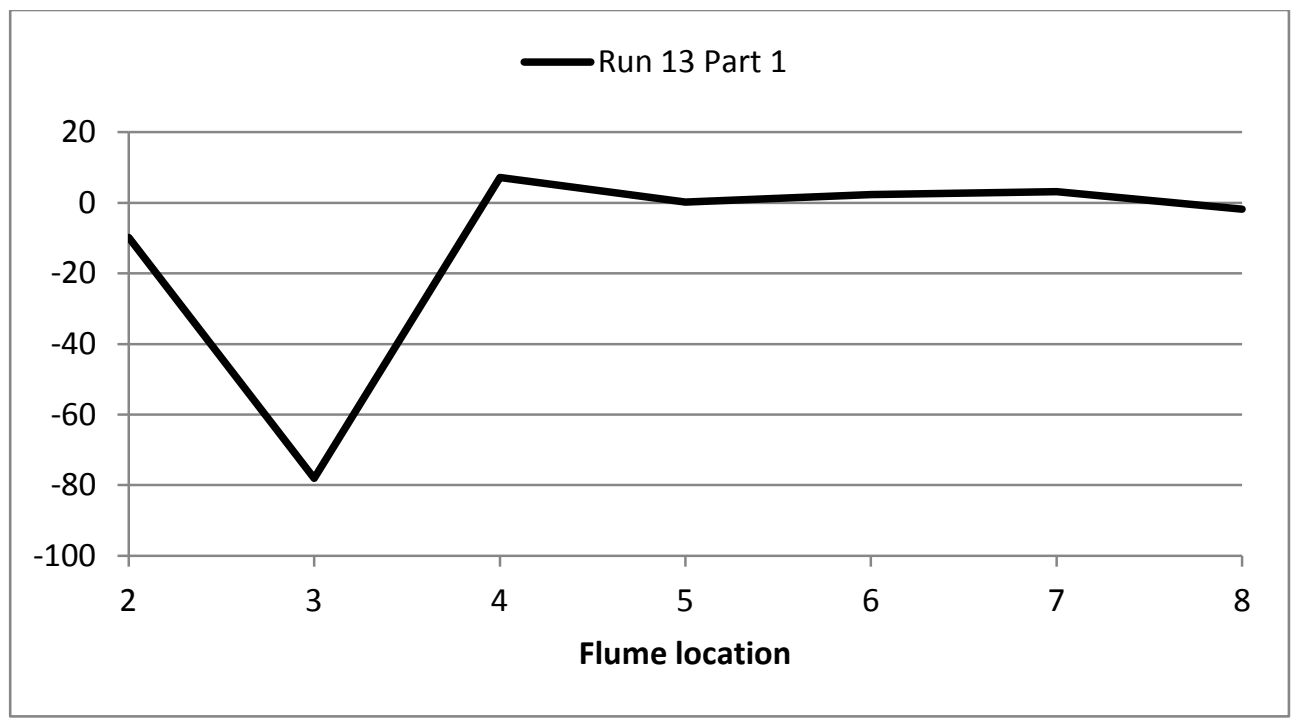

Figure 6.3.7: Longtitudinal profile of channel change (in $\mathrm{kg}$ ) following the removal of Part 1 during horizontal removal under high flows (Run 13) positive denotes aggradation and negative denotes erosion.

Following single stage dam removal (Run 15), sediment aggradation was localized to 3 and $4 \mathrm{~m}$ with erosion throughout the remainder of the channel (Figure 6.3.8).

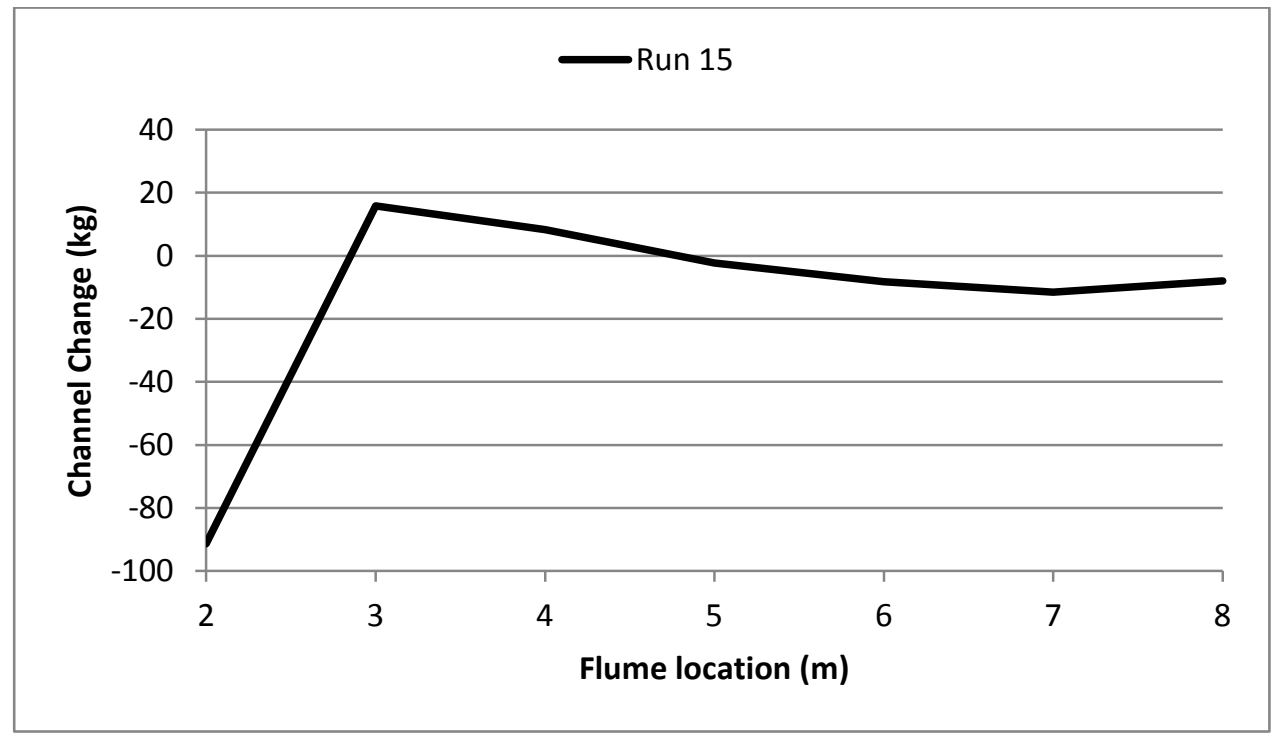

Figure 6.3.8: Longtitudinal profile of channel change (in $\mathrm{kg}$ ) following single stage dam removal (Run 15) positive denotes aggradation and negative denotes erosion.

Stepped dam removal (Run 17) was not run to completion due to excessive erosion at 3m following the removal of Part 1 (Figure 6.3.9). 


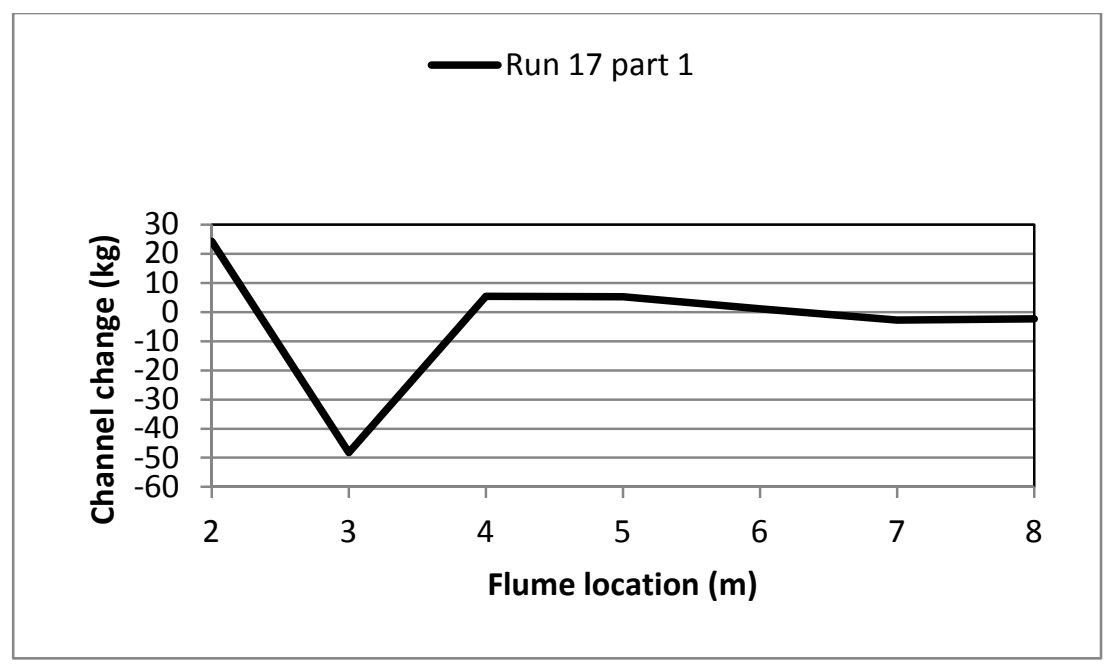

Figure 6.3.9: Longtitudinal profile of channel change (in $\mathrm{kg}$ ) following the removal of Part 1 during stepped dam removal (Run 17) positive denotes aggradation and negative denotes erosion.

The downstream channel after vertical dam removal from the side (Run 19) exhibited an overall trend of erosion immediately downstream of the dam removal location with deposition in the remainder of the downstream channel after Part 1 was removed (Figure 6.3.10). Minimal deposition or erosion occurred in the downstream channel following the removal of Part 2 and 3 (Figure 6.3.10).

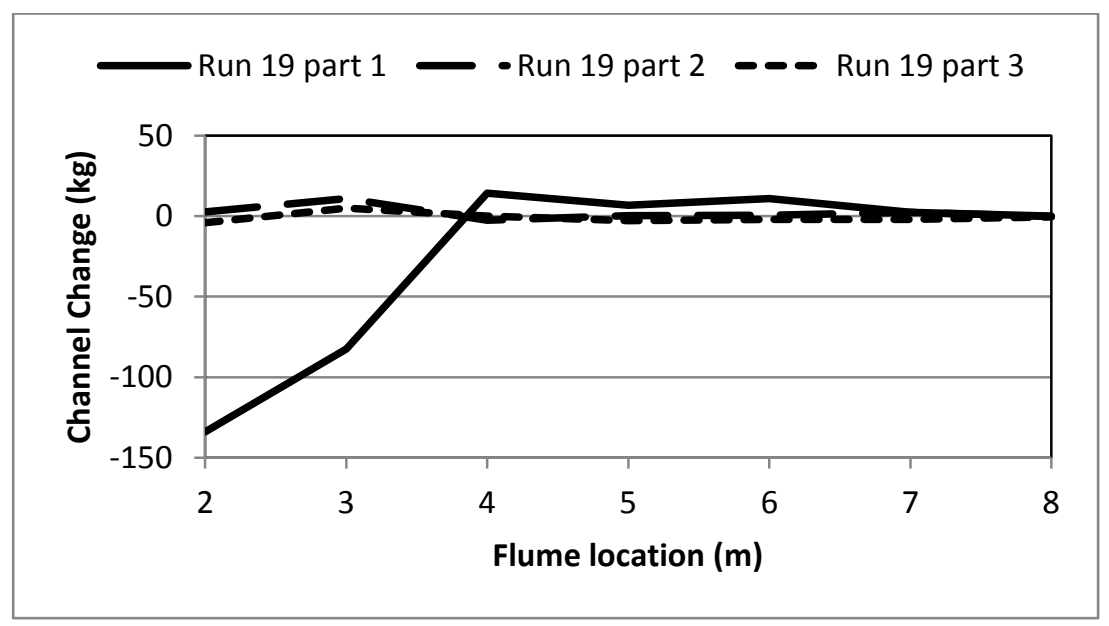

Figure 6.3.10: Longitudinal profiles of the sediment difference ( $\mathrm{y}$-axis in $\mathrm{kg}$ ) following each part of the dam removal process for vertical dam removal from the side under high flows (Run 19). Positive denotes aggradation and negative denotes erosion. 
Following vertical dam removal from the center of the channel, the downstream channel experienced a large amount of erosion in the channel immediately downstream of the location where the first dam piece was removed, with aggradation from 4 to $6 \mathrm{~m}$ (Run 21; Figure 6.3.11). Following the removal of the second piece of the structure, downstream erosion continued at $3 \mathrm{~m}$ while aggradation continued over 4-6 $\mathrm{m}$ in the downstream channel (Run 21; Figure 6.3.11). The removal of the third piece resulted in deposition at $3 \mathrm{~m}$ and erosion of the channel bed from 4 to 6m (Figure 6.3.11).

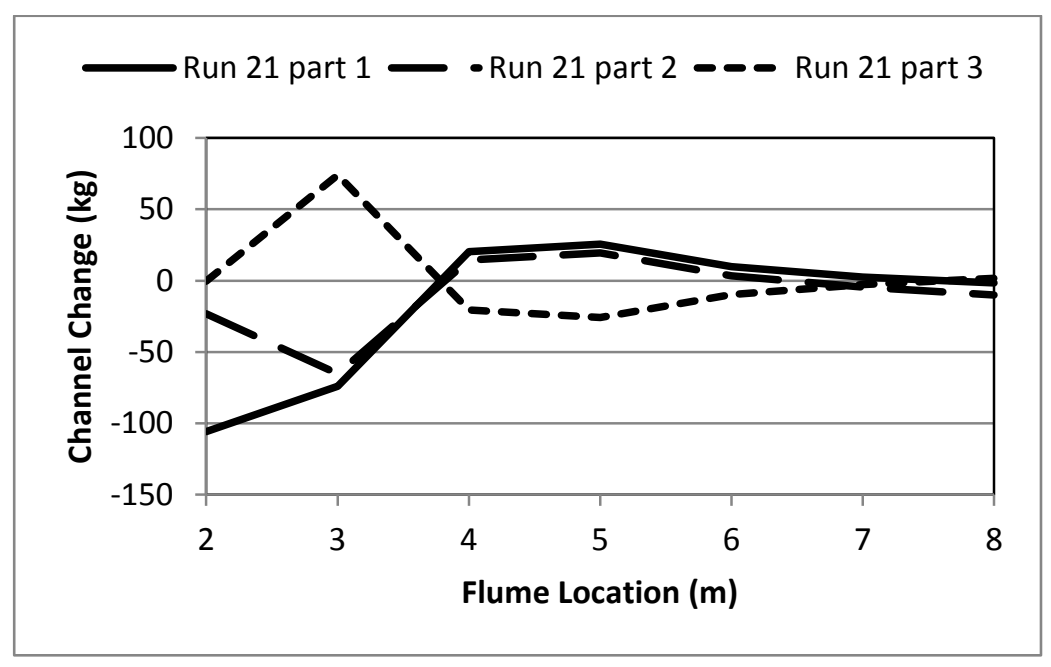

6.3.11: Longitudinal profiles of the sediment difference ( $\mathrm{y}$ axis in $\mathrm{kg}$ ) following each part of the dam removal process for vertical dam removal from the center under high flows (Run 21).

\subsection{Fine Sediment, Mixture 3}

\subsubsection{Low Flow Removals}

The sediment slug migrated downstream at a much slower rate under the third sediment mixture following horizontal dam removal (Run 22; Figure 6.4.1). There was minimal sediment transport following the removal of the first portion of the structure. The reservoir sediment deposited in the channel directly downstream of the dam location after the second piece was removed and migrated to the middle of the active downstream channel following the removal of the third piece. The sediment slug continued to migrate downstream following the removal of the 
fourth piece, but remained within the 10 active channel widths downstream of the structure (Figure 6.4.1).

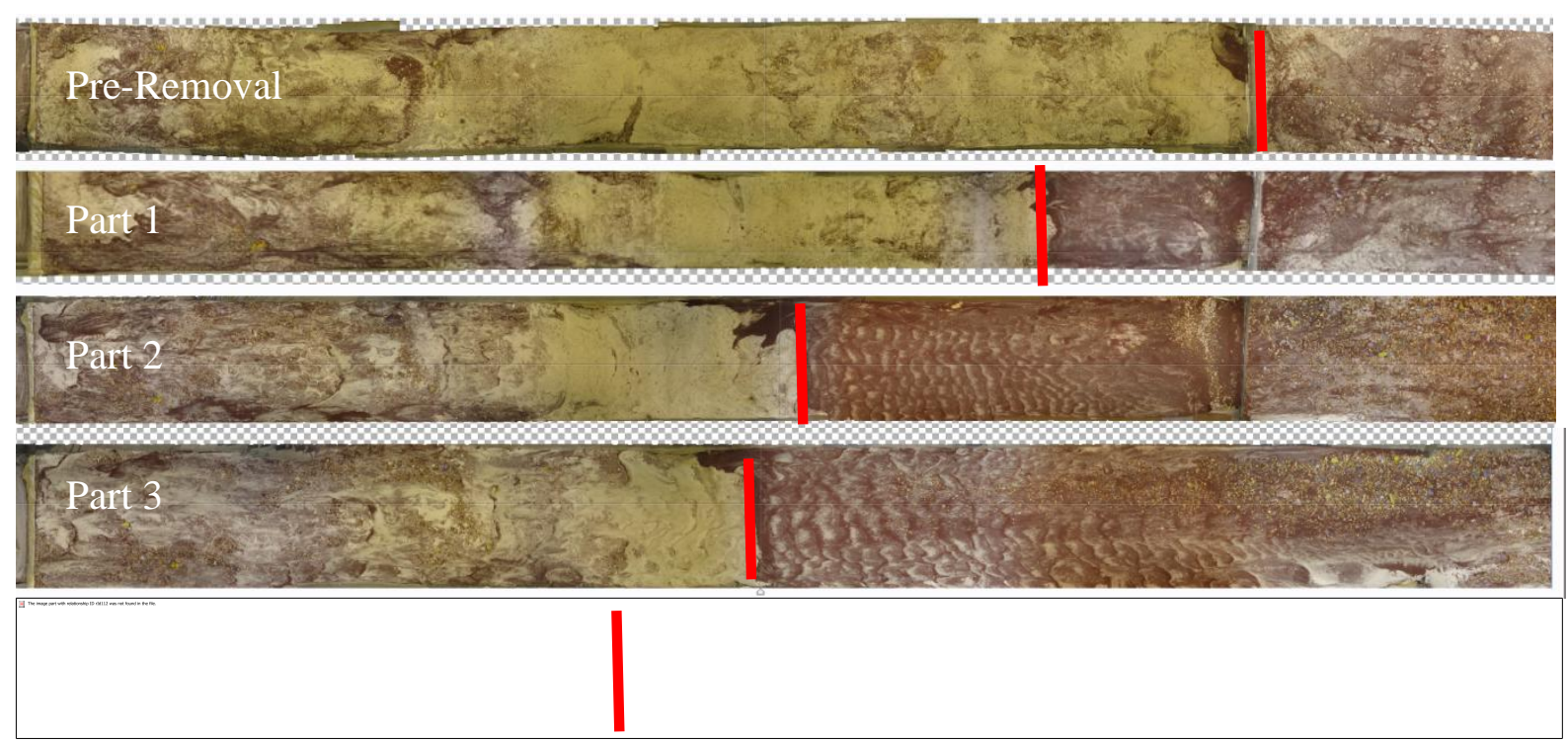

Figure 6.4.1: The panoramic photos of the channel bed following each part of the dam removal process following horizontal dam removal (Run 22). The red line identifies the extent of the visible sediment slug. Flow was from right to left

The sediment slug is also visible in the longitudinal profile of the change in the channel bed elevations in between each stage of dam removal that identify sediment deposition by meter for each portion of the Run (Figure 6.4.2). There was minimal bed elevation change following the removal of Part 1. Following the removal of the second piece of the dam, the sediment from the reservoir was primarily deposited at $4 \mathrm{~m}$, and migrated to $5 \mathrm{~m}$ following the removal of Part 3 . The removal of the fourth portion of the structure resulted in sediment deposition in the channel from 5 to $8 \mathrm{~m}$ (Figure 6.4.2). 


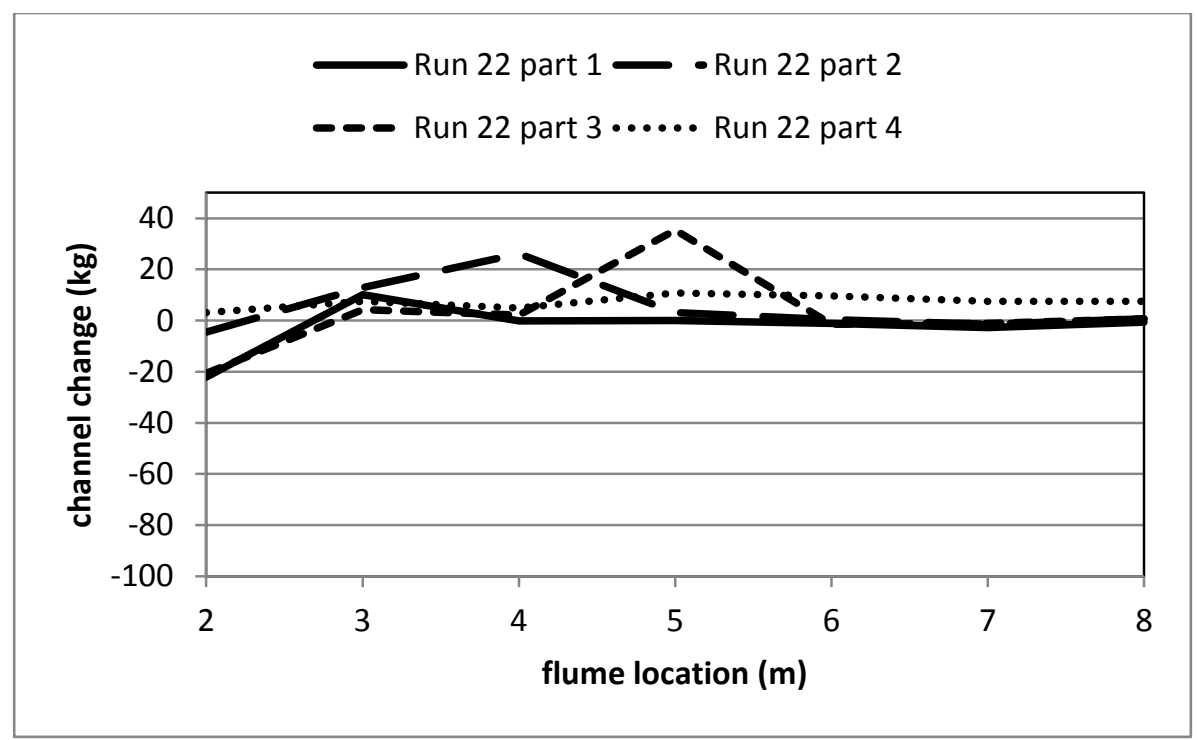

Figure 6.4.2: Longitudinal profiles of the sediment difference in the downstream channel (y-axis in $\mathrm{kg}$ ) following each part of the dam removal process for horizontal dam removal (Run 22).

The downstream channel following complete dam removal under low flow conditions also exhibited the sediment wave migrating downstream more slowly as the sediment mixture became finer. A majority of the deposition in the third sediment type (Run 24) was located from 4 to $6 \mathrm{~m}$ (Figure 6.4.3).

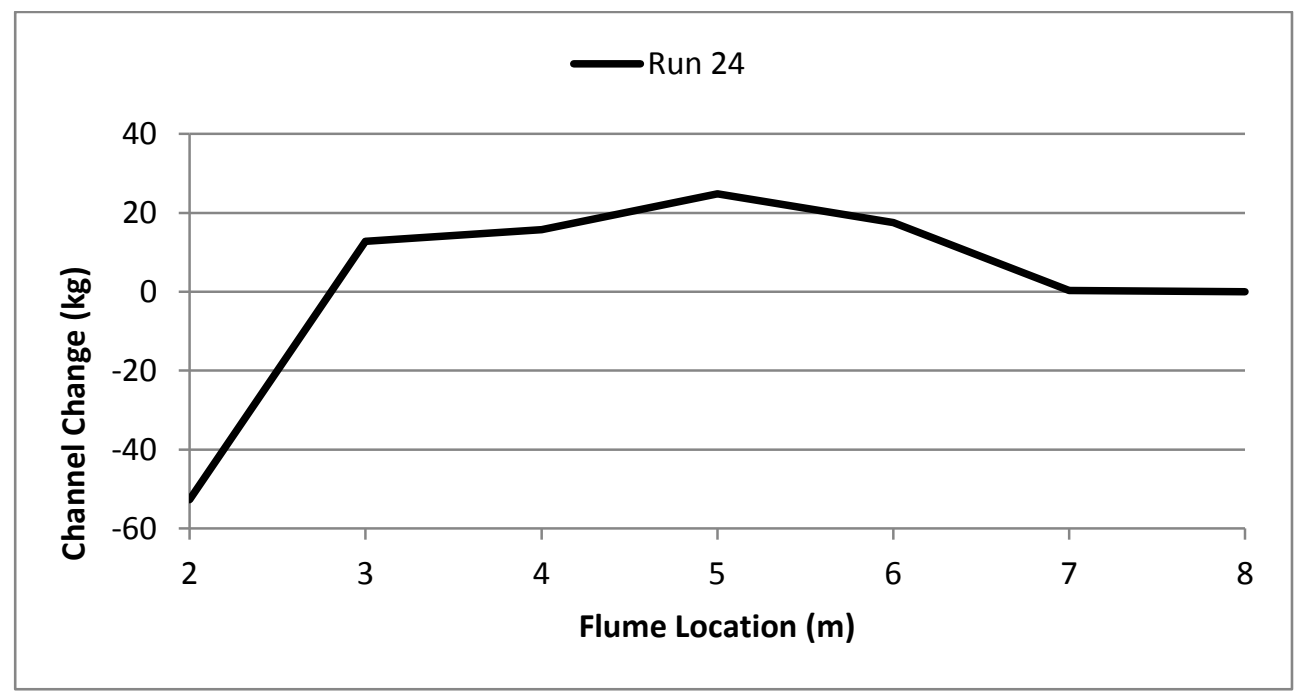

6.4.3: Longitudinal profiles of the sediment difference (y axis in $\mathrm{kg}$ ) following the single stage dam removal under low flows (Run 24). 
Following vertical dam removal from the center (Run 30) the downstream channel bed had deposition from 3 to $5 \mathrm{~m}$ with little change following the removal of Part 2 and Part 3 (Figure 6.4.4).

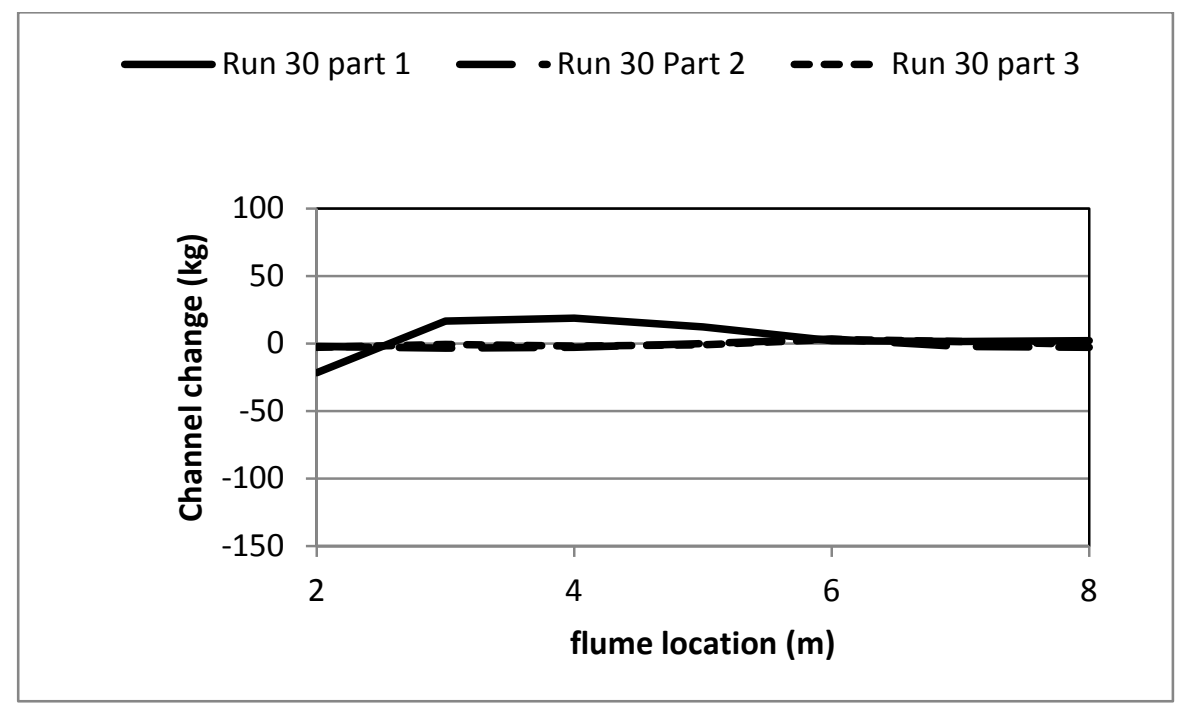

6.4.4: Longitudinal profiles of the sediment difference ( $\mathrm{y}$ axis in $\mathrm{kg}$ ) following each part of the dam removal process for vertical dam removal from the center under low flows (Run 30).

\subsubsection{High Flow Removals}

Erosion throughout the downstream channel occurred following the single stage dam removal under high flows. The largest amount of erosion in the downstream channel occurred at 4 and $5 \mathrm{~m}$ (Figure 6.4.5). 




Figure 6.4.5: Longitudinal profiles of the sediment difference (y axis in $\mathrm{kg}$ ) following single stage dam removal under high flows (Run 25).

Following vertical dam removal from the center of the channel (Run 31), the downstream channel had large quantities of downstream erosion immediately below the dam piece at $3 \mathrm{~m}$ ($95.35 \mathrm{~kg})$, for a net trend of erosion of the downstream channel $(-113.81 \mathrm{~kg})$. Following the removal of the second piece, there was sediment aggradation at $3 \mathrm{~m}$ with erosion throughout the remainder of the channel (Figure 6.4.6). Following the removal of Part 3 there was mild erosion at $3 \mathrm{~m}(-10.98 \mathrm{~kg})$ and net erosion over the entire channel $(-30.1 \mathrm{~kg}$; Table 4.2.2). Overall, following vertical dam removal from the center, the downstream channel experienced the majority of the erosion after the removal of the first dam piece, regardless of the sediment type, with minimal channel change following the removal of the third piece. 




6.4.6: Longitudinal profiles of the sediment difference (y axis in $\mathrm{kg}$ ) following each part of the dam removal process for vertical dam removal from the center under high flows (Run 31).

\subsection{Combined Influence of Sediment Mixture and Dam Removal Method}

While the sediment type present in the channel of a potential dam removal location cannot be changed, it is useful to quantify the downstream channel behavior under various flow rates and deconstruction methods with different grain size distributions present to determine the relation between the three parameters. Channel and reservoir sediment size mixture influences the downstream sediment deposition and erosion patterns, as well as the amount of sediment traveling downstream out of the channel reach, during the different methods of dam deconstruction. Understanding how mixtures of different fines and silt contents affect the downstream channel is useful in predicting the impact to downstream habitats and geomorphic variability that may occur under different dam deconstruction sequences.

\subsubsection{Horizontal Removal Methods}

During horizontal and stepped dam removals, the largest impact of the addition of silt to the sediment mixture was a significant increase in deposition volume following the removal of the dam segments (Runs 2 and 6; Figure 6.5.1). Following the removal of Part 1 in the horizontal 
dam removal process, there was more downstream deposition of reservoir sediments containing silt (14.8 kg; Run 12) than without silt present (8.38 kg; Run 2). Conversely, there was less downstream deposition following the removal of Parts $3(0.07 \mathrm{~kg}$ vs. $0.52 \mathrm{~kg})$ and $4(-13.11 \mathrm{~kg}$ vs. -19.11kg; Table 4.2.2) when there was silt in the reservoir and channel sediments. Bulk sediment silt content exhibited an analogous influence over deposition patterns during the stepped removal deconstruction sequence. After the removal of Parts 1 and 3, there was deposition in the downstream reach for those experiments using sediment mixtures containing silt (7.28 kg; Run 16) but downstream erosion when there was no silt in the sediment mixture (29.17kg; Run 6). For example, the sediment mixtures in Run 16 contained $0.6 \%$ silt and resulted in erosion following the removal of Part $3(-26.22 \mathrm{~kg})$ while Run 6 , which had no silt in the sediment mixture, resulted in deposition $(39.58 \mathrm{~kg})$. For both horizontal and stepped dam removal methods there was erosion in the downstream channel following removal of the final dam piece regardless of sediment mixture. However, there was almost 4 times as much erosion when there was no silt in the channel sediments (-12.72 kg compared to $-40.19 \mathrm{~kg}$; Figure 6.2.7) The largest amount of sediment was deposited and retained on the downstream channel when dams were deconstructed through either the horizontal or stepped dam removal method and the second sediment mixture was used which had 65\% sand and silt (Runs 12 and 16; Figure 6.5.1).

The third sediment mixture, with $87 \%$ sand and silt, was tested only with the horizontal dam removal method. The additional decrease in the $\mathrm{D}_{50}$ of the sediment from Run $12\left(\mathrm{D}_{50}\right.$ : $0.61 \mathrm{~mm})$ to Run $22\left(\mathrm{D}_{50}: 0.38 \mathrm{~mm}\right)$ resulted in an overall pattern of deposition with each step in the dam removal. When compared to the results from the second sediment mixture, the additional fines contributed to a pattern of reduced deposition following the removal of Part 1 (5.43 kg vs. $14.8 \mathrm{~kg}$ ) and Part $2(41.87 \mathrm{~kg}$ vs. $89.33 \mathrm{~kg})$, but more deposition following the 
removal of Parts 3 (39.82kg vs. $0.07 \mathrm{~kg}$ ) and 4 ( $47.91 \mathrm{~kg}$ vs. $-13.11 \mathrm{~kg}$; Figure 6.5.1). The changes to the downstream channel were primarily localized from 3 to $4 \mathrm{~m}$ following the removal of Part 1, from 3 to $5 \mathrm{~m}$ following the removal of Part 2, from 3 to $5 \mathrm{~m}$ following the removal of Part 3 and from 4 to $6 \mathrm{~m}$ following the removal of Part 4 (Figure 6.5.1), indicating the formation and migration of a sediment wave through the channel with the dam removal.

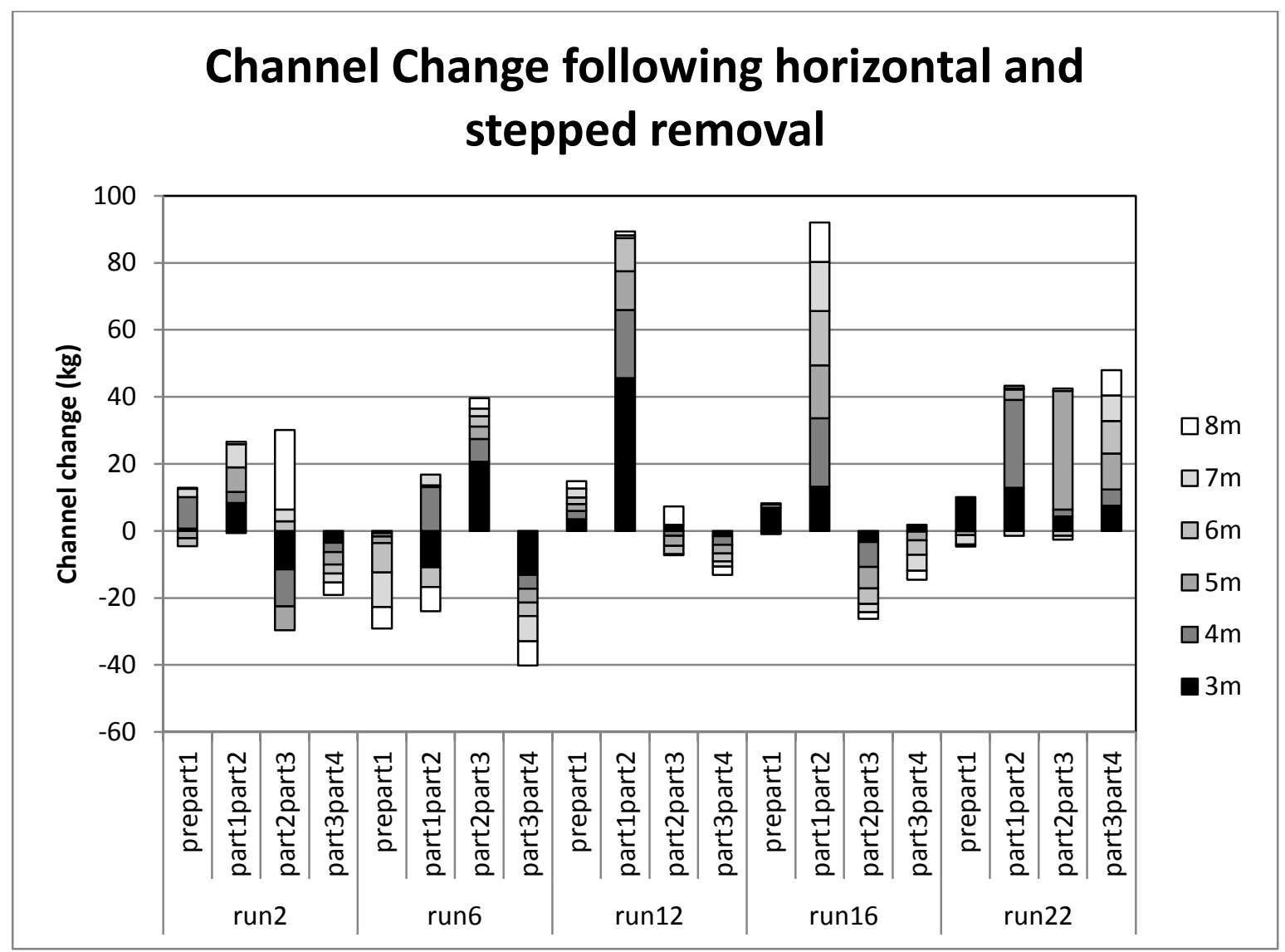

Figure 6.5.1: Summary of the change between each part of the removal process in total sediment (in $\mathrm{kg}$ ) over the downstream channel length from the dam expressed as the sediment weight. The amount of change was found by applying the raster differencing to the bed scans.

The deposition record from the trap at the downstream end of the flume reflected the quantity of sediment that would transport out of the channel reach (defined at 10 channel widths) during each step of the dam removal. The impact of silt content and overall sediment mixture 
fining was to reduce the amount of sediment accumulation in the trap during dam removal under low flow conditions and using a horizontal removal method. The largest quantity of sediment, $74.62 \mathrm{~kg}$, traveled to the trap under the coarse first sediment mixture (Run 2); there was $17.49 \mathrm{~kg}$ of sediment accumulation under the second sediment mixture (Run12); and only $3.78 \mathrm{~kg}$ under the third and finest sediment mixture (Run 22; Figure 6.5.2). Less than $1 \mathrm{~kg}$ of sediment deposited in the trap following the removal of the upper half of the dam structure for the three sediment mixtures (Figure 6.5.2). Transport rates out of the channel reach increased when the third section of the dam was removed: there was $51.9 \mathrm{~kg}$ of deposition under sediment type 1 ; $6.1 \mathrm{~kg}$ under sediment type 2 ; and $0.8 \mathrm{~kg}$ under sediment type 3 (Figure 6.5.2). The removal of the fourth piece resulted in $22.1 \mathrm{~kg}$ of sediment accumulation in the trap under sediment type 1, $10.9 \mathrm{~kg}$ under sediment type 2 , and $0.3 \mathrm{~kg}$ under sediment type 3 (Figure 6.5.2). These results show a positive correlation between sediment transport out of the channel reach and the grain size of the sediment mixture: the finer the sediment mixture, the smaller the amount of sediment that is transported out of the reach when the dam removal occurred during a low flow condition. Because the high flow condition was tested over an entire horizontal dam removal only for the coarse sediment, a definitive trend on the impact of sediment type could not be concluded. 


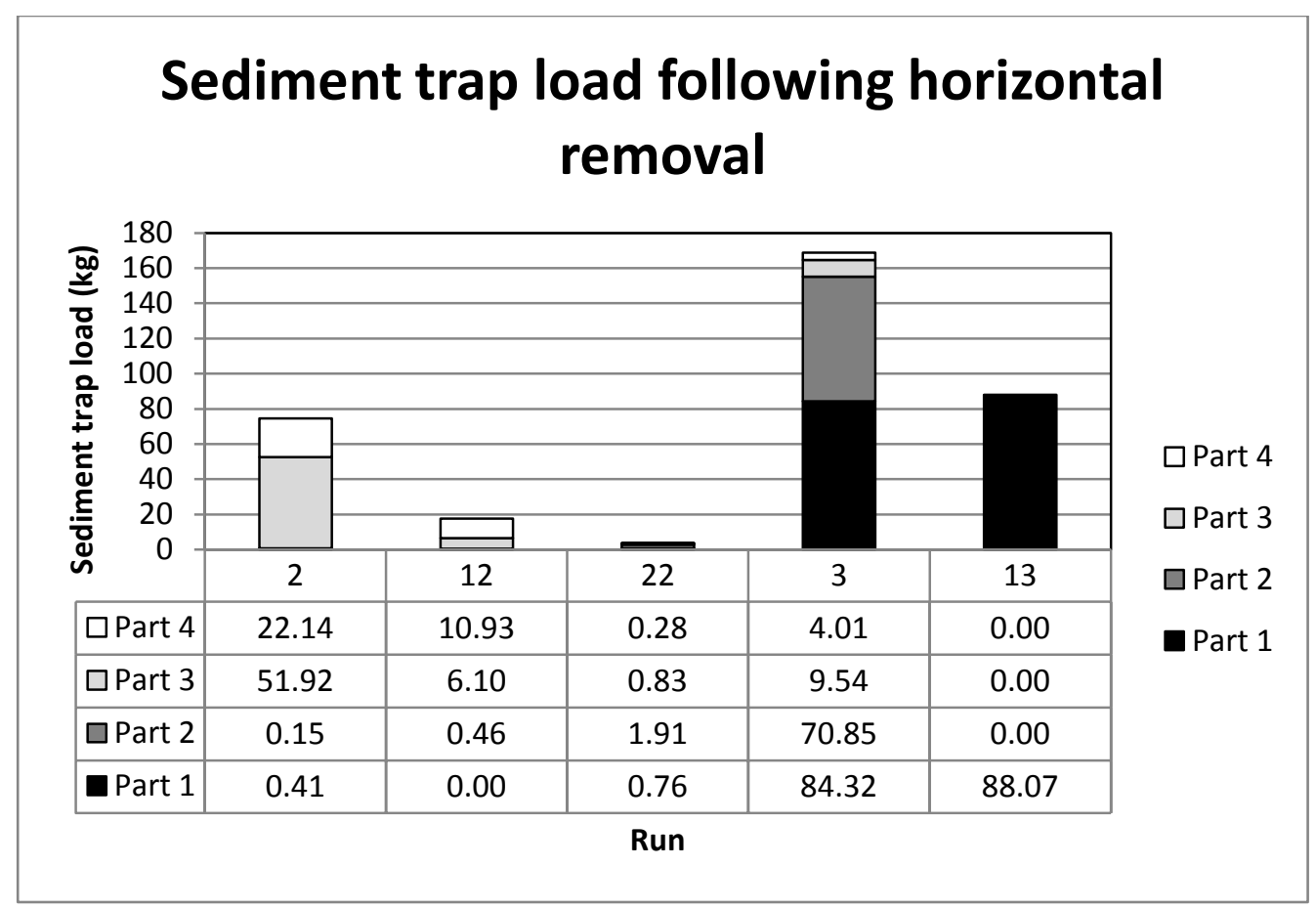

Figure 6.5.2: Sediment trap accumulation in $\mathrm{kg}$ following horizontal removal under low and high flows. Run 13 was stopped after the removal of Part 1 due to excessive erosion within the channel.

The presence of fines in the sediment mixture had less apparent influence over the transport of the sediment out of the reach when the dam was deconstructed using a stepped method. Sediment mixtures 1 and 2, with and without fines, were applied against stepped dam removals under both low and high flow conditions (Run 6, 16, 7 and 17; Figure 6.5.3). For example, when the low flow rate was applied there was a total of $42.0 \mathrm{~kg}$ of sediment deposited in the trap following Run 6 using the coarse sediment and $50.55 \mathrm{~kg}$ of sediment in the trap following Run 16 for which there were fines in the sediment. The sediment deposit was much larger during the first half of the dam removal for the coarse sediment mixture and larger in the second half of the removal for the sediment mixture containing fines (Figure 6.5.3). The same dam removal method was tested under a high flow rate. However, those experiments were not run to completion (Figure 6.5.3). 


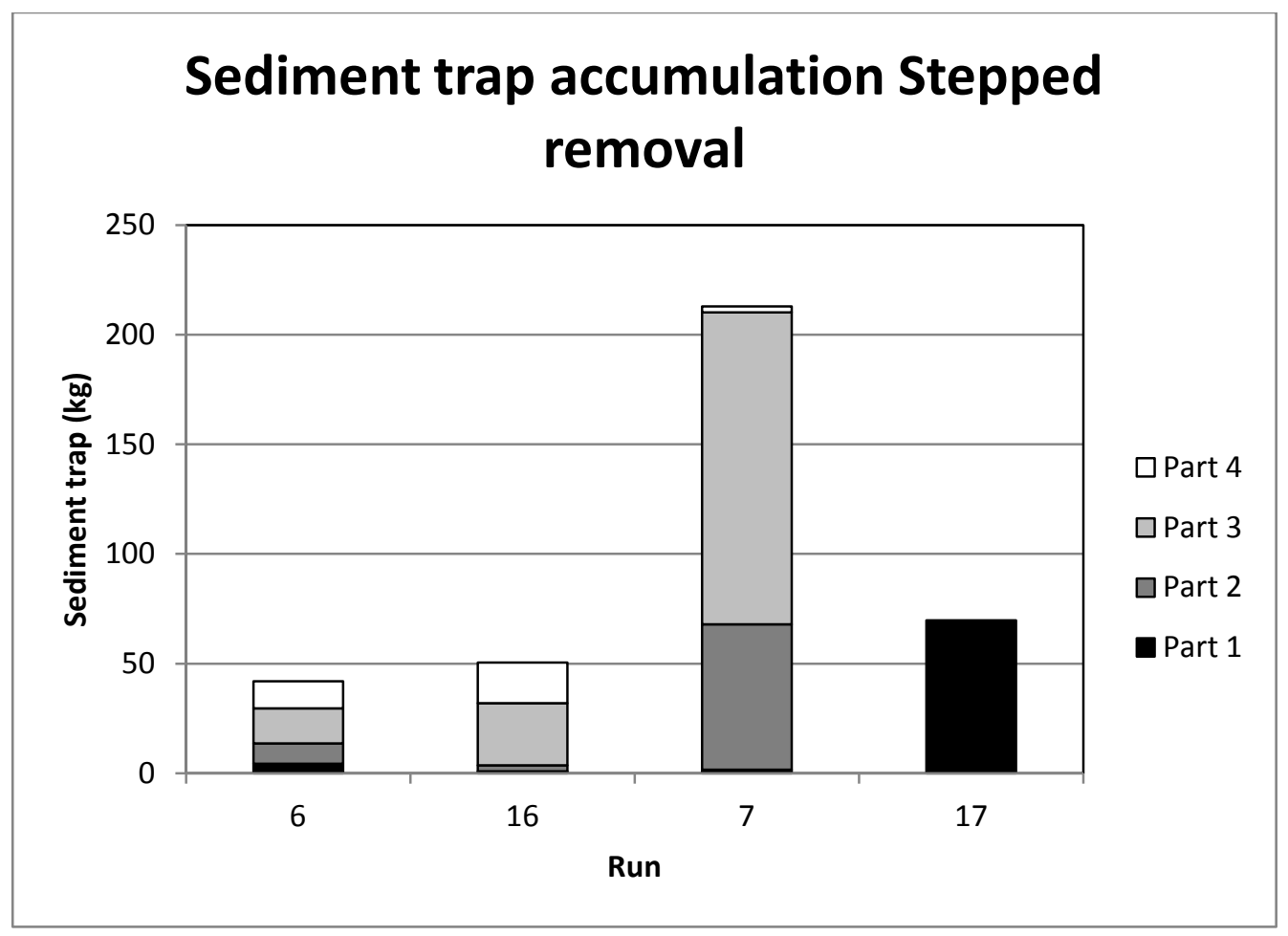

Figure 6.5.3: Sediment trap accumulation (in $\mathrm{kg}$ ) following stepped removal under high and low flow scenarios

\subsubsection{One Step Removal Method}

All three sediment mixtures and both the high and low flow rates were tested for the relative impacts on sediment deposition and erosion when the dam was removed in a single step, also called a complete removal (Run 4, 5, 14, 15, 24 and 25).

Downstream deposition characterized the impact of a complete dam removal during a low flow condition, regardless of the sediment mixture. Dam removal using the sediment mixture with $0.6 \%$ fines content (sediment type 2 ) resulted in the largest amount of downstream aggradation, depositing $105.99 \mathrm{~kg}$ over the downstream reach (Run 14). The coarse sediment mixture, type 1 (Run 4), resulted in a net amount of sediment deposition to the downstream channel of $84.04 \mathrm{~kg}$, and $71.11 \mathrm{~kg}$ of sediment deposited under finest sediment mixture, type 3 (Run 24; Figure 6.5.4). 
The results of dam removal during a high flow rate were more variable. Downstream erosion occurred when the coarse sediment mixture was used for channel and reservoir sediments (-29.17 kg; Run 5). In contrast, the downstream channel reach in Run 15, which had a sediment mixture of $65.4 \%$ sand, experienced only $5.84 \mathrm{~kg}$ of erosion and the most deposition in the downstream channel. The largest amount of erosion corresponded to the finest grain size distribution tested (-71.59 kg; Run 25). The least total channel erosion occurred following the removal of Run 15 , largely a result of the deposition that occurred in the two meters below the dam removal location. 


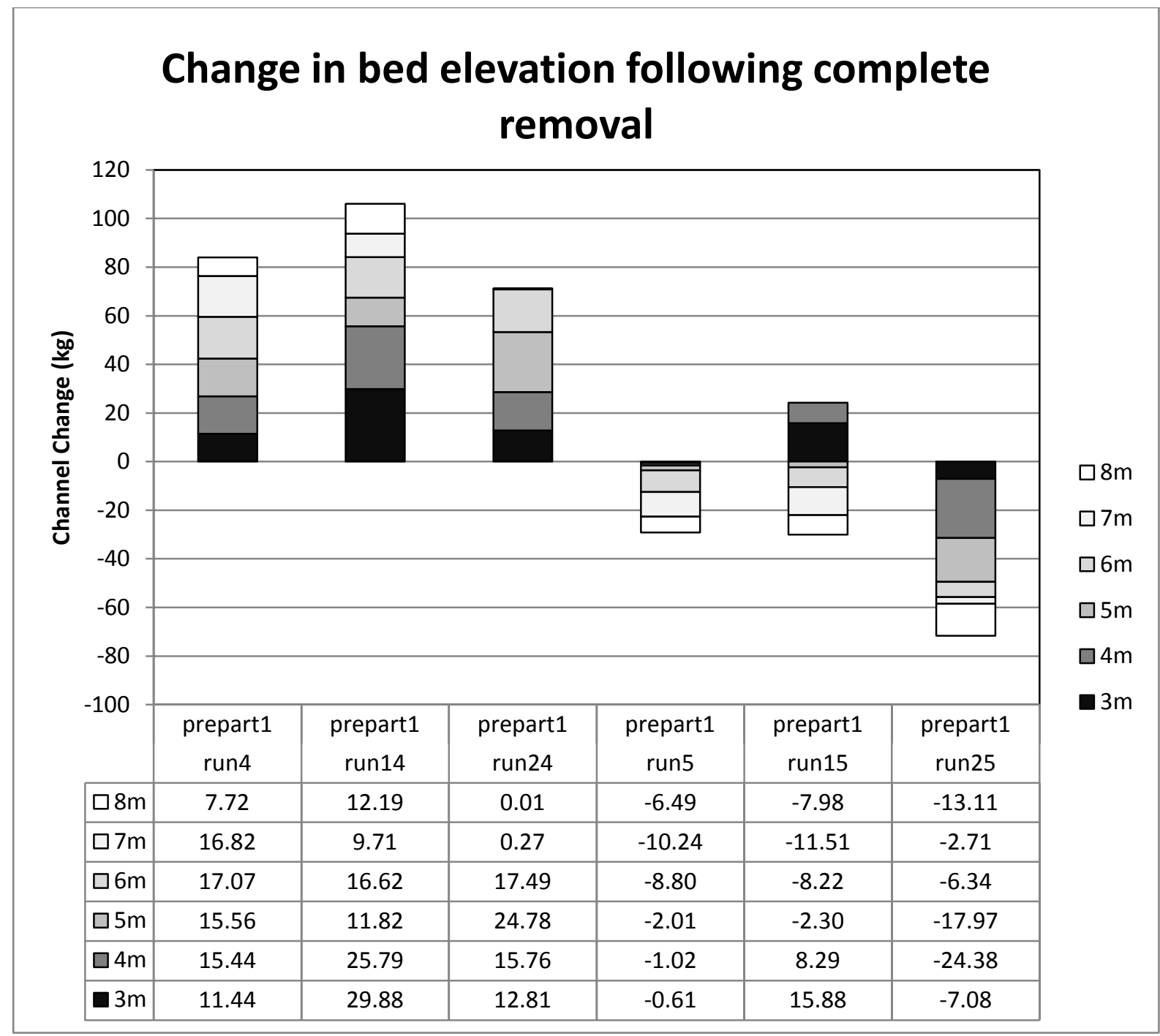

Figure 6.5.4: Summary of the change in total sediment (in $\mathrm{kg}$ ) over the downstream channel length from the dam expressed as the sediment weight found from the raster difference of the bed scans from Preremoval to Final bed following complete removal under all flow and sediment types.

The correlation between downstream channel erosion and sediment mixture was apparent in the sediment deposition in the downstream trap, for both the low and high flow single-stage dam removal condition. The largest amounts of sediment transported out of the reach and into the sediment trap was when the dam was removed using the coarse sediment mixture. Under a low flow condition this was $54.7 \mathrm{~kg}$ (Run 4), and for the high flow removal condition the accumulation was $143.8 \mathrm{~kg}$ (Run 5). In further agreement with the positive correlation, there 
was less than $1 \mathrm{~kg}$ of accumulation in the trap when there was silt in the sediment mixture and the removal flow rate was low, Runs 14 and 24 (Figure 6.5.5). This amount increased when the flow rate was high, to $129.1 \mathrm{~kg}$ and $101.27 \mathrm{~kg}$, but remained lower than that for the coarse sediment bed and reservoir material. Regardless of flow rate, the first sediment mixture corresponded to the largest sediment accumulation in the trap (Figure 6.5.5).

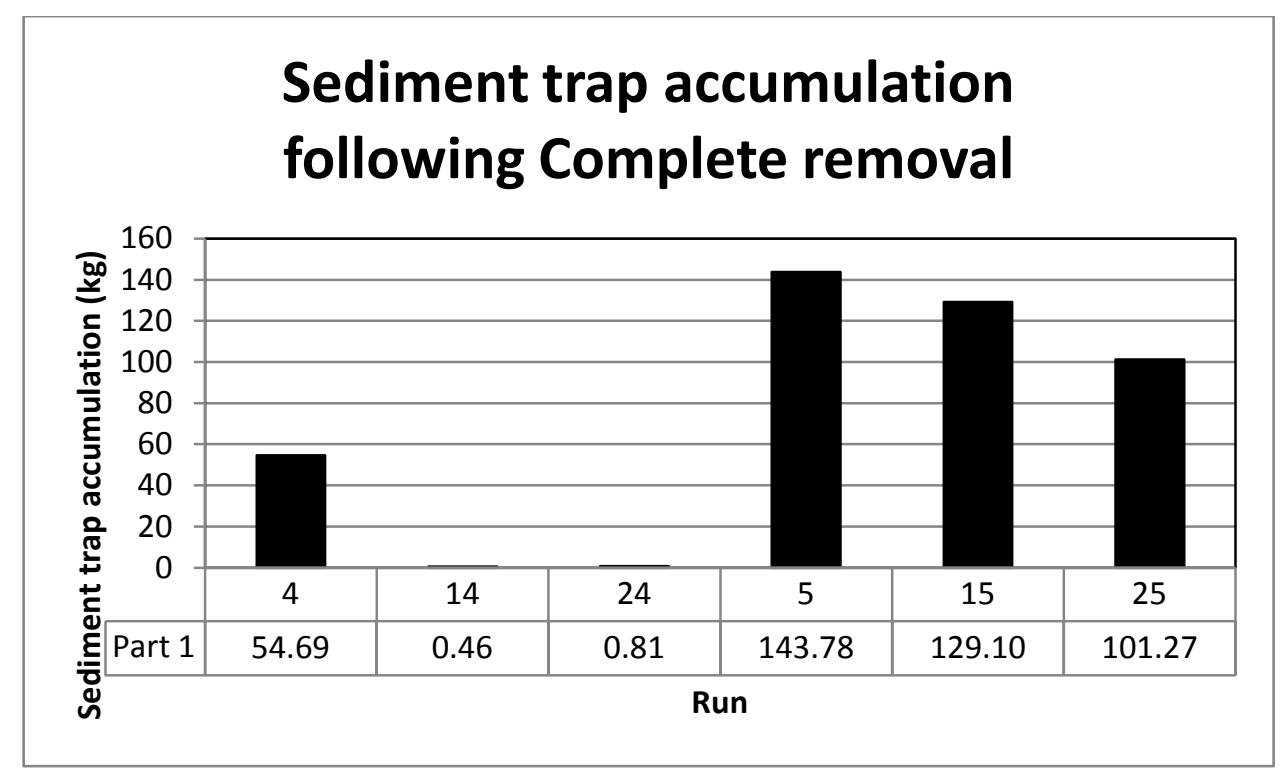

Figure 6.5.5: Sediment trap accumulation (in $\mathrm{kg}$ ) following complete removal under both high and low flow rates and all three sediment type.

\subsubsection{Vertical Dam Removal Methods}

The impact of silt in the channel bed and reservoir sediment mixtures was apparent in the measurements of downstream channel change following the method of vertical dam removal from the side under both a low and a high removal flow rates (Runs 8, 9, 18 and 19). The addition of silt to the sediment mixture resulted in a greater amount of deposition 3 and 8 meters downstream of the dam site (Run 18) although the net deposition over the downstream reach was greater when silt was not present in the sediment mixture (Run 8). The influence of silt on transport patterns following vertical dam removal from the side was greater under a high flow 
condition. There were larger amounts of erosion at 3m, with higher rates of deposition at 4, 6 and $7 \mathrm{~m}$ (Figure 6.5.6).

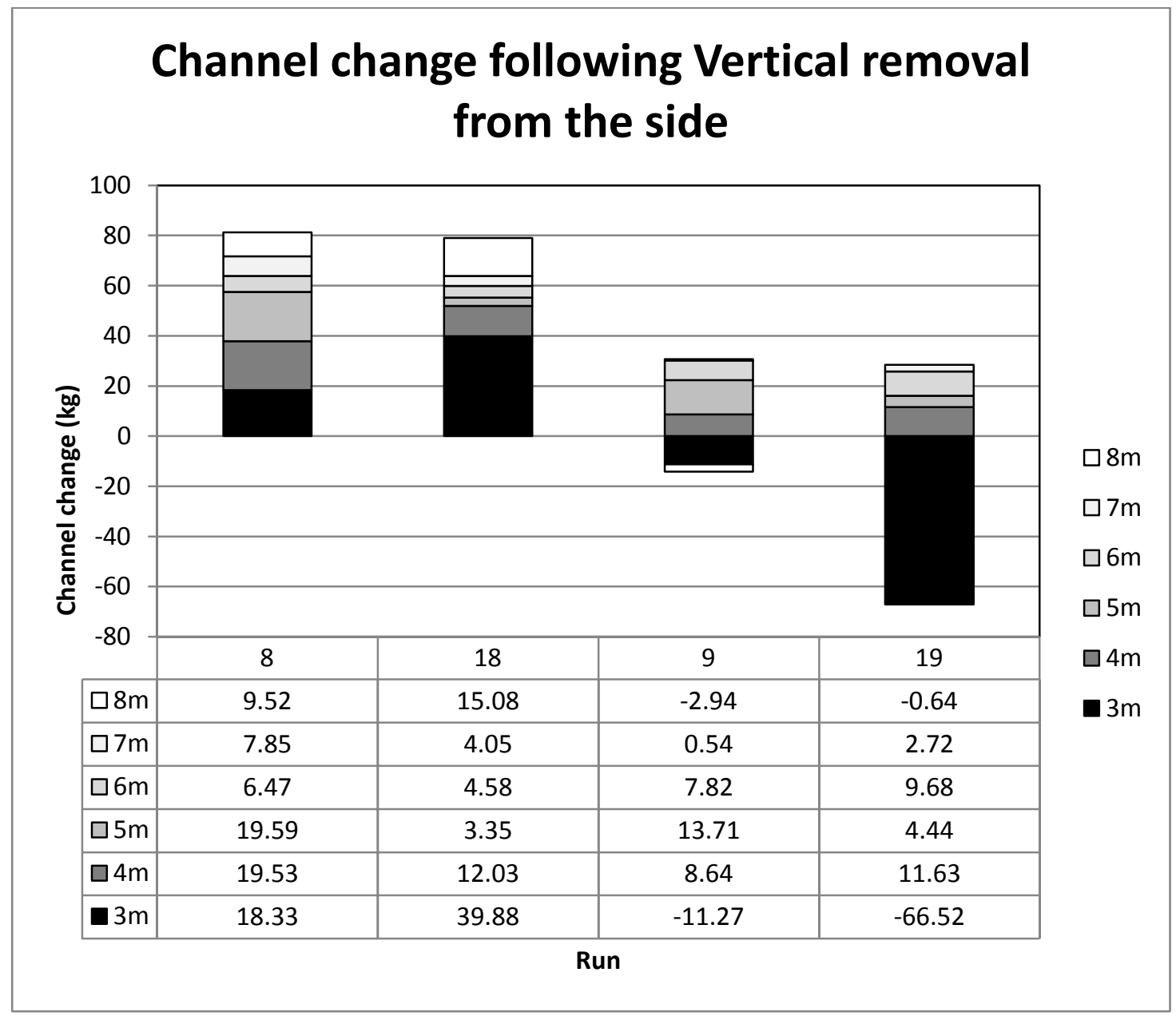

Figure 6.5.6: Summary of the change in total sediment (in $\mathrm{kg}$ ) over the downstream channel length from the dam expressed as the sediment weight found from the raster difference of the bed scans from Preremoval to Final bed for vertical dam removal from the side.

All three sediment mixtures and both the high and low flow rates were tested for the relative impacts on sediment deposition and erosion when the method of dam deconstruction was Vertical dam removal from the center (Runs 10, 11, 20, 21, 30 and 31). The downstream channel following those dam removals using the coarse sediment mixture (Runs 10 and 11) experienced net deposition under both high and low flow regimes, for Pre-Removal to Final beds (Figure 6.5.7). Downstream channel deposition occurred with the removal of the first piece of the dam; 
net erosion occurred after the removal of the second dam piece, and net deposition was measured after the removal of the third piece, regardless of flow type (Figure 4.3.1). The addition of silt to the mixture correlated to a larger amount of channel deposition $(97.55 \mathrm{~kg})$ when the flow rate was low than when the channel bed and reservoir was composed of the coarse mixture $(8.07 \mathrm{~kg}$; Table 4.2.1). The downstream channel following runs without silt present (Runs 10 and 11) had net deposition under both high and low flow regimes, for Pre-Removal to Final beds (Figure 6.5.7). The downstream channel experienced net deposition during removals under a low flow with silt present (Runs 20 and 30; $97.55 \mathrm{~kg}$ and $44.75 \mathrm{~kg}$ respectively) and net erosion for the same removals under a high flow (Runs 21 and $31 ;-42.0 \mathrm{~kg}$ and $-205.0 \mathrm{~kg}$ respectively). The downstream trends of sediment deposition and erosion appeared to correspond to the removal flow rate when silt was present in the sediment mixture. Under low flows the removal of the first piece resulted in net deposition in the downstream channel (Run 20 and 30), but the removal of the second piece resulted in net deposition in Run 20, when the silt content was $1 \%$, and net erosion in Run 30, when the silt content was increased to $1.7 \%$. The downstream channel bed experienced net erosion following the removal of the third piece for both sediment mixtures containing silt, Run 20 and Run 30. Removals under high flow conditions resulted in more erosion in the downstream channel as the silt content in the sediment mixture increased and the average grain size decreased. Net downstream bed erosion followed the removal of the first and second dam pieces under high flows for both Runs 21 and 31, while the removal of the third piece resulted in net deposition in the channel during Run 21 and net erosion during Run 31. 


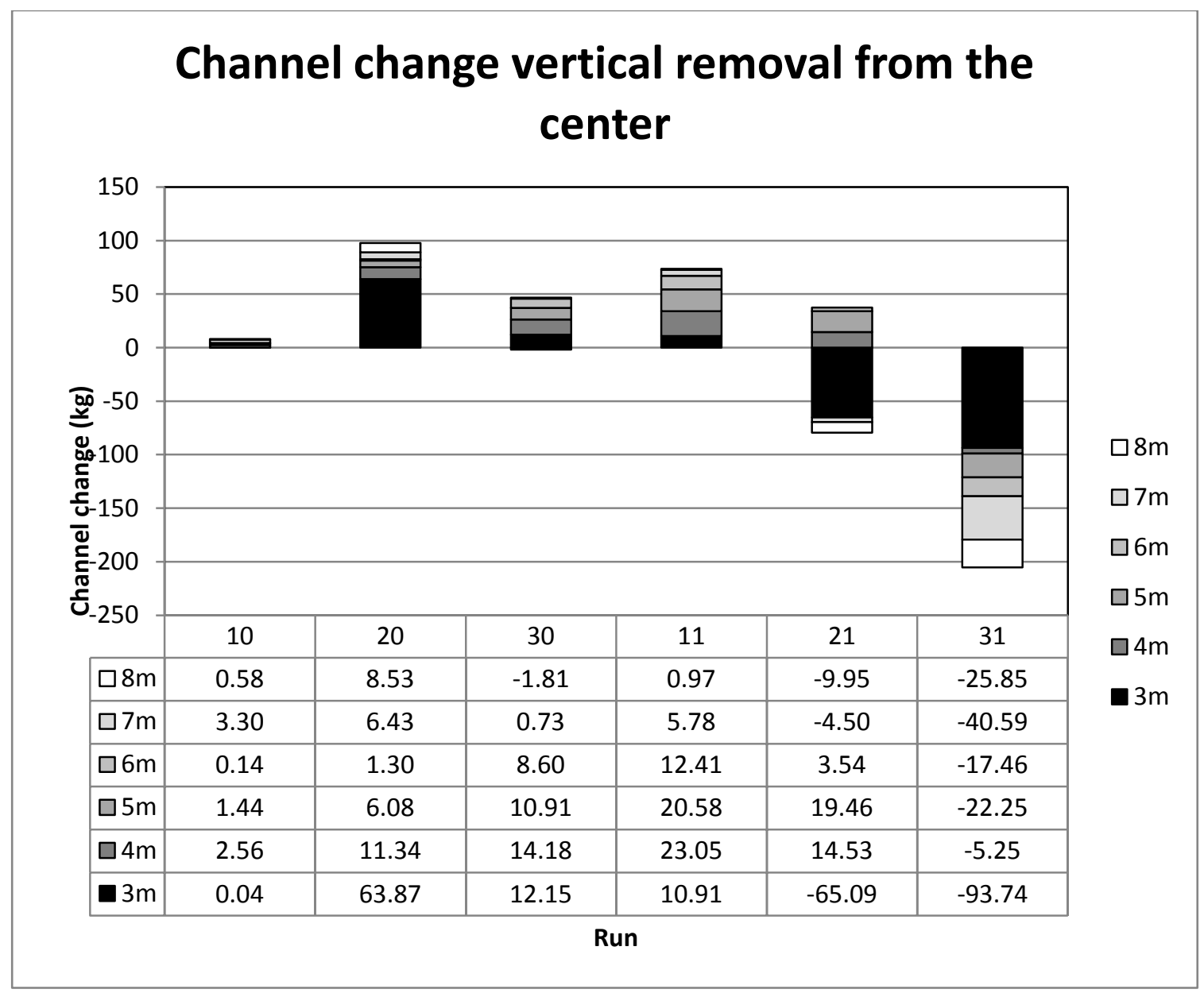

Figure 6.5.7: Summary of the change in total sediment (in $\mathrm{kg}$ ) over the downstream channel reach expressed as the sediment weight found from the raster difference of the bed scans from Preremoval to Final bed for vertical dam removal from the center.

Dam removal in vertical sections beginning from the side of the channel and from the center of the channel was tested using sediment mixtures with and without silts under both high and low flow removal conditions (Runs 8, 9, 18 and 19). The results from these experiments illustrated the influence of the flow rate during dam removal over sediment transport out of downstream channel reach. Runs $8,10,18,20$, and 30, corresponded to vertical dam removals during low flow conditions. The largest amounts of sediment transport out of the reach and accumulation in the downstream sediment trap were documented following removals when the coarse sediment mixture was used to create the channel bed and reservoir deposit (Figures 6.5.8 
and 6.5.9). As silt was added to the sediment mixture, the amount of sediment deposited downstream of the reach decreased. The largest rate of sediment deposition in the trap occurred with the removal of the third and final portion of the dam when the removal process began at the side of the channel for both of the low flow runs (Run 8 and 18). When the flow rate during dam removal was high, the amount of silt in the mixture led to higher amounts of sediment accumulation in the downstream sediment trap. When removal began from the side of the channel, the downstream sediment deposit increased from $120.68 \mathrm{~kg}$ (Run 9) to $171.96 \mathrm{~kg}$ with the addition of silt to the sediment mixture (Run 19). Similarly, when the removal began with the section in the center of the channel, sediment deposition in the downstream trap increased from $90.68 \mathrm{~kg}$ (Run 11) to $166.86 \mathrm{~kg}$ when silt was $1 \%$ of the bulk sediment (Run 21) and upon a further increase in silt to $1.7 \%$ of the sediment mixture, the deposit increased to $210.05 \mathrm{~kg}$ (Run 31; Figure 6.5.9). Thus, downstream sediment transport out of the reach was lower when the median grain size of the sediment was finer and the flow rate during removal was low, but larger when the sediment mixture was finer sediment and the flow rate high during removal (Figure 6.5.8). Under high flows the removal timing had a larger impact on downstream sediment behavior following vertical dam removal from the center than the sediment type. 


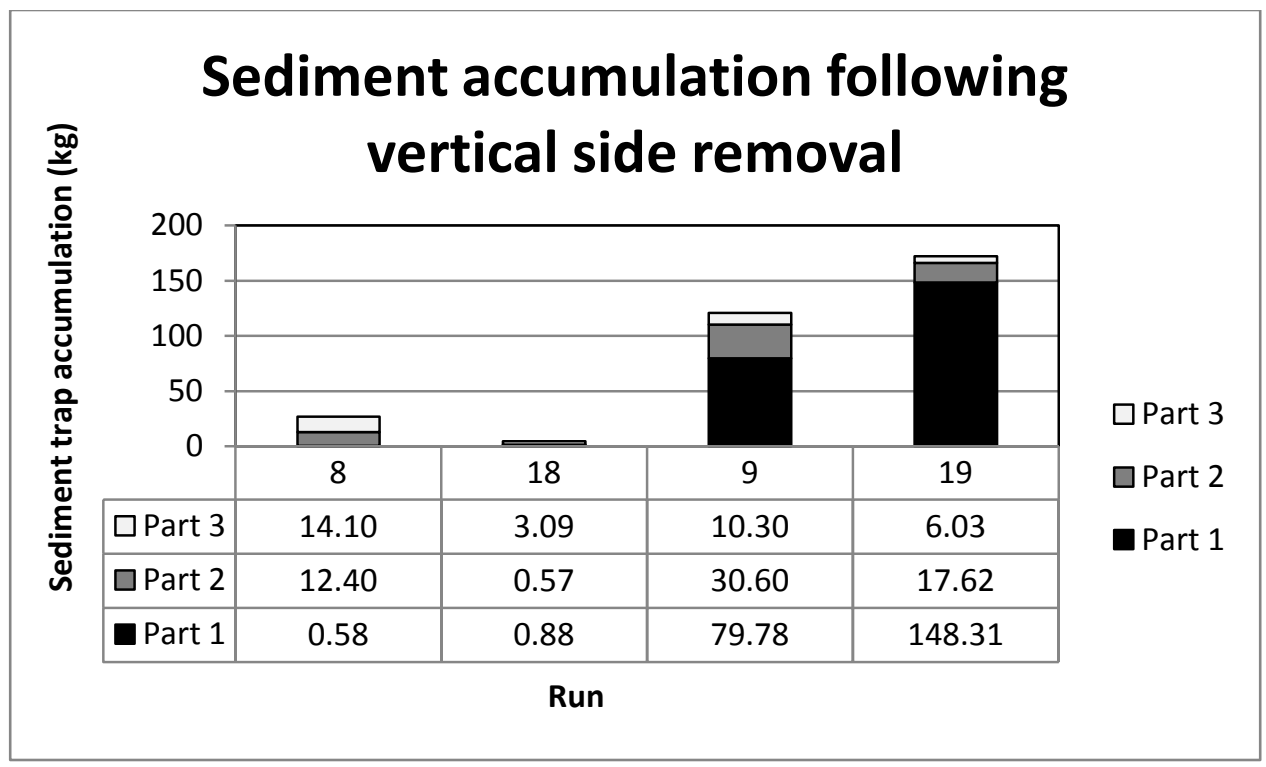

Figure 6.5.8: Sediment trap accumulation (in $\mathrm{kg}$ ) following vertical dam removal from the side under sediment type 1 and 2 under high and low flow removals.

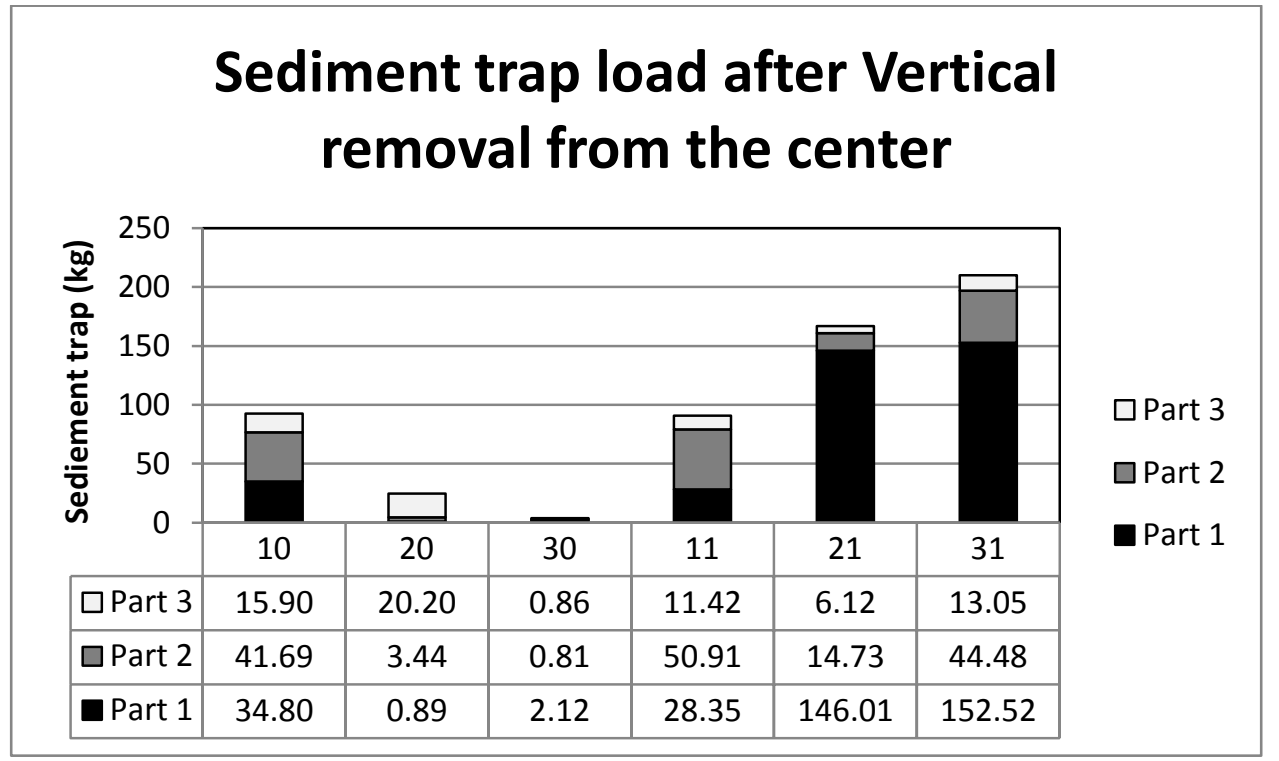

Figure 6.5.9: Sediment trap accumulation (in $\mathrm{kg}$ ) following vertical dam removal from the center under high and low flow rates.

\subsection{Summary}

Three sediment types were tested in this series of experiments to quantify the impact of grain size distributions on downstream channel behavior following various dam deconstruction methods. Building on the results of Doyle (2003) which found that channel development 
following dam failure was strongly controlled by the composition of the reservoir sediment I expected the rate of transport of the reservoir material to vary with sediment composition. The overarching hypothesis for the impact that sediment characteristics would have on the transport and deposition of the reservoir sediment was that the sediment released would be transported downstream at a rate dependent on the gravel:sand:silt content.

A river following dam deconstruction has locally increased water-surface gradients, flow velocities and bed shear stresses in the reservoir area, resulting in the entrainment and downstream transport of sediment stored in the reservoir (Evans, 2000; Doyle, 2002, 2003; Burroughs 2009, Csiki 2010). Reservoir sediment mobilized with the dam removal has been shown to move through the downstream channel as sediment waves through a combination of dispersion and advection, depending on the grain size composition of the wave. Dispersion dominated the movement and deposition of the sediment wave when gravel was present in the wave sediment (Lisle et al, 2001). In these experiments, gravels were expected to move primarily as bedload, while the fine sediment sizes were predicted to move as both bedload and in suspension. With the exception of dam removal in vertical sections and during a high flow rate, the bulk of the sediment transported upon dam removal migrated downstream as a wave at a rate that slowed as the silt content of the reservoir and channel material increased. This effect of silt content on downstream sediment transport rates was also reflected in the amount of sediment evacuating the channel reach and accumulating in the downstream sediment trap. Field studies have shown reservoir materials that are composed of predominantly fine and cohesive materials retain up to 85\% of their original deposit following dam removal (Sawaske and Freyberg, 2012), resulting in less sediment entering the downstream channel. One reason cohesive deposits typically experience less erosion than non-cohesive deposits is due to the likelihood of the 
formation of upstream migrating knickpoints in the field that reduced the width of the eroded reservoir area (Pizzuto, 2002; Doyle, 2003a; Sawaske and Freyberg, 2012). Less than 15\% of the reservoir volume was eroded following the staged removals of the Brewster, Stronach and LaValle dams and each of these removals involved the formation of reduced incising channel heights, consolidation, and vegetation colonization on the fine deposit material (Sawaske and Freyberg, 2012). Therefore, the field data indicated that a combination of staged dam removal method and the presence of fine sediment in the reservoir sediment significantly reduced the reservoir erosion volumes and sediment transported to the downstream channel.

High flow vertical dam removal from the side and center were the only removal techniques that did not follow the overall trend of decreased sediment into the trap with the increased amount of silt present. For vertical dam removal, the results indicate that the lack of silt present does not result in a dramatic change from high to low flow (Run 10 and Run 11); however with silt present the high flows had more sediment entering the trap than the corresponding low flow runs. During dam removals under a high flow rate a majority of the sediment transported following the removal of the first portion of the structure (Part 1).

Understanding the erosion and deposition patterns within the 10 channel widths below the site of a dam removal can lead to improved predictions of how a downstream channel will respond to dam removal under a given set of conditions. Previous research suggested that sediment would deposit over a longer distance and in larger quantities when the reservoir material was composed primarily of sand and silt sized material (Cui 2006a, 2006b). However, the results from these experiments showed that the amount of fine sediment present in the mixture did not have a consistent impact on the sediment deposition patterns in the 10 channel widths below the structure. A positive correlation was measured between the amount of sediment 
deposition and the median grain size for those dam removals occurring during low flow rates and following the stepped and vertical dam removal methods where the first section removed was from the center of the channel and also the complete dam removal and stepped dam removal methods during high flow conditions. An inverse relationship was measured between the amount of deposition in the downstream sediment trap and the grain size distribution in the channel and reservoir for which sediment deposition increased as the sediment composition became finer when dam removal occurred during low or high flow rates in horizontal layers and under high flow rates following a method of vertical dam removal starting from either the channel side or center.

The addition of silt to the sediment mixture combined with the dam deconstruction method affected deposition and erosion patterns within the downstream channel reach under low flows. During complete dam removal the initial addition of silt to the mixture (sediment type 2; Run 14) resulted in more deposition in the channel than was measured in sediment type 1 (Run 4). Run 24 ( $\mathrm{D}_{50}$ of $0.38 \mathrm{~mm}$ ) had a lower median grain size than Run 14 ( $\mathrm{D}_{50}$ of $\left.0.61 \mathrm{~mm}\right)$, but had less sediment deposition than Run 4 (Figure 6.2.3). Unlike the first two sediment types, Run 24 had minimal amounts of sediment deposition at 7 and 8 meters (Figure 6.4.3). The addition of the silt may have reduced the reservoir erosion rate and subsequent downstream transport rate, accounting for the decrease in sediment deposition at the downstream end of the reach and overall channel aggradation from Run 14 to Run 24. The most reservoir erosion and the largest amount of deposition in the downstream sediment trap under low flows following a single-step deconstruction occurred when the sediment mixture did not contain any silt (Run 4). The two sediment types with silt present in the mixture had less than $1 \mathrm{~kg}$ of sediment accumulate in the trap. The likely discrepancy in the additional silt not corresponding to higher quantities of 
deposition is that the finer mixture travels through the downstream channel more slowly. This delay in deposition was also noticeable in the horizontal dam removal scenarios. Under low flows, a larger amount of sediment deposited in the downstream channel for those sediment mixtures containing silt with the dam was removed following the horizontal deconstruction method. The highest silt content (Run 22) had less sediment deposition following the removal of Part 2, but larger quantities of deposition following the removal of Parts 3 and 4 than was observed for experiments where the sediment had a lower silt content (Run 12). Following low flow horizontal dam removal without silt present (Run 2), the downstream channel had less sediment deposited than the corresponding Runs where silt was present (Runs 12 and 22). These results illustrate the reduced rate of transport of the sediment slug when there were additional fines in the sediment mixture. The observed temporal variation in sand transport in the downstream channel has been previously associated with bedform migration and the release of sand temporarily stored in pools (Cheng and Granata 2007; Lisle 2000; Wohl and Cenderelli 2000). The sediment wave that was observed tended to move slower when finer sediment was present in the mixture, which contradicts previously reported trends from the Klamath River Dam removal simulation in DREAM-1 that predicted that sand and coarser sediment released following dam removal would travel slower than fine sediments due to the attenuation of bedload transport (Stillwater Sciences, 2008). These findings expand on those results and quantify sediment wave volume and movement following the removal of a dam either in sections or one piece.

The impact of the composition of the sediment mixture on the transport of the sediment wave was overshadowed by the flow rate during the dam removal. Erosion in the downstream channel reach was much more prevalent during dam removals occurring under a high flow rate 
while downstream aggradation occurred as a result of dam removals occurring during a low channel flow rate. However, the location of the majority of the sediment deposited in the channel reach varied with dam removal method. For the stepped dam removal method, the majority of the channel change occurred at $3 \mathrm{~m}$, or approximately one meter downstream of the dam site. Erosion during the stepped deconstruction method and high channel flow rate was focused at 3 meters, making the sediment deposited downstream likely a result of this erosion.

The shear stress acting on the channel bed and responsible for mobilizing and transporting channel sediments varies under changing flow depths, channel bed slopes, and grain size distributions. The higher the shear stress, the larger the force acting on the channel bed. When the coarse sediment mixture was used, the calculated shear stresses averaged 9.91Pa for the high flow rate and $2.25 \mathrm{~Pa}$ for the low flow rate. The change to the second sediment mixture, which contained $1 \%$ silt and was finer overall, the average shear stresses decreased to $15.65 \mathrm{~Pa}$ for the high flow condition and 2.10 Pa for the low flow situation. The third sediment mixture, which was the finest mixture with $1.6 \%$ silt, developed a channel with near equal average shear stresses for the flow rates. Channel high flows had an average shear stress of 2.40Pa while the shear stress averaged 2.39Pa during the low flow rate (Figure 6.6.1). 




Figure 6.6.1: The observed shear stress in the channel for each Run (average of the parts for Runs that had multiple stages of removal)

One method of estimating the capacity of the channel to transport sediment under a defined flow rate is to compare the channel shear stress to the critical shear stress for the median grain size in the channel bed sediment distribution. The average ratio of shear stress to critical shear stress following each dam removal was calculated as an indication of the ability of the channel to transport the available sediment load. Values over 1 indicate that the calculated shear stress was larger than the critical shear stress for the D50 grain size of the sediment mixture. Using the coarse sediment mixture the average shear stress ratio for all the dam removals that occurred during a low flow rate was 4.7 and for the same dam removal methods under a high flow rate it was 19.72 . For the second sediment mixture with a $\mathrm{D}_{50}$ of $0.61 \mathrm{~mm}$ the shear stress ratio was 4.8 for the low flow condition and 35.24 for the high flow removal condition. The third sediment type, with was the finest with a D50 $=0.38 \mathrm{~mm}$, the shear stress ratio decreased to an average ratio of 8.74 for the low flow dam removals and 8.64 for the high flow dam removals. 


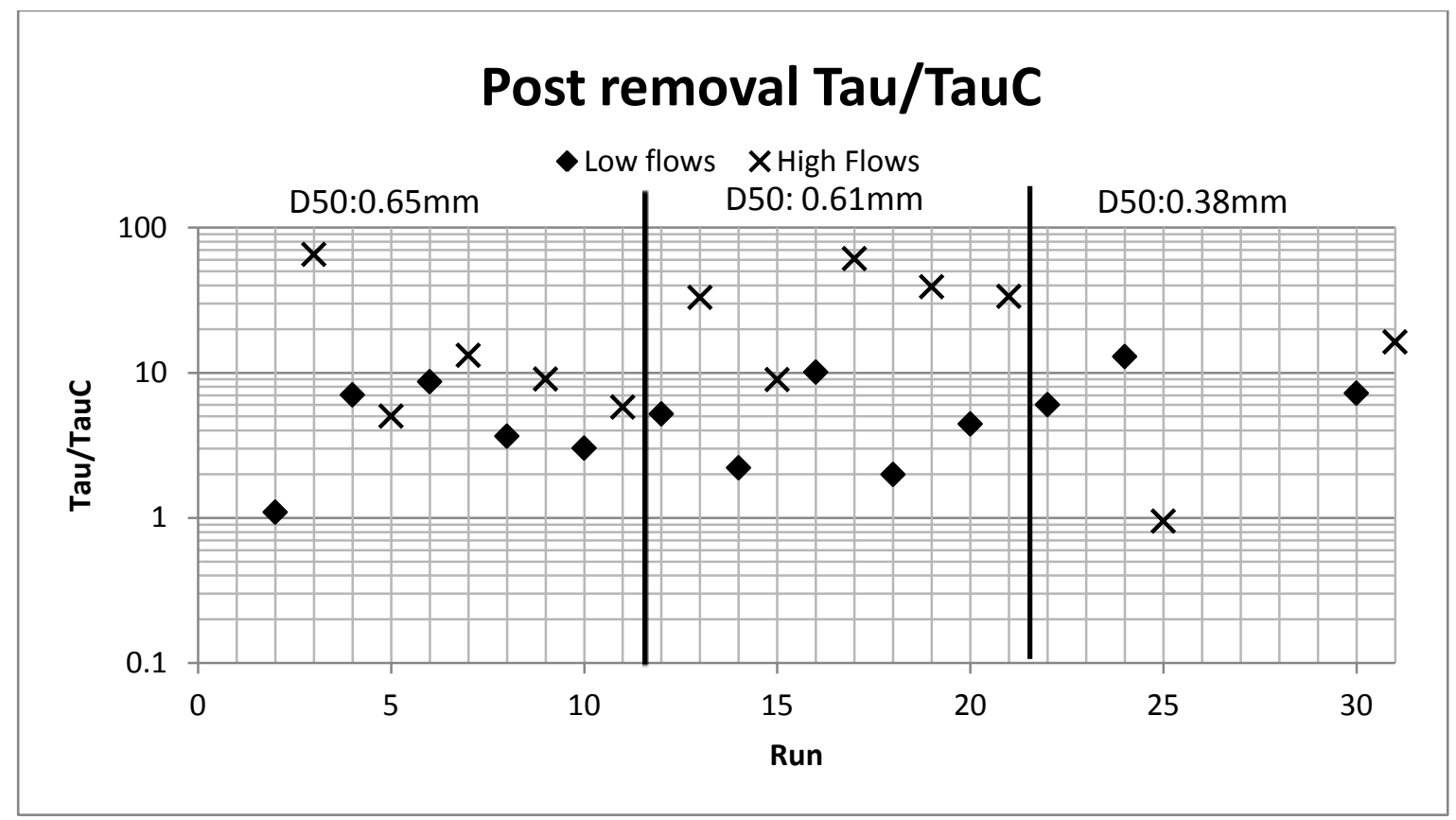

Figure 6.6.2: The ratio of observed shear stress to the critical shear stress for the median grain size of the sediment mixture.

The larger shear stress ratios were associated with the dam removals that occurred under a high flow rate and which also experienced a large amount of downstream channel erosion. The larger flow depth that was associated with increased bed erosion led to a higher calculated shear stress in the channel. The ratios of shear stress to critical shear for the various sediment types, however, did not consistently align with the highest amounts of erosion or deposition within the same deconstruction methods. The shear stress ratio for horizontal removal is highest for the second sediment type (Run 12) and the lowest for the first sediment type (Run 2), but Run 2 had the least amount of deposition in the downstream channel. Similarly, stepped removal under both high and low flows had the highest shear stresses under the second sediment mixtures, but the least amount of deposition in the downstream channel under the first. In conclusion, shear stresses acting on the channel were higher under high flows that corresponded to less deposition than the low flow counterparts, but no consistent trends between shear stress and sediment type were able to be extracted from this series of data. 


\subsection{Conclusion from the sediment type impacts}

The results from these experiments show that the addition of silt impacted the rate of sediment transport through the downstream channel following a low head dam removal. Silt content of the channel and reservoir sediment affected deposition rates and volumes in the channel below the dam as well as sediment transport out of the downstream reach as documented by accumulation in the sediment trap. The influence of sediment type was secondary to the impact of the flow rate on the sediment transport, deposition, and erosion in the downstream channel. Downstream channel erosion and sediment transport volumes out of the downstream reach increased when the dam removal occurred under a high rate in the channel. Dam removals under a low flow rate released sediment that transported downstream as a sediment wave. As the silt content of the sediment mixture increased, the transport rate of the sediment wave decreased. The implication of these results to the field situation are that for reservoirs composed of fine materials the timing of the sediment deposits to the downstream channel will need to be considered during the removal planning, as it will take longer for the sediment to transport downstream than if the reservoir was composed of coarser material under the same flow rates.

Following complete dam removal, net deposition was observed in the downstream channel following low flows and net erosion following high flows, regardless of the sediment type present, quantitatively supporting the theory that if deposition is desired downstream of the dam removal site, complete removal under low flows would be an ideal removal methodology, regardless of the sediment type present. Similarly, if deposition downstream would have detrimental impacts, removal during high flows would be ideal.

In summary, a majority of the sediment accumulation downstream of the active channel occurred immediately following the removal of the first piece of the dam structure during high 
flows, and following the removal of Parts 2 and 3 during low flows. The impact to the area 10 channel widths downstream of the dam structure took place immediately following the removal of the first portion of the structure under high flows and decreased as additional sections were removed. Following low flows, a majority of the sediment accumulated in the downstream trap towards the end of deconstruction, corresponding to a delay in the impact to the area further than 10 channel widths downstream in the field. If there is concern over the amount of sediment evacuating the area immediately downstream of the removal location, it is important to take flow rate into account, not only for total quantity moving downstream, but also for when the largest sediment pulses will occur. 


\section{Chapter 7 Conclusions}

Outcomes from less than $5 \%$ of the approximately 680 dam removals that have taken place over last 100 years (Gleick 2009; Kibler, 2011) have been published in the scientific literature (Hart, 2002). Of the observations and conceptual models that have been published, a majority are focused on the transient effects of dam removal and the short term patterns of upstream sediment mobilization and downstream sediment storage (Skalak, 2009). Large uncertainty about the consequences of dam removal exists (Aspen Institute, 2002; Kibler, 2011), specifically surrounding the magnitude, timing and spatial extent of physical and ecological impacts (Hart, 2002; Heinz Center 2002; Stanley and Doyle, 2003). Data analysis from this research provides a series of qualitative and quantitative descriptions of small dam removals under a range of boundary conditions. From the results of these experiments it is possible to identify, for given impounded size and sediment characteristics, the sequence of dam deconstruction with the least amount of negative impact on the downstream channel form, and therefore downstream aquatic ecosystem. By employing the different geometric scaling ratios, the results are broadly applicable around the US. This series of experiments is geared towards answering one of the most important unanswered questions surrounding dam removal, the likely course of channel change following the dam removal (Graf, 2005) under various deconstruction types, flow rates and sediment compositions.

Uncertainties impeding the release of sediment during dam removal include the potential for that sediment to smother the downstream channel bed or increase bed scour, in either case causing the aquatic ecosystem to suffer. These concerns are based on field studies of channels impacted by reservoir-sediment releases have described channel response to a given set of parameters (discharge, channel morphology, sediment-release scenario; e.g. Wohl and 
Cenderelli, 2000), without the ability to manipulate those parameters and observe the corresponding channel responses (Hotchkiss, Barber and Wohl, 2001). As a result, design of best-case dam removal scenarios using existing information has been largely estimated from inferences, rather than demonstrated relations between channel geometry and water and sediment discharge regimes (Hotchkiss, Barber and Wohl, 2001). The research presented here shows that dam removals under high flows limit the amount of sediment deposition in the area 10 channel widths below the dam, while increasing the amount of sediment evacuating into the channel further downstream than the same scenarios under low flows. During low flows the presence of silt also influences how long the area immediately below the dam will be affected by the sediment release, with higher silt contents resulting in the sediment wave moving downstream more slowly.

Patterns of deposition or scour were mapped after each part of a dam removal and consistent areas of degradation and aggradation were identified and tied to both the characteristics of the impounded sediment and the sequence of dam deconstruction. Five dam removal methods were investigated during this project: horizontal removal, where the dam decreased in height at the same rate in the vertical direction; complete removal, where the dam was removed in one instantaneous step; stepped removal, which was a modification of the horizontal removal method with the sides and base of the structure left in place; vertical removal, where one third of the structure was removed and exposed a portion of the reservoir sediment (the first piece was removed from the side and from the center).

The general trends observed following horizontal and stepped methods of dam removal were low amounts of sediment deposition within the 10 channel widths immediately downstream of the dam and high amounts of sediment transport out of the reach. This finding is directly 
transferrable from the flume to field case studies, with sediment expected to be transported outside of the channel immediately downstream of the structure. Dam deconstruction as a sequence of constant decreases in elevation was measured to have a majority of the sediment deposition when the elevation of the structure was below the elevation of the reservoir sediment. The horizontal removal of the Brewster Creek Dam near St. Charles, Illinois was removed in 5 horizontal stages (Straub, 2007). Sixty tons of sediment evacuated the reservoir following the removal of the upper 3 horizontal segments and 382 tons following the removal of the last two portions, when the structure height was below the reservoir sediment height (Straub, 2007). During this removal, the first three stages of deconstruction could have been combined to minimize construction costs without increasing the risk of releasing large amounts of sediment to the downstream channel.

A partial dam removal with a portion of the structure left in place, or stepped removal, is common to reduce construction costs as well as a form of historic preservation (Randle and Greimann, 2006). It is also a common practice if the goal of the project is to create wetland habitat or to minimize the downstream transport of nutrients and sediment (Ahearn and Dahlgren, 2005). The results presented here in combination with field studies (Randle and Greimann, 2006) suggest that staged removal over multiple years should be considered to avoid excessive aggradation of the downstream river bed.

A large amount of sediment accumulation in the downstream channel occurred following the methods of vertical dam removal starting from either the side or center of the dam, as well as complete removal. The location of the first part of the vertical dam removal, from the side or center, only impacted the 1.67 channel widths immediately downstream of the structure, with erosion occurring downstream of the removal location and deposition behind the remaining 
structure. The flume results indicate that field application of these dam deconstruction methods will result in sediment deposition immediately below the dam, with minimal amounts of sediment transporting further downstream. Both vertical dam removal methods tested in the flume experiments resulted in erosion downstream of the removal location with deposition downstream of the areas where the structure remained intact. This pattern was also observed when the Anaconda Dam on the Naugatuck River, CT was partially breached during a high flow storm event prior to the dams scheduled removal (Wildman and MacBroom, 2005). When removal takes place under low flows and involves vertical removal from either location or complete removal, the majority of the impact to the downstream channel can be expected to occur following the removal of the first portion of the structure, when the reservoir sediment is exposed.

In addition to the impact of deconstruction method, the results of these experiments in combination with previous reported dam removal case studies (Hotchkiss, Barber and Wohl, 2001) showed that the most important parameter determining what will happen to the downstream channel is the flow rate during the time of removal. Dam removals during High flows generally led to a greater amount of sediment evacuating from the reservoir as well as net erosion in the downstream channel (typically erosion) and more sediment transported out of the channel reach, than the low flow counterparts under the same removal technique and sediment type. If the goal of a dam removal project is to transport sediment through reach immediately below the structure or replenish the amount of sediment further downstream, dam deconstruction during a high flow would be preferable. Erosion occurred in the 10 channel widths below the removal location following dam removals during high channel flows. High flows during dam removal also led to a coarser Final bed surface. If disturbances to the downstream channel are a 
concern or deposition in the reach immediately below the dam is desired, removal under low flows would be best. Dam removals during low flow conditions led to deposition and surface fining in the 10 channel widths below the removal location when the Pre-Removal channel bed was compared to the Final channel bed, regardless of the dam removal method and channel sediment type. Stepped dam removal and vertical dam removal starting from the center were shown to be the methods of dam deconstruction that minimized the amount of deposition following dam removal during low channel flow rates, with complete and horizontal dam removal methods resulting in the highest amounts of downstream deposition.

During the stages of a dam removal, the portion of the structure that was removed acted as the controlling parameter over the impact on the downstream channel reach. The removal of the first portion of the dam in vertical removal scenarios and the removal of the second portion of the dam in horizontal removals resulted in the largest amount of deposition in the downstream channel, regardless of flow rate or shear stress. Complete dam removal and vertical dam removal from the side during a high flow, the experiments most comparable to dam failure during a storm event, resulted in the least amount of downstream erosion. The highest amounts of erosion in the downstream channel occurred when dams were removed during a high channel flow through the stepped and vertical removal from the center when silt was present in the sediment mixture.

The sediment present at a site cannot be changed, as opposed to the timing of the dam removal with respect to channel flows and the deconstruction method, therefore, the impact of fine sediment in the channel sediment mixture on the downstream channel behavior was also analyzed. The largest impact of the addition of silt was a reduction in the rate of sediment transport through the downstream channel. This was measured through deposition distance in the channel below the dam following each step of a dam removal as well as sediment trap deposition 
volume. The impact of sediment type was overshadowed by the impact of the flow rate on the channel. Greater amounts of sediment deposited in the downstream and a larger amount of in channel erosion occurred following dam removals that occurred under high flows than low flows regardless of the sediment type present. The higher the silt content and the finer the reservoir material is, the longer the sediment wave will take to migrate downstream. The implications in the field are that the timing of the sediment deposits to the downstream channel will need to be taken into account for reservoirs composed of fine materials as it will take longer for the sediment to work downstream when compared to coarser reservoir materials under the same flow rates.

In summary, when planning a dam removal during the low flow season or when low flows are anticipated, it would be advised to use horizontal or stepped dam removal sequence in channels where additional sediment would be detrimental to the system. However, if under these same flow conditions, downstream sediment deposition is not a concern or the downstream channel would benefit from channel aggradation, vertical or complete dam removal would be the preferential dam deconstruction method. Complete dam removal in a single step resulted in the highest amount of downstream sediment deposition under low flow rates in the channel, with vertical dam removal also resulting in large amounts of deposition on the downstream channel.

One big lesson from the flume results combined with the case studies, is that under low flows, a majority of the sediment that travels downstream occurs once the height of the reservoir sediment is higher than the remaining structure and the sediment is easily available for transport. If project managers take this information and reduce the height of the dam to the reservoir height in a single step, the reservoir will dewater, channel initiation can take place and vegetation can 
begin to establish, and it also would allow more time in-between the final stages of removal, which would make the impact from those stages more gradual. 


\section{Chapter 8 References}

Ackers, P., and White, W. R. (1973). "Sediment Transport: New approach and analysis." Journal of the Hydraulics Division, 99(11), 2041-2060.

Ahearn DS, Dahlgren RA. 2005. Sediment and nutrient dynamics following a low-head dam removal at Murphy Creek, California. Limnology and Oceanography 50: 1752-1762.

Akan, A. O. (2008). Open Channel Hydraulics. Elsevier Ltd.

American Society of Civil Engineering. (2007). "Virginia Infrastructure Report Card for 2005." ASCE Virginia Section Newsletter, 44(1), 1-13.

American Society of Civil Engineers. (2000). Hydraulic Modeling: Concepts and Practice. American Society of Civil Engineers, Reston, Va.

Bartley, R., and Rutherford, I. (2005). "Measuring the reach-scale geomorphic diversity of streams: applications to a stream disturbed by a sediment slug." River Res. Applic., 21 3959.

Battige, D.S., Fields, B.L., Sowers, D.L., 1997. Removal of Stronach Dam. Proceedings of the International Conference on Hydropower (WaterPower 1997) 2, 1341-1350.

Becker, D. H. (2006). "The challenges of dam removal: the history and lessons of the Condit dam and potential threats from the 2005 Federal Power Act Amendments." Envtl. L., 36 811.

Bednarek, A. T. (2001). "Undamming Rivers: A review of the ecological impacts of dam removal." Environmental Management, 27(6), 803-814.

Binger, R. L., and Langendoen, E. J. (1997). "Impact of instream structures on channel evolution within Goodwin Creek Watershed." S. S. Y. Wang, E. J. Langendoen, and F. D. Shields Jr., eds.,University, MS, 765.

Blank, C. (2009). "Sinking Missouri River threatens bridges, communities." Associated Press.

Bond, N. R. and Downes, B. J. (2003), The independent and interactive effects of fine sediment and flow on benthic invertebrate communities characteristic of small upland streams. Freshwater Biology, 48: 455-465. doi: 10.1046/j.1365-2427.2003.01016.x

Boorstein, M. (2005). "Dam's demise lures fish to their Rappahannock Roots." The Washington Post.

Brandt, S. A. (2000). "Classification of geomorphological effects downstream of dams." Catena, 40(4), 375-401. 
Bromley, C., Cantelli, A., and Wooster, J. (2005). "Experimental research on dam removal." NCED River Restoration News Letter, (fall).

Bromley, C. (2008). "The morphodynamics of sediment movement through a reservoir during dam removal." PhD thesis.

Burroughs, B. A., Hayes, D. B., Klomp, K. D., Hansen, J. F., and Mistak, J. (2009). "Effects of Stronach Dam removal on fluvial geomorphology in the Pine River, Michigan, United States." Geomorphology, 110(3), 96-107.

Bushaw-Newton, K. L., Hart, D. D., Pizzuto, J. E., Thomson, J. R., Egan, J., Ashley, J. T., Johnson, T. E., Horwitz, R. J., Keeley, M., Lawrence, J., Charles, D., Gatenby, C., Kreeger, D. A., Nightengale, T., Thomas, R. L., and Velinsky, D. J. (2002). "An integrative approach towards understanding ecological responses to dam removal: the Manatawny Creek Study." JAWRA Journal of the American Water Resources Association, 38(6), 1581-1599.

Cannatelli, K. (2010). "A case study of partial dam removal on the Coastal Plain of Virginia: Evaluation of the dominant parameters controlling stream morphological development." Masters thesis, University of Virginia.

Cannatelli, K., and Curran, J. (2012). "The importance of hydrology on channel evolution following dam removal: a case study and conceptual model." Journal of Hydraulic Engineering. 138 (5): 377-390.

Canovaro, F., Paris, E., and Solari, L. (2007). "Effects of macro-scale bed roughness geometry on flow resistance." Water Resour. Res., 43 W10414.

Cantelli, A., Paola, C., and Parker, G. (2004). "Experiments on upstream-migrating erosional narrowing and widening of an incisional channel caused by dam removal." Water Resour. Res., W03304.

Cenderelli, D. A., and Cluer, B. L. (1998). "Depositional processes and sediment supply in resistant-boundary channels: Examples from two case studies." Rivers Over Rock: Fluvial Processes in Bedrock Channels.

Chanson, H. (1999). The Hydraulics of Flow in Open Channels. Arnold, London.

Cheng, F., and Granata, T. (2007). "Sediment Transport and Channel Adjustments associated with dam removal: Field observations." Water Resour. Res., 43.

Chin, D. A. (2006). Water-Resources Engineering. Pearson Prentice Hall.

Church, M. (2006). "Bed Material transport and the morphology of alluvial river channels." Annu. Rev. Earth Planet. Sci., 34 325-354. 
Collins, A., Rosenberger, R., and Fletcher, J. (2005). "The economic value of stream restoration." Water Resour. Res., 41.

Conyngham, J., Fischenich, J. C., and White, K. D. (2006). "Ecological and engineering aspects of dam removal- An overview." EMRRP Technical Notes Collection (ERDCTNEMRRP-SR-80).

Csiki, Shane, and Bruce L. Rhoads. "Hydraulic and geomorphological effects of run-of-river dams." Progress in physical geography 34.6 (2010): 755-780.

Cui, Y. (2007). "The Unified Gravel-Sand (TUGS) model: simulating sediment transport and gravel/sand grain size distributions in gravel-bedded rivers." Water Resour. Res., 43.

Cui, Y., Braudrick, C., Dietrich, W. E., Cluer, B. L., and Parker, G. (2006a). "Dam Removal Express Assessment Model (DREAM) Part 2: Sample Runs/ sensitivity test." J. Hydraul. Res., 44(3), 308-323.

Cui, Y., Parker, G., Braudrick, C., Dietrich, W. E., and Cluer, B. L. (2006b). "Dam Removal Express Assessment Models (DREAM) Part 1: model development and validation." $J$. Hydraul. Res., 44(3), 291-307.

Cui, Y., Wooster, J. K., Venditti, J. G., Dusterhoff, S. R., Dietrich, W. E., and Sklar, L. S. (2008). "Simulating Sediment Transport in a Flume with Forced Pool-Riffle Morphology: Examinations of Two One-Dimensional Numerical Models." J. Hydraul. Eng., 134(7).

Curran, J. C., and Wilcock, P. R. (2005). "Effect of sand supply on transport rates in a gravel-bed channel." Journal of Hydraulic Engineering, 131(11), 961-967.

Curran, J. C. (2007). "The decrease in shear stress and increase in transport rates subsequent to an increase in sand supply to a gravel-bed channel." Sediment.Geol., 202(3), 572-580.

Davies, T. R. H. (1980). "Bedform spacing and flow resistance." J. Hydraul. Div., 106 423-433.

Department of Conservation and Recreation. (2010). "Virginia Impounding Structure Regulations (Dam Safety)." Virginia Soil and Water Conservation Board.

Doyle, M. W., E.H. Stanley, and J.M. Harbor. (2003). "Channel Adjustments following two dam removals in Wisconsin." Water Resour. Res., 3(1), 1011.

Dunagan, Christopher. "Dramatic Changes following Elwha Dam Removal." Kitsap Sun [Port Angeles] 2 Mar. 2013.

El Kadi Abderrezzak, K., and Paquier, A. (2011). "Applicability of sediment transport capacity formulas to dam-break flows over movable beds." Journals of Hydraulic Engineering, 209. 
El Kadi Abderrezzak, K., Paquier, A., and Gay, B. (2008). "One- Dimensional numerical modeling of dam-break waves over movable beds: application to experimental and field cases." Environ Fluid Mech, 8 169-198.

Engelund, F., and Hansen, E. (1967a). A monograph on sediment transport in alluvial streams. Teknisk Vorlag, Copenhagen, Denmark.

Engelund, F., and Hansen, E. (1967b). "A monograph on sediment transport in alluvial streams." Teknisk Forlag, Copenhagen, Denmark.

Epstein, J. A., and Wilcox, A. C. (2008). "Reservoir sediment evacuation and channel evolution: Upstream geomorphic response of the Blackfoot River, Montana, to removal of Milltown Dam.".

Evans JE, Mackey SD, Gottgens JF, Gill WM. 2000. Lessons from a dam failure. Ohio Journal of Science 100: 121-131.

Everitt, B. (1993). "Channel Response to declining flow on the Rio Grande between Ft. Quitman and Presidio, Texas." Geomorphology, 6 225-242.

Every Single Place. "Dams in Virginia, United States." http://www.everysingleplace.com/admin1_codes/features/4267-virginiainformation?fcid=289 (February 22, 2011).

Fassnacht, H., McClure, E. M., Grant, E., and Klingeman, P. C. (2003). "Downstream effects of the Pelton-Round Butte hydroelectric project on bedload transport, channel morphology, and channel-bed texture, lower Deschutes River, Oregon.".

Fountain, H. (2011). "Danger Pent up Behind Aging Dams." The New York Times.

Francisco, E. (2004). "Tales of the Undammed." Science News Online, 165(15).

Garcia, M. (2008). Sedimentation Engineering: Processes, Measurements, Modeling and Practice. American Society of Civil Engineers, Reston, Virginia.

Gonzalez, T. (2011). "Dam demolition plan divides community." The News Virginia.

Gordon, E., and Meentemeyer, R. K. (2006). "Effects of dam operation and land use on stream channel morphology and riparian vegetation." Geomorphology, 82(3-4), 412-429.

Graf, W. L. (1999). "Dam Nation: A geographic census of American dams and their large-scale hydrologic impacts." Water Resour. Res., 35(4), 1305-1311.

Graf, W. L. (2006). "Downstream hydrologic and geomorphic effects of large dams on American rivers." Geomorphology, 79(3-4), 336-360. 
Grant, G.E., J.D.G. Marr, C. Hill, S. Johnson, K. Campbell, O. Mohseni, J.R. Wallick, S.L. Lewis, J.E. O'Connor, J.J. Major, and B.K. Burkholder, 2008. Experimental and Field Observations of Breach Dynamics Accompanying Erosion of Marmot Cofferdam, Sandy River, Oregon. Proceedings of the World Environmental and Water Resources Congress, Ahupua'a Hawaii, R.W.Babcock, andR.Walton (Editors). American Society of Civil Engineers, Reston, Virginia, pp. 1-10.

Grant, G. E., Schmidt, J., and Lewis, S. (2003). "A geologic framework for interpreting downstream effects of dams on rivers." Water Science and Application 7.

Harris, N. R. (2008). "Sedimentological Response of the 2007 Removal of a Low-Head Dam, Ottawa River, Toledo, Ohio." PhD thesis, Bowling Green State University.

Hart, D. D., Johnson, T. E., Bushaw-newton, K., Horwitz, R. J., Bednarek, A. T., Charles, D. F., Kreeger, D. A., and Velinsky, D. J. (2002). "Dam Removal: Challenges and Opportunities for Ecological Research and River Restoration." Bioscience, 52(8), 669.

Heinz Center. (2002). "Dam Removal Research: Status and Prospects." Paper Presented at The Heinz Center's Dam Removal Research Workshop Oct. 23-24.

Herald-Zeitung. (2006). "Flood Projects vital for safety." The Herald-Zeitung.

Hickey, Hannah. "Tracking Sediments' Fate in Largest-ever Dam Removal." UWToday 7 Mar. 2013

Hotchkiss, Rollin H., Michael E. Barber, and Ellen E. Wohl. "Dam Decommissioning: Decisions and Unresolved Sediment Transport Issues." Proceedings of the Seventh Federal Inter Agency Sedimentation Conference, March 25 to 29, 2001, Reno, Nevada

Hough-Snee, Nate. "The Ecology of Dams and Dam Removal: Fast times in the American West (Part 1)." Early Career Ecologists 7 Mar. 2013

ICF Consulting, and Woodlot Alternatives. (2005). "A summary of Existing Research on LowHead Dam Removal Projects.".

James, L.A., 1989, Sustained storage and transport of hydraulic gold mining sediment in the Bear River, California. Annals of the Association of American Geographers, 79, 570-592.

Kibler, K., Tullos, D. and Kondolf, M. (2011), Evolving Expectations of Dam Removal Outcomes: Downstream Geomorphic Effects Following Removal of a Small, GravelFilled Dam. JAWRA Journal of the American Water Resources Association, 47: 408423. doi: 10.1111/j.1752-1688.2011.00523.x

Kober, Amy. "65 Dams Removed to Restore Rivers in 2012." Water Currents 14 Mar. 2013 
Kondolf, G. M. (1997). "Hungry water: Effects of dams and grave; mining on river channels." Environmental Management, 21(4), 533-551.

Kondolf, G. M., and Wilcock, P. R. (1996). "The flushing flow problem: Defining and evaluating objectives." Water Resources Research, 32(8), 2589-2599.

Kuhnlw R. 1991: Bed load transport on two small streams. Proceedings of the Fifth Federal Interagency Sedimentation Conference, Las Vegas, Nevada, 4-139, 4-146.

Kuhnle, R. A. (1992), Bed load transport during rising and falling stages on two small streams. Earth Surf. Process. Landforms, 17: 191-197. doi: 10.1002/esp.3290170206

Landers, J. (2004). "River Renaissance." Civil Engineering, 74(7), 52-59.

Lane, S. N. (2005). "Roughness- time for a re-evaluation?" Earth Surf. Process. Landforms, 30(2), 251-253.

Langendoen, E. J. (2000). "CONCEPTS-Conservational Channel Evolution and Pollutant Transport System." Rep. No. 16, USDA Agricultural Research Service, National Sedimentation Laboratory, Oxford, Mississippi.

Langendoen, E. J., Thomas, R. E., and Bingner, R. (2002). "Numerical simulation of the morphology of the Upper Yalobusha River Mississippi between 1968 and 1997." 931939.

Laursen, E. M. (1958). "The total sediment load of streams." Journal of the Hydraulic Division, ASCE, 84(HY1), 1530.1-1530.36.

Laronne, J., Y. Alexandrov, N. Bergman, and H. Cohen. "The Continuous Monitoring of Bedload Flux in Various Fluvial Environments." Erosion and Sediment Transport Management in Rivers: Technological and Methodological Advances (2003)

Leopold, L. D., Wolman, M. G., and Miller, J. P. (1964). Fluvial Processes in Geomorphology. W.H. Freeman, New York.

Lewis, J. (1991) An improved bed load sampler. In Fifth Federal Interagency Sedimentation Conference (ed. by Fan, S. and Kuo, Y.), Vol. 6, 1-8. Las Vegas, Nevada.

Lisle, T. E., Pizzuto, J., Ikeda, H., Iseya, F., and Koama, Y. (1997). "Evolution of a sediment wave in an experimental channel." Water Resources Research, 33(8), 1971-1981.

Lisle, T. E., Cui, Y., Parker, G., Pizzuto, J. E., and Dodd, A. M. (2001). "The dominance of dispersion in the evolution of bed material waves in gravel-bed rivers." Earth Surf.Process.Landforms, 26(13), 1409-1420.

Lisle, T.E., 1982, Effects of aggradation and degradation on riffle-pool morphology in natural gravel channels, northwestern California. Water Resources Research, 18, 1643-1651. 
Lorang, M. S., and Aggett, G. (2005). "Potential sedimentation impacts related to dam removal: Icicle Creek, Washington, U.S.A." Geomorphology, 71(1-2), 182-201.

J. McDaniel. (2007). "Woolen Mills dam removal." www.WVIRNBC29.com (August 15, 2007).

Madej, M.A. and Ozaki, V., 1996, Channel response to sediment wave propagation and movement, Redwood Creek, California, USA. Earth Surface Processes and Landforms, 21, 911-927.

Major, Jon J., Jim E. O'Connor, Charles J. Podolak, Mackenzie K. Keith, Kurt R. Spicer, Rose J. Walker, Heather M. Bragg, Smokey Pittman, Peter R. Wilcock, Abagail Rhode, and Gordon E. Grant. (2010) "Evolving Fluvial Response of the Sandy River Oregon, following Removal of Marmot Dam." Proceedings 9th Federal Interagency Sedimentation Conference, Las Vegas, NV, June 27-July 1, 2010

Major JJ, O'Connor JE, Grant GE, Spicer KR, Bragg HM, Rhod A, Tanner DQ, Anderson CW, Wallick JR. 2008. Initial fluvial response to the removal of Oregon's Marmot Dam. EOS 89: 241-243. DOI: 10.1029/2008EO270001.

Maser, Andy, and Steve Stampfli. "White Salmon Restored: A Timelapse Project." White Salmon Restored A Timelapse Project. N.p., 3 Dec. 2012. Web. 13 Apr. 2013.

Meyer-Peter, E., and Muller, R. (1948). "Formulas for bedload transport." 39-64.

Michael, F., and Gerhard, G. (2006). "Description of a flume channel profilometry tool using laser line scans." Aquatic Ecology, 40 493-501.

Montgomery, D.R., Panfil, M.S., and Hayes, S.K., 1999, Channel-bed mobility response to extreme sediment loading at Mount Pinatubo, Geology, 27, 271-274

Moss, Tracy. "Hearing Set on Removing Dams in Danville." News-Gazette.com [Danville] 20 Mar. 2013

F. D. Michigan DNR. (2007). "Michigan Dam removal case studies." http://www.a2gov.org/government/publicservices/systems_planning/Environment/hrimp/ Documents/Completed\%20dam\%20removals\%20in\%20MI.pdf .

National Parks Service a. "2012 Year in Review." National Parks Service, 09 Apr. 2013. http://www.nps.gov/olym/naturescience/damremovalblog.htm. 13 Apr. 2013.

National Parks Service b. "Dam Removal- Overview." National Parks Service, 09 Apr. 2013. http://www.nps.gov/olym/naturescience/dam-removal-overview.htm. 13 Apr. 2013.

NCED. (2009). "Sediment dynamics for dam operation and removal overview." www.nced.umn.edu (January 12, 2009). 
Nikora, V. I., Goring, D. G., and Biggs, B. J. F. (1998). "A Simple Model of Stream PeriphytonFlow Interactions." Oikos, 81(3), pp. 607-611.

NRCS. (2006). "Dam rehabilitation fact sheet for Pohick Creek Watershed." www.nrcs.usda.gov January 12, 2009).

Orr, C. H., and Stanley, E. H. (2006). "Vegetation development and restoration potential of drained reservoirs following dam removal in Wisconsin." River Research and Applications, 22(3), 281-295.

Pacific Gas and Electric. (2007). "Marmot Dam." http://marmotdam.com (February 27, 2009).

Park, I. and Jain, S.C., 1986, River-bed profiles with imposed sediment load. Journal of Hydraulic Engineering, 112, 267-280.

Parker, G. (2004). "The uses of sediment transport and morphodynamic modeling in stream restoration." 1-10.

Peakall, J., Ashworth, P., and Best, J. (1996). "Physical modeling in fluvial geomorphology: principles, applications and unresolved issues." The Scientific Nature of Geomorphology: Chichester, U.K. John Wiley \& Sons, 221-253.

Pearson, A., Snyder, N., and Collins, M. (2011). "Rates and processes of channel response to dam removal with a sand-filled impoundment." Water Resour. Res., 47

Pejchar, L., and Warner, K. (2001). "A river might Run through it again: criteria for consideration of dam removal and interim lessons from California." Environmental Management, 28(5), 561-575.

Petts, G. E., and Gurnell, A. M. (2005). "Dams and geomorphology: Research progress and future directions." Geomorphology, 71(1-2), 27-47.

Phillips, J. D. (2003). "Toledo Bend Reservoir and geomorphic response in the Lower Sabine River." River Res. Applic., 19 137-159.

Phillips, J. D., Slattery, M. C., and Musselman, Z. A. (2005). "Channel adjustments of the lower Trinity River, Texas, downstream of Livingston Dam." Earth Surf.Process.Landforms, 30(11), 1419-1439.

Pizzuto, J. (2002). "Effects of Dam Removal on River Form and Process." Bioscience, 52(8), 683.

Podolak, C.J., and Wilcock, P.R. (2009). "The formation and growth of gravel bars in response to increased sediment supply following the Marmot Dam removal", Geological Society of America Abstracts with Programs, Annual Meeting, Portland, OR, 41(7), abstract 2254. 
Poff, N. L., and Hart, D. D. (2002). "How Dams Vary and Why It Matters for the Emerging Science of Dam Removal." Bioscience, 52(8), 659.

Pohl, M. (2004). "Channel Bed Mobility Downstream from the Elwha Dams, Washington*." The Professional Geographer, 56(3), 422.

Pohl, M. M. (2002). "Bringing down our dams: trends in American Dam removal rationales." JAWRA Journal of the American Water Resources Association, 38(6), 1511-1519.

Provence, L. (2006). "Dam Demo: breach at Woolen Mills good for Shad." The Hook.

Randle, T. J. (2003). "Dam Removal and Sediment Management." Dam Removal Research: Status and Prospects.

Randle, T., and Greimann, B. (2006). "Chapter 8: Dam Decommissioning and Sediment Management." Erosion and Sedimentation Manual, US Department of the interior Bureau of Reclamation, Denver Colorado.

Rathburn, S., and Wohl, E. (2003). "Predicting fine sediment dynamics along a pool-riffle mountain channel." Geomorphology, 55(1-4), 111-124.

Reid, I., J. T. Layman, and L. E. Frostick. "The Continuous Measurement Of Bedload Discharge." Journal of Hydraulic Research 18.3 (1980): 243-49. Print.

Rickenmann, D. (2001). "Comparison of bed load transport in torrents and gravel bed streams." Water Resour. Res., 37(12), 3295-3305.

Rickenmann, D. (1991). "Hyperconcentrated flow and sediment transport at steep slopes " Journals of Hydraulic Engineering, 117(11), 1419-1439.

S. Rosen. (2007). "Woolen Mills Dam set for removal." www.dailyprogress.com August 14, 2007.

Salant, N. L., Renshaw, C. E., and Magilligan, F. J. (2006). "Short and long-term changes to bed mobility and bed composition under altered sediment regimes." Geomorphology, 76(1-2), 43-53.

Sawaske,Spencer R., Freyberg, David L. 2012. A comparison of past small dam removals in highly sediment-impacted systems in the U.S., Geomorphology, Volumes 151-152, Pages 50-58.

Schmidt, J. C., and Wilcock, P. R. (2008). "Metrics for assessing the downstream effects of dams." Water Resour. Res., 44.

Schumm, S.A., Mosely, M.P., and Weaver, W.E., 1987, Experimental fluvial geomorphology. John Wiley and Sons, New York, 413 pp. 
Sears, D.A., Damon, W., Booker, D.J. \& Anderson, D.G. (2000) A load cell based continuous recording bedload trap. Earth Surf. Processes and Landforms 25, 659-672.

Sharp, J. J. (1981). Hydraulic Modeling. Buttersworths, London.

Simon, A., Binger, R. L., Langendoen, E. J., and Alonso, C. V. (2002). "Actual and reference sediment yields for the James Creek watershed- Mississippi." Research Report no. 31, U.S. Department of Agricultural, Agricultural Research Service, National Sediment Laboratory, Oxford, $M S$.

Skalak, K., Pizzuto, J., and Hart, D. D. (2009). "Influence of Small Dams on Downstream Channel Characteristics in Pennsylvania and Maryland: Implications for the Long-Term Geomorphic Effects of Dam Removal." J.Am.Water Resour.Assoc., 45(1), 97-109.

Slack, K. (2011). "Battle Brewing over Waynesboro's Rife-Loth Dam." NBC29.

Slagel, M., and Griggs, G. B. (2008). " Cumulative losses of sand to the California coast by dam impoundment, Journal of Coastal Research." Journal of Coastal Research, 24 571-584.

Stampfli, Steve. "White Salmon Restored: A Timelapse Project." White Salmon Restored A Timelapse Project. N.p., n.d. Web. 01 July 2013.

Stanley, E. H., and Doyle, M. W. (2003). "Trading Off: the ecological effects of dam removal." Front. Ecol. Environ., 1(1), 15-22.

Stanley, E. H., and Doyle, M. W. (2002). "A Geomorphic Perspective on Nutrient Retention Following Dam Removal." Bioscience, 52(8), 693.

Stewart, G. 2006. Patterns and processes of sediment transport following sediment-filled dam removal in gravel bed rivers. Ph.D. Dissertation, Oregon State University.

Stillwater Sciences. "Klamath River Dam Removal Study: Sediment Transport DREAM-1 Simulation." Technical Report (2008): 1-73. Web. <http://act.americanrivers.org/site/DocServer/KlamathDamRemSedTranRep2008.pdf?do cID=9121\&JServSessionIda004=745xlngod1 .app257d>.

Thomson, J. R., Hart, D. D., Charles, D. F., Nightengale, T. L., and Winter, D. M. (2005). "Effects of Removal of a Small Dam on Downstream Macroinvertebrate and Algal Assemblages in a Pennsylvania Stream." J.N.Am.Benthol.Soc., 24(1), pp. 192-207.

Toffaleti, F. B. (1969). "Definite computations of sand discharges in rivers." Journal of the Hydraulic Division, ASCE, 95(1), 225-248.

Toffaleti, F. B. (1968). "A procedure for computation of the total river sand discharge and detailed distribution, bed to surface." Technical Report no. 5, Committee on Channel 
Stabilization, U.S. Army Corps of Engineers Waterways Experiment Station, Vicksburg Mississippi.

Tomsic, C. A., Granata, T. C., Murphy, R. P., and Livchak, C. J. (2007). "Using a coupled ecohydrodynamic model to predict habitat for target species following dam removal." Ecol.Eng., 30(3), 215-230.

Vericat, D., and Batalla, R. J. (2005). "Sediment transport in a highly regulated fluvial system during two consecutive floods (lower Ebro River, NE Iberian Peninsula)." Earth Surf.Process.Landforms, 30(4), 385-402.

Vericat, D., Batalla, R. J., and Garcia, C. (2006). "Breakup and reestablishment of the armor layer in a large gravel-bed river below dams: The lower Ebro." Geomorphology, 76(1-2), 122-136.

Wallick, R., Major, J.J., Spicer, K.R., Rhode, A., Keith, M., O’Connor, J.E., Burkholder, B., Grant, G., Tanner, D.Q., and Saunders, D. (2008). "Erosion and redeposition of reservoir sediment in response to removal of Marmot Dam, Sandy River, Oregon", EOS, Transactions of the American Geophysical Union, 89(53), Fall Meeting Supplement, abstract H43B-0995.

Walter, C., and Tullos, D. D. (2010). "Downstream Channel changes after a small dam removal: Using aerial photos and measurement error for context; Calapooia River, Oregon." River Research and Applications, 26 1220-1245.

Walter, R. C., and Merritts, D. J. (2008). "Natural Streams and the Legacy of Water-Powered Mills." Science, 319(5861), 299-304.

Wells, R. R., Langendoen, E. J., and Simon, A. (2007). "Modeling Pre- and Post-Dam Removal Sediment Dynamics: the Kalamazoo River, Michigan." J.Am.Water Resour.Assoc., 43(3), 773-785.

Wilcock, P. R., and Crowe, J. C. (2003). "Surface-base transport model for mixed size sediment." Journal of Hydraulic Engineering, 129(2), 120-128.

Wilcock, P. R., Kenworthy, S. T., and Crowe, J. (2001). "Experimental study of the transport of mixed sand and gravel." Water Resources Research, 37(12), 3349-3358.

Wilcox, A. C., Peckarsky, B. L., Taylor, B. W., and Encalada, A. C. (2008). "Hydraulic and geomorphic effects on mayfly drift in high-gradient streams at moderate discharges ." Ecohydrol., 1 176-186.

Wildman, L. A. S., and MacBroom, J. G. (2005). "The evolution of gravel bed channels after dam removal: Case study of the Anaconda and Union City Dam removals." Geomorphology, 71(1-2), 245-262. 
Williams, G. P., and Wolman, M. G. (1984). " Downstream effects of dams on alluvial rivers." U.S.G.S. Geol. Surv. Prof. Pap., 1286.

Wohl, E. E., and Cenderelli, D. (2000). "Sediment deposition and transport patterns following a reservoir sediment release." Water Resources Research, 36(1), 319-333.

Wood, P. J., and Armitage, P. D. (1997). "Biological Effects of Fine Sediment in the Lotic Environment." Environmental Management, 21(2), 203-217.

Yalin, M. S. (1971). Theory of Hydraulic Models. MacMillan, London.

Yang, C. T., Molinas, A., and Wu, B. (1996). "Sediment Transport in the Yellow River." J. Hydraul. Res., 122(5), 237-244.

Yang, Z., Wang, H., Saito, Y., Milliman, J. D., Xu, K., Qiao, S., and Shi, G. (2006). "Dam impacts on the Changjiang (Yangtze) River sediment discharge to the sea: The past 55 years and after the Three Gorges Dam." Water Resour. Res., 42. 


\section{Appendix A Scaling:}

\section{Froude Numbers:}

Initial flow conditions: Q1: $F r=\frac{U}{\sqrt{g H}}=$

$$
0.2=\frac{U}{\sqrt{(9.81) 0.1}}
$$

$$
\mathrm{U}=0.198 \mathrm{~m} / \mathrm{s} \text { therefore } Q 1=0.0118 \mathrm{cms}
$$

The dam will not be in place during the initial stage of each experiment and the depth will be set at $0.1 \mathrm{~m}$ and exhibit a low flow rate.

High flow conditions: Q3: $F r=\frac{U}{\sqrt{g H}}=0.6=\frac{U}{\sqrt{(9.81) 0.1}}$

$$
\mathrm{U}=0.6 \mathrm{~m} / \mathrm{s} \text { therefore } Q 3=0.036 \mathrm{cms}
$$

Maximum water depth possible in the flume is $0.1 \mathrm{~m}$ with the dam in place, so that is a limiting factor

\section{Field scaling:}

In order to scale to removals in the field, a modification to the Froude number relationship was used. The depth upstream of the dams provided in the literature included a combination of sediment and water. In order to best emulate field conditions (prototype, $p$ ) during a planned removal, the depth in the model $(\mathrm{m})$ includes sediment and water depths.

Low flow conditions: Q2: $\frac{U p}{\sqrt{g H p}}=\frac{U m}{\sqrt{g H m}}=0.034$

$$
\frac{U m}{\sqrt{g(H m s+H m w)}}=\frac{U p}{\sqrt{g(H p s+H p w)}}=0.034
$$

Where $\mathrm{H}_{\mathrm{ms}}$ is the height of the model sediment, $\mathrm{H}_{\mathrm{mw}}$ is the height of the model water, $\mathrm{H}_{\mathrm{ps}}$ is the height of the prototype sediment and $\mathrm{H}_{\mathrm{pw}}$ is the height of the prototype water. From 26 case studies, the average value for this parameter is 0.034 .

The sediment depth upstream of the dam will be $0.225 \mathrm{~m}$ ( $75 \%$ of the dam height) and the water will be overtopping the $0.3 \mathrm{~m}$ dam, so a water depth of $0.1 \mathrm{~m}$ is realistic. Inputting these values:

$$
\frac{U m}{\sqrt{9.81(0.22+0.1)}}=0.034
$$

Solving for $\mathrm{U}_{\mathrm{m}}: \mathrm{U}_{\mathrm{m}}=0.06024 \mathrm{~m} / \mathrm{s}$ and $\mathrm{Q} 2=0.0116 \mathrm{cms}$. 


\section{Reynolds Number:}

Verifying that the Reynolds number will be reasonably large:

$\mathrm{Q} 1: R e=\frac{4 U R}{v}=\frac{4\left(0.198 \frac{\mathrm{m}}{\mathrm{s}}\right)((0.6 * 0.1) /(0.6+(2 * 0.1))}{10^{-6} \mathrm{~m} 2 / \mathrm{s}}=97044.32$

$\mathrm{Q} 2: R e=\frac{4 U R}{v}=\frac{4\left(0.06 \frac{\mathrm{m}}{\mathrm{s}}\right)((0.6 * 0.32) /(0.6+(2 * 0.32))}{10^{-6} \mathrm{~m} 2 / \mathrm{s}}=37310.23$

$\mathrm{Q} 3: R e=\frac{4 U R}{v}=\frac{4\left(0.594 \frac{\mathrm{m}}{\mathrm{s}}\right)((0.6 * 0.1) /(0.6+(2 * 0.1))}{10^{-6} \mathrm{~m} 2 / \mathrm{s}}=178281.8$

\section{Critical water depth:}

Q1: $\mathrm{y}_{\mathrm{c}}=\sqrt[3]{\frac{q^{2}}{g}}=0.0342 \mathrm{~m}<0.1 \mathrm{~m}$ Subcritical

Q2: $\mathrm{y}_{\mathrm{c}}=\sqrt[3]{\frac{q^{2}}{g}}=0.0338 \mathrm{~m}<0.1 \mathrm{~m}$ Subcritical

Q3: $\mathrm{y}_{\mathrm{c}}=\sqrt[3]{\frac{q^{2}}{g}}=0.072 \mathrm{~m}<0.1 \mathrm{~m}$ Subcritical

\section{Appendix B: Flume step by step guide}

Flume step by step guide

\section{Pre-Removal}

1. Make sure the bed is well mixed

2. Take grab samples from the upstream, middle and downstream reaches and Run GSD on them to ensure that the grain sizes are constant between Runs and align with those in the proposal

3. Run water over the bed for approx. 10 hours to replicate a natural channel bed. Set the flume to $10 \mathrm{hz}$ for this portion to minimize erosion of the sediment during this step

4. Ensure there is no longer sediment in motion and turn the flume off

5. Put dam pieces in place 
6. Create the reservoir sediment using additional material composed of the same GSD as the bed

7. Run water again to simulate pre removal conditions

8. Preform a laser scan of the channel bed

a. Cosmos: wizard-identify motors set 11000 steps 5 steps per second on motor 3 for the length of the flume and 41500 steps and 2000 steps per second on motor 1 to traverse the flume (for a total of 5 scans)

b. Labview: Program name $\mathrm{XXXX}$ in block diagram reassign saving location

c. Run scan 5 times and ensure that the cart does not get stuck

d. Start the scan in the sediment trap above the plexi-glass piece holding the bed back.

9. Run a camera scan of the bed

a. Remove the micro epsilon

b. Install the camera to the rod on the cart

c. Run the panorama labview program with the carts initial position at the upstream end of the flume.

d. Walk along with the camera, taking pictures every time the cart stops moving (approx. every $5 \mathrm{~cm}$ )

e. Download the images from the camera into the computer and save them in the appropriate Run, Part file

f. Run ptgui

g. Import the images from the appropriate file location

h. Crop the images so the metal cart piece does not remain 
i. Click align images

j. Click image optimizer

k. Create panorama

\section{Part 1:}

1. Set up ceiling cam

a. Make sure camera is plugged into a power source and the Ethernet cable is attached from the camera to the big computer

b. Pylon ip address configure, temp assign ip address

c. National instruments icon on the desktop- click grab or snap to acquire images

d. If the connection is working, have one person on the ladder adjusting the camera to ensure that the entire flume is visible and aligned in the view field

e. Open labview: snapgrab.vi

f. Make sure to reassign the location where the images are being saved

2. Set up video camera

a. Make sure that the battery is charged and the tape is re-winded back to the beginning of the roll

b. Set up on the side of the flume closest to the outside door with visibility of both the reservoir area and the section immediately downstream of the dam

3. Transducers

a. Open signal express 2010: transducers

b. In the edit feature, reassign the location of where the files are being saved to

c. Click Run and note the start time of the transducers so the amount of time prior to removal can be noted in the data set (and potentially deleted)

4. Start the video camera 
5. Carefully remove the first piece of plexiglass, while one person hits Run on the labview program for the overhead camera

6. Grab samples must be collected every 2 minutes in the downstream end and every 5 minutes in the upstream end in the appropriately labeled bottles

7. Meanwhile, a second person must continuously be noting time and bed elevations every 3 minutes in the channel, and water elevation levels every 6 minutes.

8. Still camera photos must be taken of the area by the dam as well as the sediment trap as the experiment is going on.

9. After about 10 minutes, go into the ceiling camera program and click stop on the first Partto switch over to a higher delay in-between photos.

10. After 30 minutes, stop the water and let it drain

11. Turn off the video camera

12. Stop the transducers program in signal express

13. Stop the ceiling camera

14. Still photos must be taken after the flume has drained of the area near the dam and the sediment trap as well as a color shot of the entire length of the flume

15. Preform a laser scan of the channel bed

a. Cosmos: wizard-identify motors set 11000 steps 5 steps per second on motor 3 for the length of the flume and 41500 steps and 2000 steps per second on motor 1 to traverse the flume (for a total of 5 scans)

b. Labview: Program name $\mathrm{XXXX}$ in block diagram reassign saving location

c. Run scan 5 times and ensure that the cart does not get stuck (around 45 minutes-1 hour per scan) 
d. Start the scan in the sediment trap above the plexi-glass piece holding the bed back.

16. Run a camera scan of the bed

a. Remove the micro epsilon

b. Install the camera to the rod on the cart

c. Run the panorama labview program with the carts initial position at the upstream end of the flume.

d. Walk along with the camera, taking pictures every time the cart stops moving (approx. every $5 \mathrm{~cm}$ ) (takes around an hour)

e. Download the images from the camera into the computer and save them in the appropriate Run, Partfile

f. Run ptgui

g. Import the images from the appropriate file location

h. Crop the images so the metal cart piece does not remain

i. Click align images

j. Click image optimizer

k. Create panorama

17. While the scan is Running, download the video onto JCCs laptop

a. It make take several tries as the computer often overheats, rename each additional file using letters

b. Upload it to drop box and download it into the appropriate folder on the big computer 
18. Download the stills from the camera into the appropriate files on the big computer. Put into a summary sheet with captions while the details are still fresh

19. Run suspended sediment samples

a. Mark the bottles with water locations (R1P1: Run1Part 1)

b. Write identifiable notation on the porous paper (R1P1 5u/s: Run1Part 1 at 5 min in the upstream location)

c. Shake up the bottles and start pouring them onto the paper

d. Once the paper is wet, turn on the vacuum pump

e. Empty the entire sample with care not to over top the funnel, making sure no sediment is left on the sides

f. Turn off the vacuum pump

g. Remove the paper and put it on an old sieve to dry

h. After it is dry, get the weight of the filter paper using a high accuracy scale

i. Meanwhile, find the total volume of the sample using the marks on the bottle

j. Record all of this data into excel

k. Create a graph of the upstream and downstream suspended sediment amounts

20. Remove all of the sediment from the sediment trap

a. Collect the wet weight of the total sediment that was present

b. From that, take a grab sample and collect the initial wet weight of that

c. Put the sub sample in the oven

d. When it is dry, remove and write down the dry weight

e. Run the sediment through the sieve stack to identify the GSD of the sediment that was in the trap for that Run 


\section{Bed elevations}

a. Input the bed elevation data into excel

b. Create a graph of the information

REPEAT FOR PARTS 2, 3 AND 4

\section{Appendix C: Bedload Monitoring}

Load cells and pressure pillows have been used to measure bedload transport rates in the field. Reid bed load samplers are a common method of monitoring bedload transport rates in an active stream channel using pressure pillows. To install a pressure pillow system, a large precast liner is placed in the channel to maintain the streambed excavation and an inner box is installed within the larger liner and is loosely constrained by shimmed nylon Runners (Reid, 1980). The inner box rides on vulcanized water filled rubber pressure pillows that respond to the combined and changing mass of the trapped sediment and the water column (Reid, 1980). The hydraulic pressure is transmitted through a small bore neoprene tubing to an external pressure bulb transducer connected to a mechanical chart recorder (Reid 1980). The pressure changes associated with the changing water levels in the stream were accounted for using a synchronous record of stream water stage and later using a pressure transducer (Reid, 1980; Harris and Richards, 1995). The Reid bedload sampler system was modified over time to use an electrical analogue transducer with output recorded on a scientific datalogger instead of a mechanical chart reader which allows for the data to be collected at continuous measurements as fine as one second and also to be downloaded to a laptop for immediate analysis (Harris and Richards 1995, Garcia, Laronne, Sala, 2000). Other modifications include using a stilling well with a water stage sensor to continuously monitor water depth (Garcia, Laronne, Sala, 2000). 
A modified pressure pillow system was chosen over the load cells since, in addition to the huge expense associated with load cells (and we would need 3-4 per 1 meter section), they are very sensitive to balanced load and since the sediment is not necessarily being distributed evenly when it is in motion after a dam removal. Previous experiments had mentioned issues with uniformity and sealing within the pressure pillows. Harris and Richards (1995) noted the importance of taking extra care when filling the pillow with water to exclude air bubbles, which could lead to hysteresis in the pressure response since air is taken into solution under pressure. To avoid this we used manufactured bike tire tubes and filled them with water to avoid buoyancy issues as well as to increase strength. The valve of the bike tube was then attached to a thin plastic tube Running the length of the flume attached to a pressure gage. This gage was attached to a data acquisition system and data was continuously recorded using National Instruments Signal Express program.

The benefits of using a pressure pillow and transducer system are that the neoprene pillows rarely puncture, the response is linear (when the water fill does not contain much soluble gas) and standard errors of estimates of bedload are typically $+/-0.3 \mathrm{~kg}$ for small samplers (Laronne, Alexabdrov, Bergman, Cohen). Several problems with the pressure pillow and transducers systems have been reported. To minimize the presence of air in the water within the pressure system, it is important to place the transducers at the same level as the pressure pillows, as well as to bleed them regularly via a valve or through the use of a bubble trap (Sear, 2000, Laronne, Alexabdrov, Bergman, Cohen). Careful design of the overlaying material must be taken, as well as extra care while unloading the sediment to prevent the puncturing of the pressure pillows (Sear, 2000). Regular calibrations are imperative to minimize unstable pillow calibration (Sear, 2000). The system that I developed in the Sustainable Rivers Lab was 
calibrated three times, before each of the sediment types. Thermal drift in the transducer and electrical system must also be avoided (Sear, 2000). To avoid this, the temperature in the lab was kept consistent throughout all of the Runs.

\section{Calibrating the transducers:}

The transducers were calibrated before each new sediment type for a total of three calibrations.

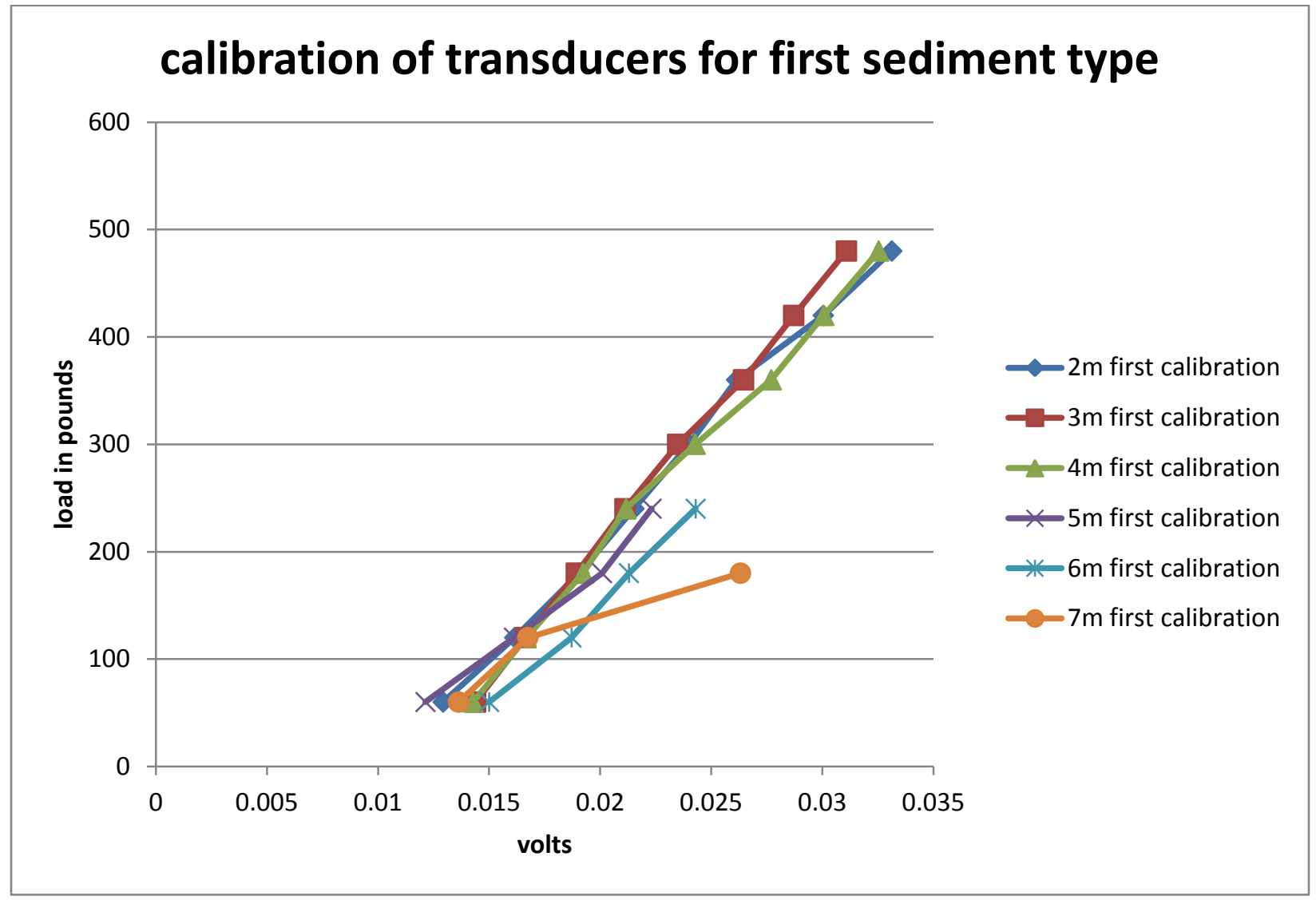

Line of best fit first calibration:

2m: $y=12393 x-219.25$ r2 $=0.9957$

3m: $y=24896 x-292.64$ r2 $=0.9988$

$4 m: y=22488 x-252.62 \quad r 2=0.9966$ 
5m: $y=17131 x-152.57 \mathrm{r} 2=0.9849$

6m: $y=19586 x-238.32 \mathrm{r} 2=0.9947$

7m: $8705.7 \mathrm{x}-44.479 \mathrm{r} 2=0.9206$

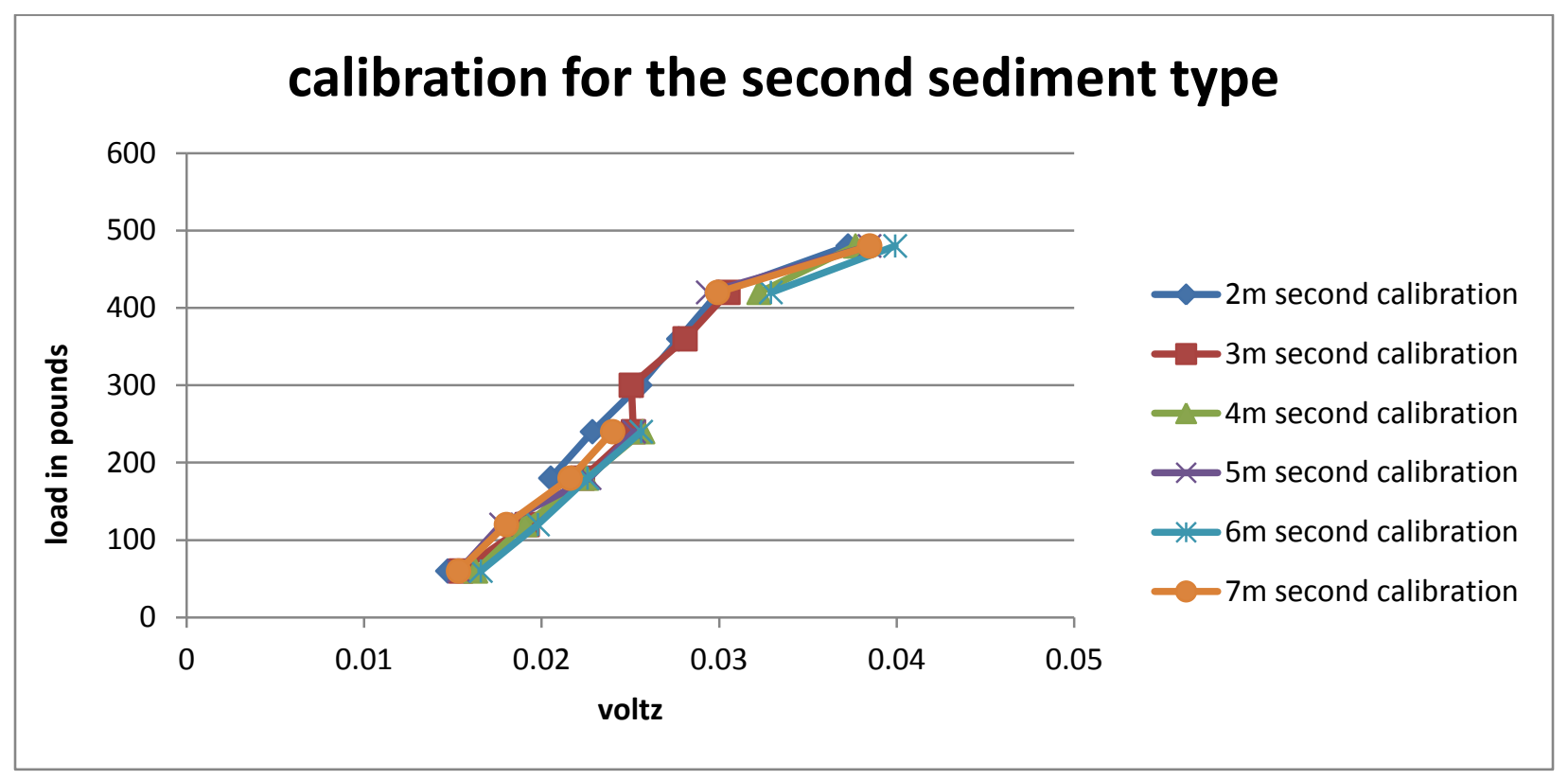

Lines of best fit for the second sediment type:

$2 \mathrm{~m}: \mathrm{y}=19691 \mathrm{x}-210.83 \mathrm{r} 2=0.9626$

$3 \mathrm{~m}: \mathrm{y}=24667 \mathrm{x}-343.94 \mathrm{r} 2=0.9643$

4m: $y=20490 x-274.14 r 2=0.9881$

5m: $y=19268 x-227.76 r 2=0.9346$

6m: $y=18976 x-247.72 r 2=0.9796$

7m: $y=19269 x-223.08 \mathrm{r} 2=0.9552$ 


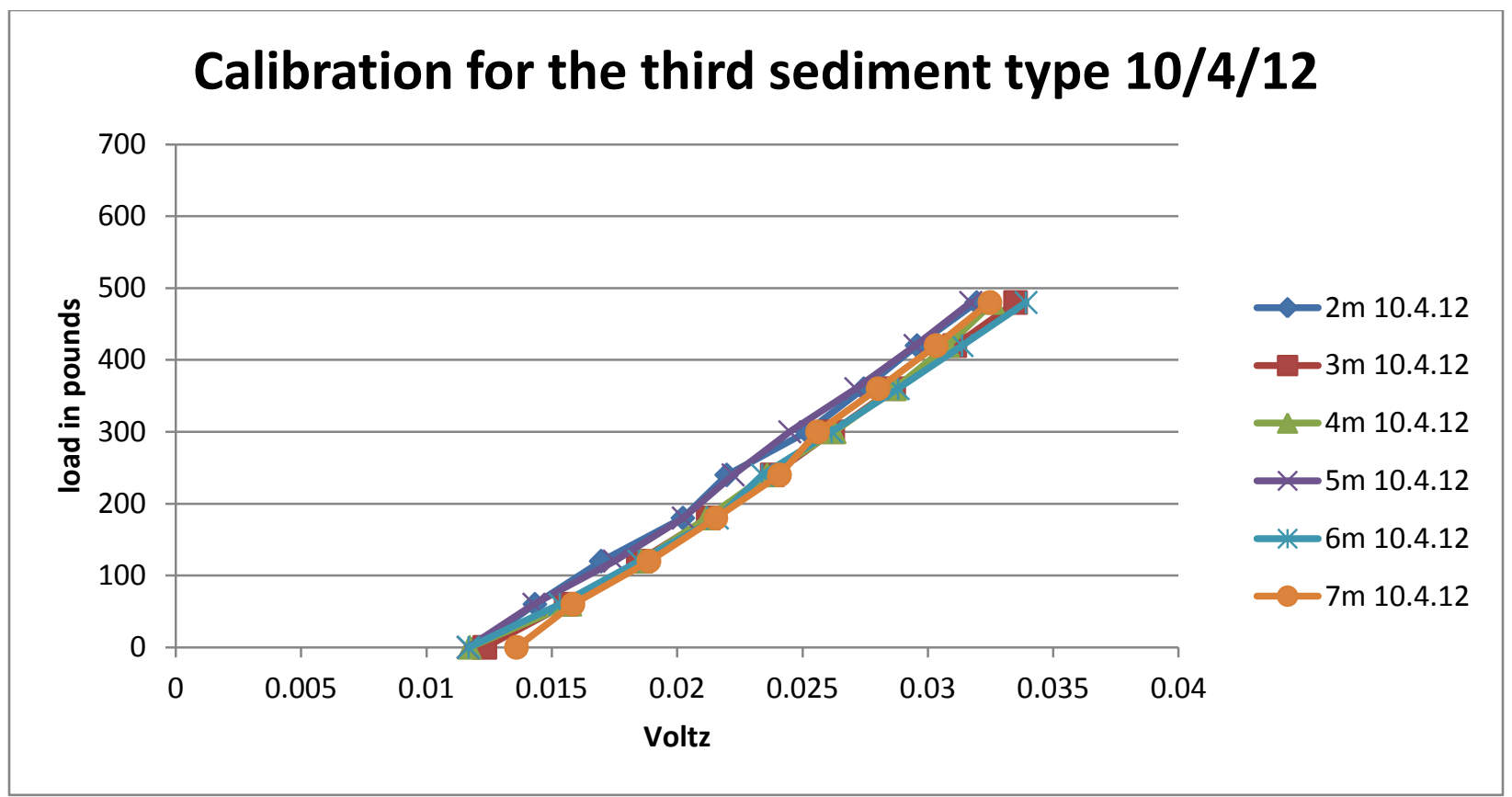

Line of best fit for the third set of calibrations:

2m: $\mathrm{y}=23677 \mathrm{x}-284.99 \mathrm{r} 2=0.9976$

$3 \mathrm{~m}: \mathrm{y}=22945 \mathrm{x}-297.39 \mathrm{r} 2=0.9976$

4m: $y=23179 x-298.48$ r2 $=0.9917$

5m: $y=24040 x-290.86$ r2 $=0.9972$

6m: $y=22082 x-276.96$ r $2=0.9955$

7m: $y=25372 x-352.99$ r2 $=0.9961$

\section{On the computer:}

Click start button go up to labview signal express 2010 click it, be patient it takes a bit to open in signal express click open->computer->OS(C:)->kristen->transducer

On the top bar in signal express there are several tabs, click on the "step setup" tab on the left hand side of the signal express screen there are 4 boxes that say "save to ASCII/LVM" you will need to click on each of those boxes to rename the saving location to do this, click on the "save to ASCII/LVM" button and change the export file path to c: lkristenlcalibratingtransducerlxxx the file path will be the same for all four save locations 
under the same load (so if you have 400 pounds on $3 \mathrm{~m}$, you will change all of the export path names to c: Kristenlcalibratingtransducer 400 poundson $3 \mathrm{~m}$ and then a description about which of the files it will be. I can't get on to see exactly what I was naming them but in the mean file it would make sense to name it c: lkristenlcalibratingtransducer 400 poundson 3 mmean and the filtered mean could be c: kristenlcalibratingtransducer 400 poundson3mfilteredmean. Just keep it simple and logical and write notes as you go through if you think it will be confusing.

once all of the saved locations have been fixed, put the weights in place and click the Run button on the top toolbar. Let it Run for about a minute or two without any adjustments to the weight stack and then click the stop button.

Rename the file location and then repeat.

\section{Appendix D: Laser scans}

Laser scans all Runs using Pre-Removal terrains for all remaining parts Run 1

$$
\begin{aligned}
& \text { cievauu! } \\
& 325.145-342.018 \\
& 310.925-325.145 \\
& 289.29-310.925 \\
& \text { 마. } 268.43-289.29 \\
& \text { - } 260.265-268.43 \\
& \text { - } 254.679-260.265 \\
& \text { - } 251.325-254.679 \\
& \text { - } 248.289-251.325 \\
& \text { - } 246.158-248.289 \\
& \text { - } 244.31-246.158 \\
& \text { - } 242.479-244.31 \\
& 240.749-242.479 \\
& \text { - 239.248- } 240.749 \\
& \text { - } 237.882-239.248 \\
& \text { - } 236.464-237.882 \\
& \text { D } 234.796-236.464 \\
& 232.78-234.796 \\
& 230.63-232.78 \\
& \text { - } 228.501-230.63 \\
& \text { - } 226.367-228.501 \\
& \text { - } 223.993-226.367 \\
& \text { - } 221.194-223.993 \\
& \text { - 217.904- } 221.194 \\
& \text { 무 } 214.062-217.904 \\
& \text { - } 210.369-214.062 \\
& \text { - } 207.023-210.369 \\
& \text { 203.633-207.023 } \\
& 199.716-203.633 \\
& 193.049-199.716 \\
& 178.784-193.049 \\
& \text { - } 133.417-178.784 \\
& 106.87-133.417
\end{aligned}
$$


Pre-Removal



Part 1

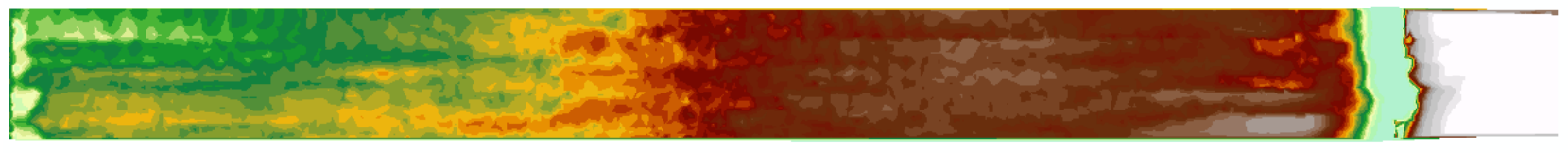

Part 2

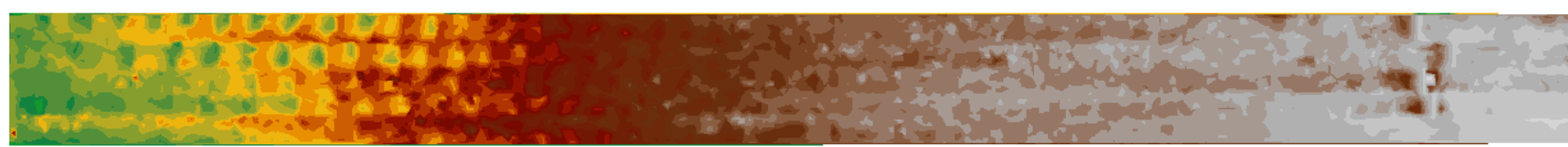

Part 4



Run 2

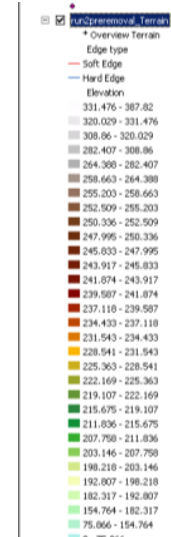

Pre-Removal:



Part 1 


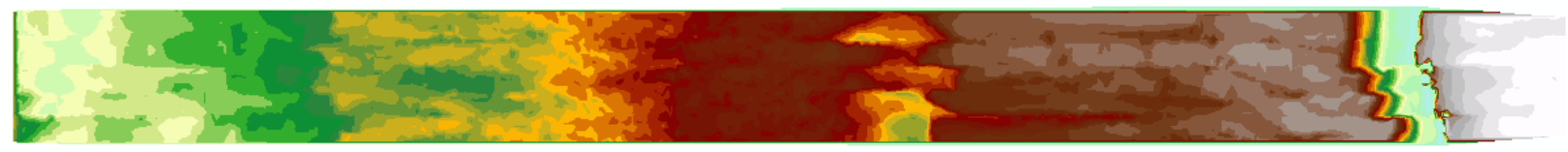

Part 2

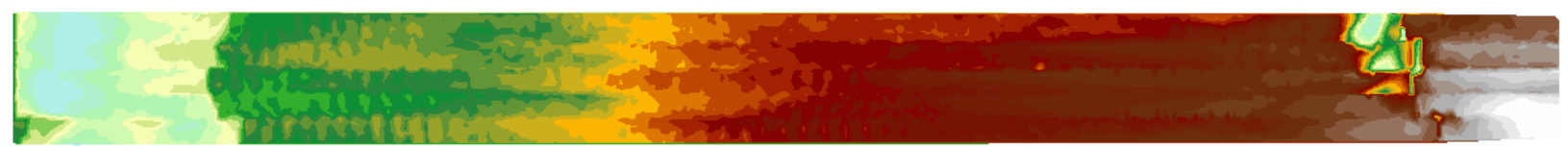

Part 3

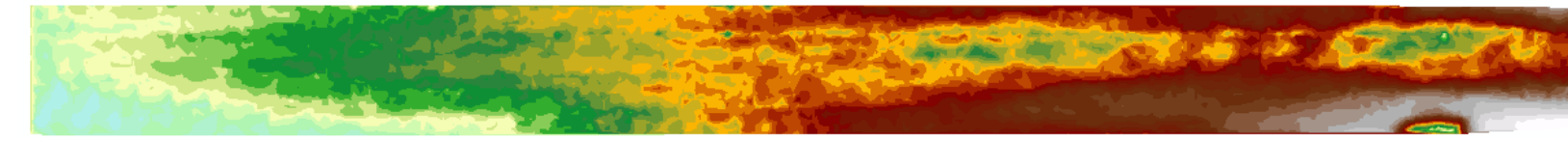

Part 4

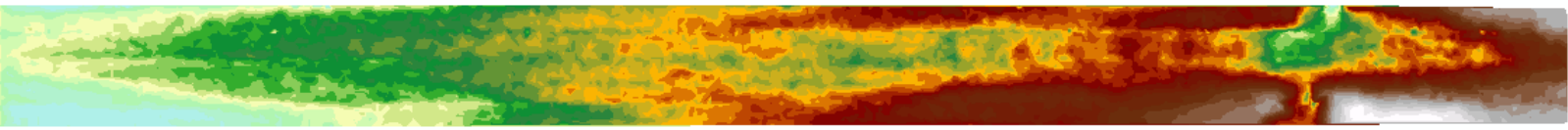

Run 3

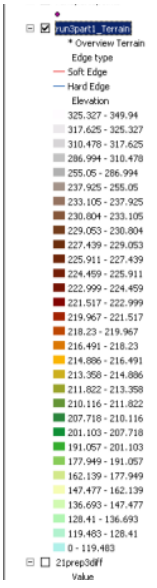

Part 1:
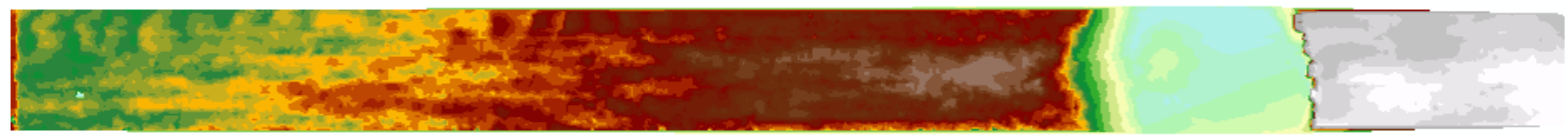

Part 2:

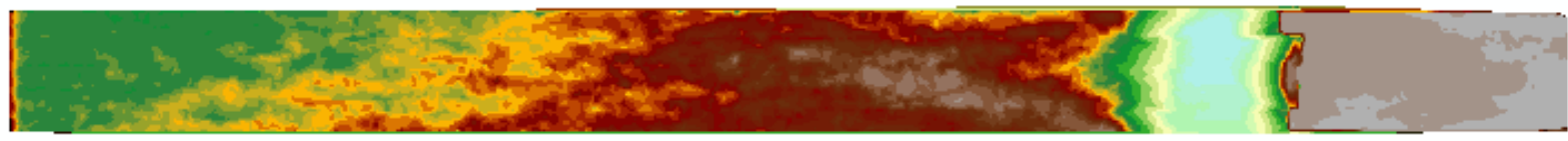

Part 3:

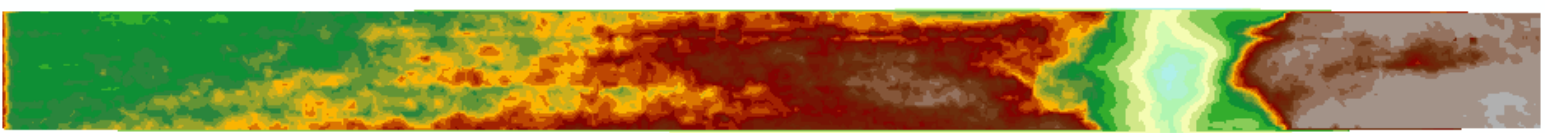

Part 4:

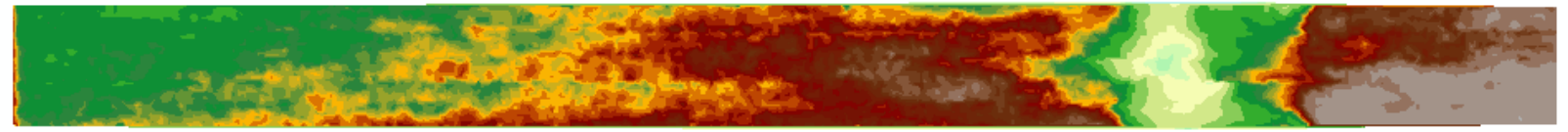




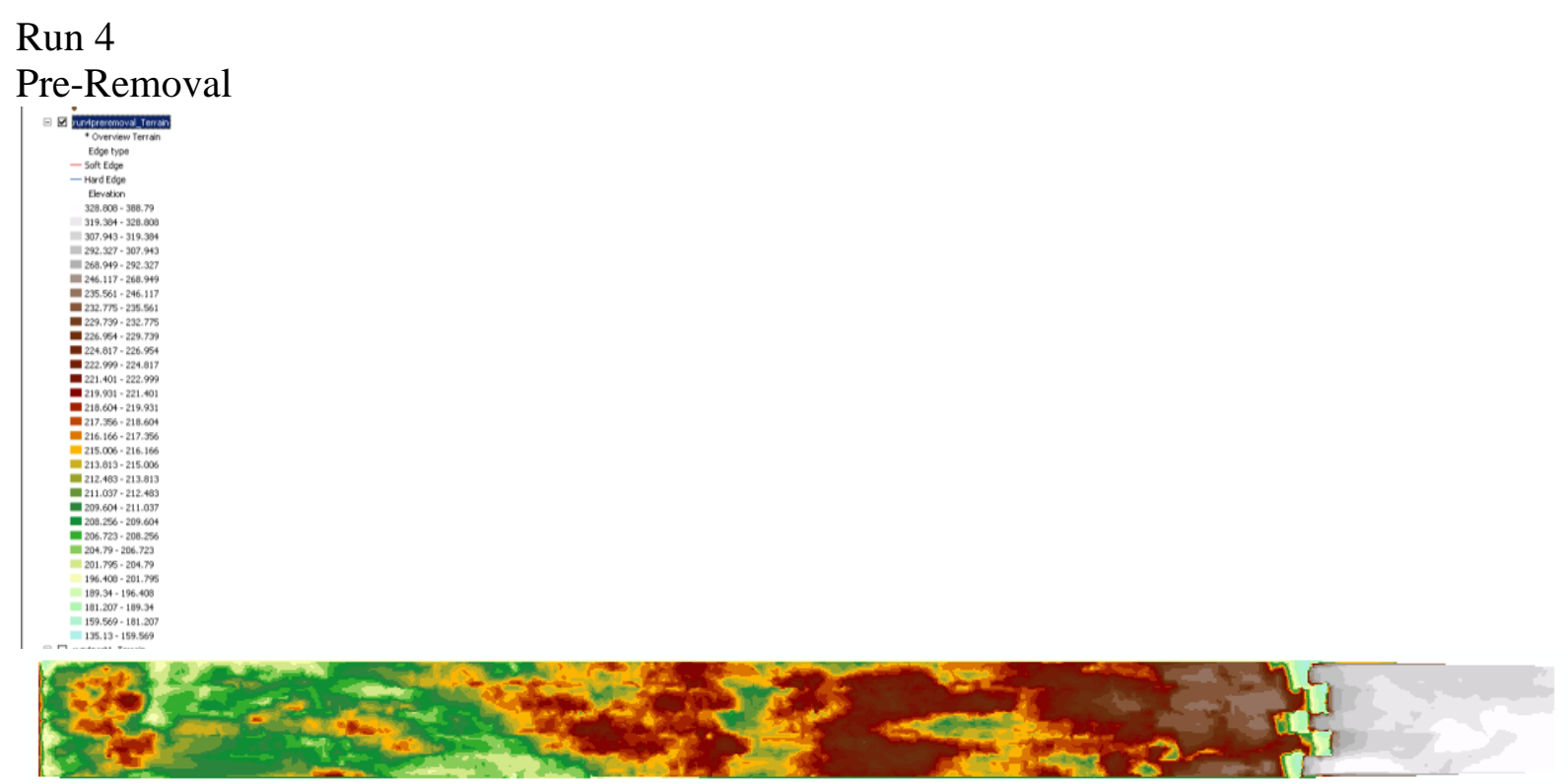

Part 1

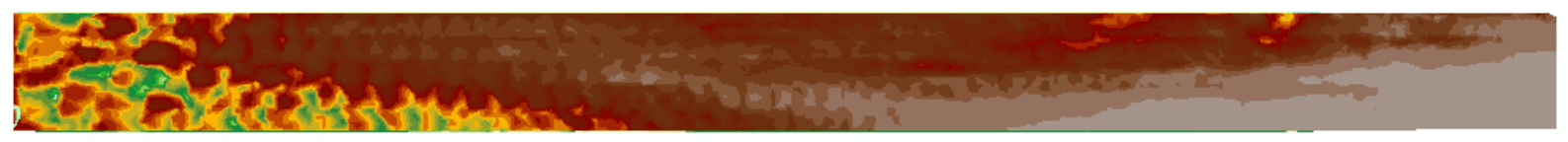

Run 5

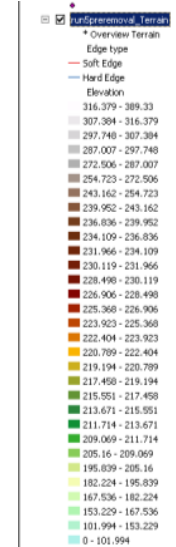

Pre-Removal:

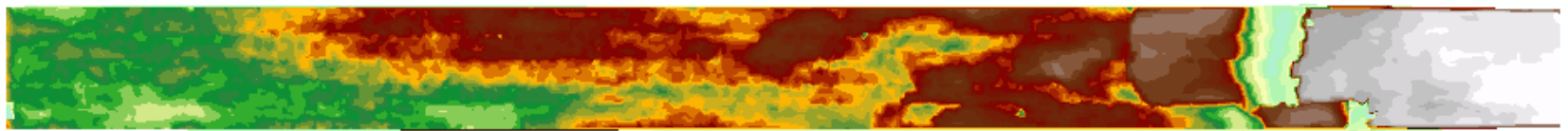

Part 1

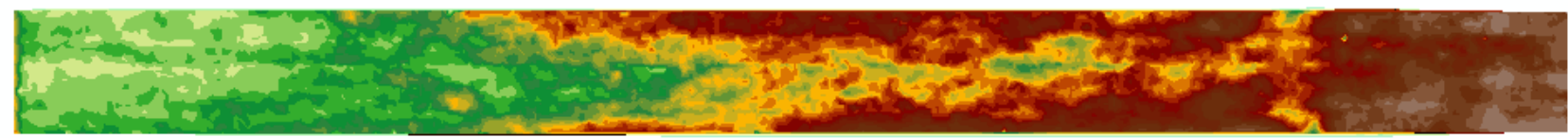

Run 6 


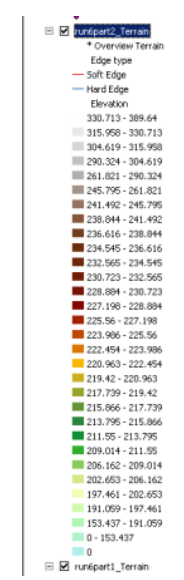

Pre-Removal

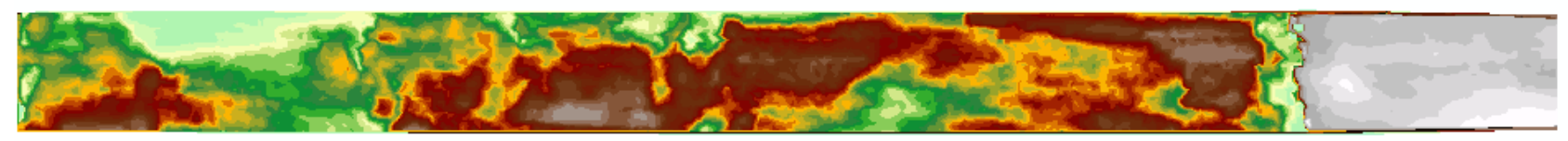

Part 1

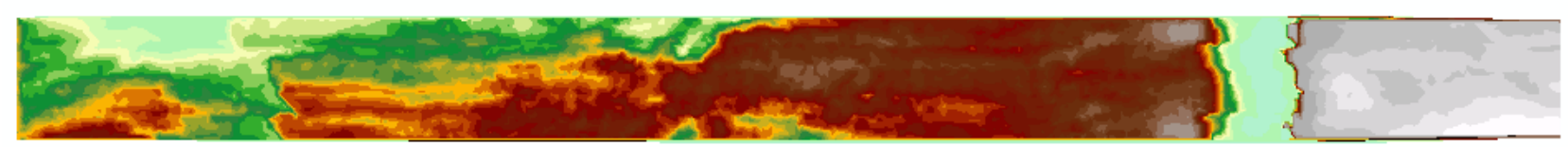

Part 2

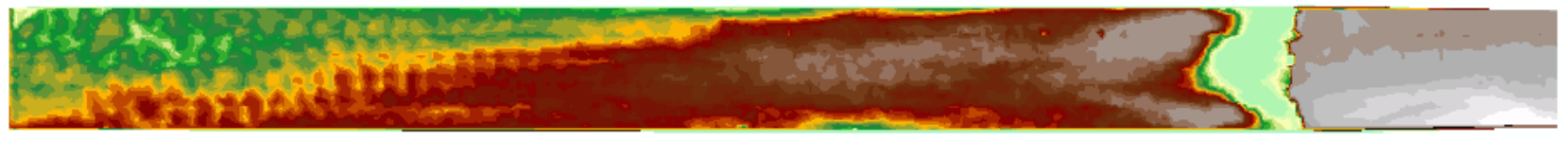

Part 3



Part 4

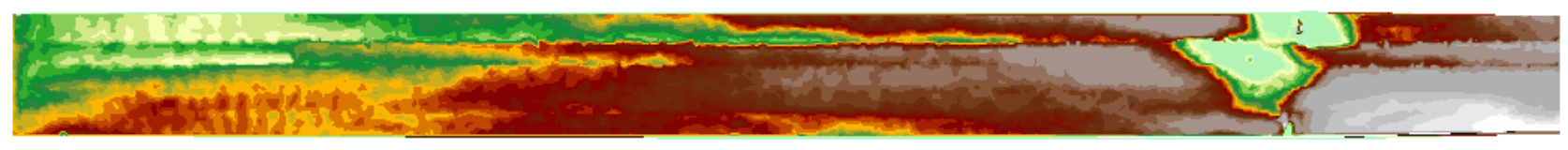

Run 7

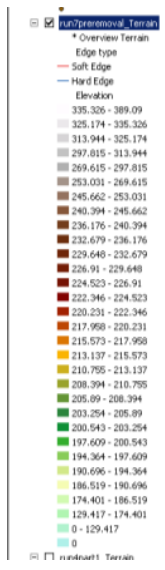


Pre-Removal

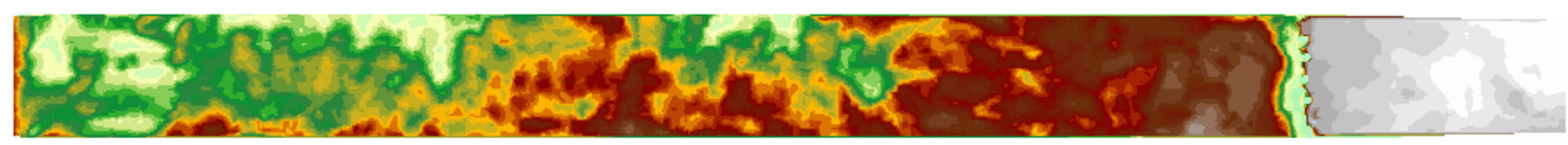

Part 1

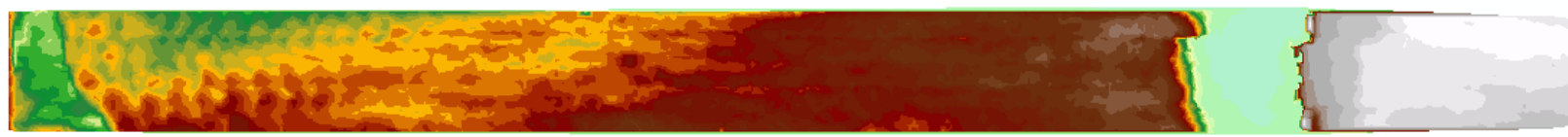

Part 2

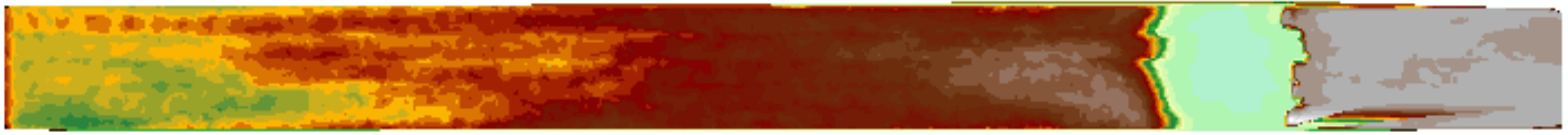

Part 3

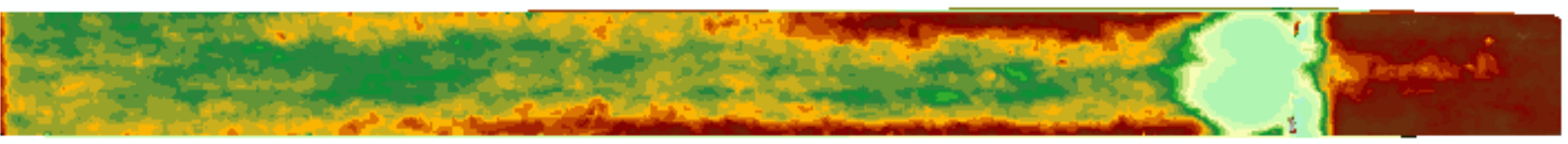

Part 4

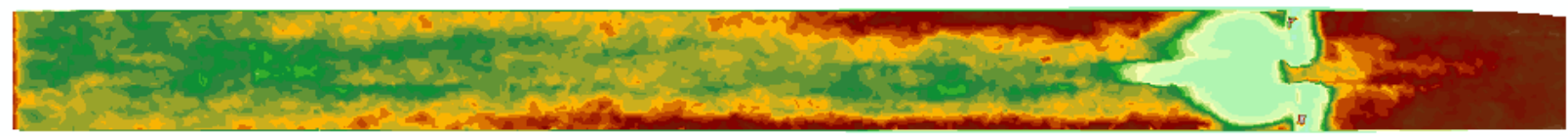

Run 8

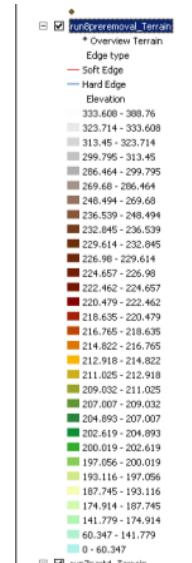

Pre-Removal

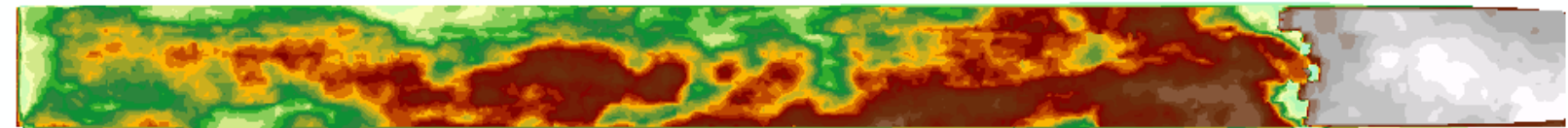

Part 1

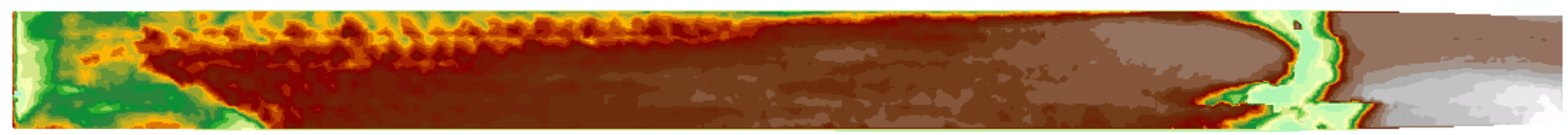

Part 2 


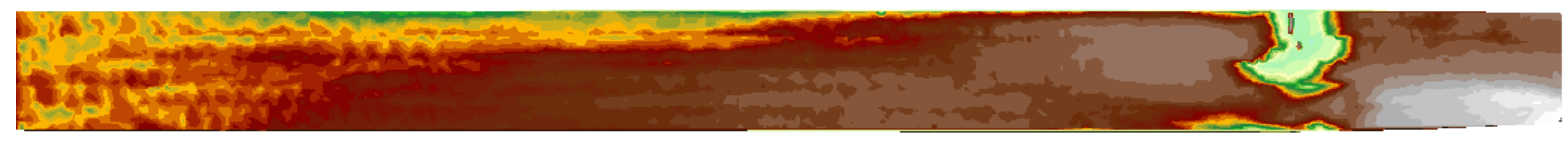

Part 3

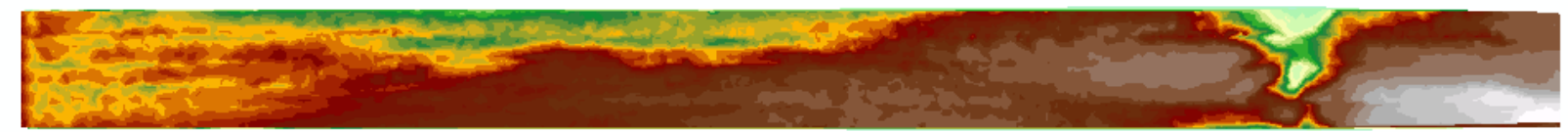

Run 9

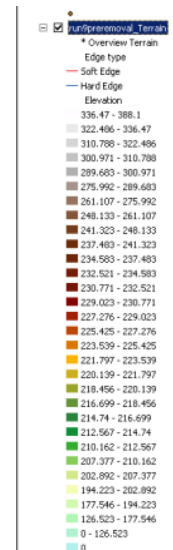

Pre-Removal



Part 1

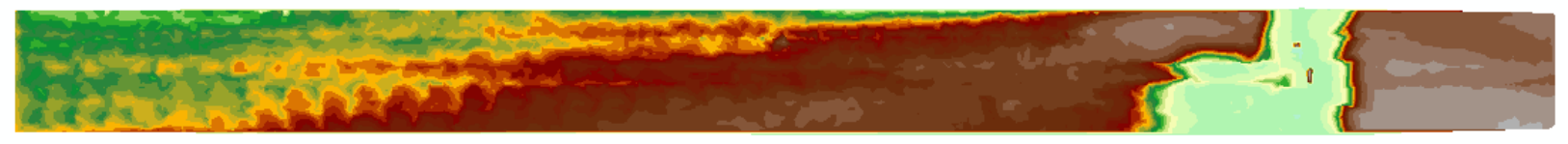

Part 2



Part 3

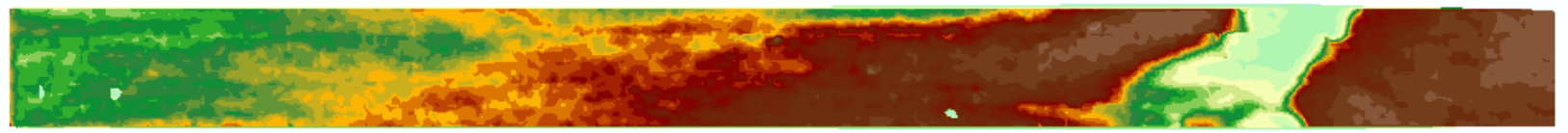

Run 10 


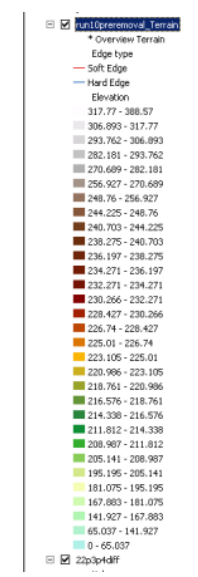

Pre-Removal

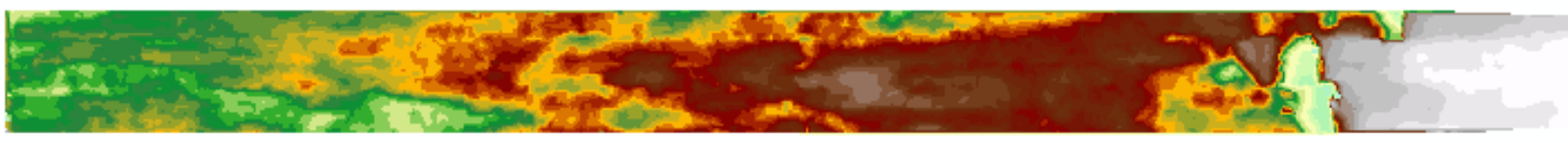

Part 1

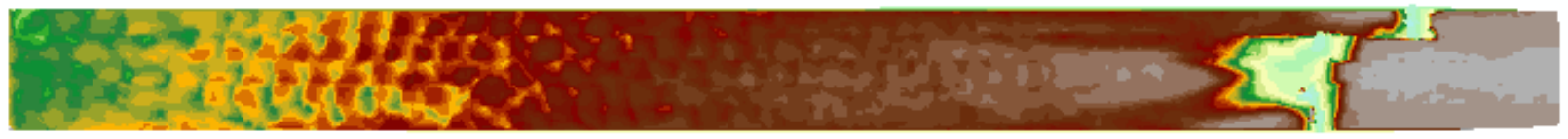

Part 2

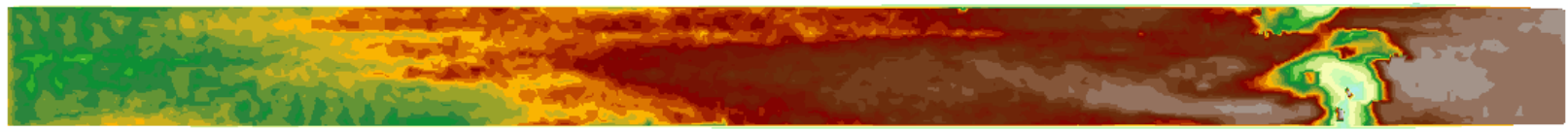

Part 3

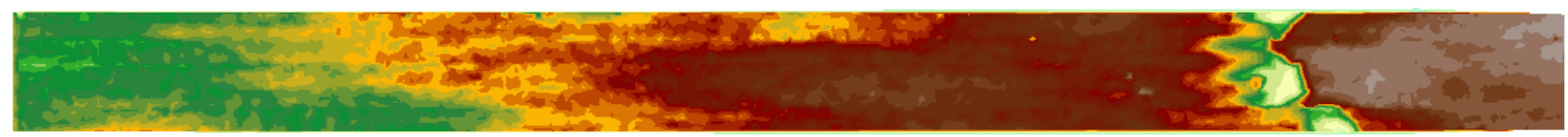

Run 11

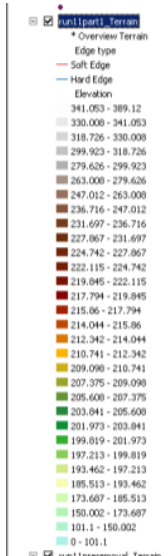

Pre-Removal

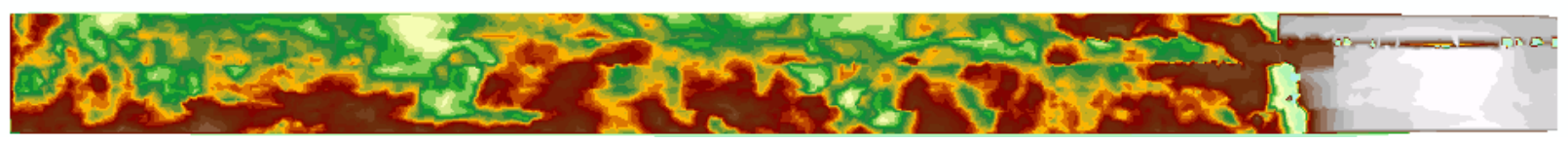

Part 1 


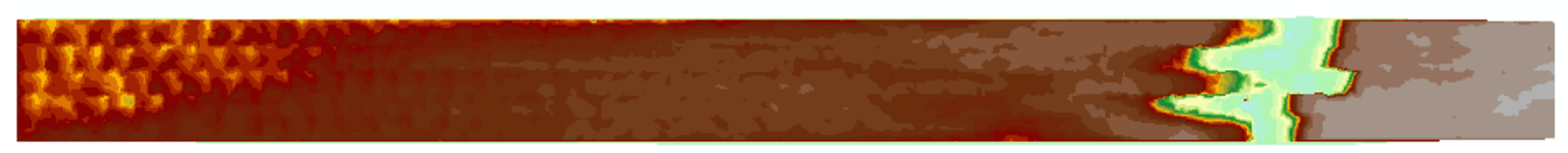

Part 2

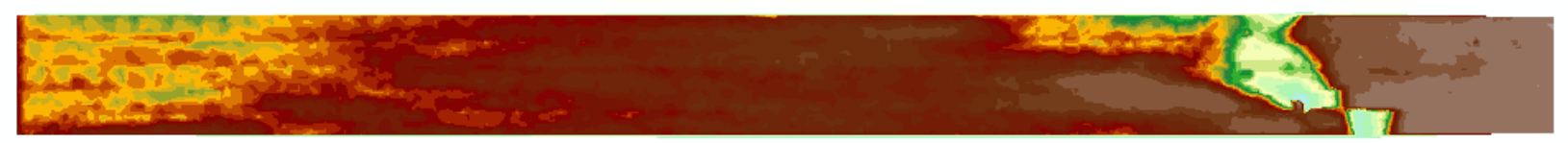

Part 3



Run 12



Pre-Removal:

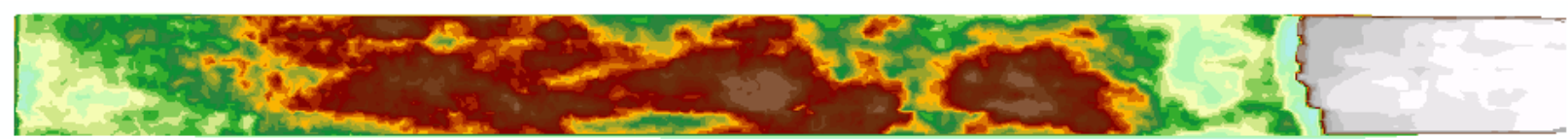

Part 1



Part 2



Part 3



Part 4




Run 13: high horizontal removal, not Run through all parts

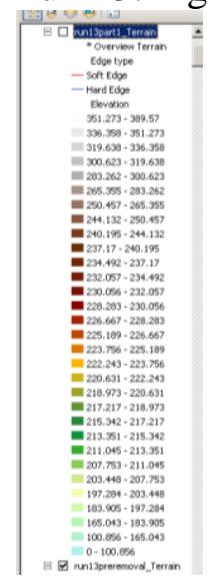

Run 13 Pre-Removal

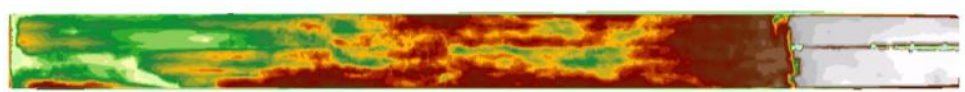

Run 13 Part 1



Run 14

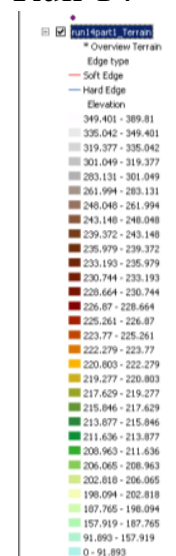

Pre-Removal



Part 1

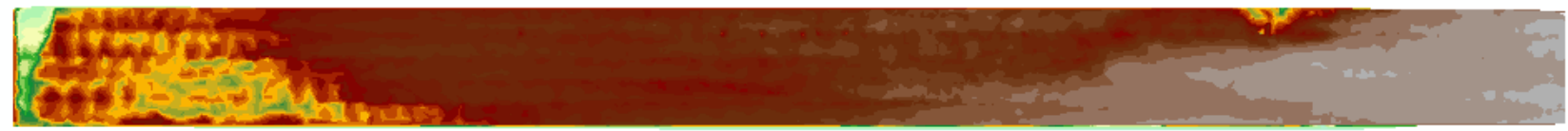

Run 15 


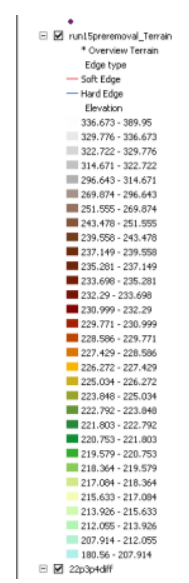

Pre-Removal:

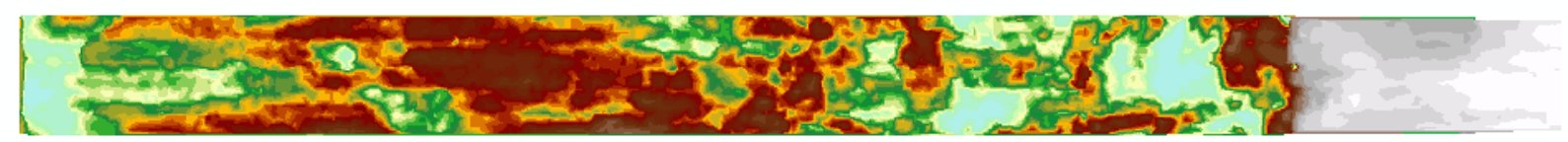

Part 1

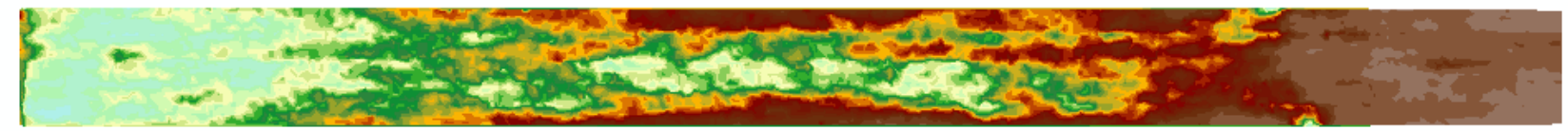

Run 16

Pre-Removal:

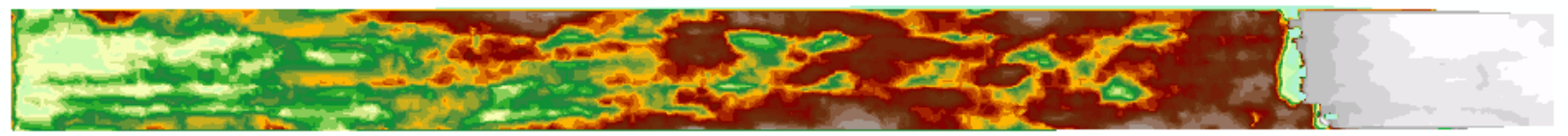

Part 1

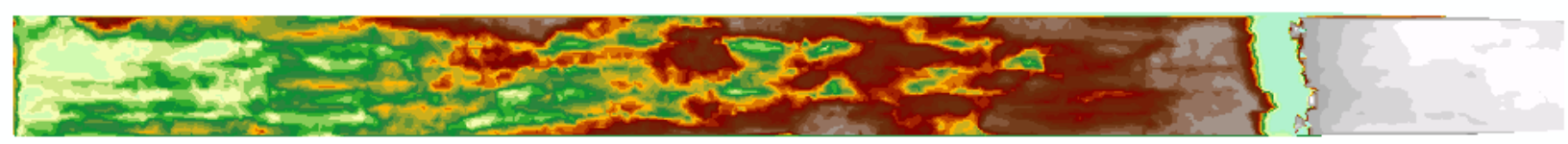

Part 2



Part 3

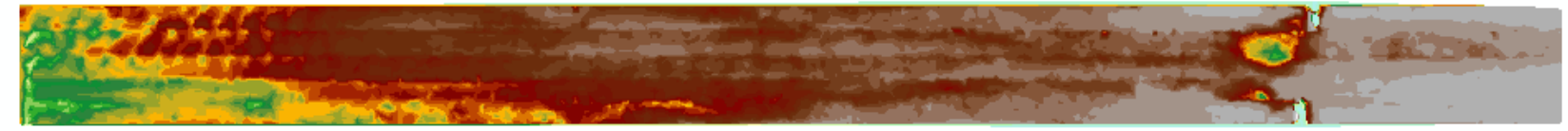

Part 4

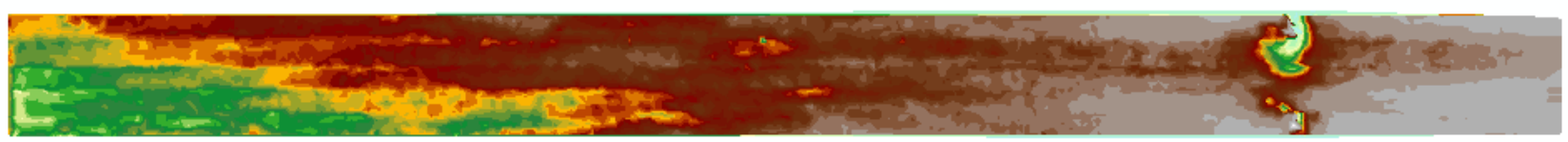

Run 17 


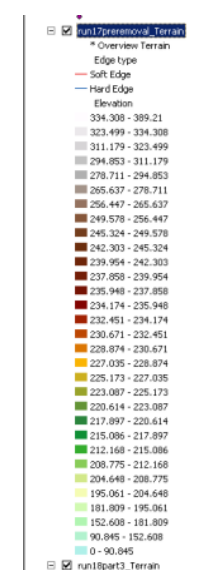

Pre-Removal

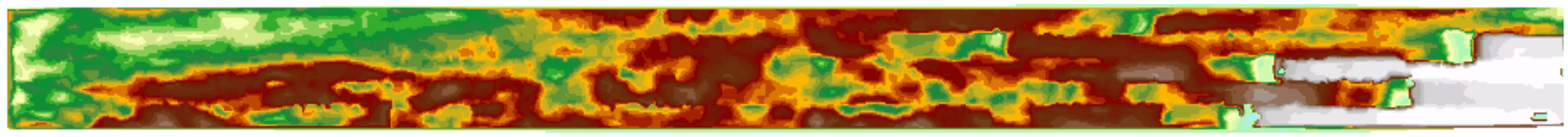

\section{Part 1}

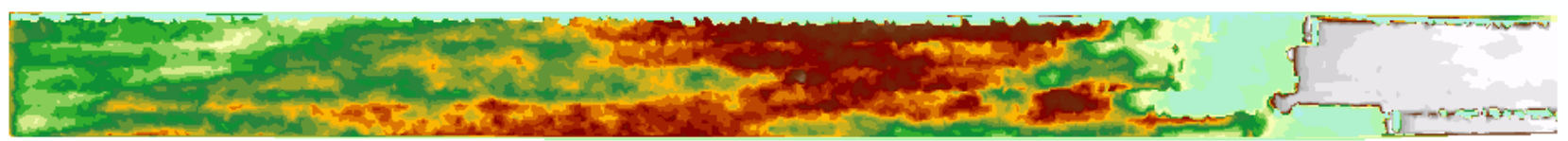

\section{Run 18}



Pre-Removal

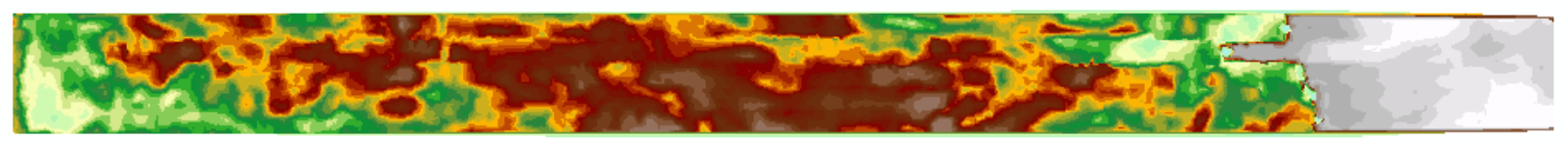

Part 1



Part 2

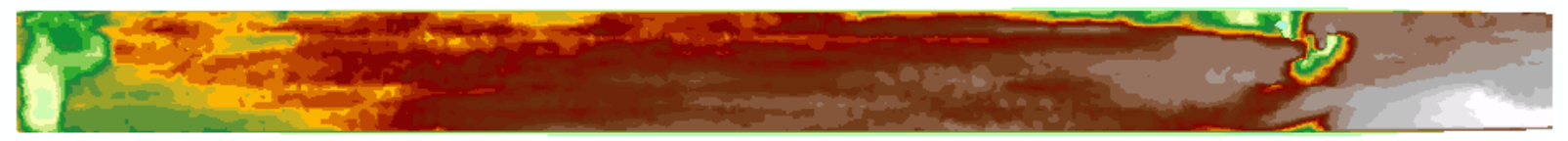


Part 3
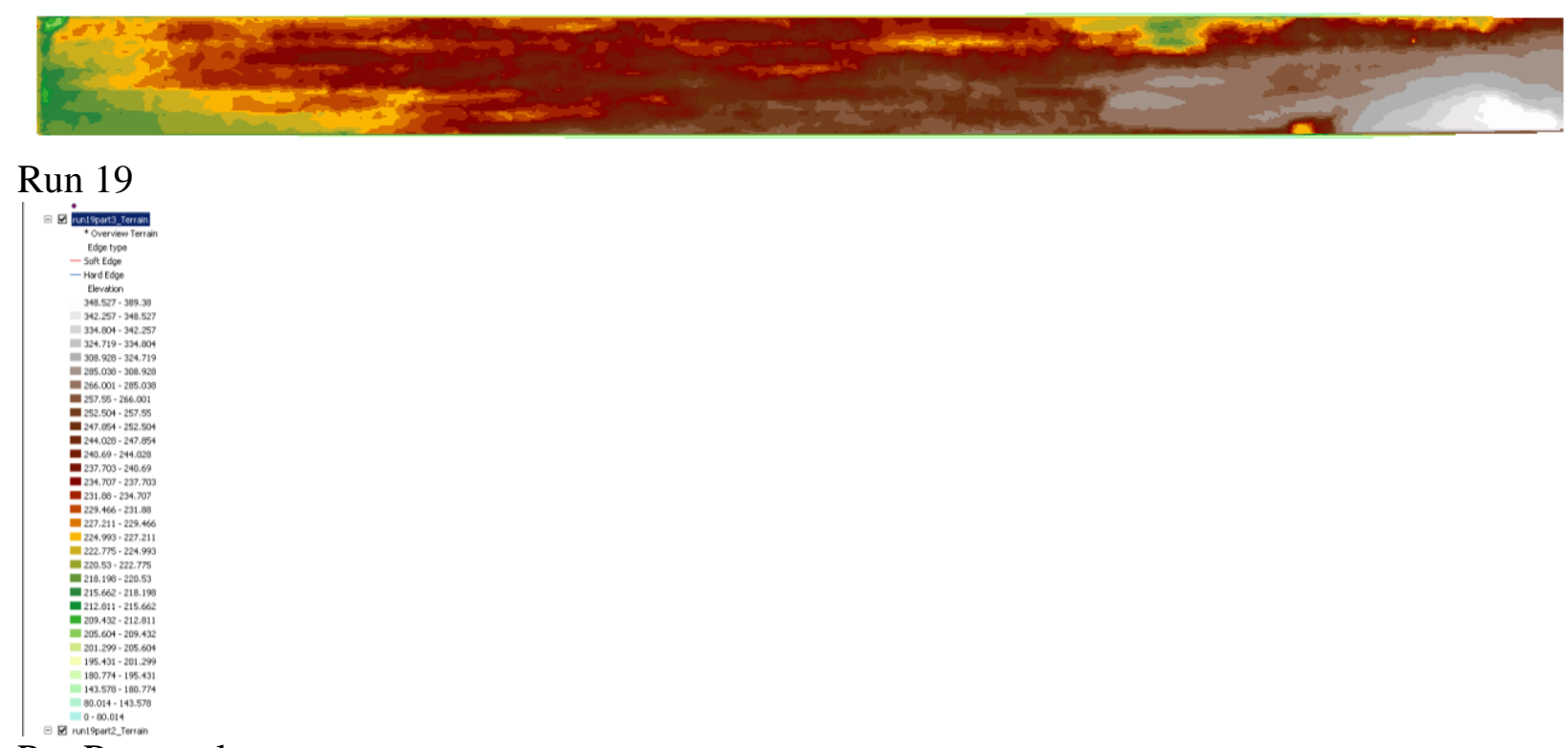

Pre-Removal

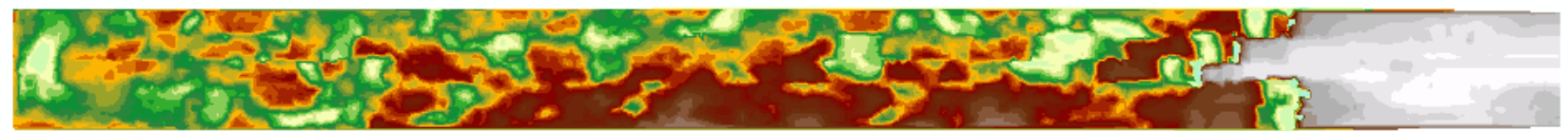

\section{Part 1}

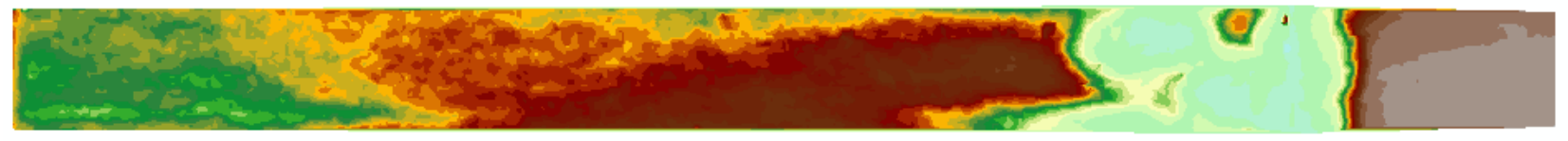

Part 2

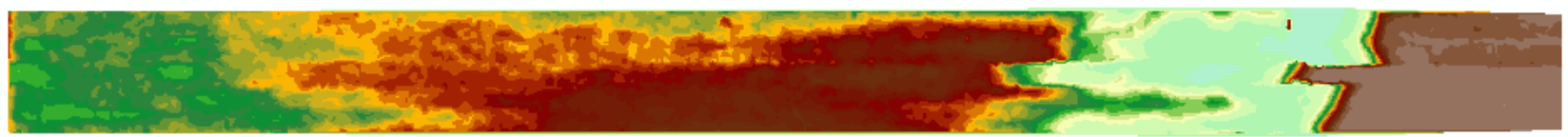

Part 3

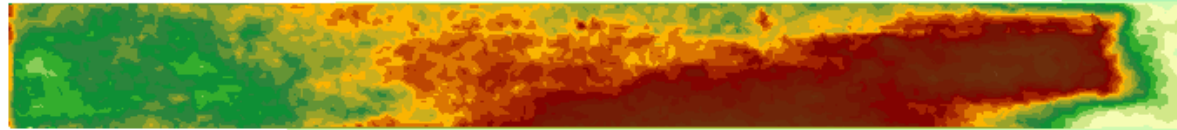

Run 20 


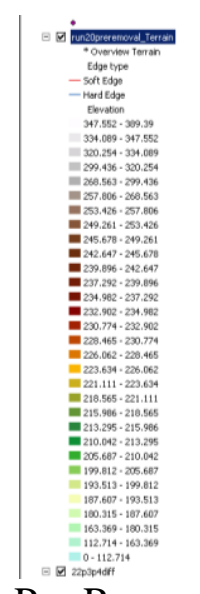

Pre-Removal

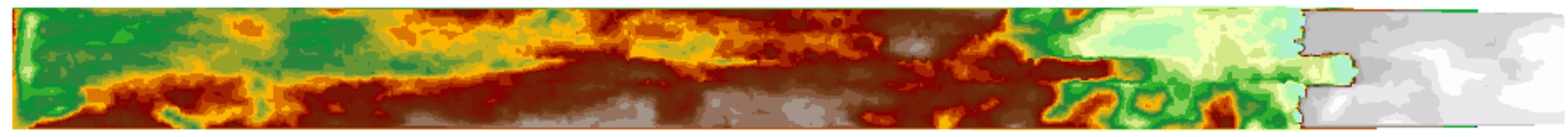

Part 1

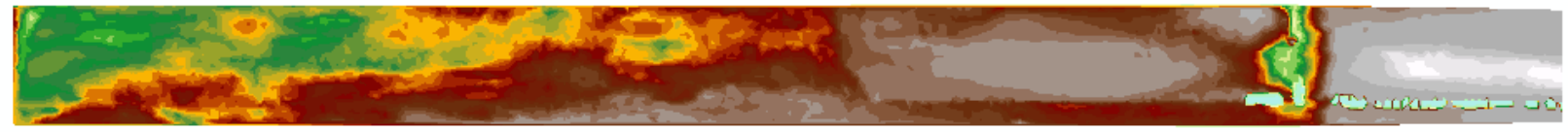

Part 2

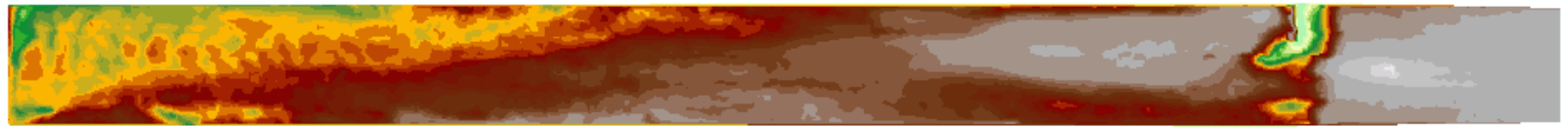

Part 3



Run 21

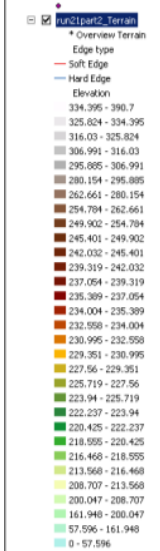

Pre-Removal




Part 1

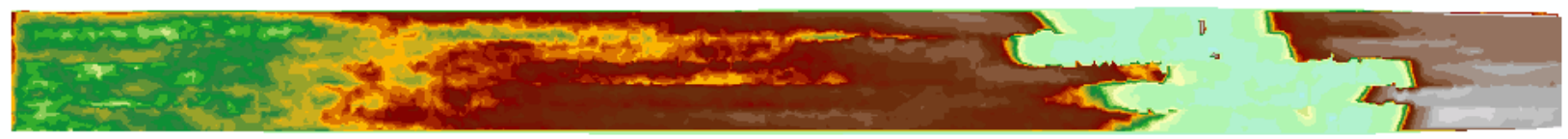

Part 2:



Part 3



Run 22:

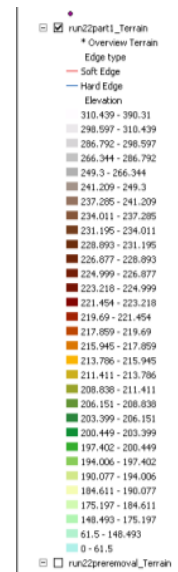

Pre-Removal:

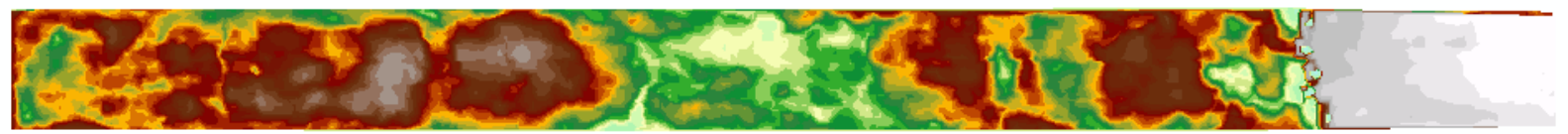

Part 1:



Part 2:

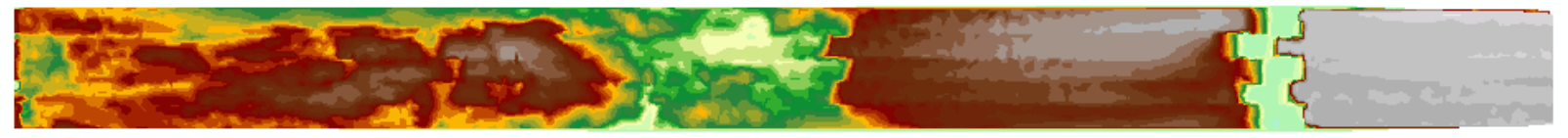

Part 3:



Part 4: 




Run 24

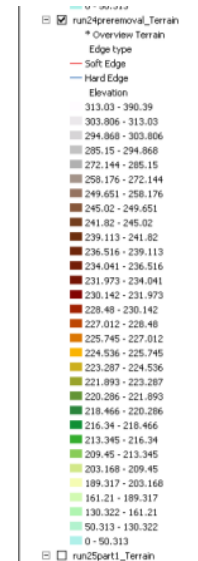

Pre-Removal:

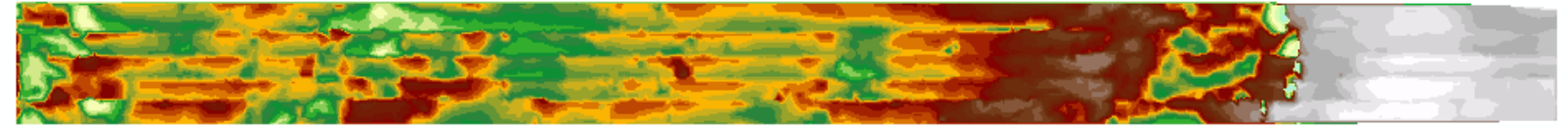

Part 1:

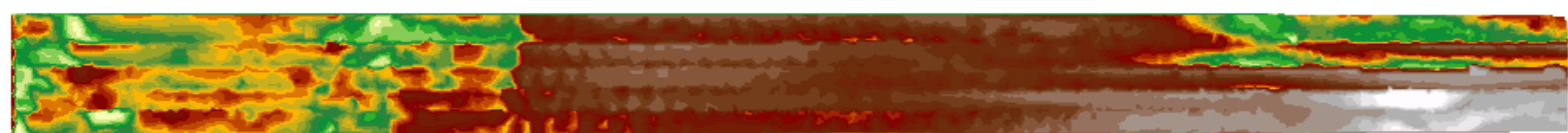

Run 25

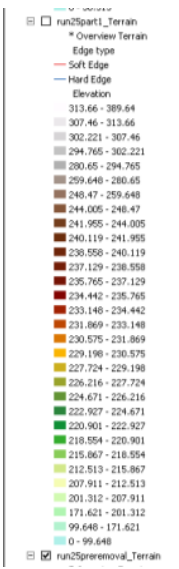

Pre-Removal:

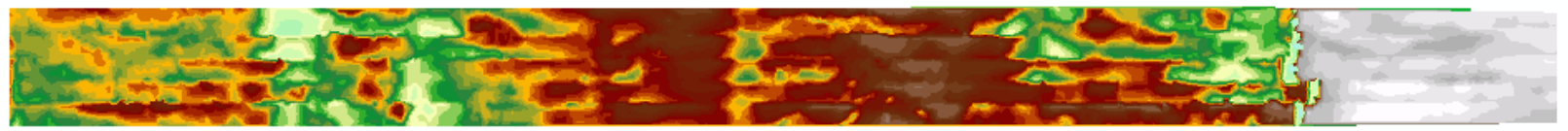

Part 1:

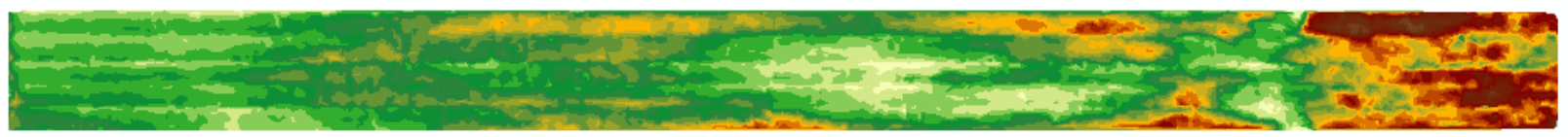




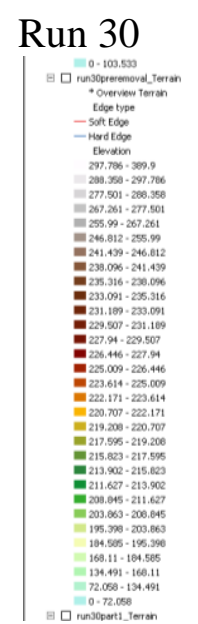

Pre-Removal:



Part 1:

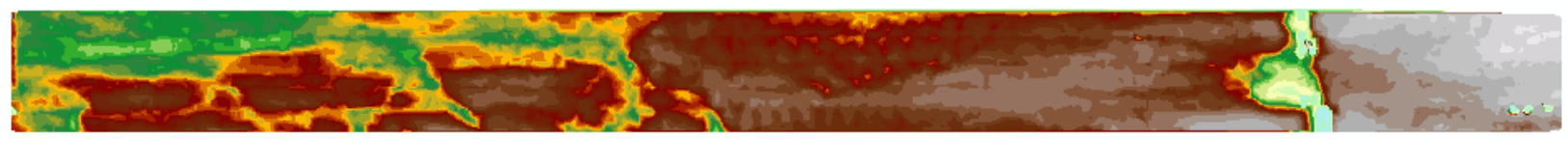

Part 2:

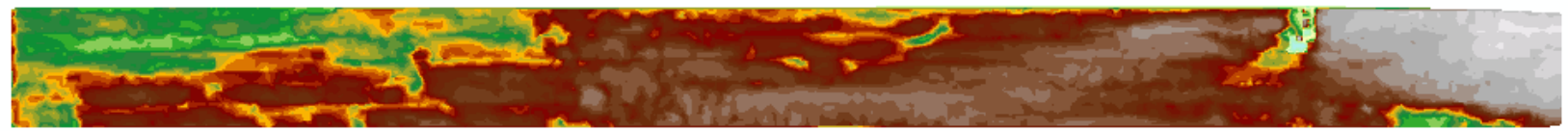

Part 3:

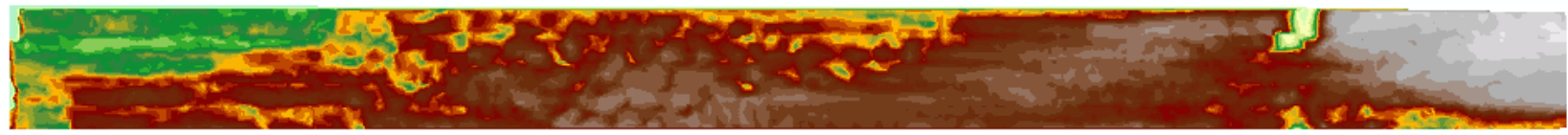

Run 31 


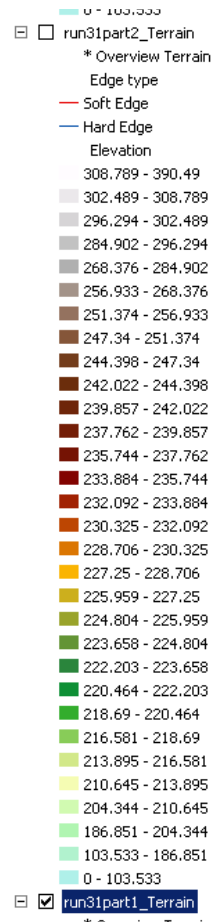

Pre-Removal

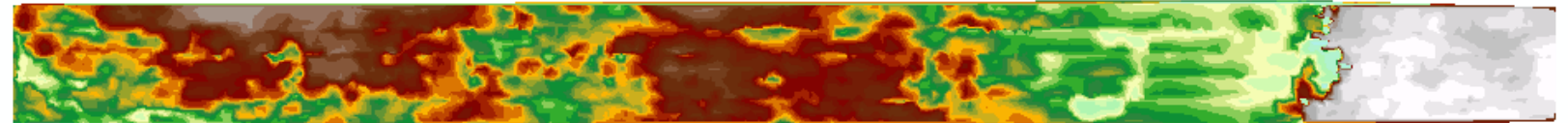

\section{Part 1}

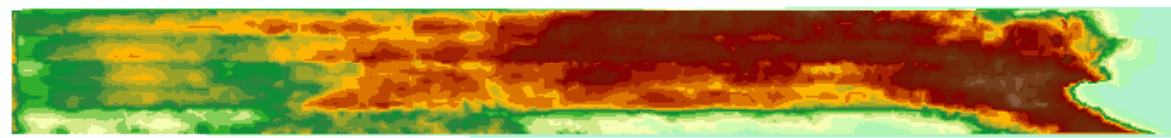

2

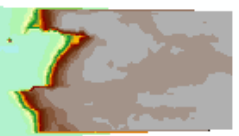

Part 2
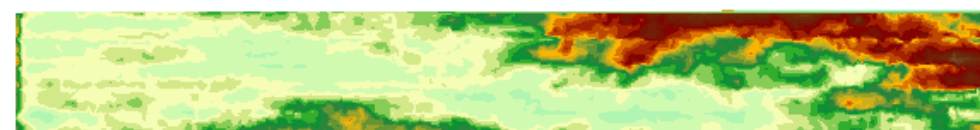

Part 3
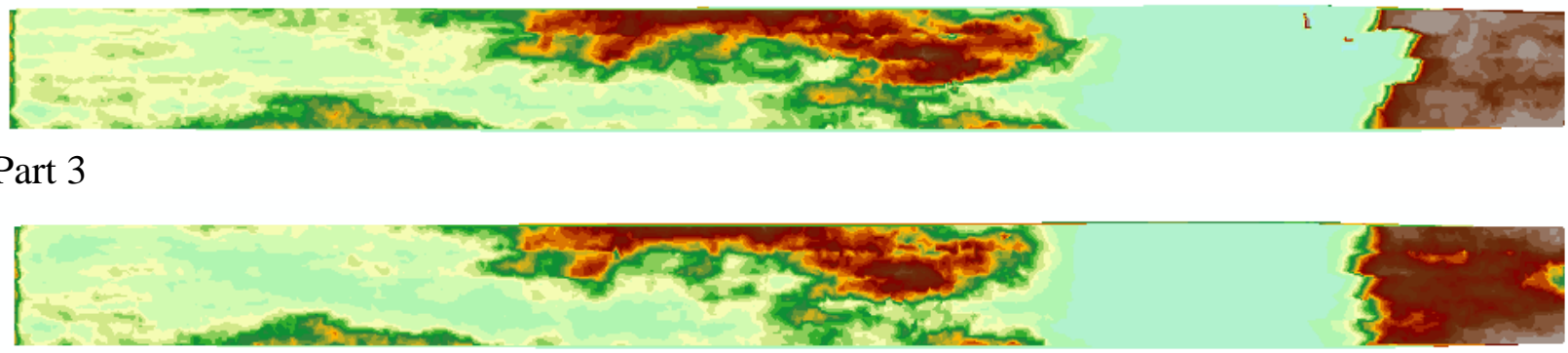

\section{Part 3}

$1=-$ 


\section{Appendix E: Camera scans}

Run 1



Run 2
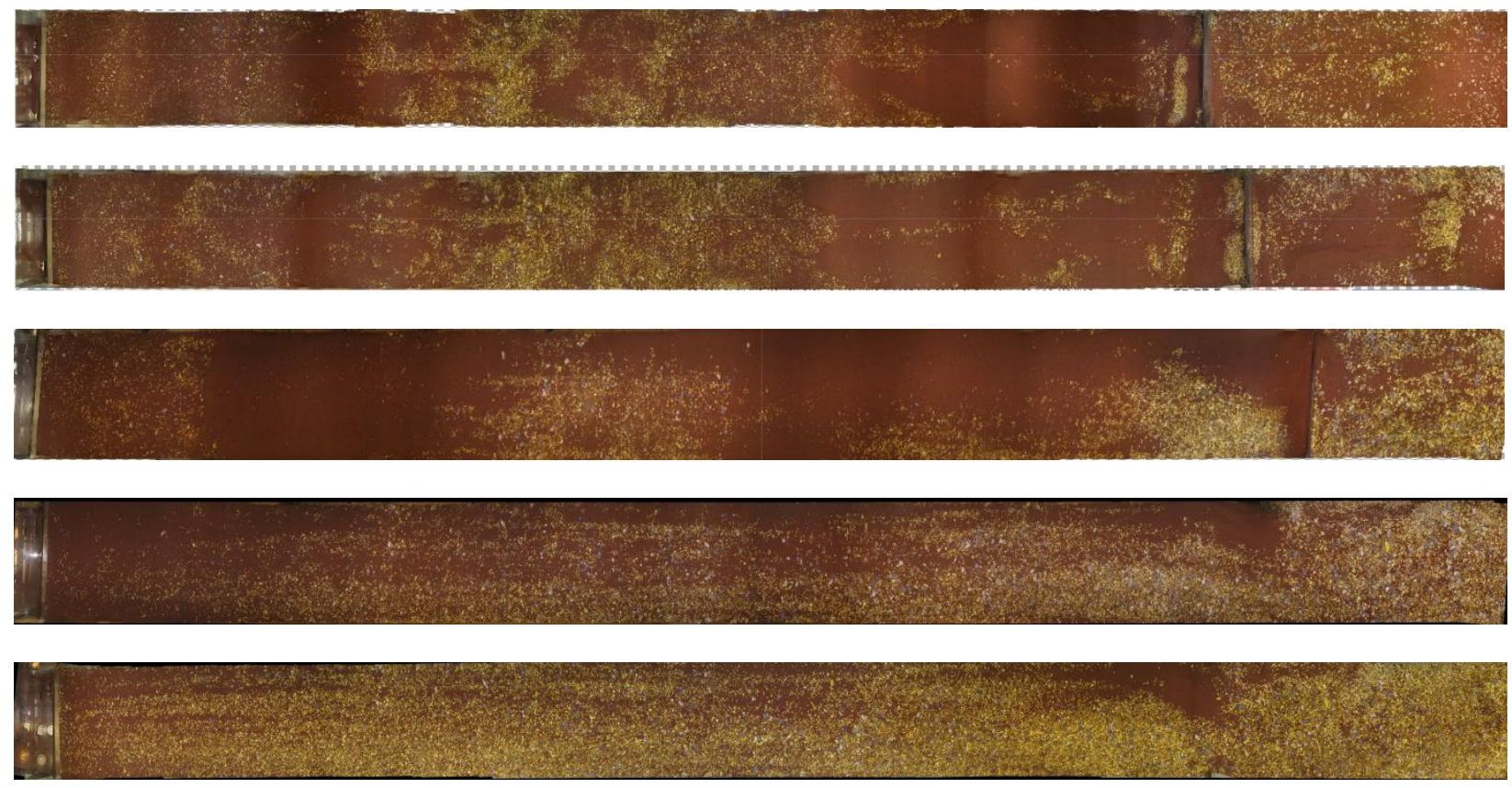

Run 3

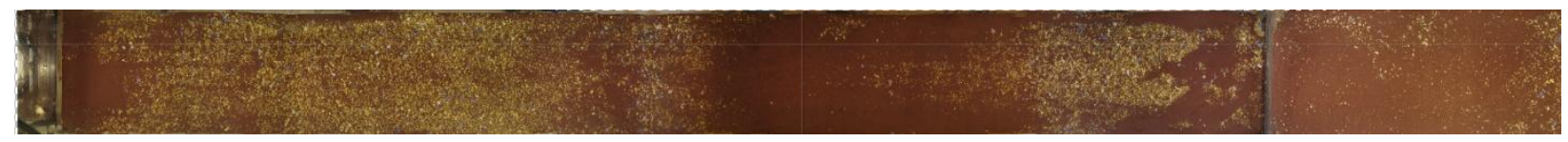



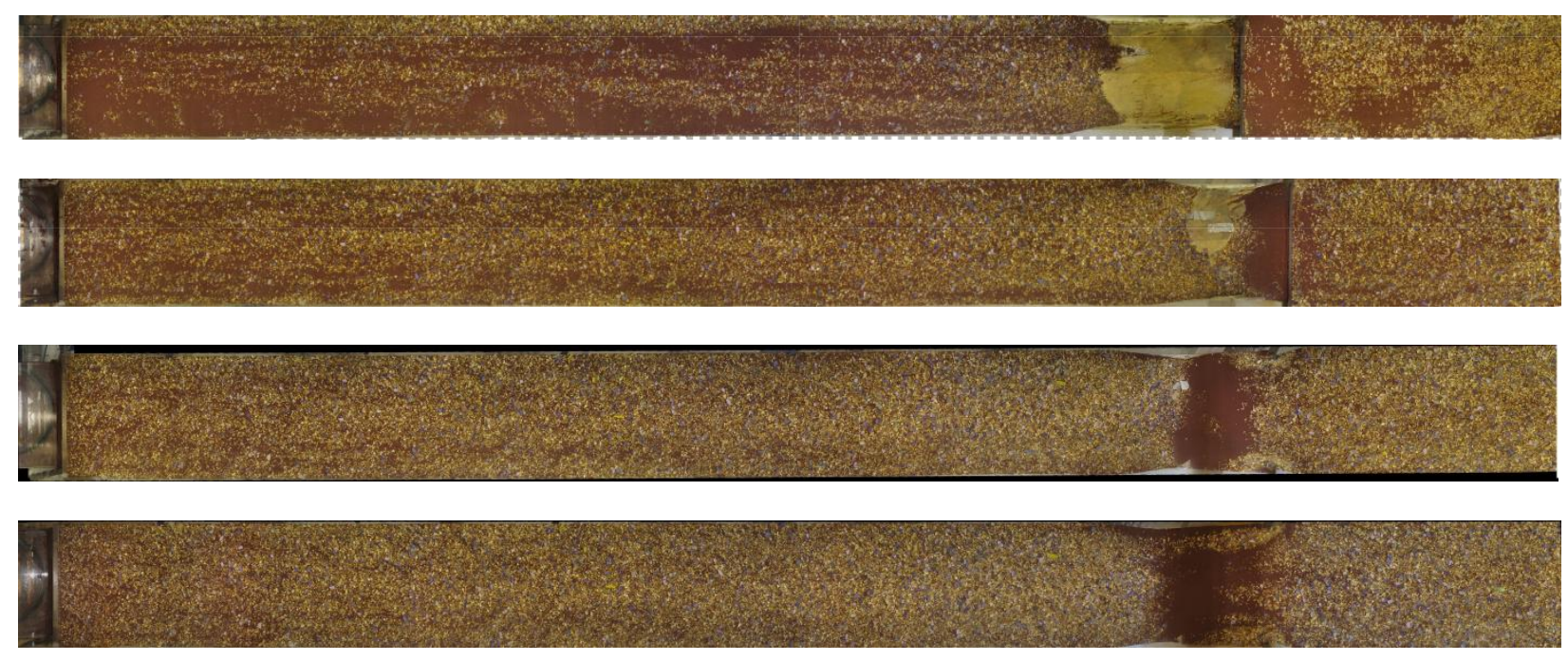

Run 4


Run 5


Run 6
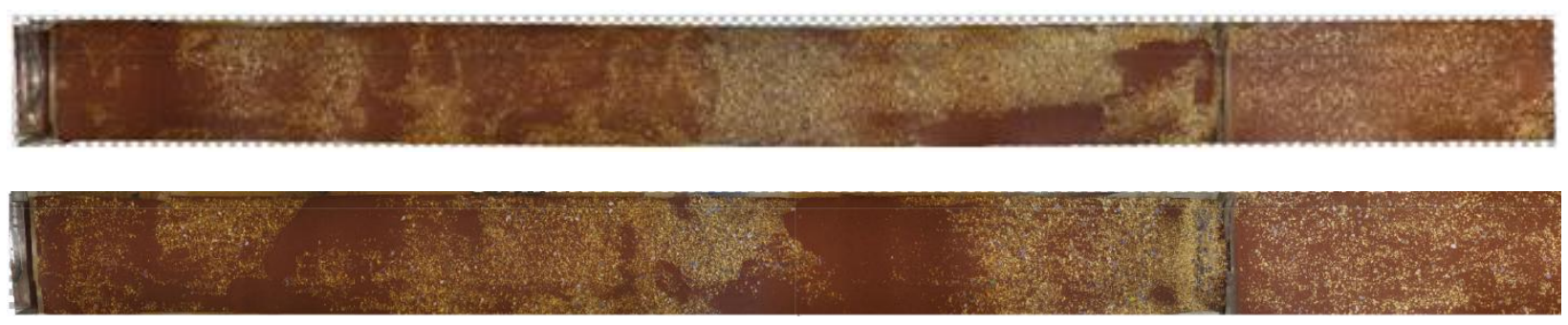

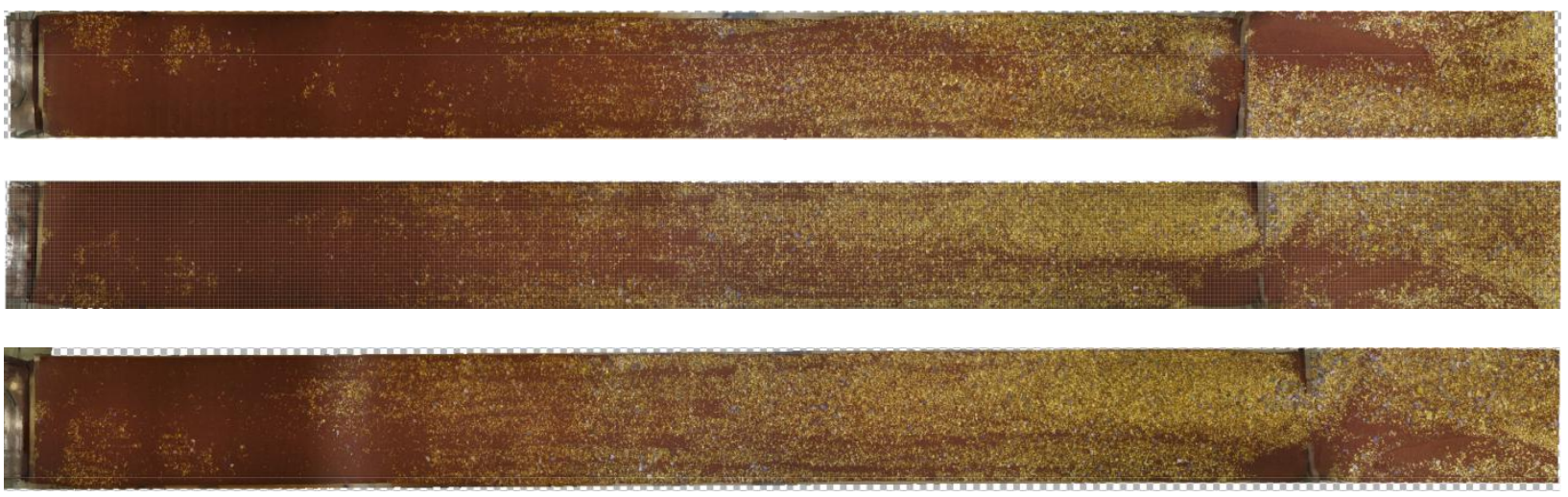

Run 7


Run 8



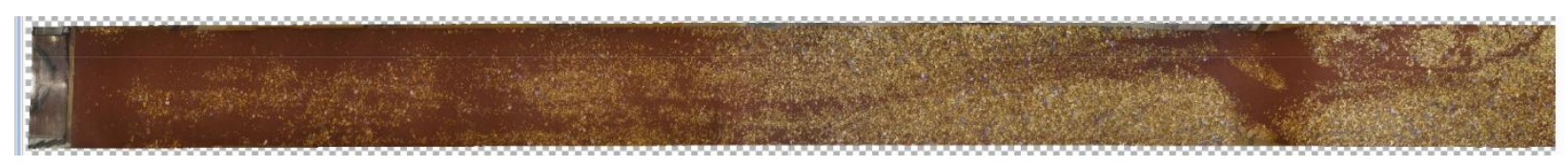

Run 9
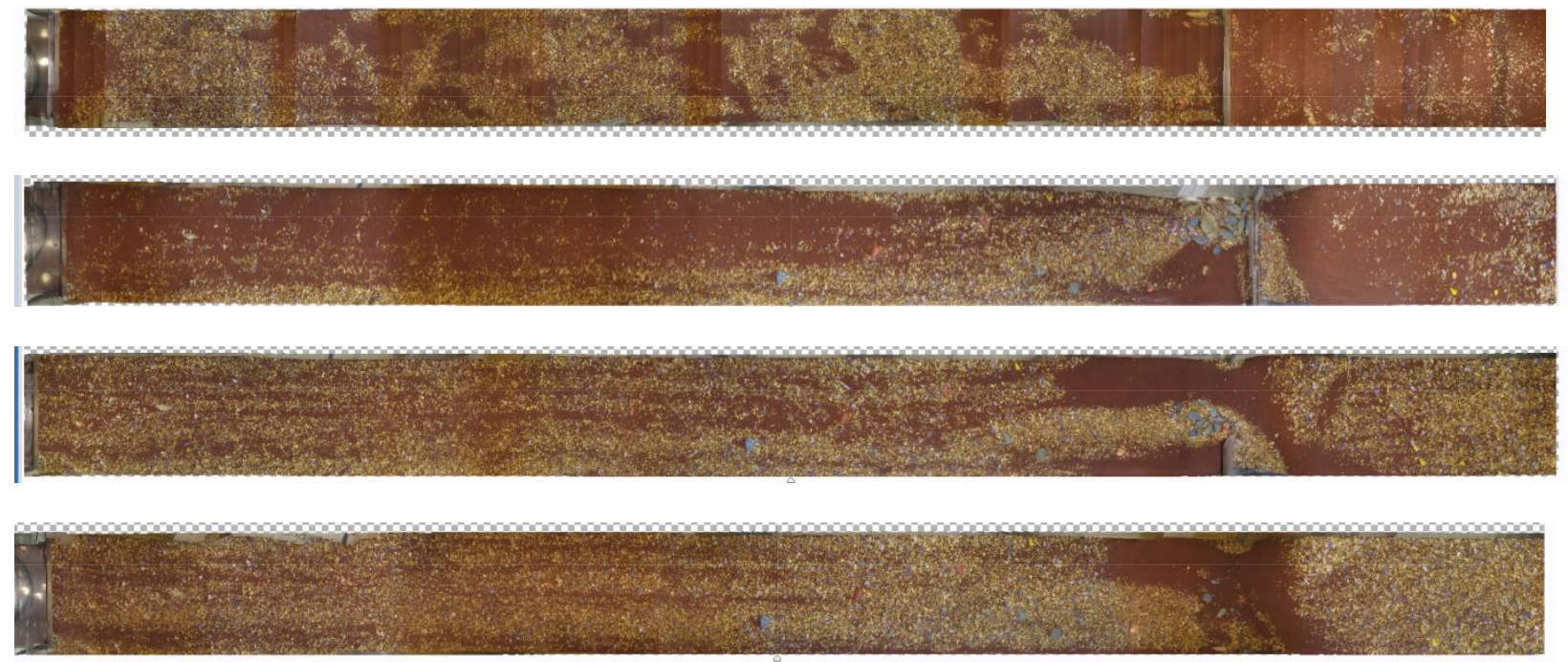

Run 10
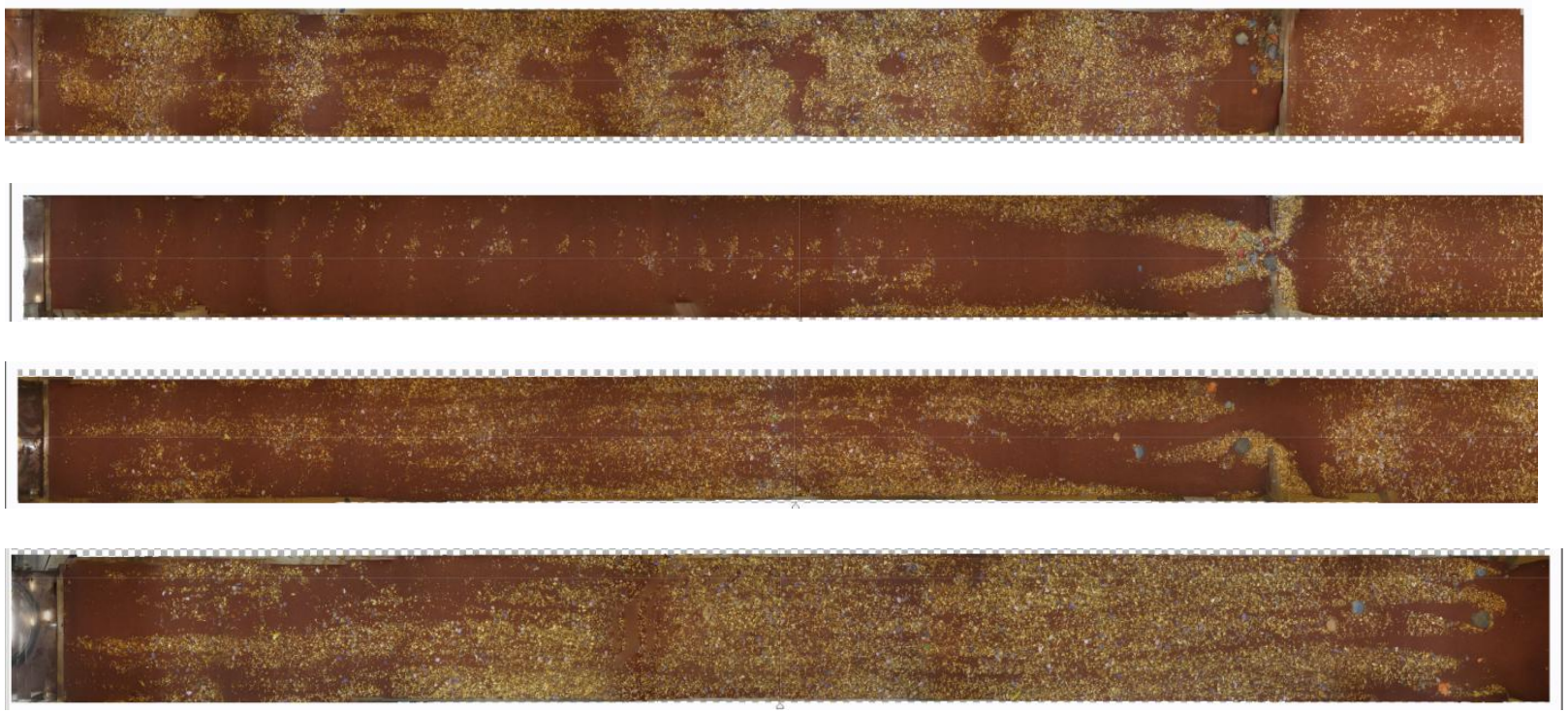

Run 11

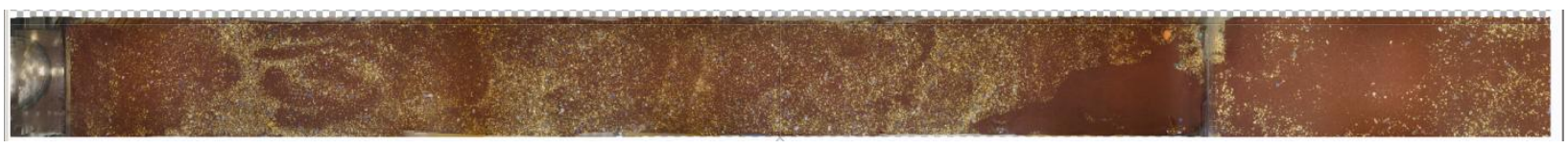



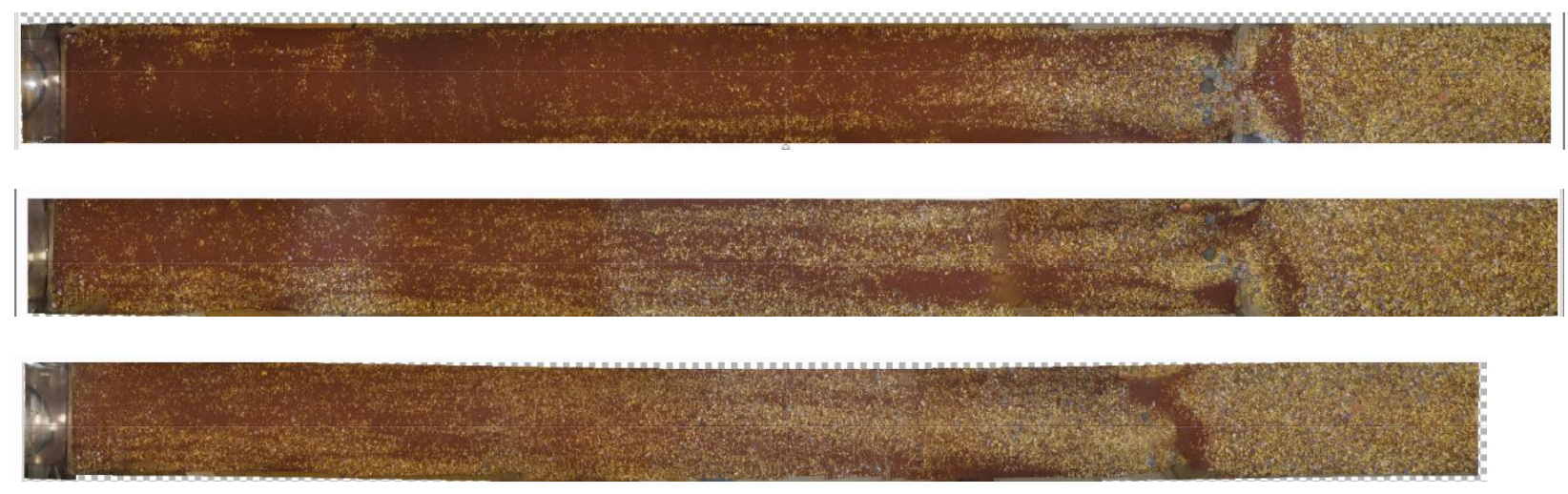

Run 12
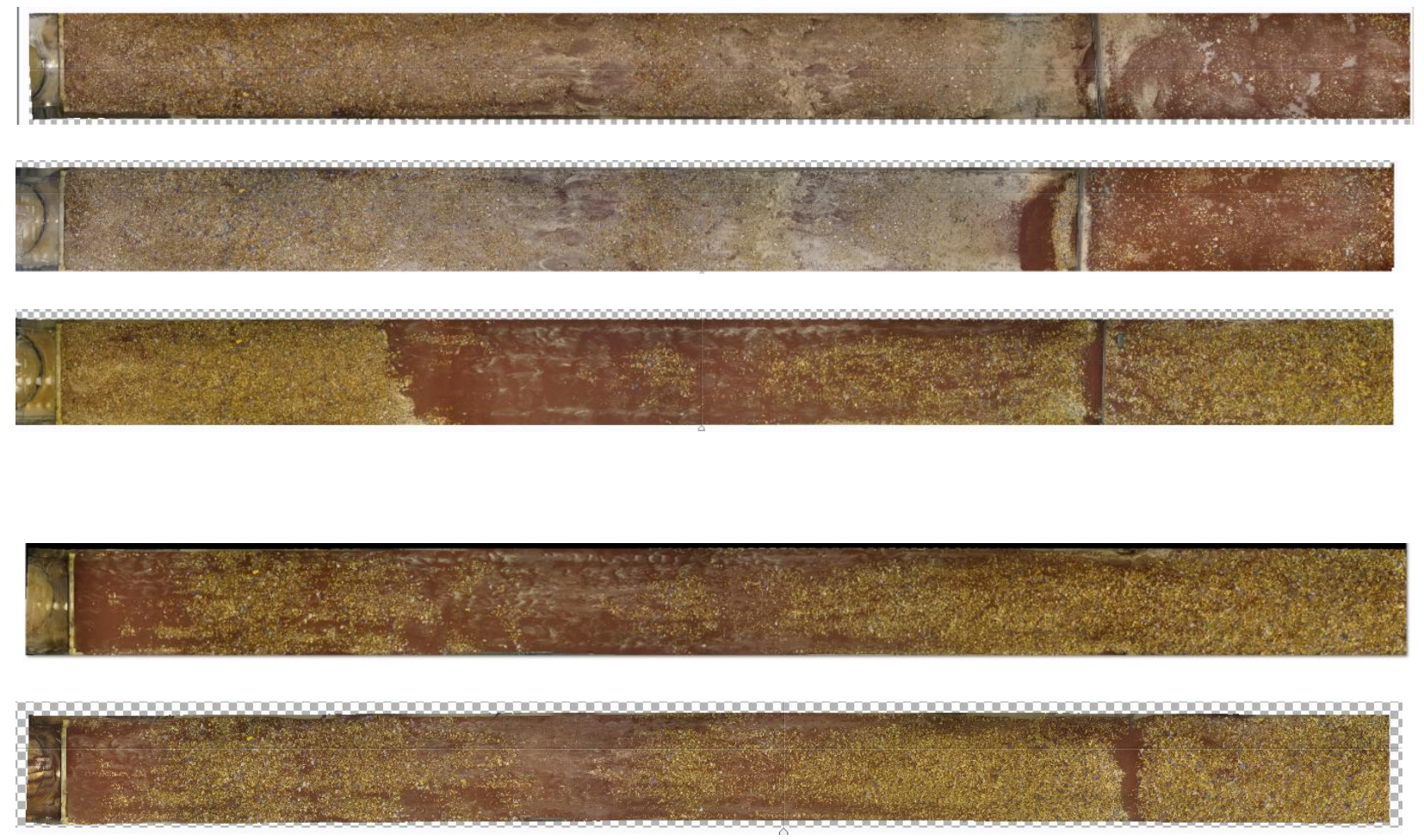

Run 13
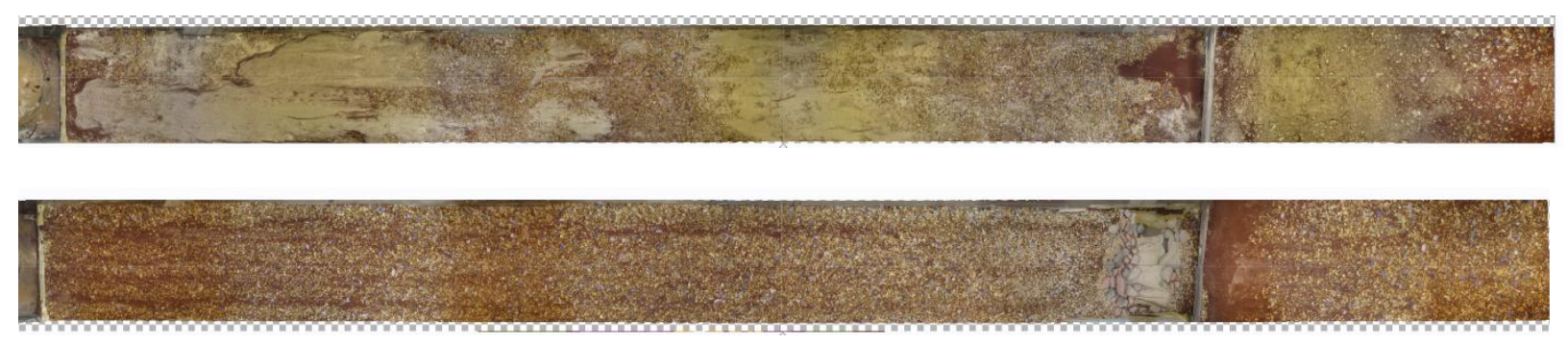

Run 14 

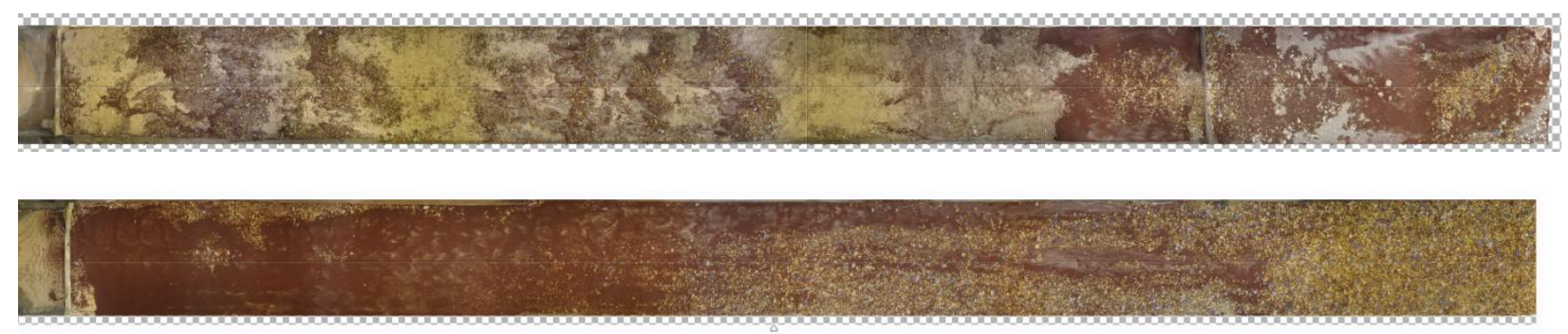

Run 15
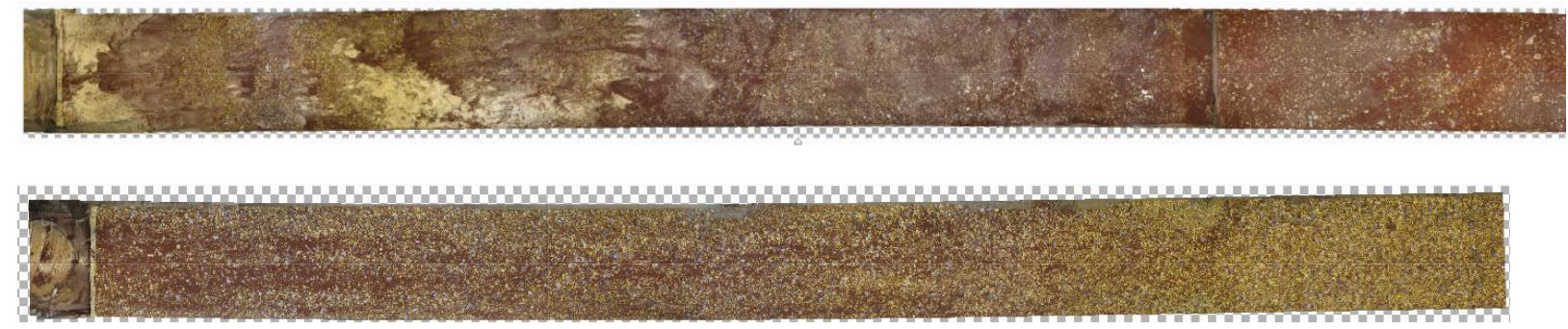

\section{Run 16}
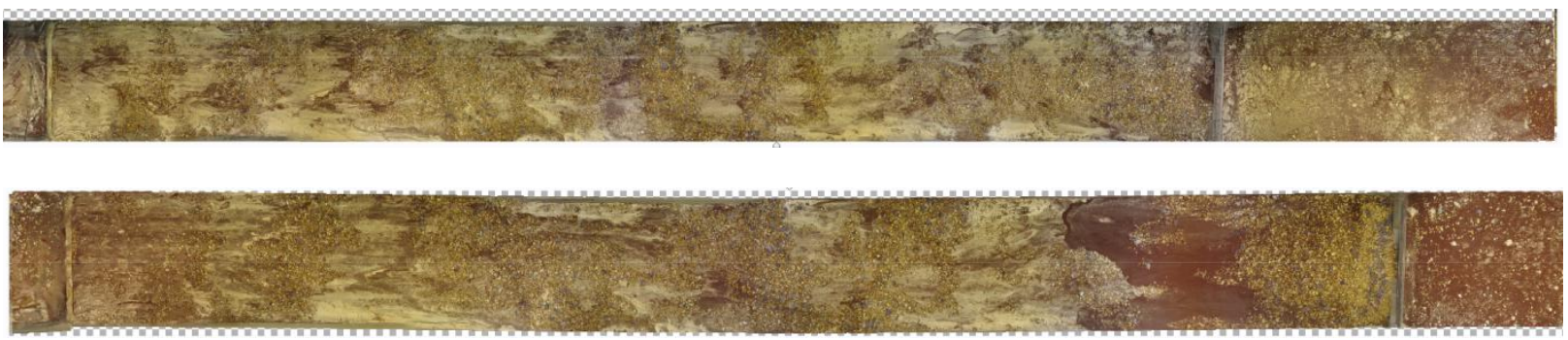

\section{Run 17}


Run 18

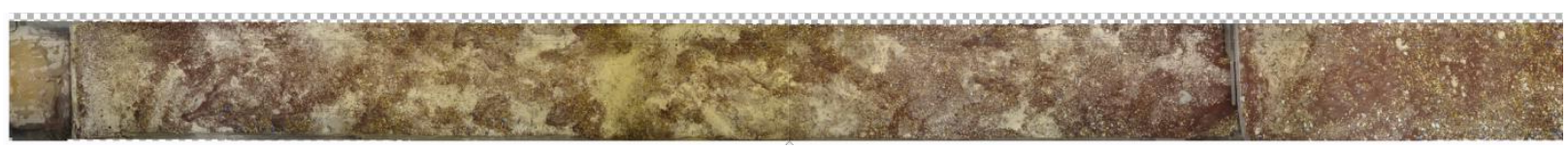



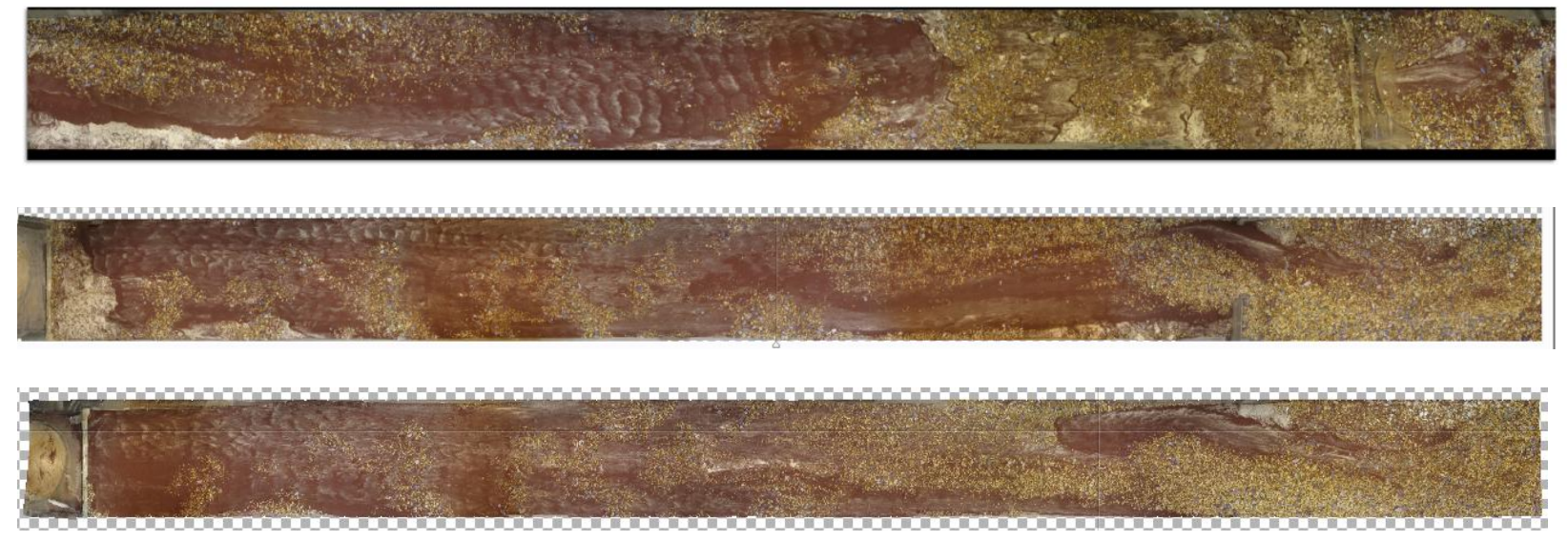

Run 19
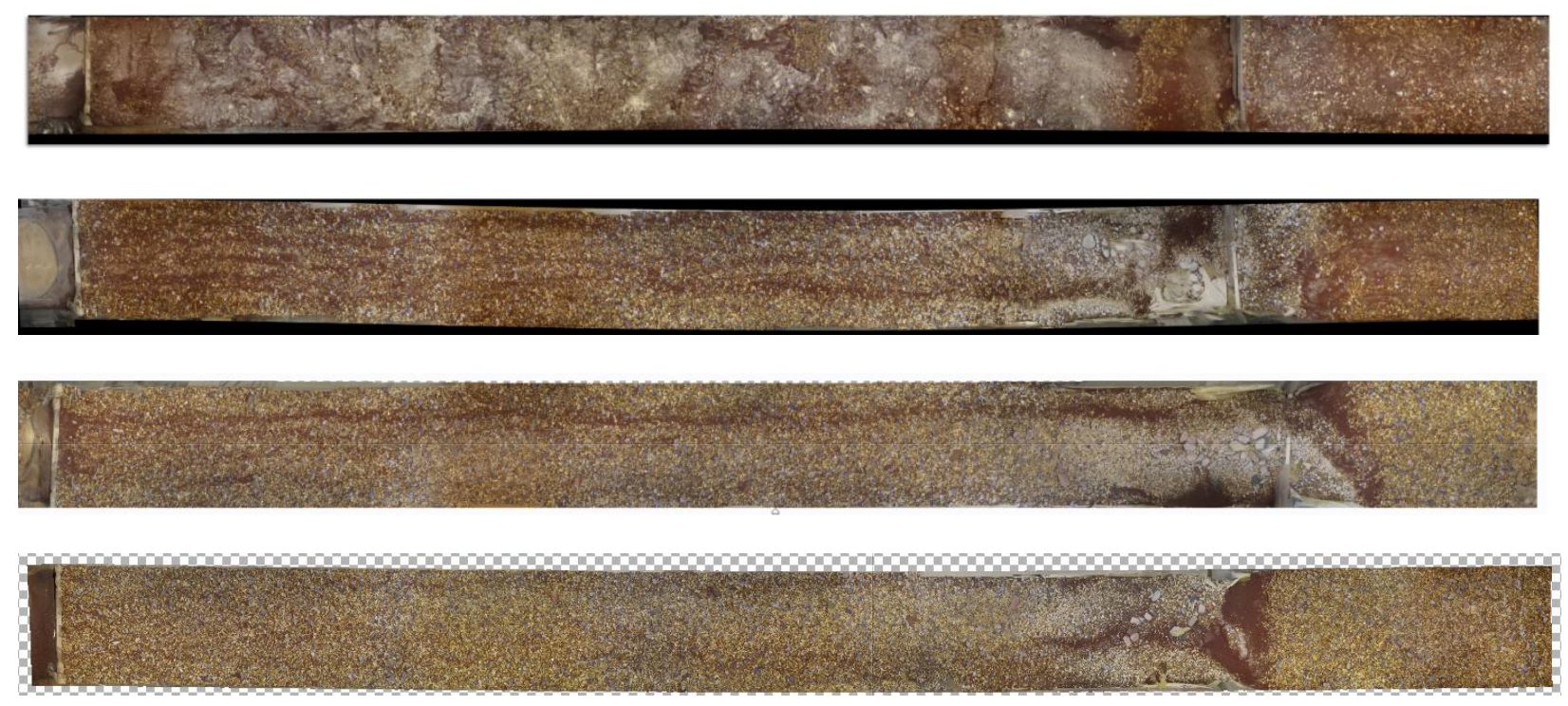

Run 20

Run 21
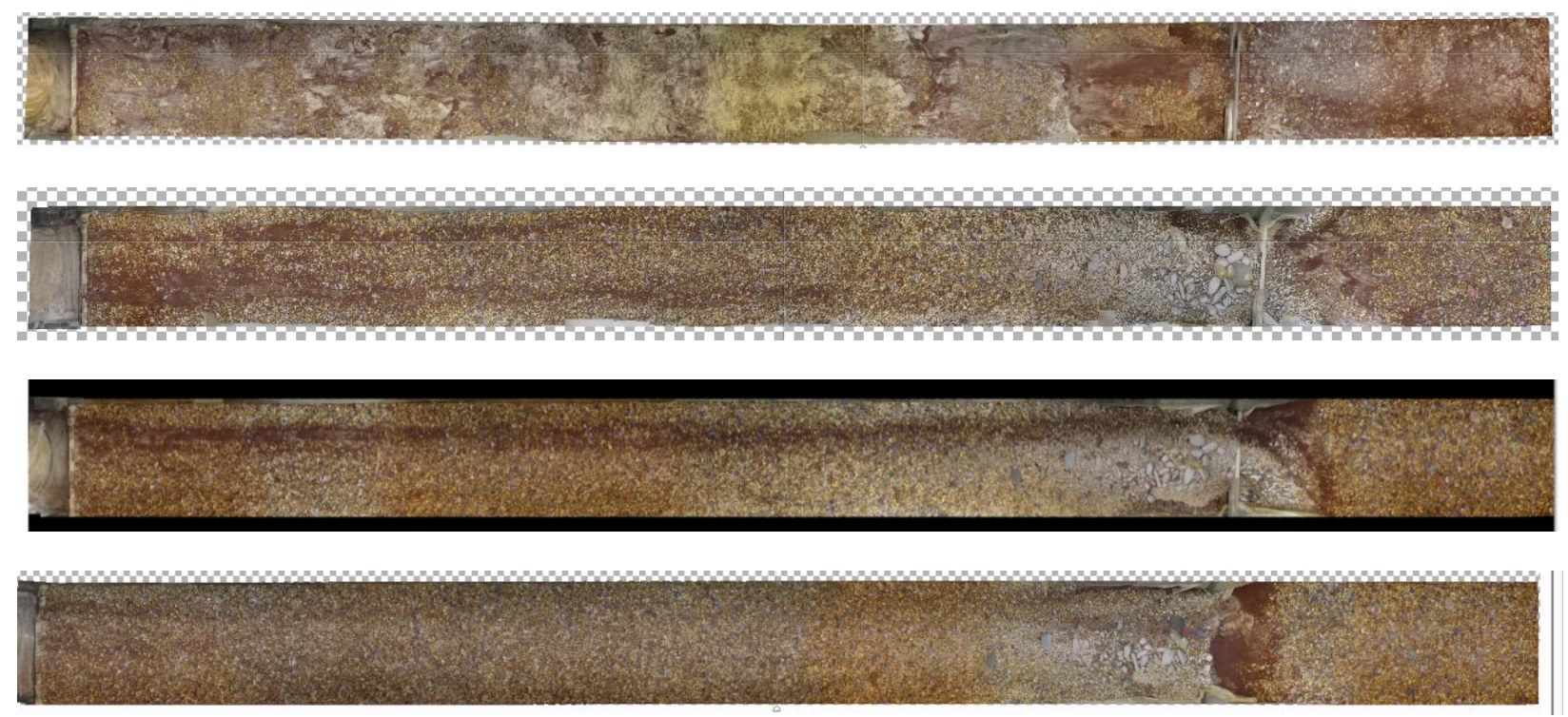

Run 22


Run 24

\section{Pre-Removal}

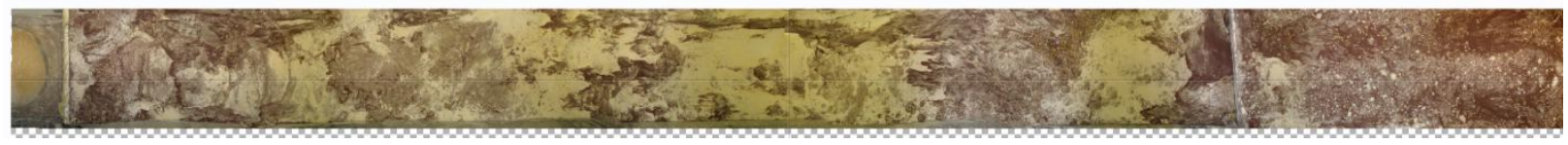


Part 1

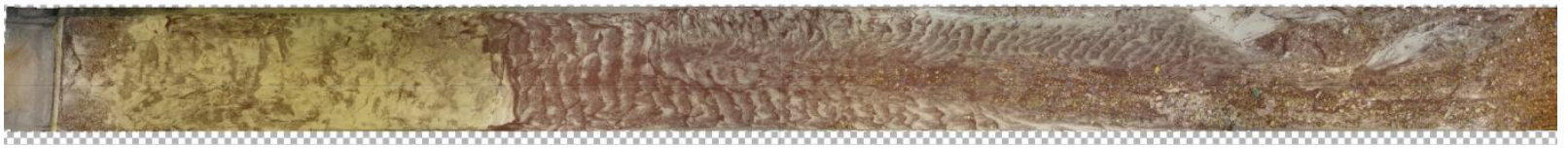

Run 25

Pre-Removal

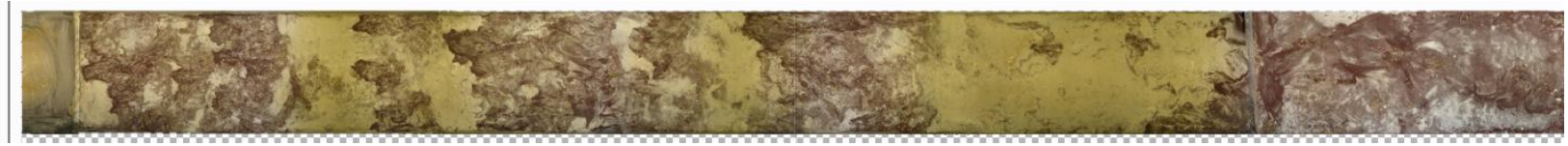

Part 1

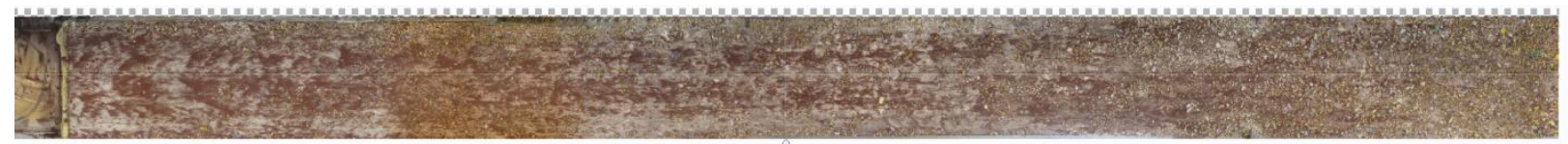

Run 30

Pre-Removal



Part 1

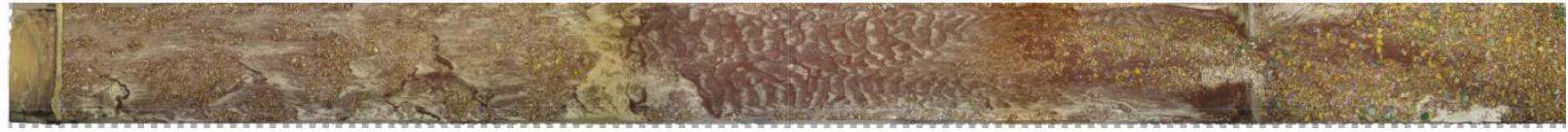

Part 2

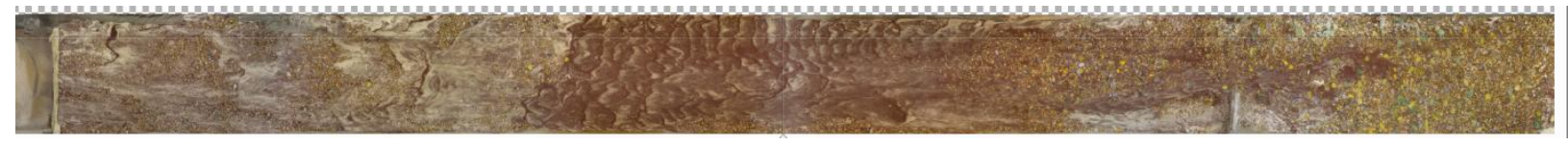

Part 3



Run 31 


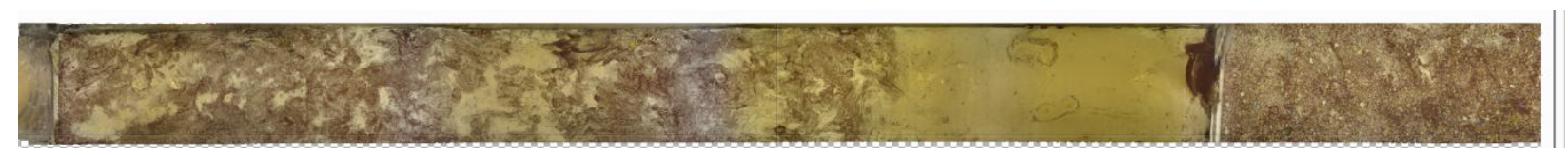

Part 1



Part 2

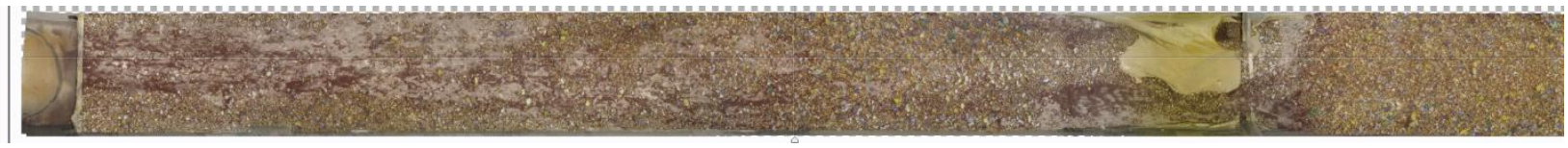

Part 3

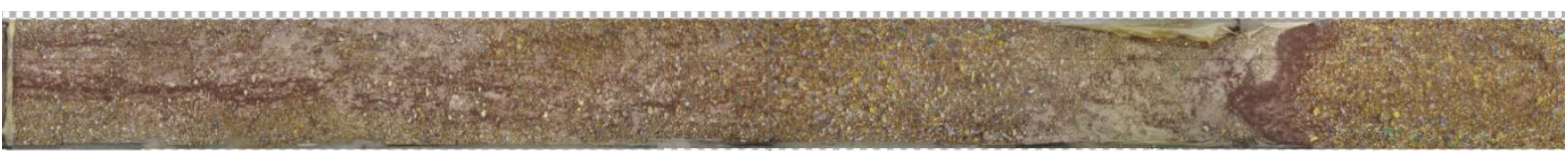

\section{Appendix F: raster differencing}

Blue is deposition, red is erosion

$$
\begin{aligned}
& \text { Run } 2 \\
& \square \square \text { minusfull } 2 \\
& \text { Value } \\
& \text { High : } 40 \\
& \text { Low : }-40
\end{aligned}
$$

Pre-Removal to Final

\section{Run 3}

$$
\begin{gathered}
0-119.48 \\
\text { Minusfull } \\
\text { Value } \\
\text { High : } 100 \\
\text { Low : }-50
\end{gathered}
$$

Pre-Removal to Final 


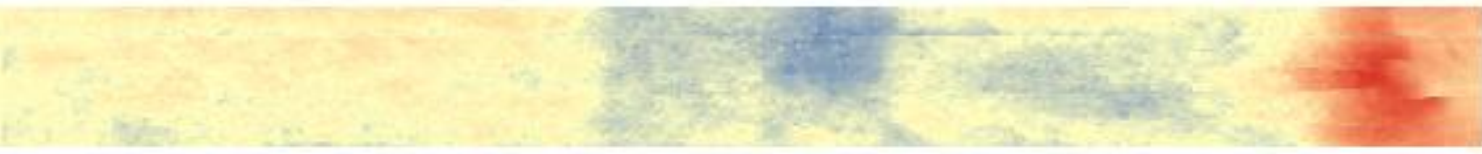

Part 1 to Part 2

Part 2 to Part 3

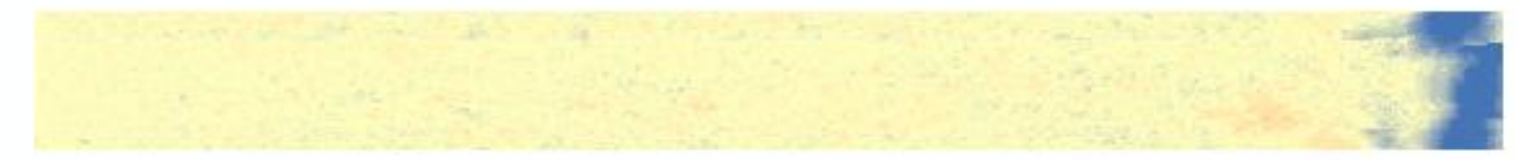

Part 3 to Part 4



Run 4

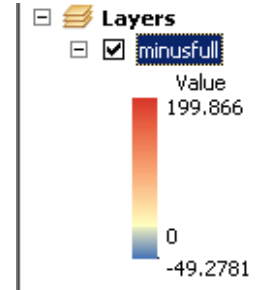

Pre-Removal to Part 1

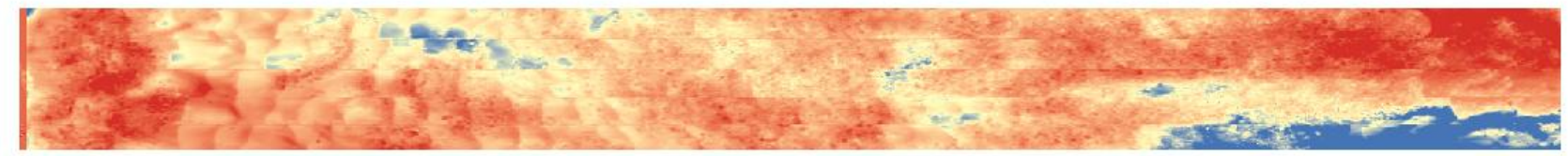

Run 5

$\square \square$ Sprep1diff

Value

High : 33.7287

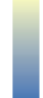

Low : -105.188

Pre-Removal to Part 1

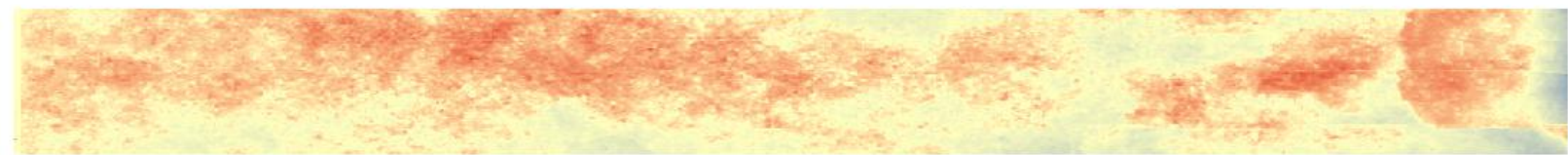

Run 6 


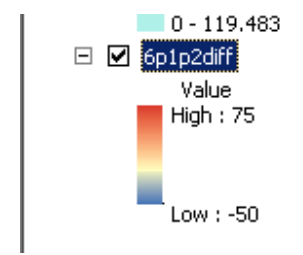

Pre-Removal to Final

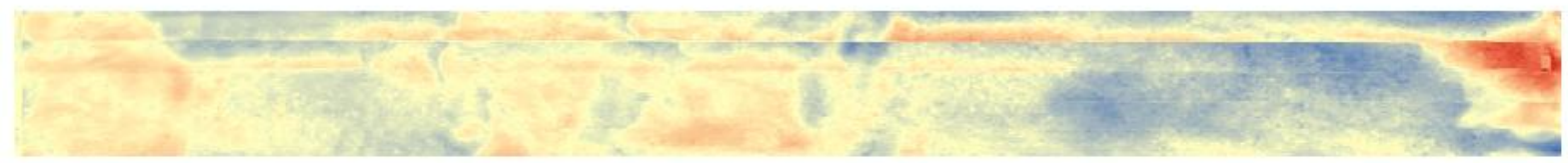

Pre-Removal to Part 1



\section{Part 1 to Part 2}

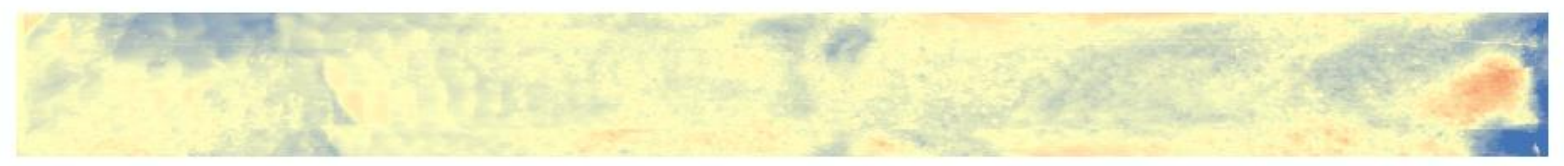

Part 2 to Part 3

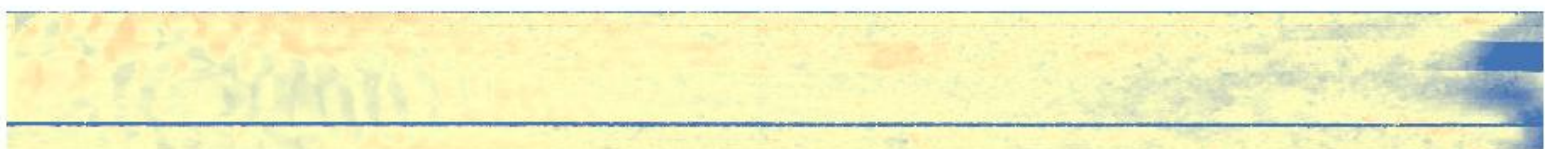

Part 3 to Part 4

Run 7

$\square \square$ imun7prep1

Value

High : 100

Low : -50

Pre-Removal to Final

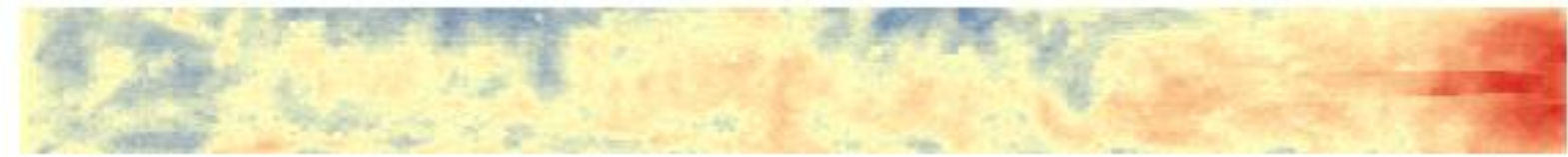

Pre-Removal to Part 1 




Part 1 to Part 2



Part 2 to Part 3

Part 3 to Part 4

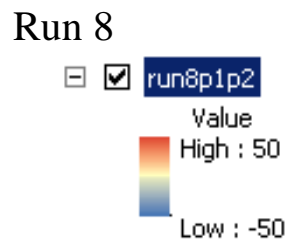

Pre-Removal to Final

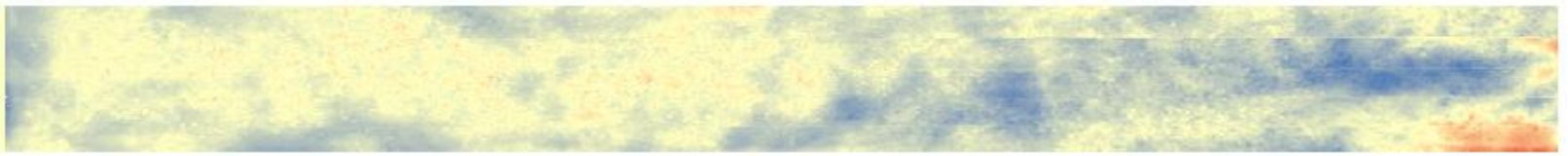

Pre-Removal to Part 1

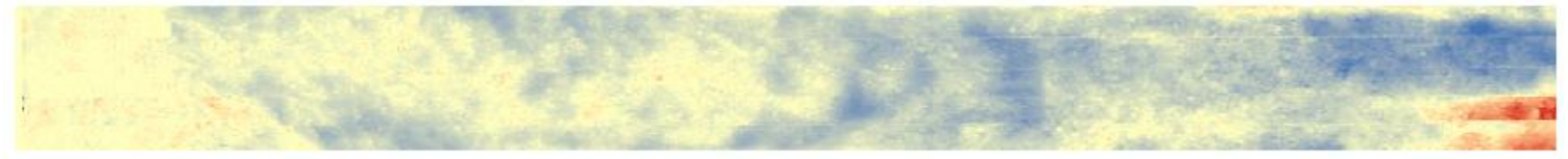

Part 1 to Part 2

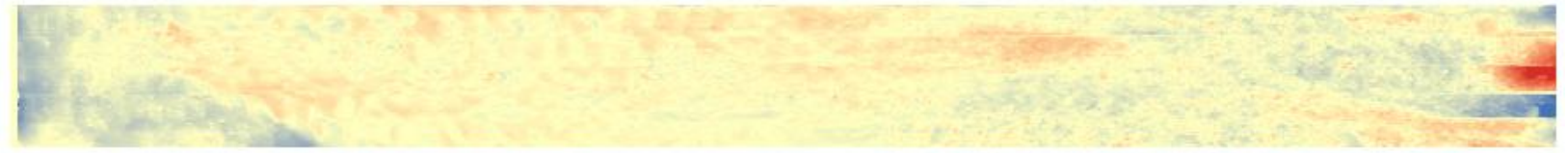

Part 2 to Part 3 


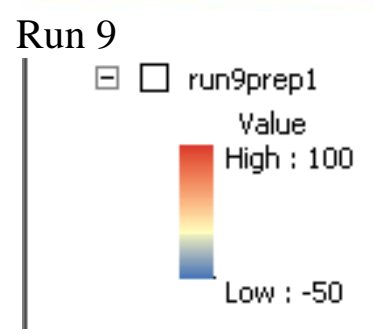

Pre-Removal to Final

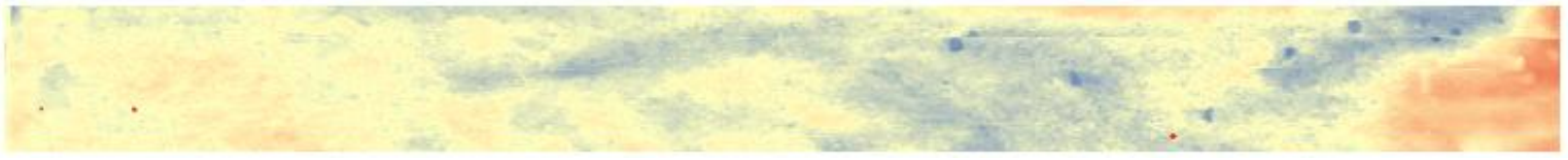

Pre-Removal to Part 1

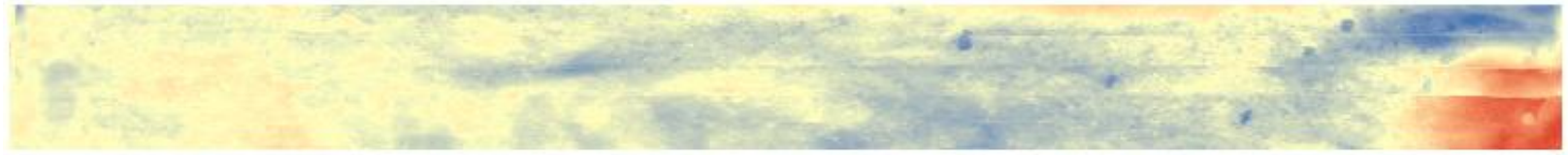

Part 1 to Part 2

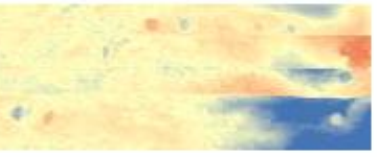

Part 2 to Part 3



Pre-Removal to Final

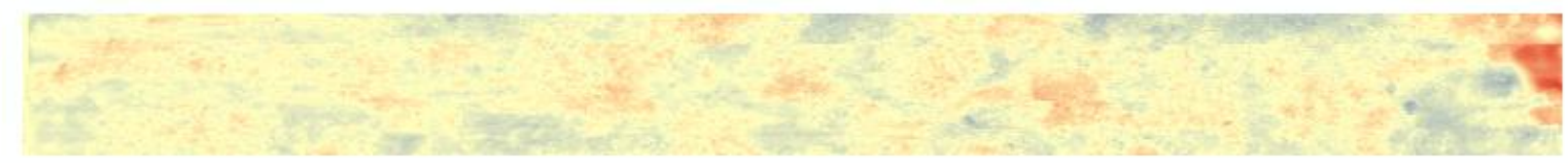

Pre-Removal to Part 1 
Part 1 to Part 2

Part 2 to Part 3

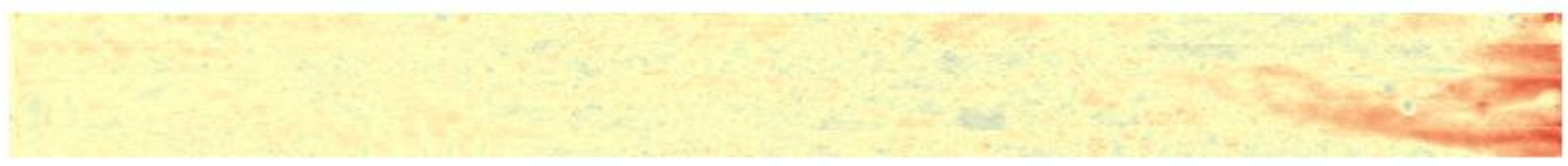

\section{Run 11}

$\square \square$ 11p1p2diff

Value

High : 50

Low : -50

Pre-Removal to Final

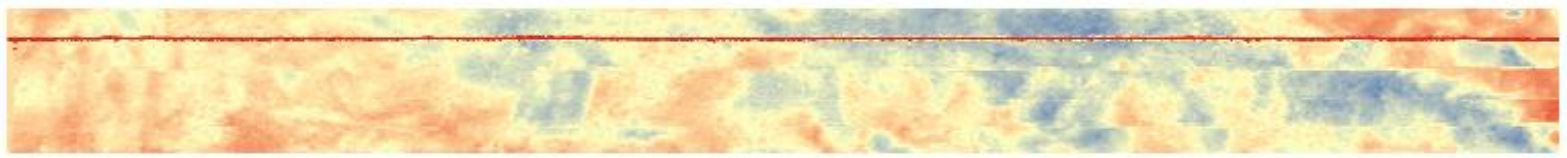

Pre-Removal to Part 1

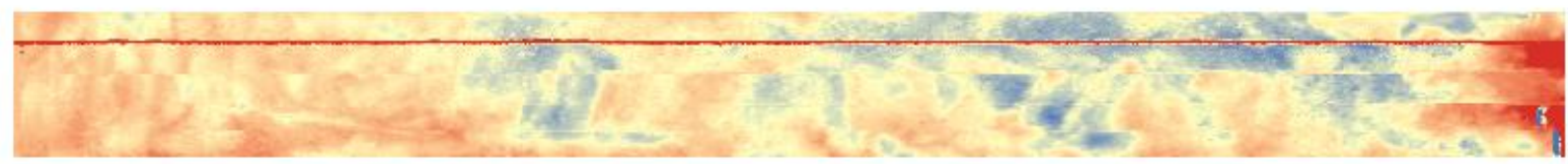

Part 1 to Part 2



Part 2 to Part 3

Run 12

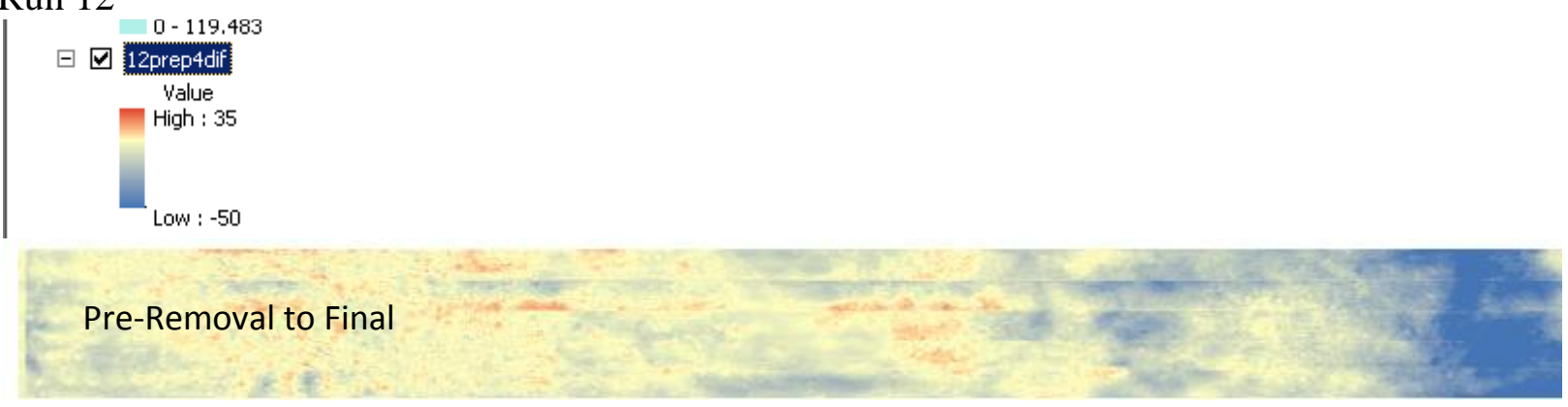


Pre-Removal to Part 1

Part 1 to Part 2

Part 2 to Part 3

Part 3 to Part 4

Run 13



Pre-Removal to Part 1

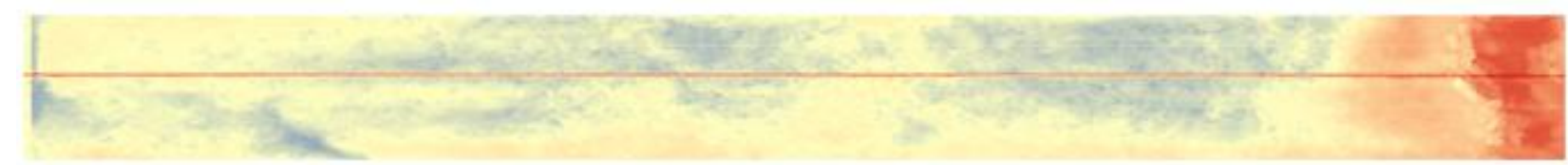

Run 14



Pre-Removal to Final

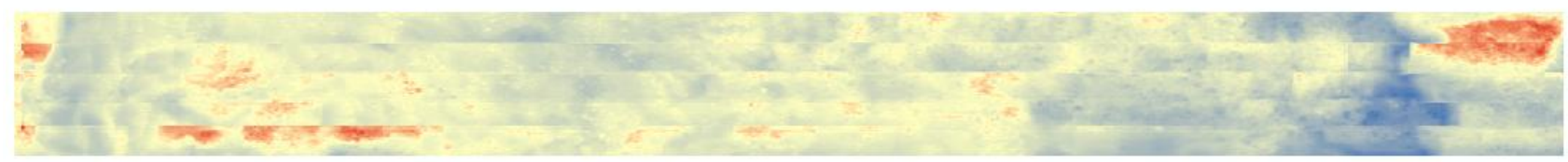

Run 15 

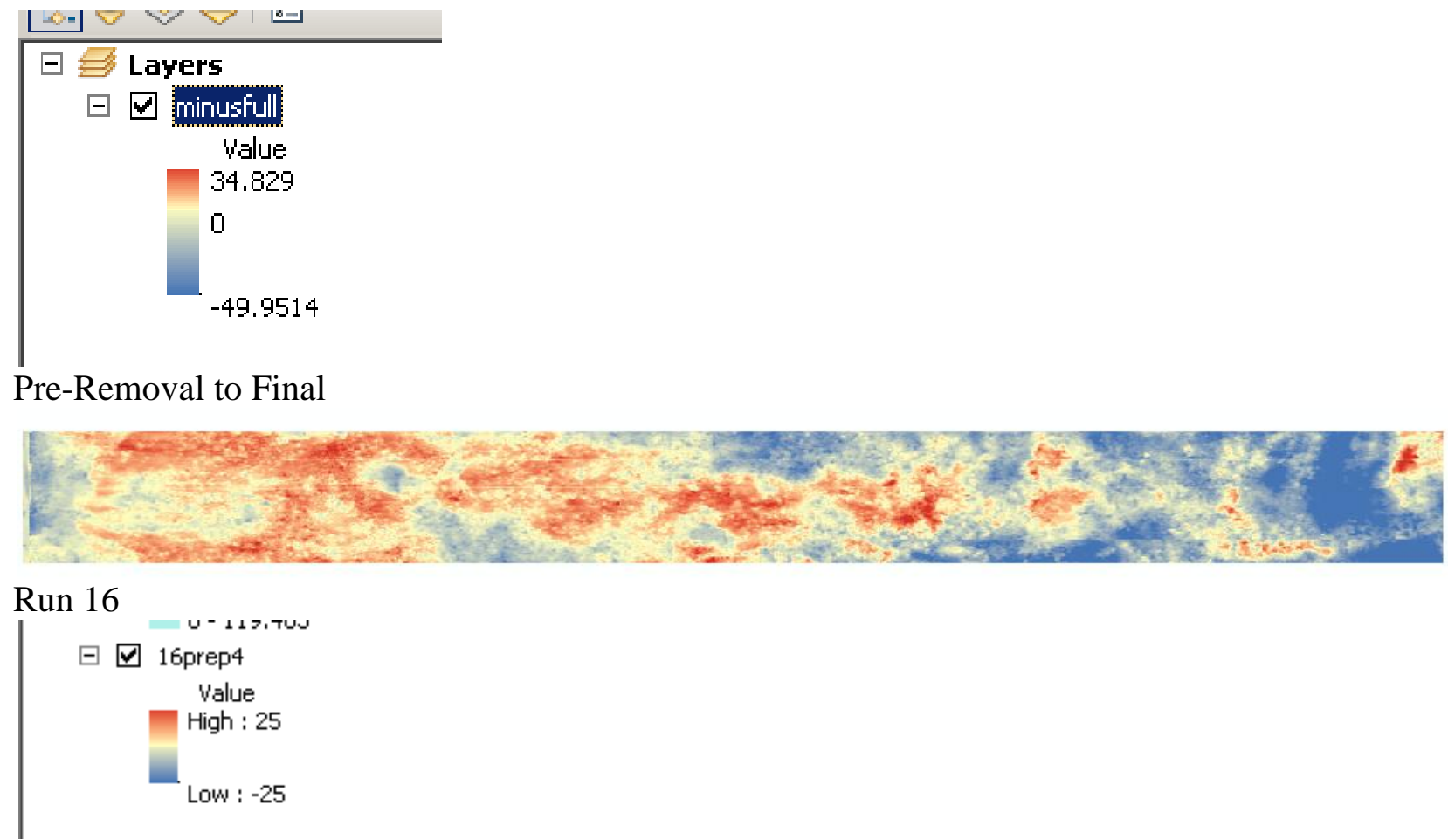

Pre-Removal to Final

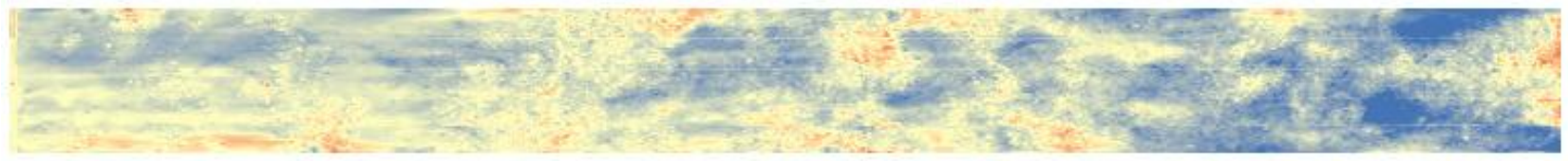

Pre-Removal to Part 1

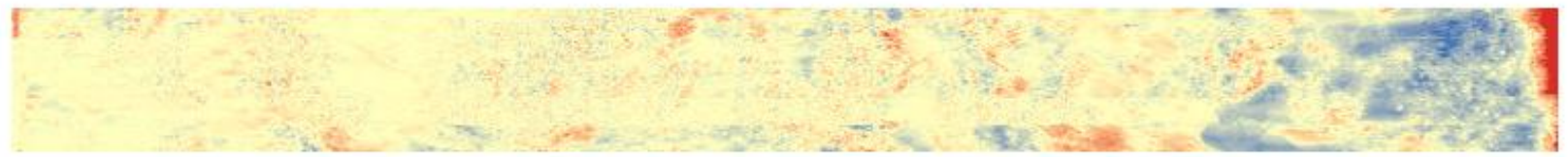

Part 1 to Part 2

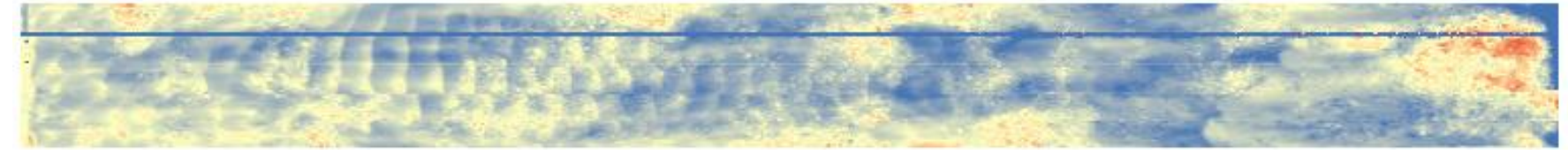

Part 2 to Part 3

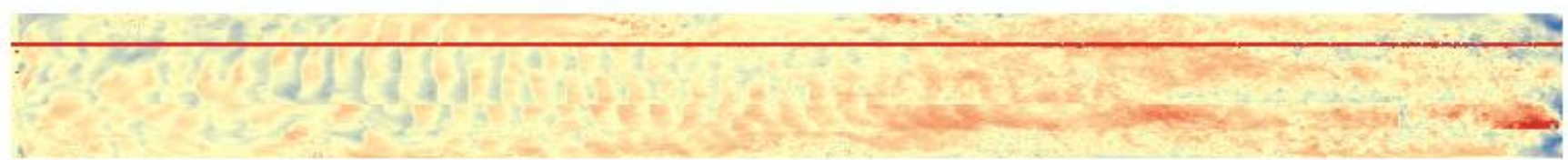

Part 3 to Part 4 



This Run was stopped after Part 1 due to excessive erosion Pre-Removal to Part 1
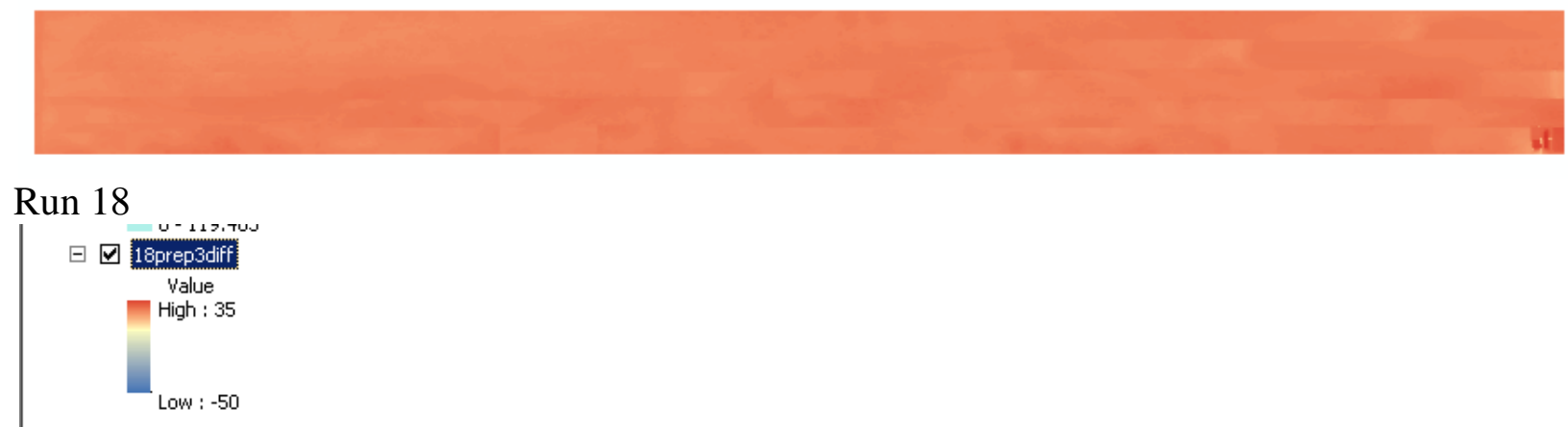

Pre-Removal to Final



Pre-Removal to Part 1

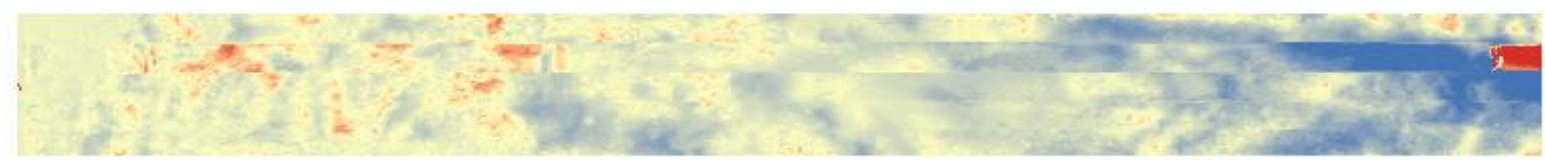


Part 1 to Part 2



Part 2 to Part 3

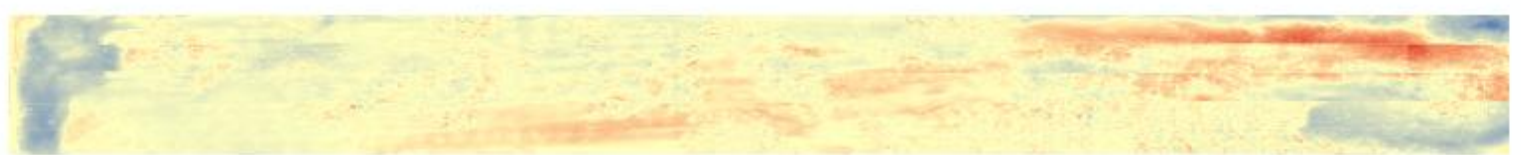

Run 19

$\square \square$ 19prep3dif



Pre-Removal to Final

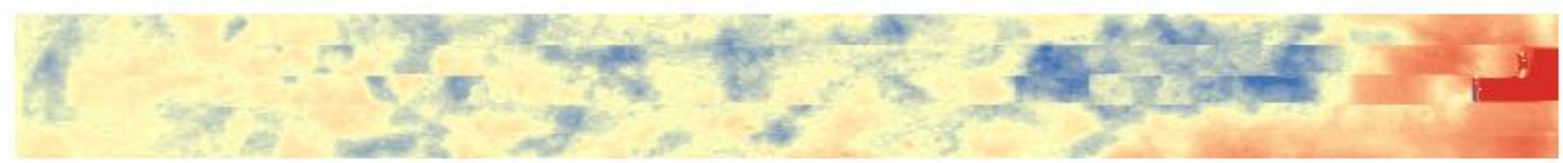

Pre-Removal to Part 1

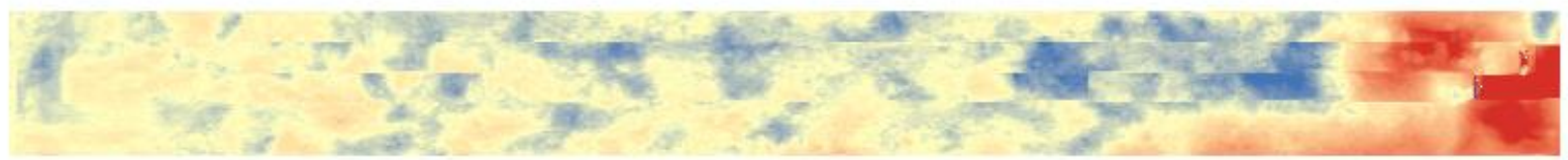

Part 1 to Part 2

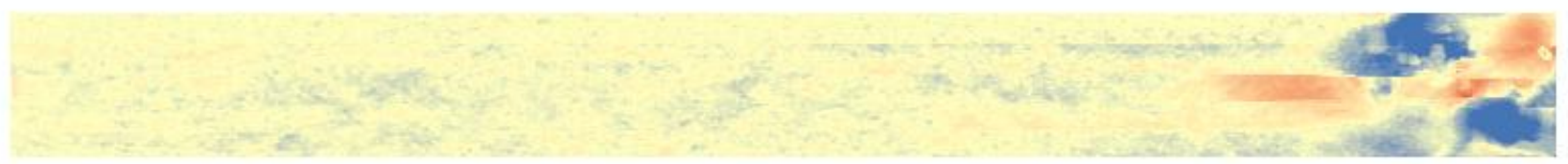

Part 2 to Part 3



Run 20 
$\square \square 20 \mathrm{p} 2 \mathrm{p} 3 \mathrm{diff}$

value

High : 25

Low : -50

Pre-Removal to Final

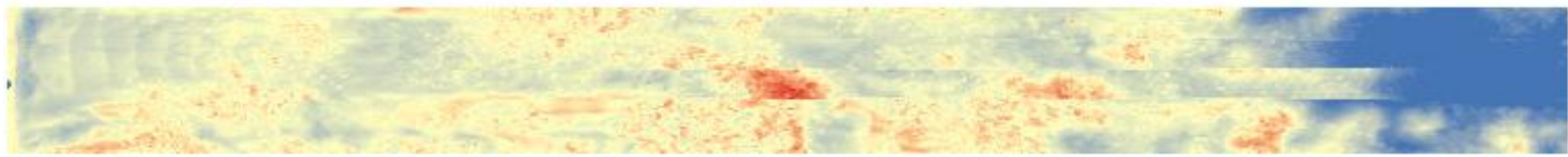

Pre-Removal to Part 1

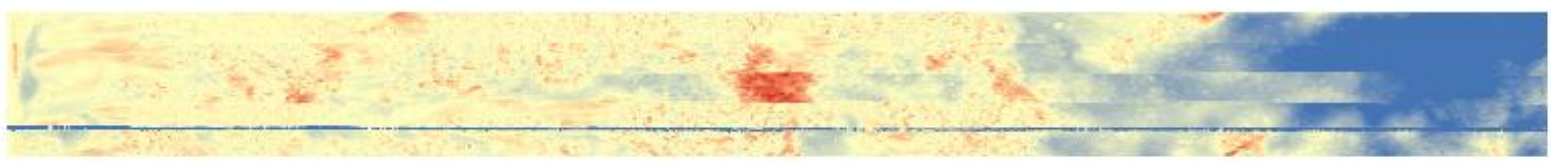

Part 1 to Part 2

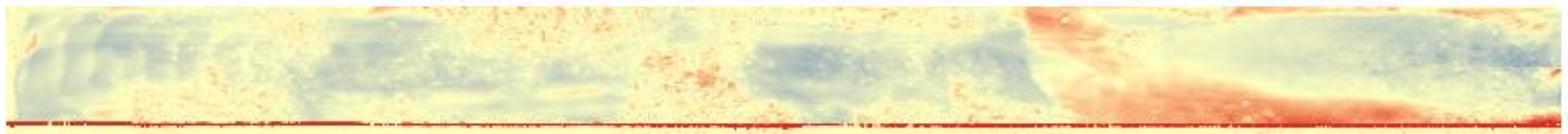

Part 2 to Part 3

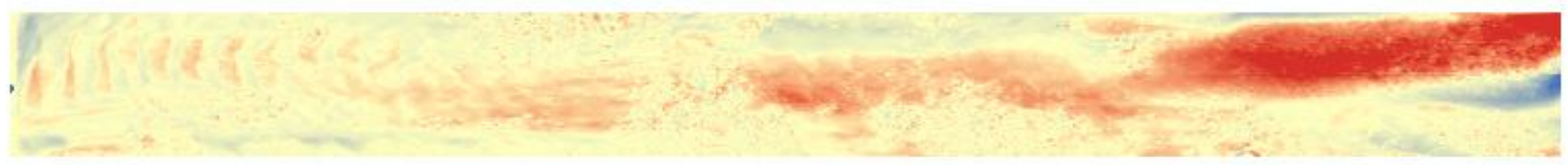

Run 21

$\square \square$ 21prep1diff

Value

High : 75

Low : -75

Pre-Removal to Final

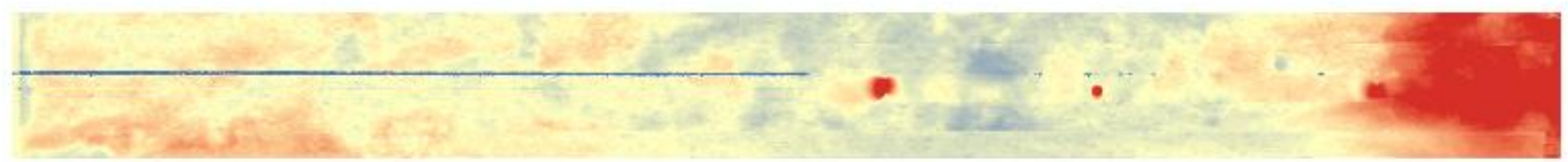

Pre-Removal to Part 1

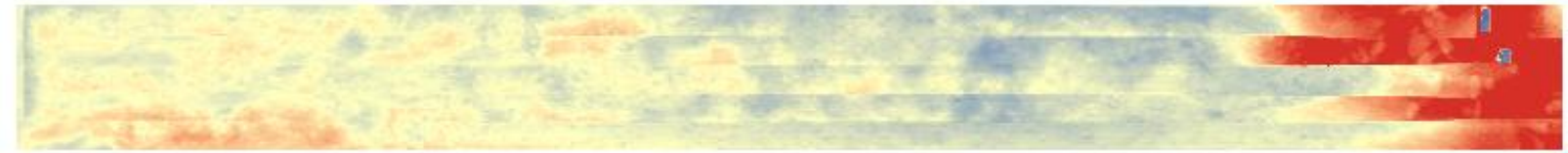

Part 1 to Part 2 


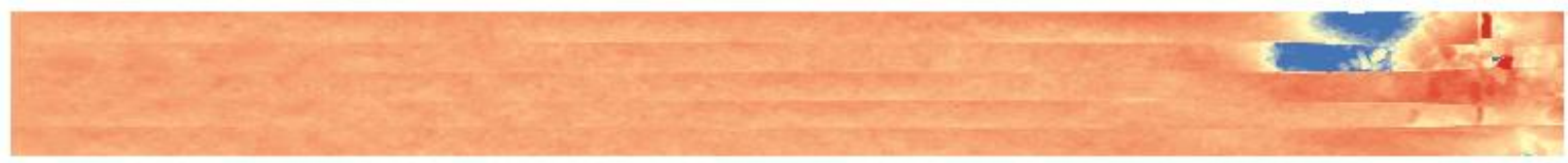

Part 2 to Part 3
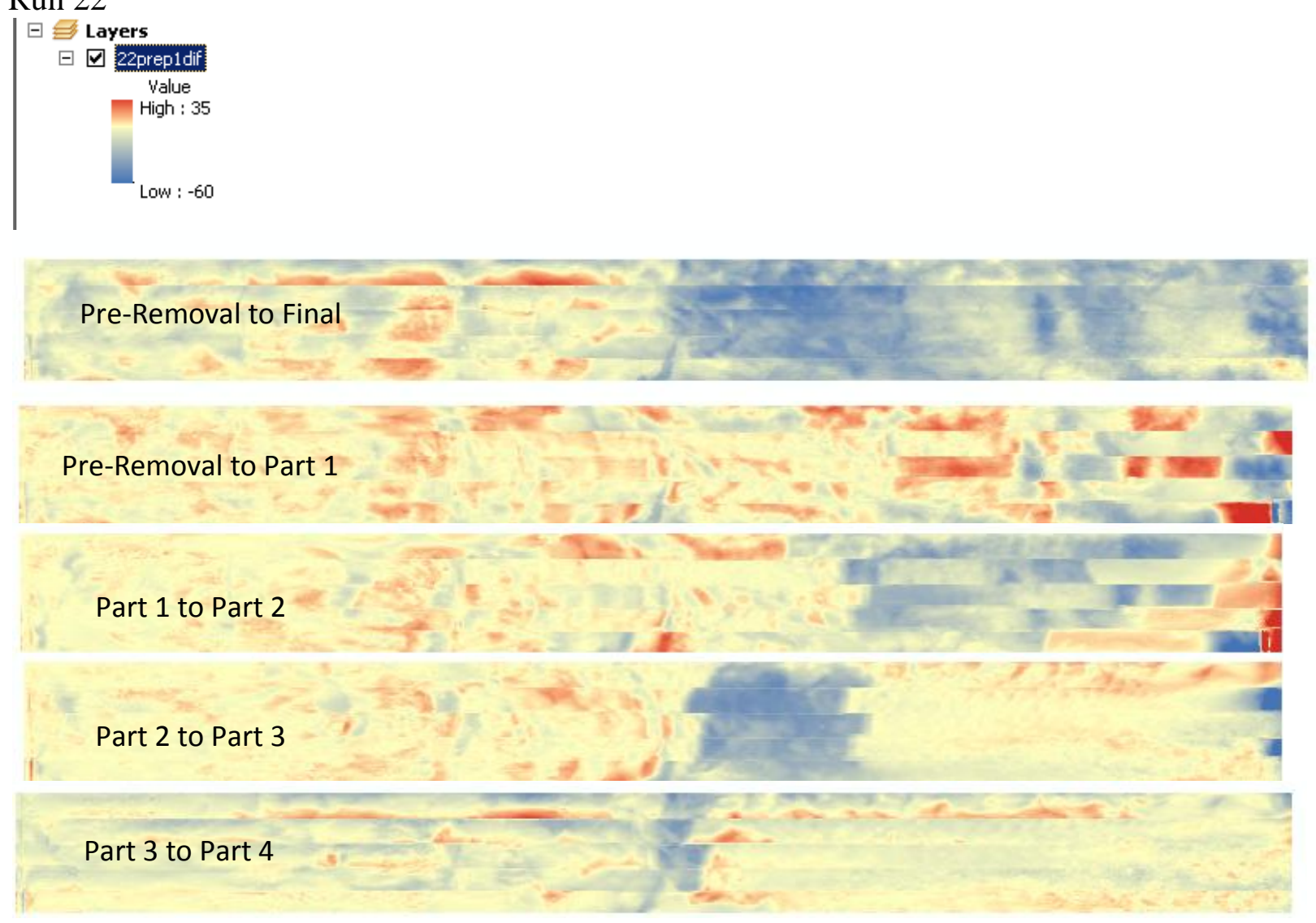

\section{Run 24}






\section{Run 25}

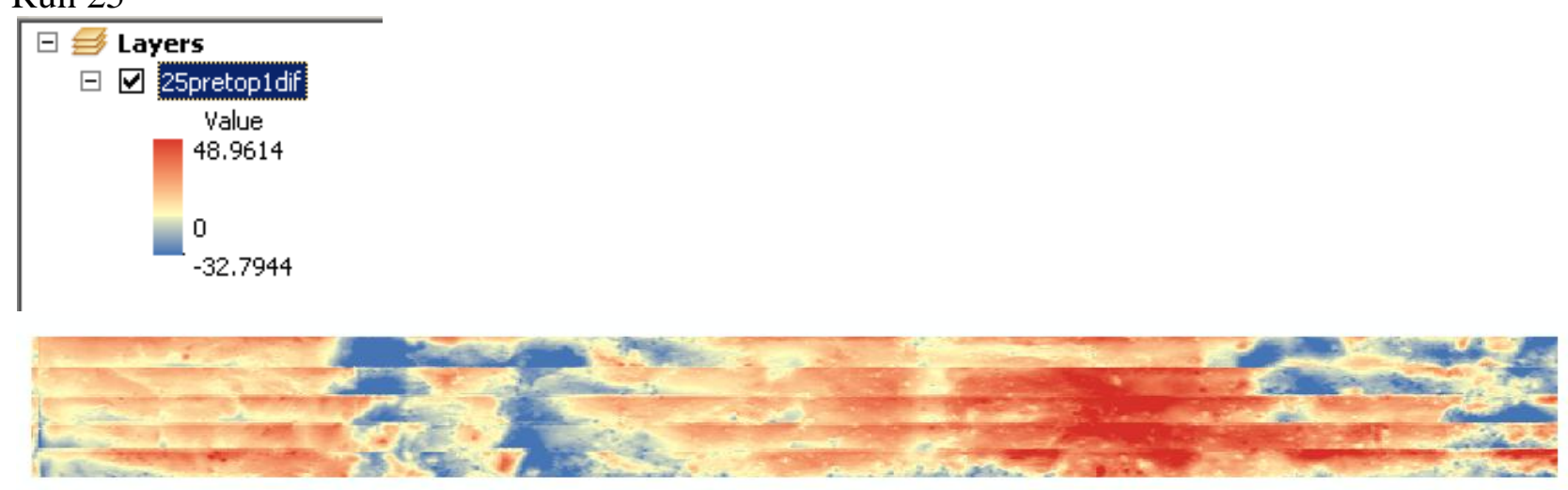

Run 30

$\square \square 30 p 1 p 2 d i f$

Value

High : 25

Low : -25

Pre-Removal to Final

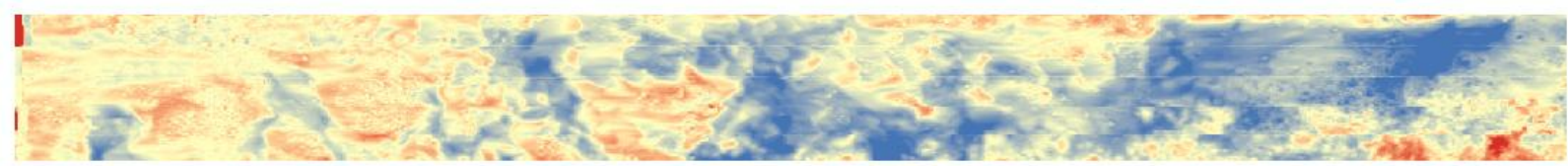

Pre-Removal to Part 1

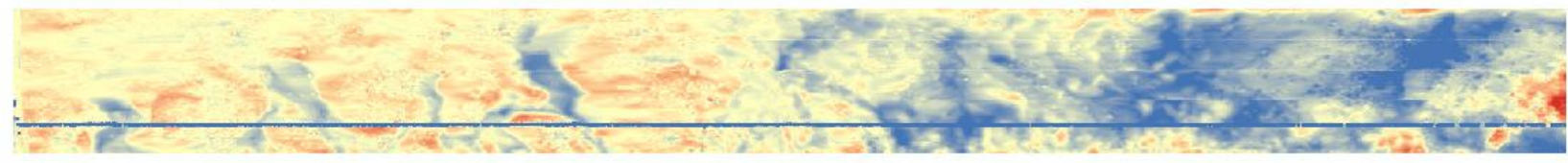

Part 1 to Part 2

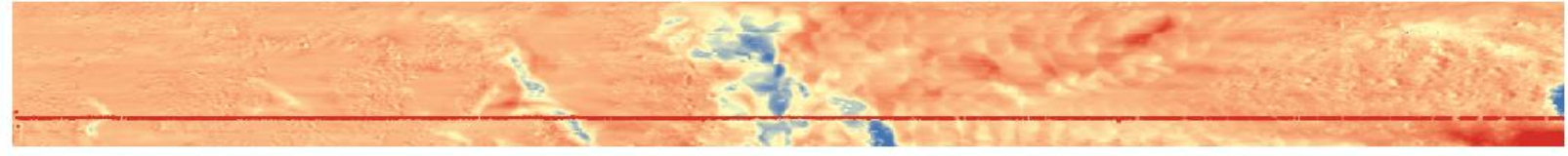

Part 2 to Part 3

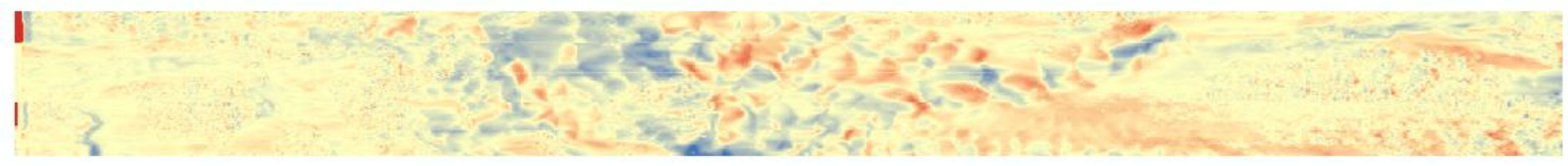

Run 31 




Pre-Removal to Final



Pre-Removal to Part 1

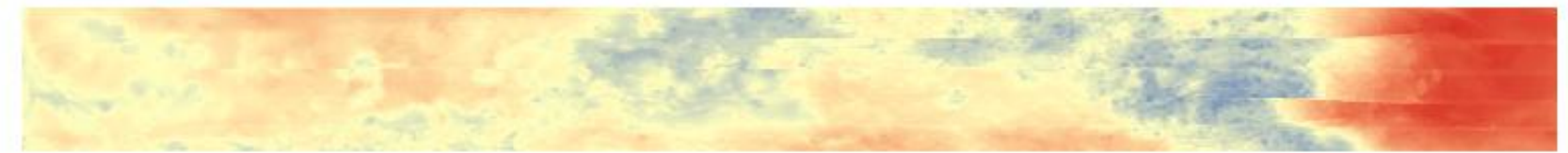

Part 1 to Part 2

Part 2 to Part 3

\section{Appendix G: Matlab Code}

function [root,ea,iter] $=$ newtraph(func,deriv,xr,es,maxit $)$

$\%$ newtraph: Newton-Raphson root location

$\% \quad[$ root,ea,iter $]=$ newtraph(func,deriv,xr,es,maxit) uses Newton-Raphson

$\%$ method to find the foot of func

$\%$ Input:

$\%$ func $=$ name of function

$\%$ deriv $=$ name of derivative of function

$\% \mathrm{xr}=$ initial root guess

$\%$ es $=$ desired relative error $($ default $=0.0001 \%)$

$\%$ maxit $=$ maximum number of iterations $($ default $=50)$ 


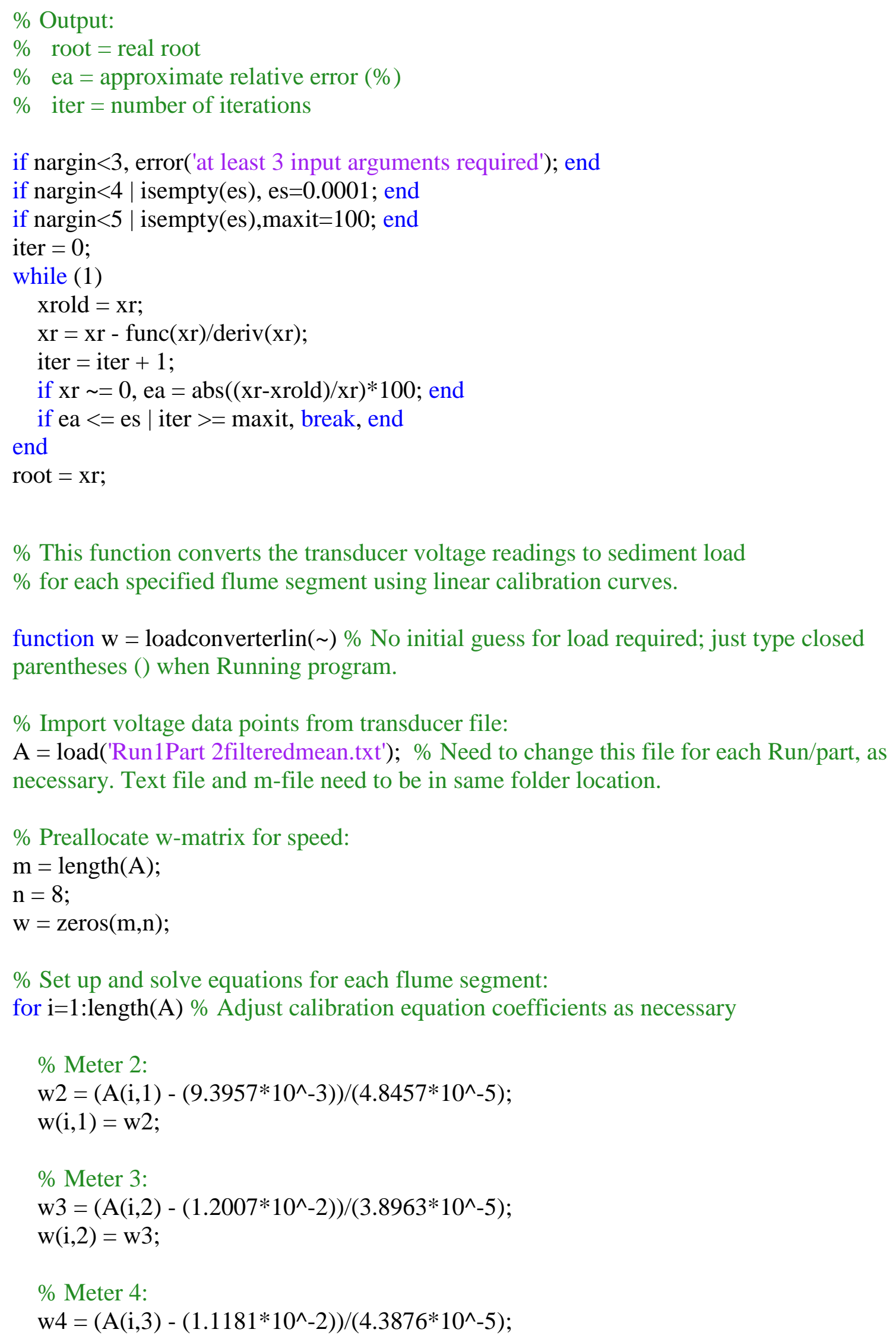




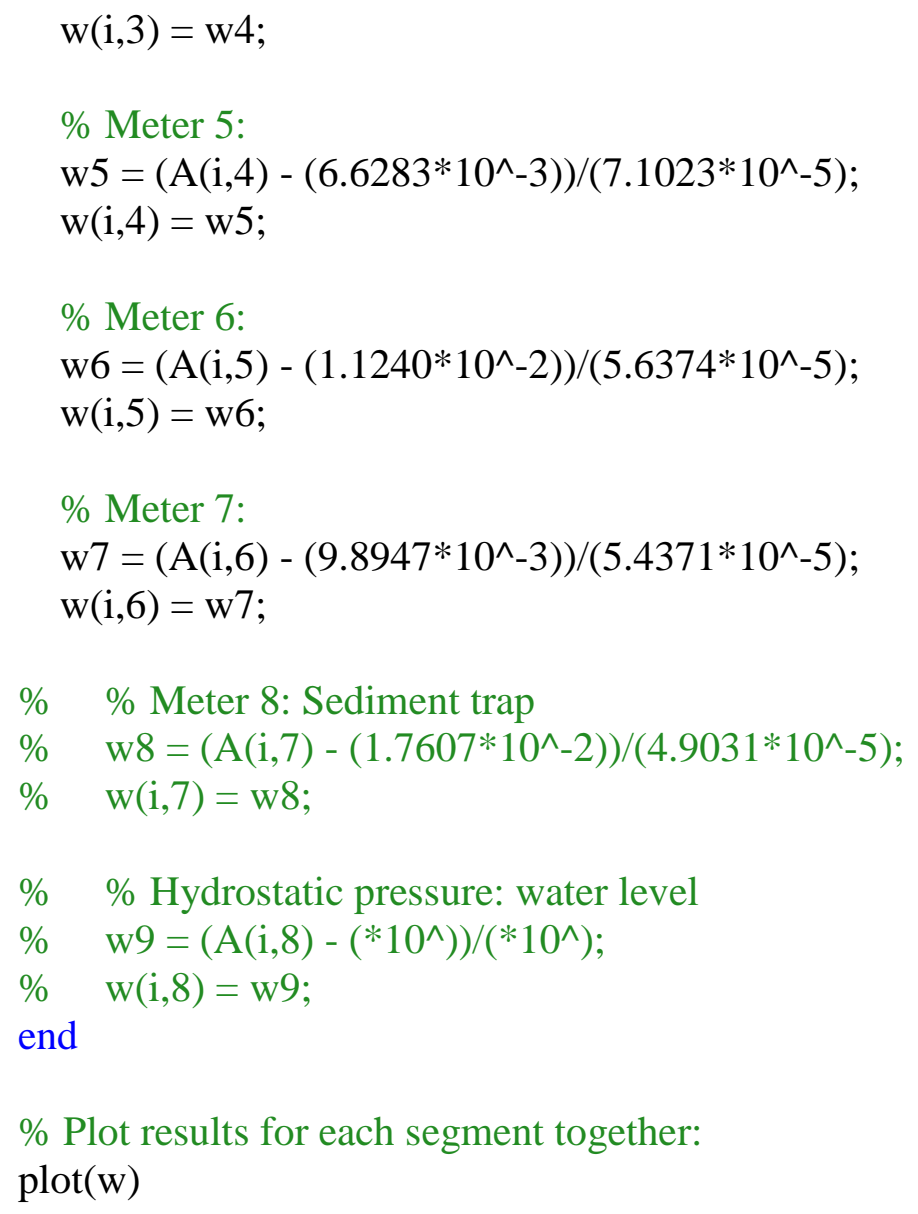


$\%$ Set up and solve equations for each flume segment using Newton-Raphson numerical rootfinding method:

for $\mathrm{i}=1$ :length(A) \% Adjust calibration equation coefficients as necessary

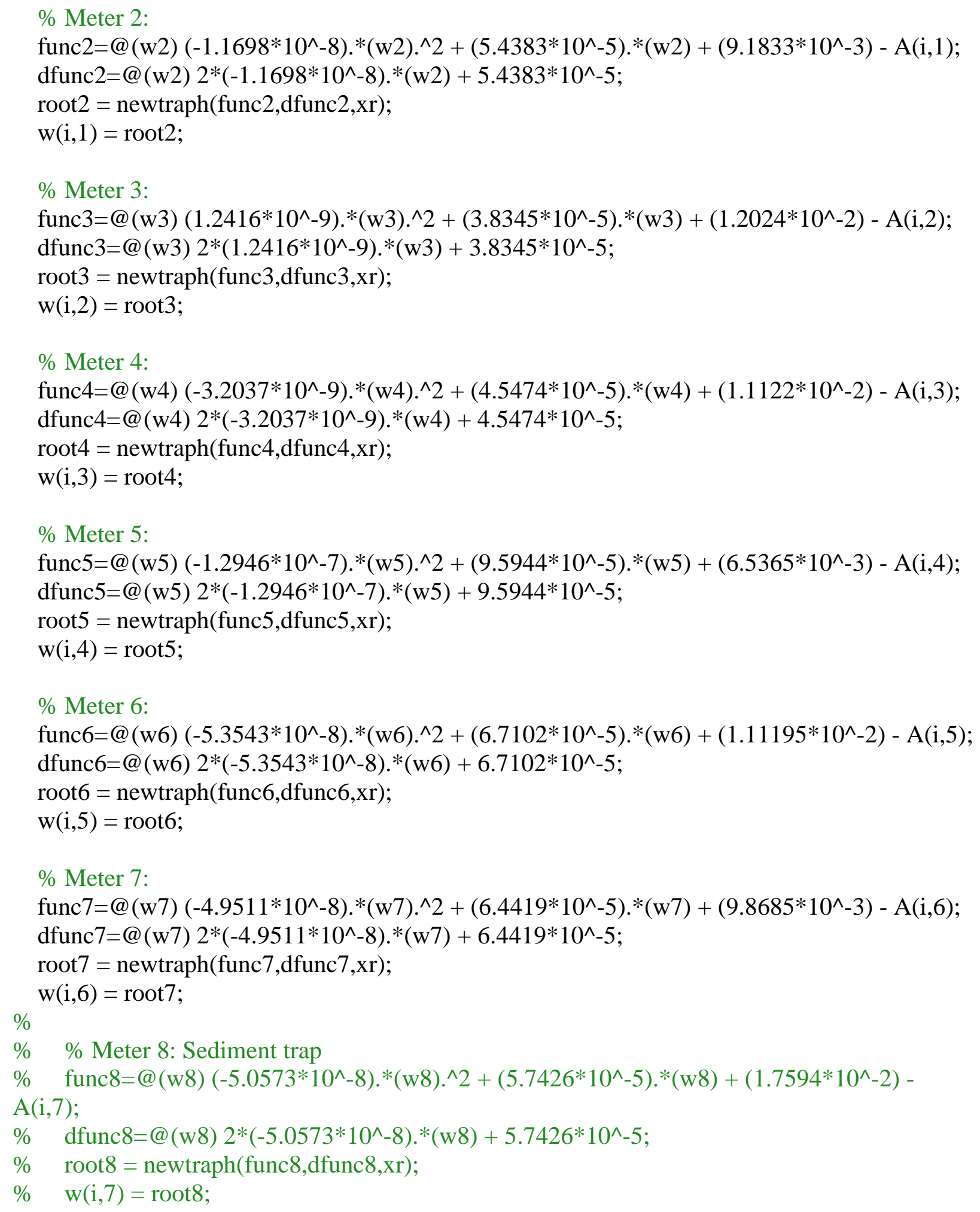


$\% \quad \%$ Hydrostatic pressure: water level

$\%$ func9=@(w9) $\left(-4.4903 * 10^{\wedge}-8\right) . *(w 9) . \wedge 2+\left(5.6857 * 10^{\wedge}-5\right) . *(w 9)+\left(1.7594 * 10^{\wedge}-2\right)-$ $\mathrm{A}(\mathrm{i}, 8)$;

$\%$ dfunc9=@(w9) $2 *\left(-4.4903 * 10^{\wedge}-8\right) *($ w9) + 5.6857*10^-5;

$\% \operatorname{root} 9=$ newtraph$($ func 9, dfunc $9, \mathrm{xr}$ );

$\% \quad \mathrm{w}(\mathrm{i}, 8)=\operatorname{root} 9$;

end

$\%$ Plot results for each segment together:

$\operatorname{plot}(\mathrm{w})$

$\%$ Write results to tab-delmited text file:

dlmwrite('Run1Part 4loads.txt',w,'It'); \% Adjust name for each Run/Partas necessary

\section{Run 2 Part 4}



\section{Run 3 Part 1}




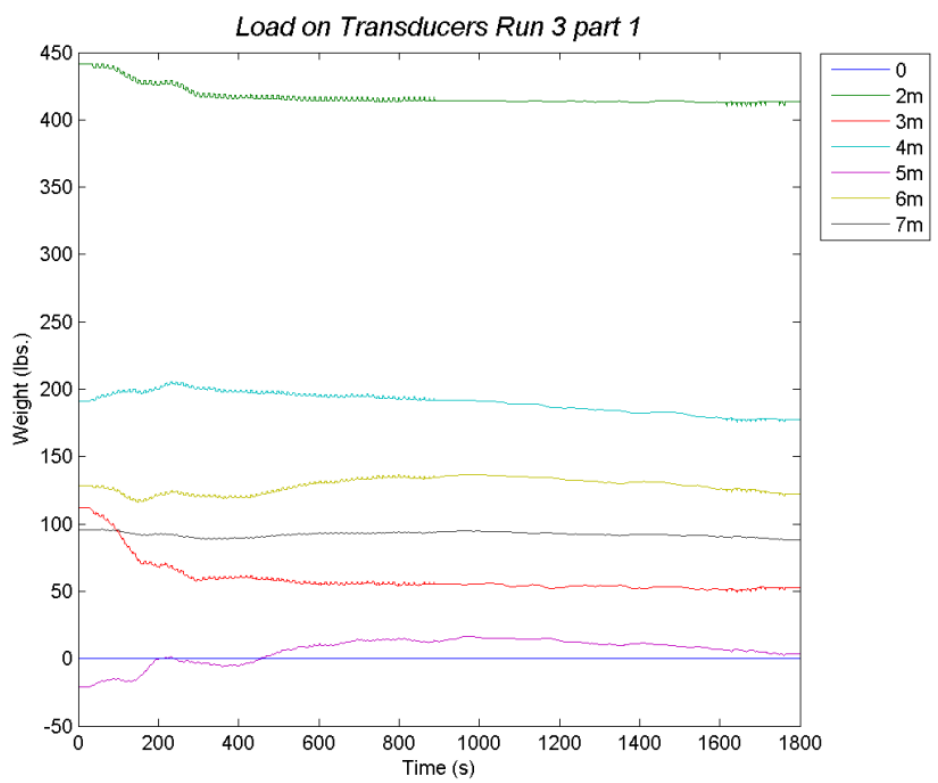

\section{Run 3 Part 3}

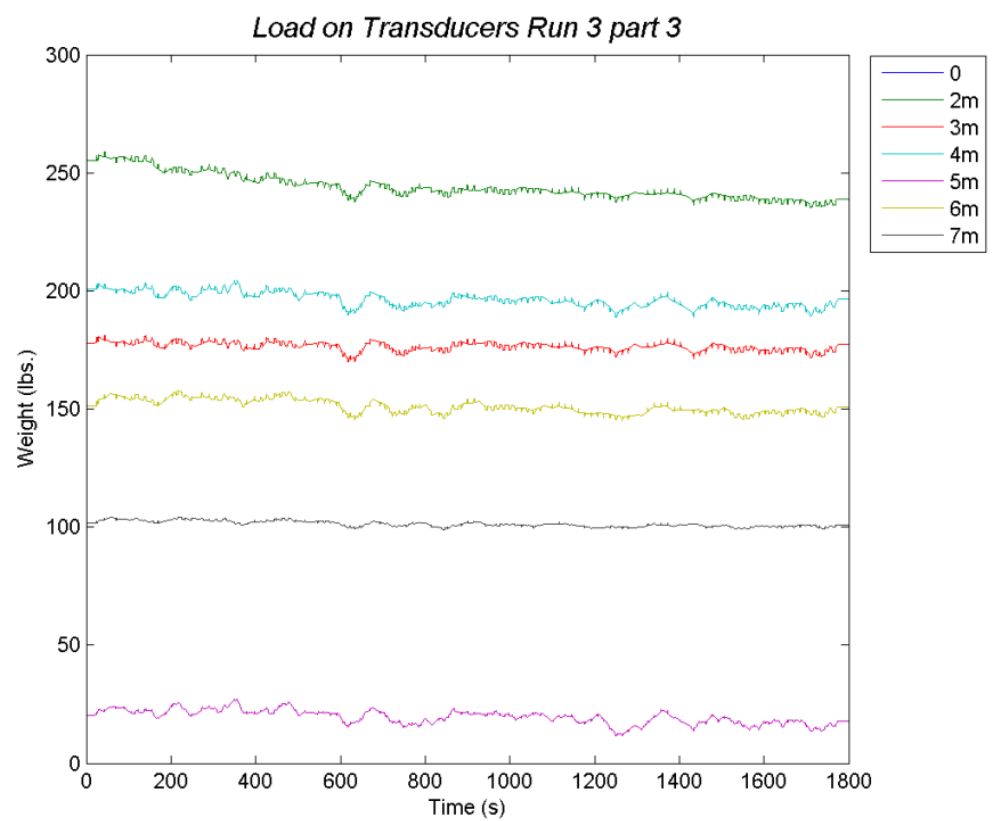

Run 3 Part 4 


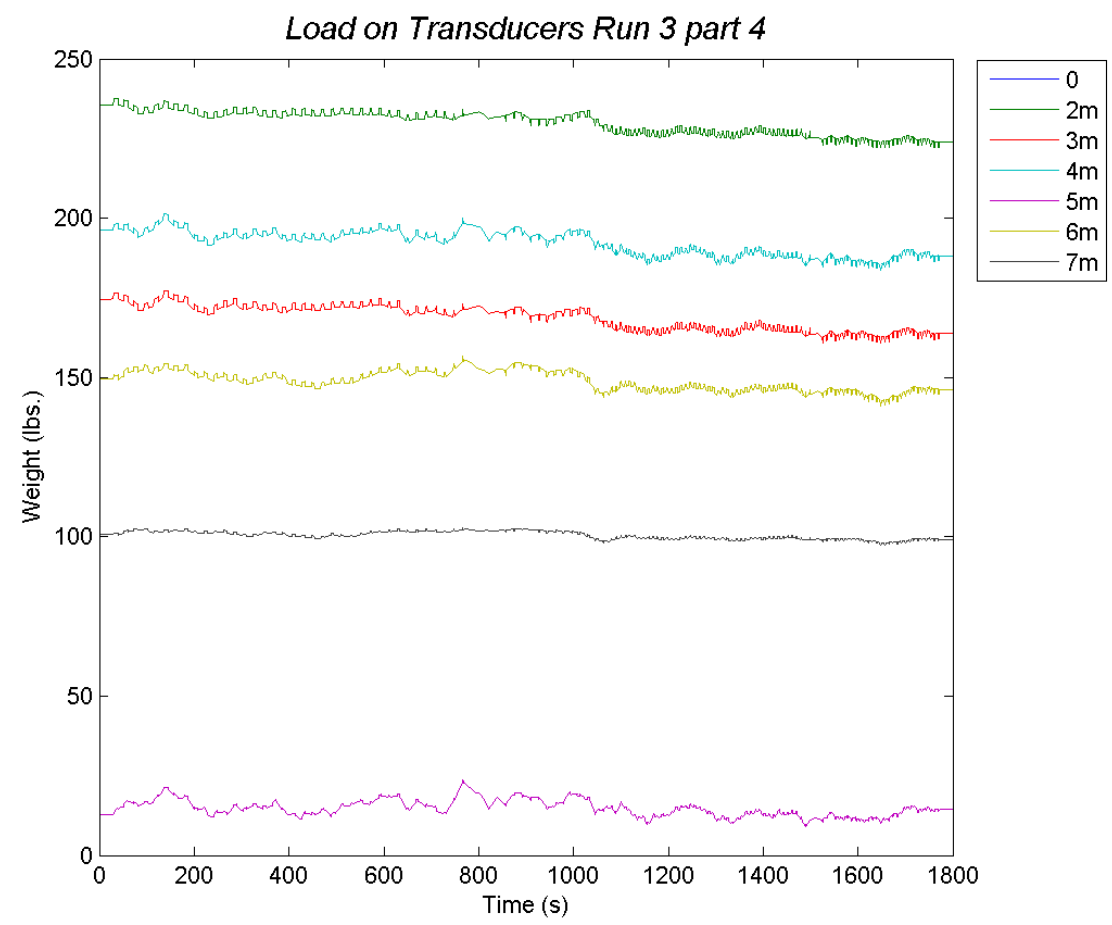

\section{Run 4 Part 1}

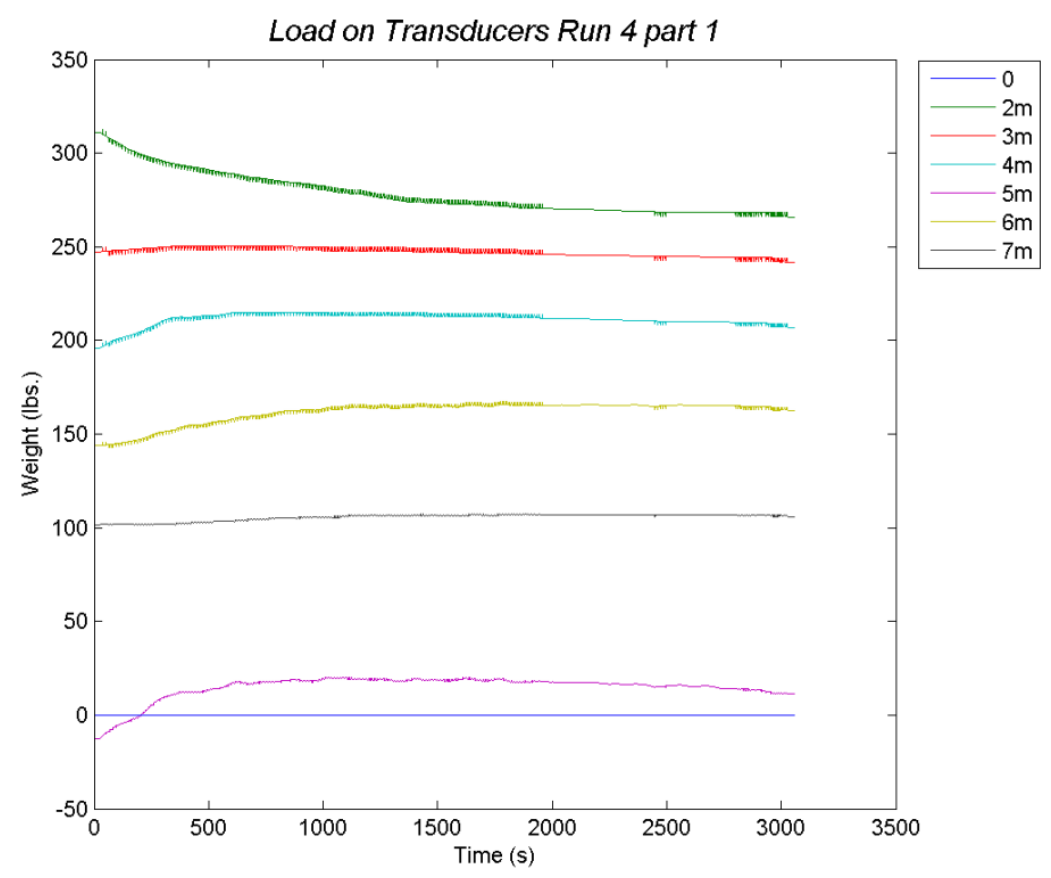


Run 6 Part 1

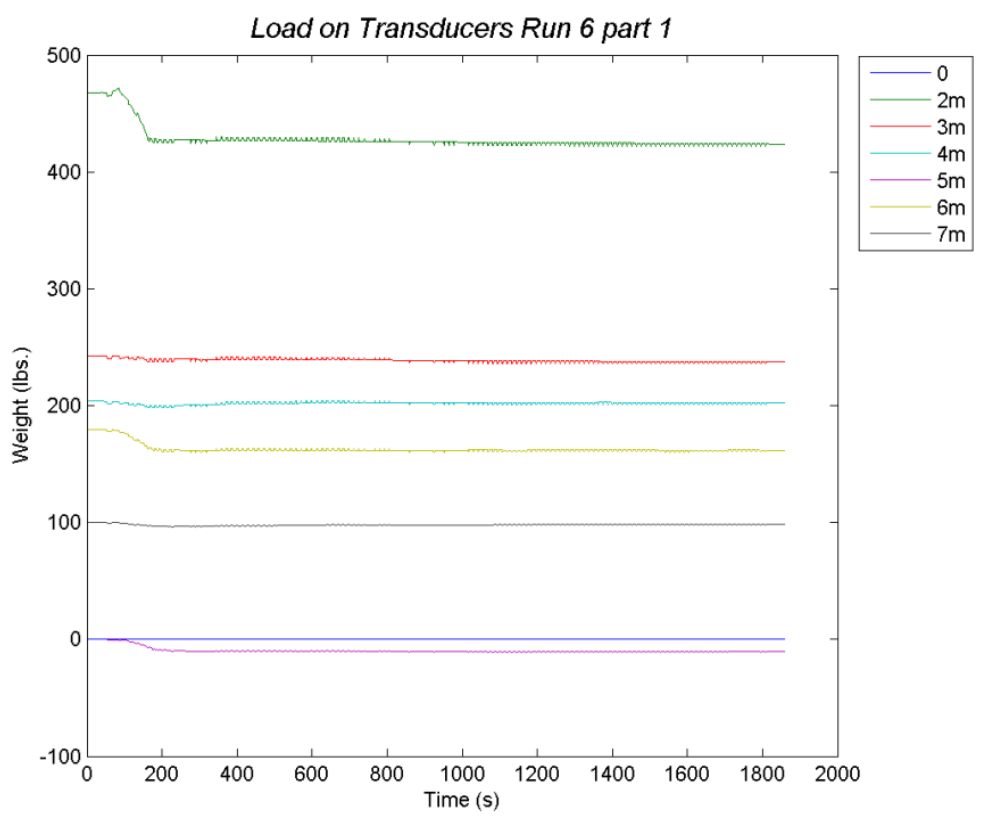

Run 6 Part 2



Run 6 Part 3 


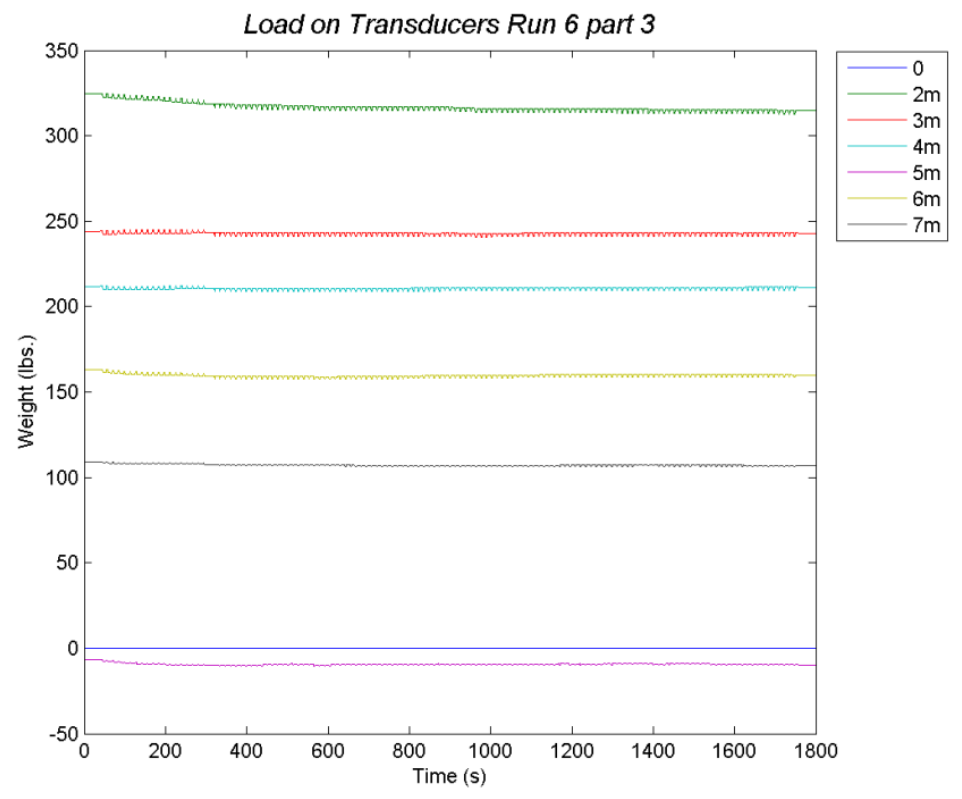

Run 7 Part 1

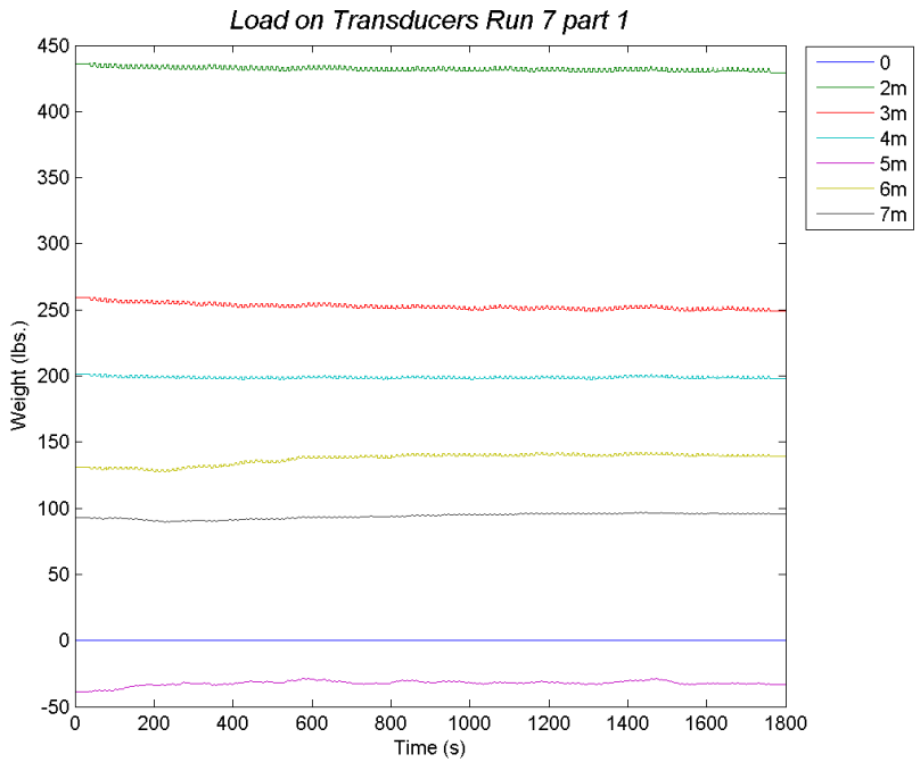

Run 8 Part 1 


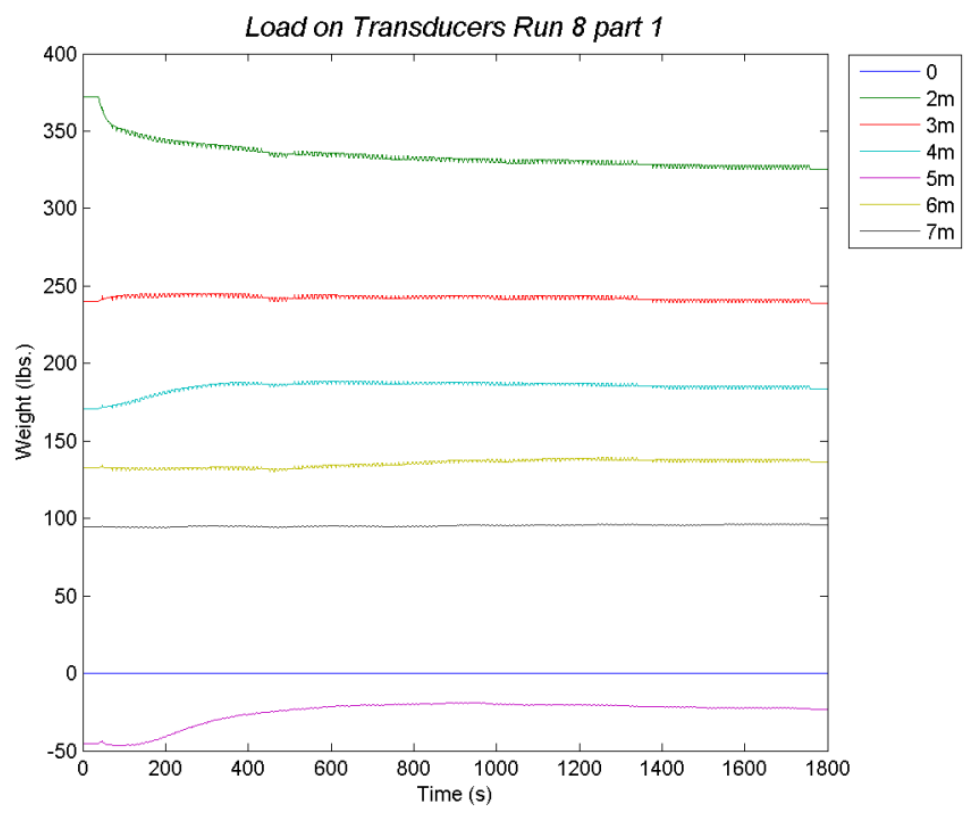

Run 8 Part 3



Run 9 Part 1 


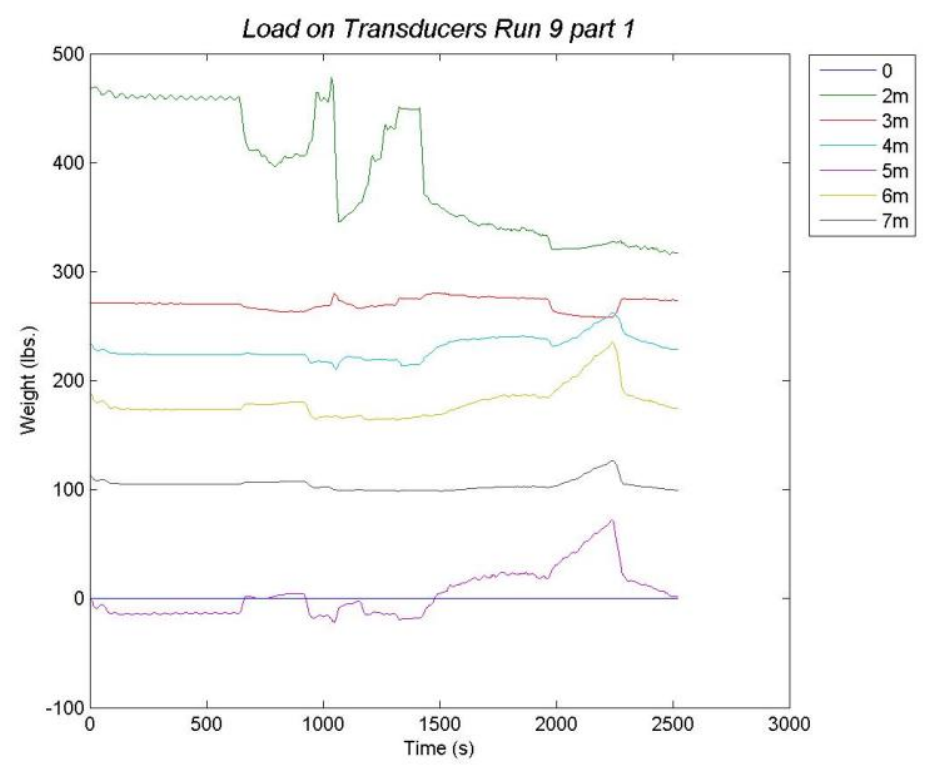

\section{Run 9 Part 2}

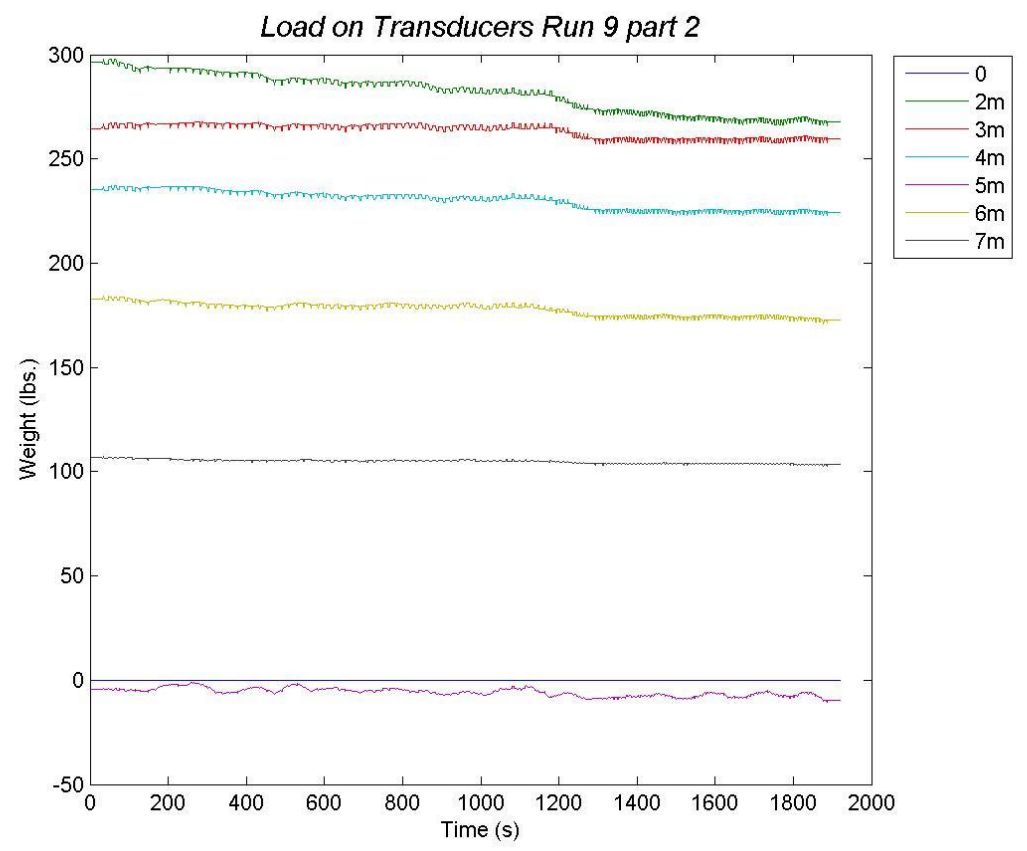

Run 9 Part 3 


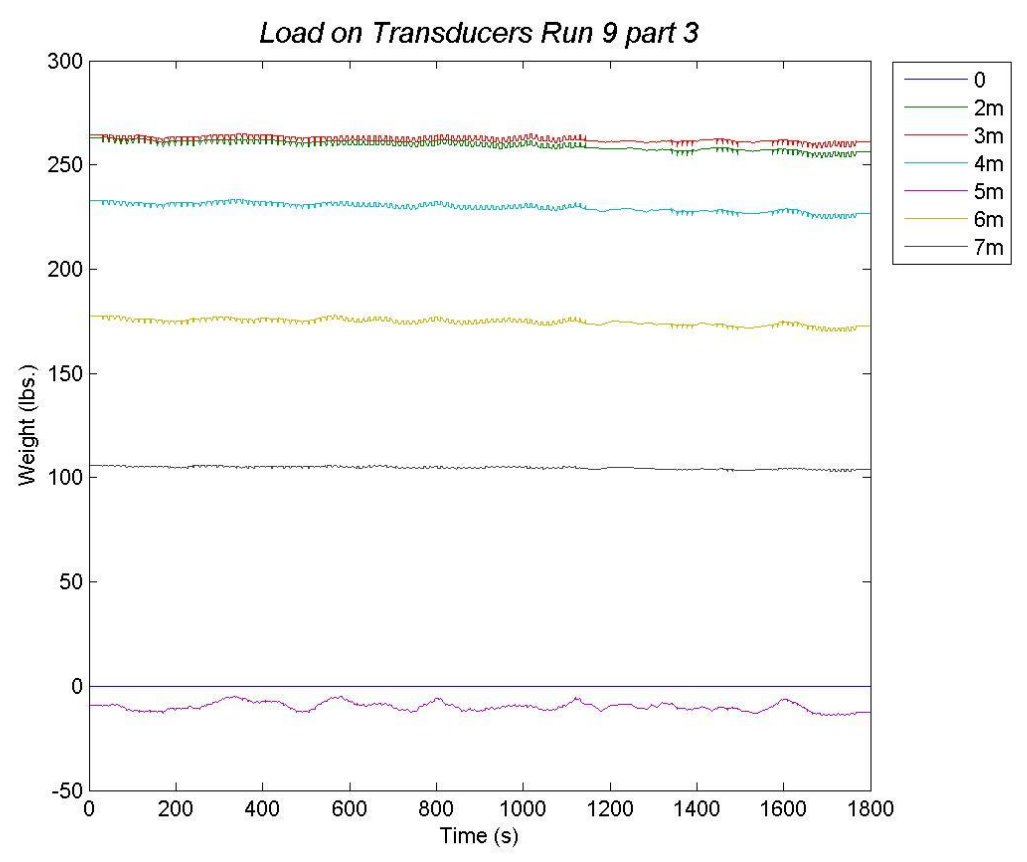

Run 10 Part 1

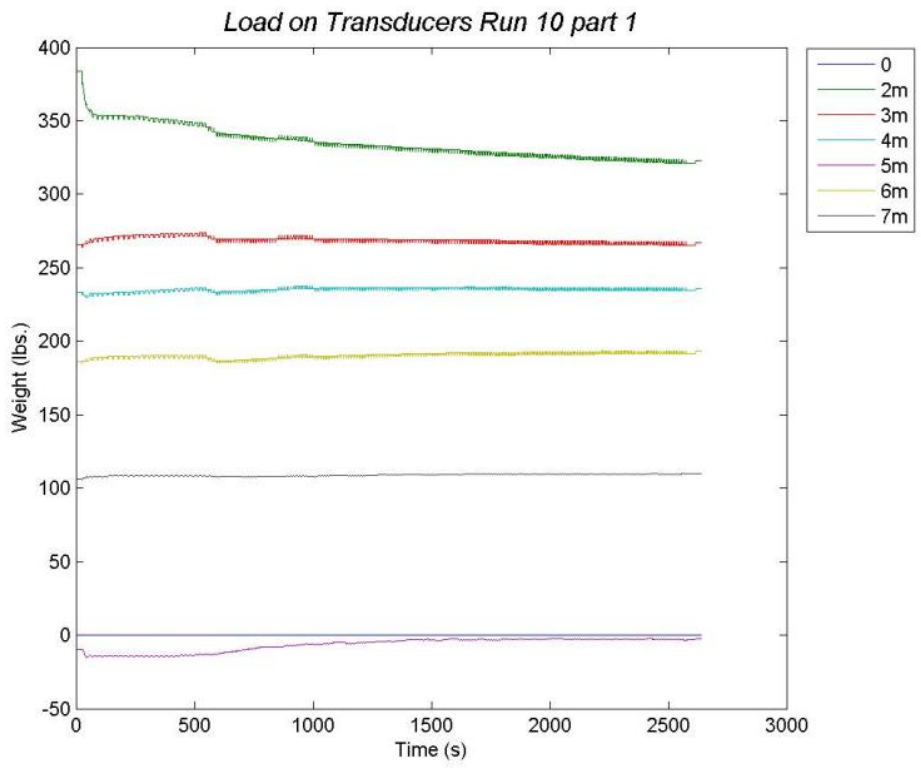

Run 10 Part 2 




Run 10 Part 3

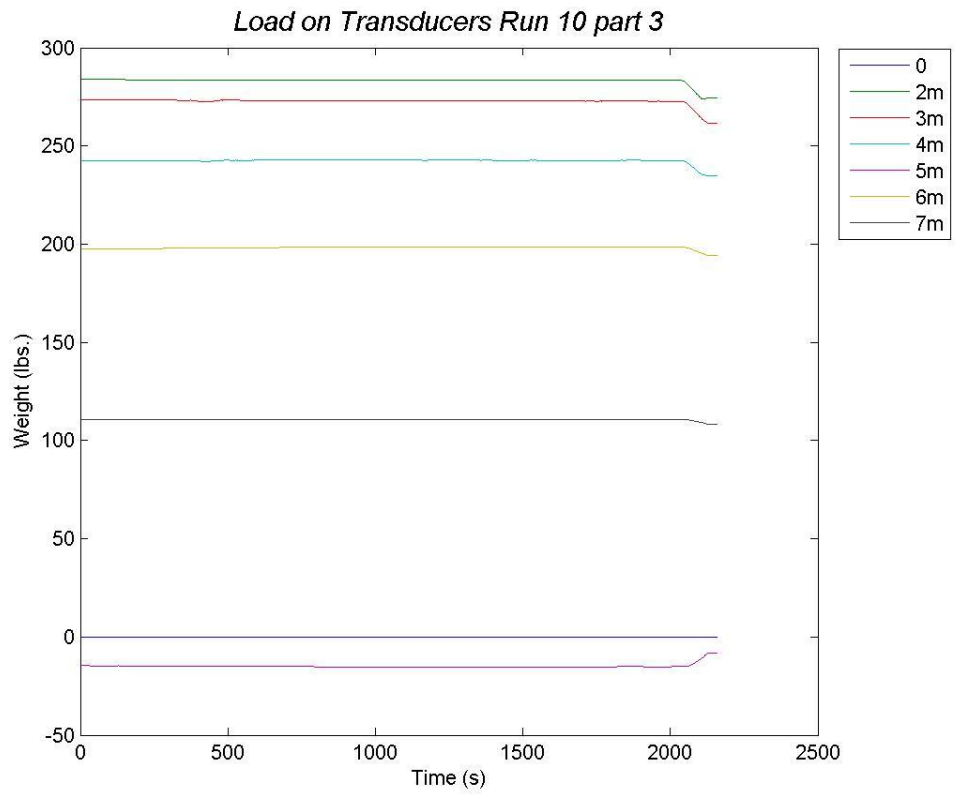

\section{Run 11 Part 1}




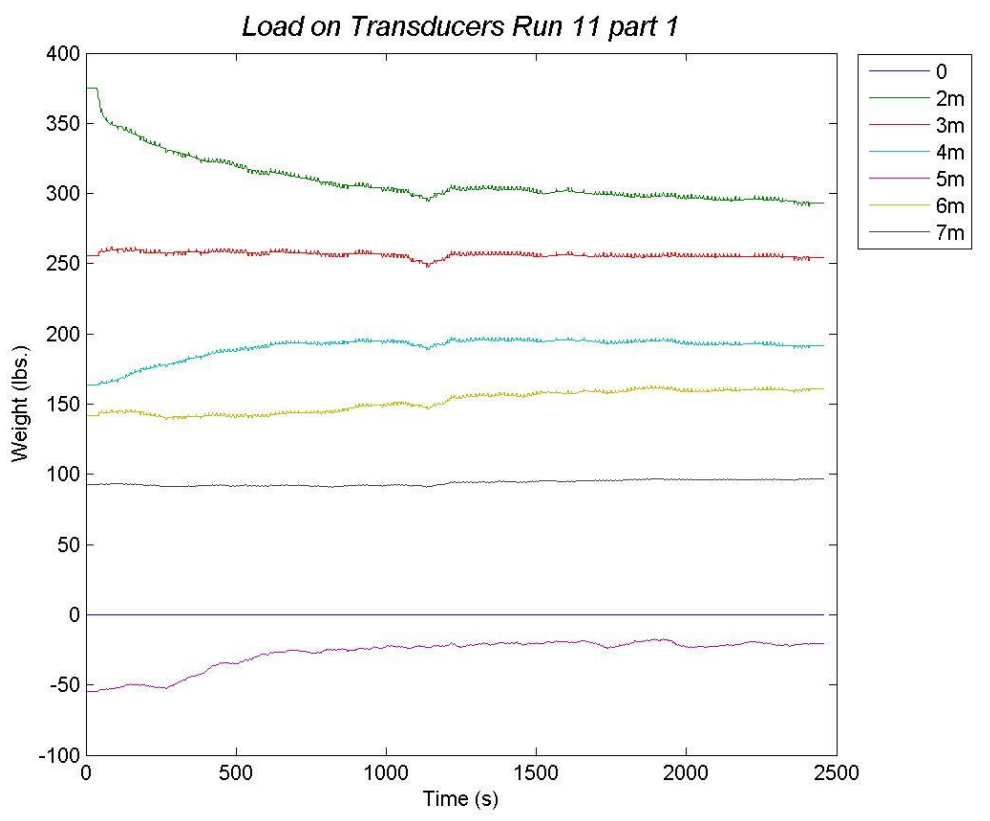

Run 11 Part 2

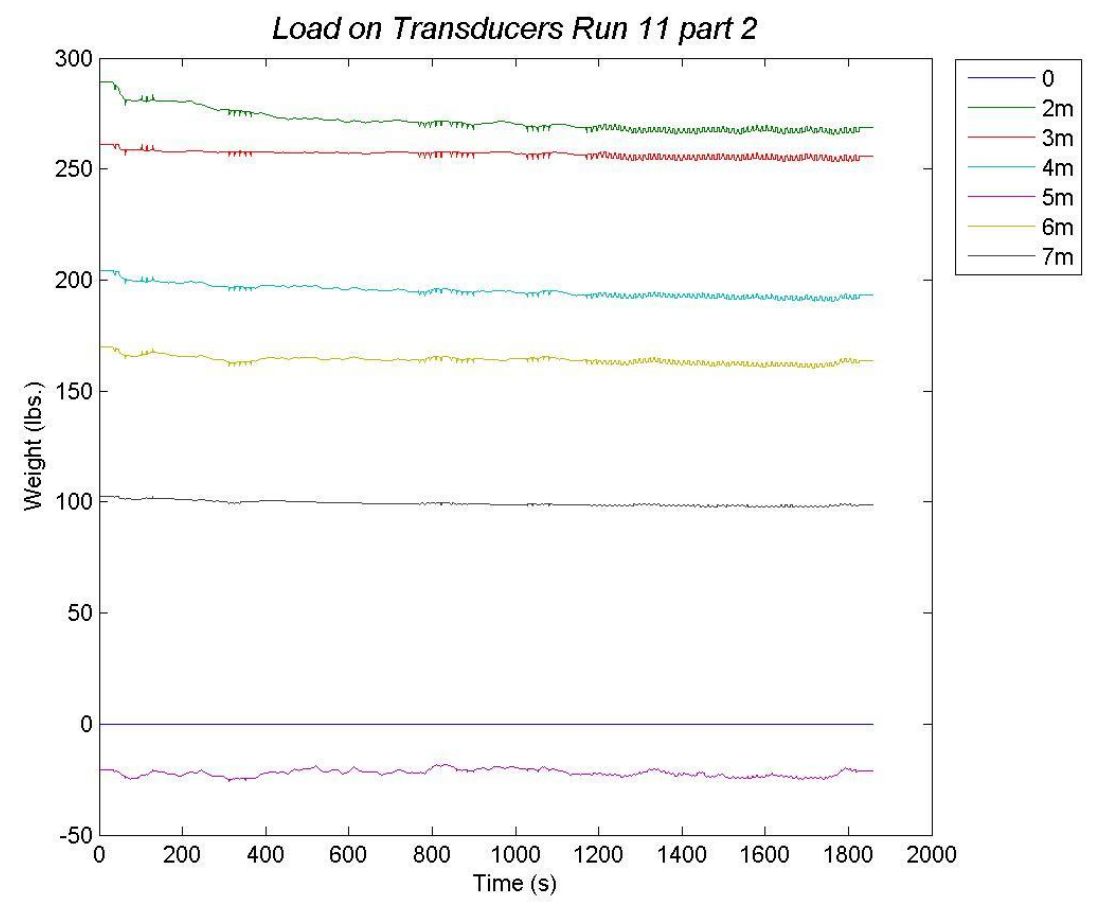

Run 11 Part 3 


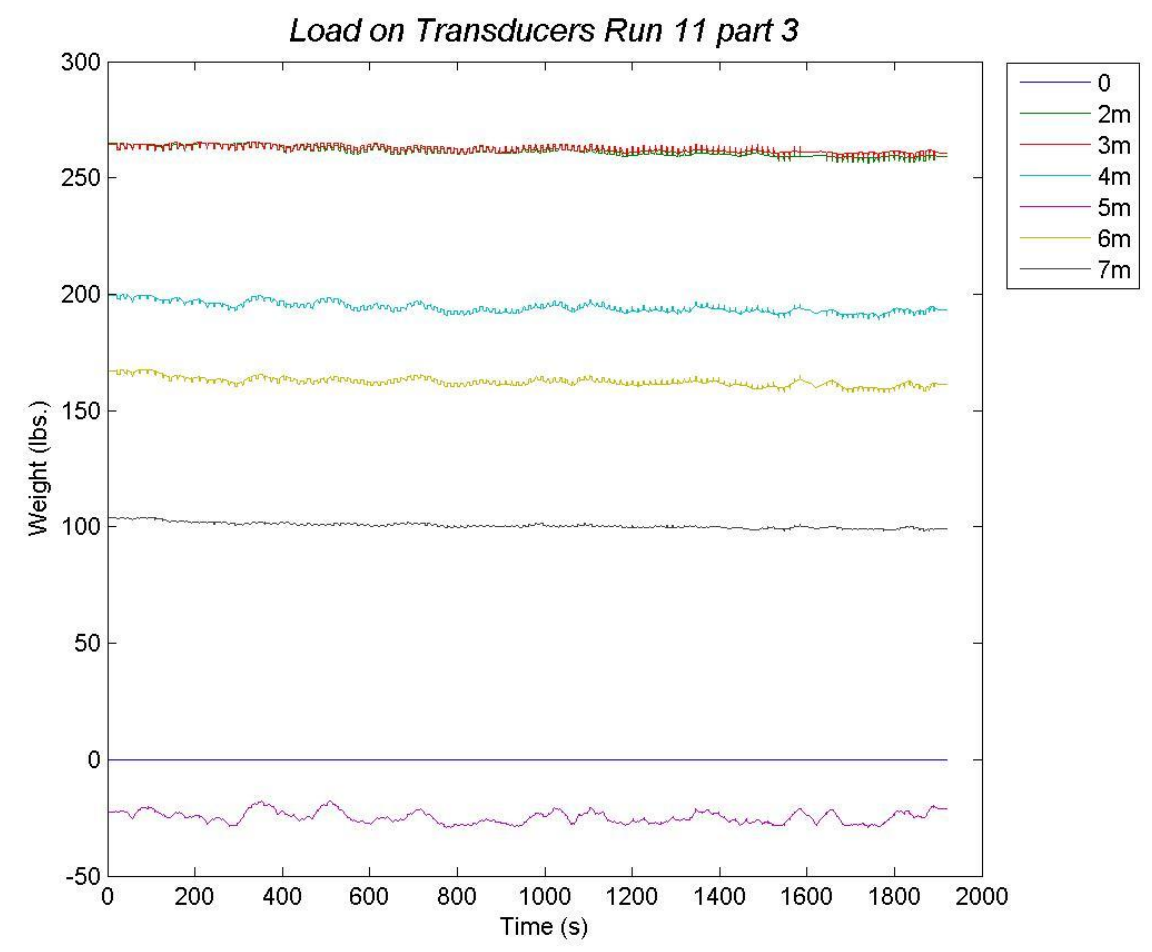

Run 12 Part 4

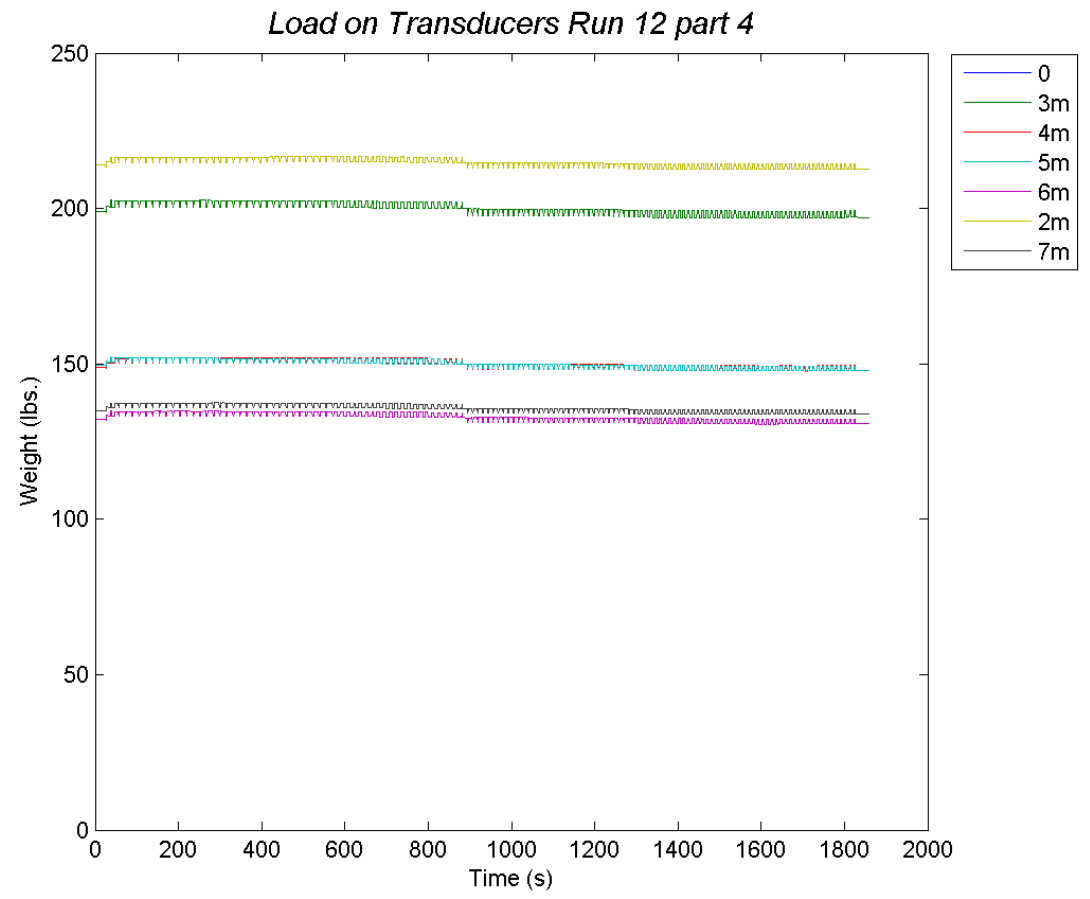

Run 15 Part 1 




Run 16 Part 4



\section{Run 19 Part 1}




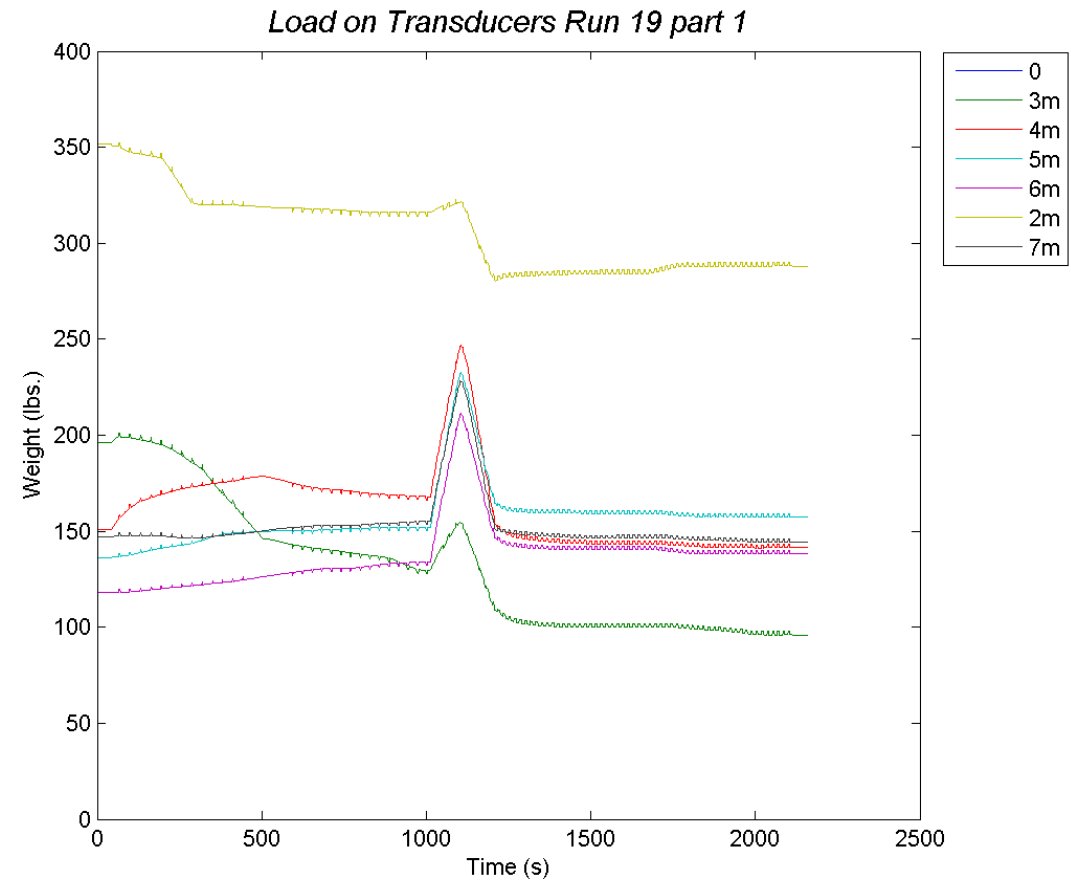

Run 19 Part 2



Run 19 Part 3 


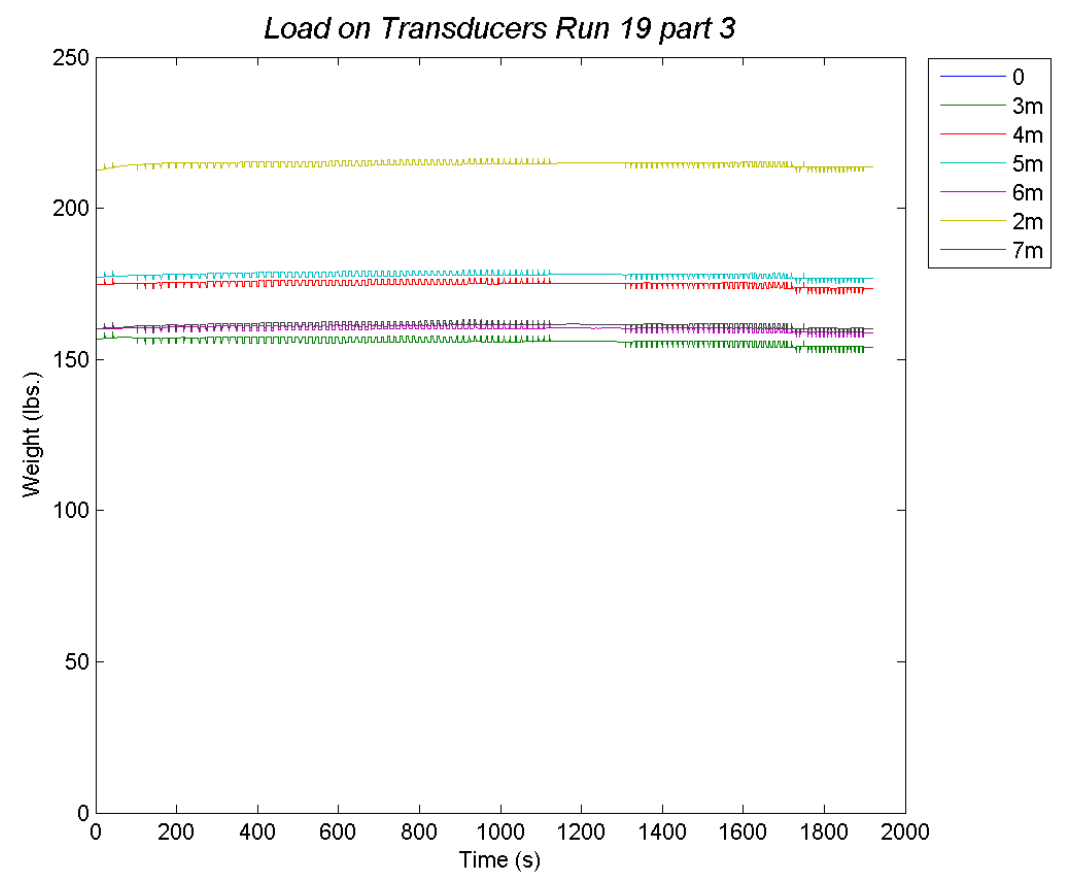

Run 22 Part 1



Run 22 Part 2 


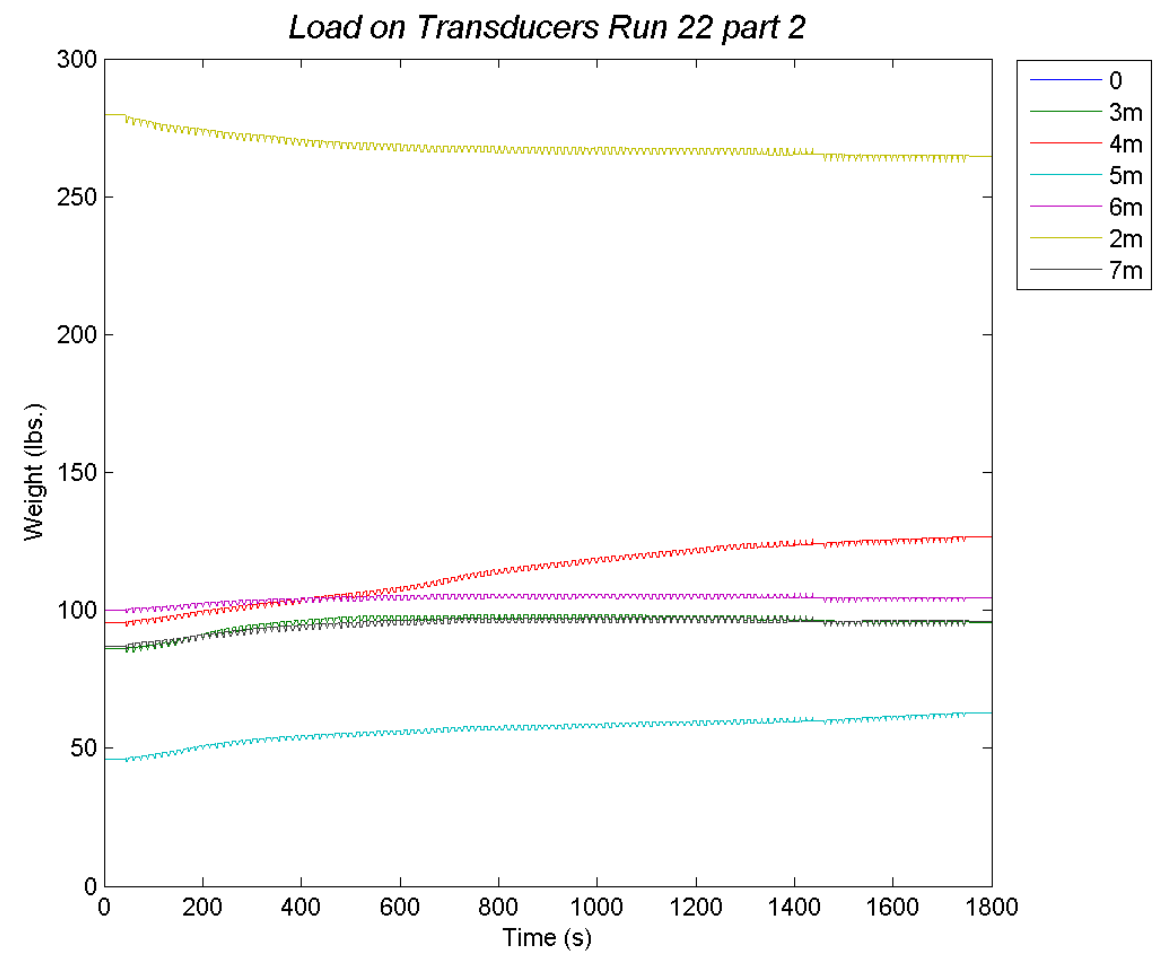

Run 22 Part 3

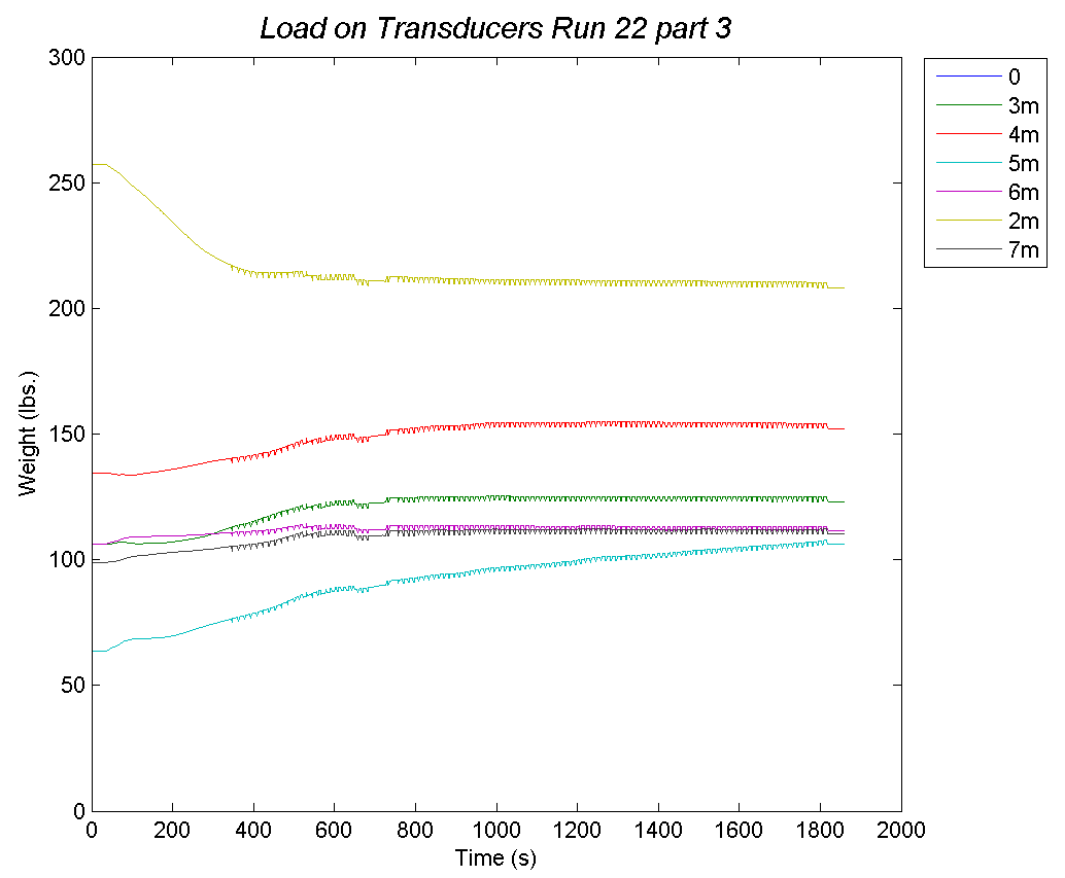

Run 22 Part 4 




\section{Run 24 Part 1}

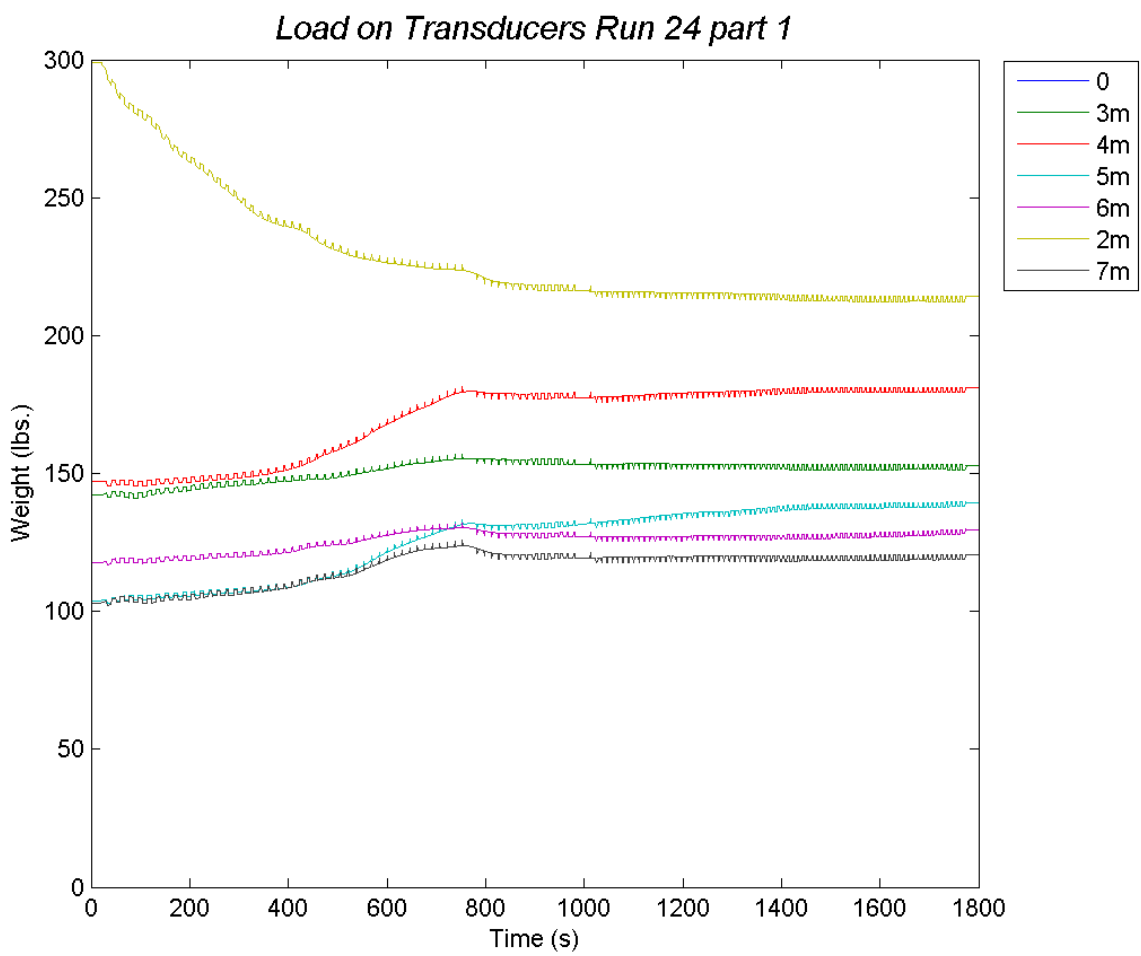

Run 25 Part 1 




Run 30 Part 1

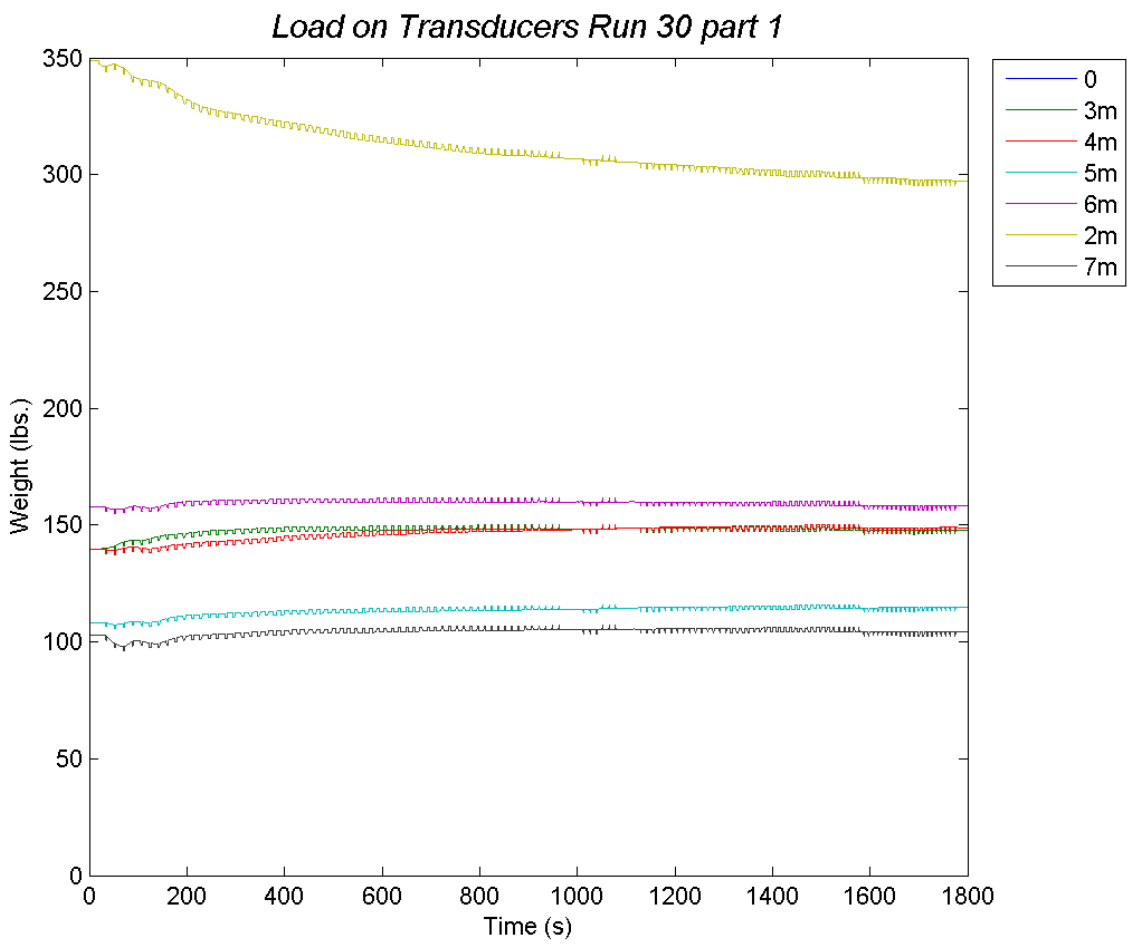

Run 30 Part 2 


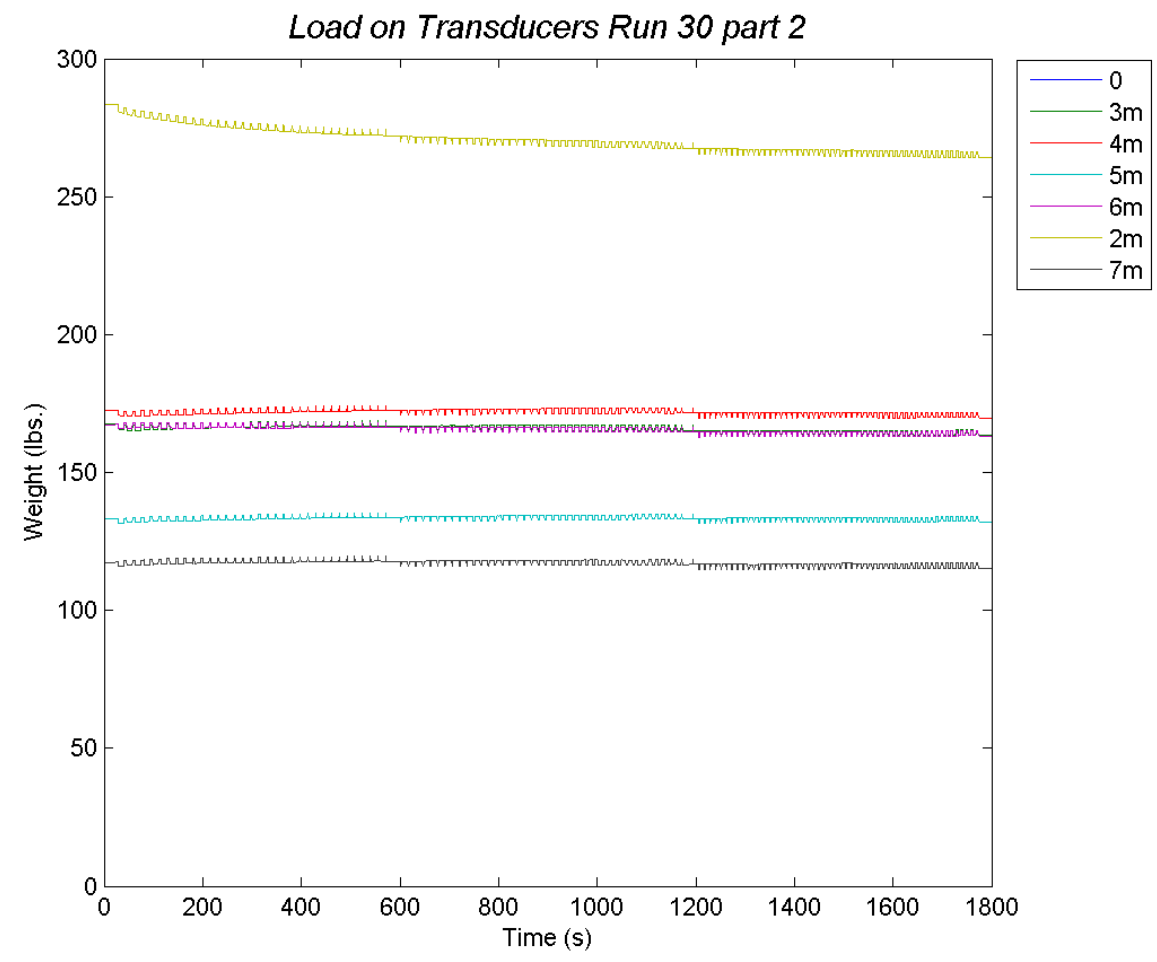

Run 30 Part 3



Run 31 Part 2 


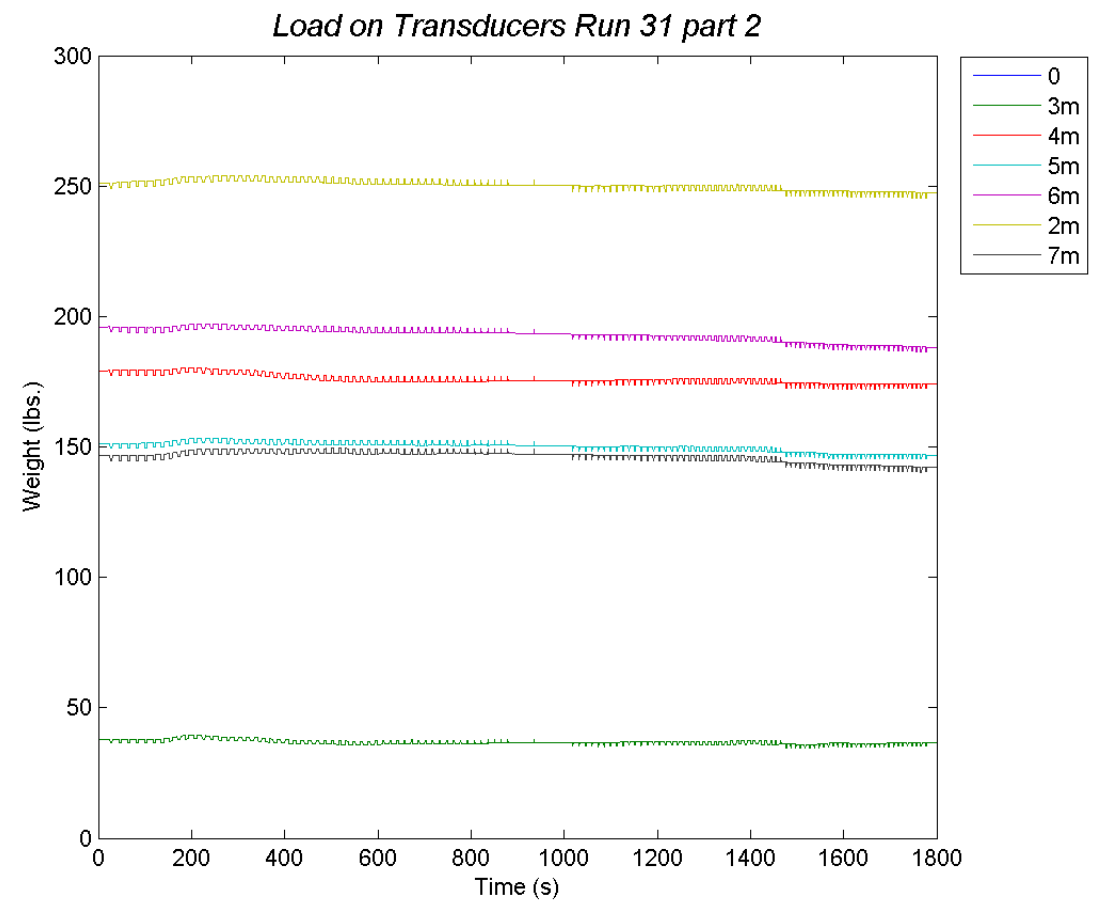

Appendix H: Comparing Run 1 and Run 2





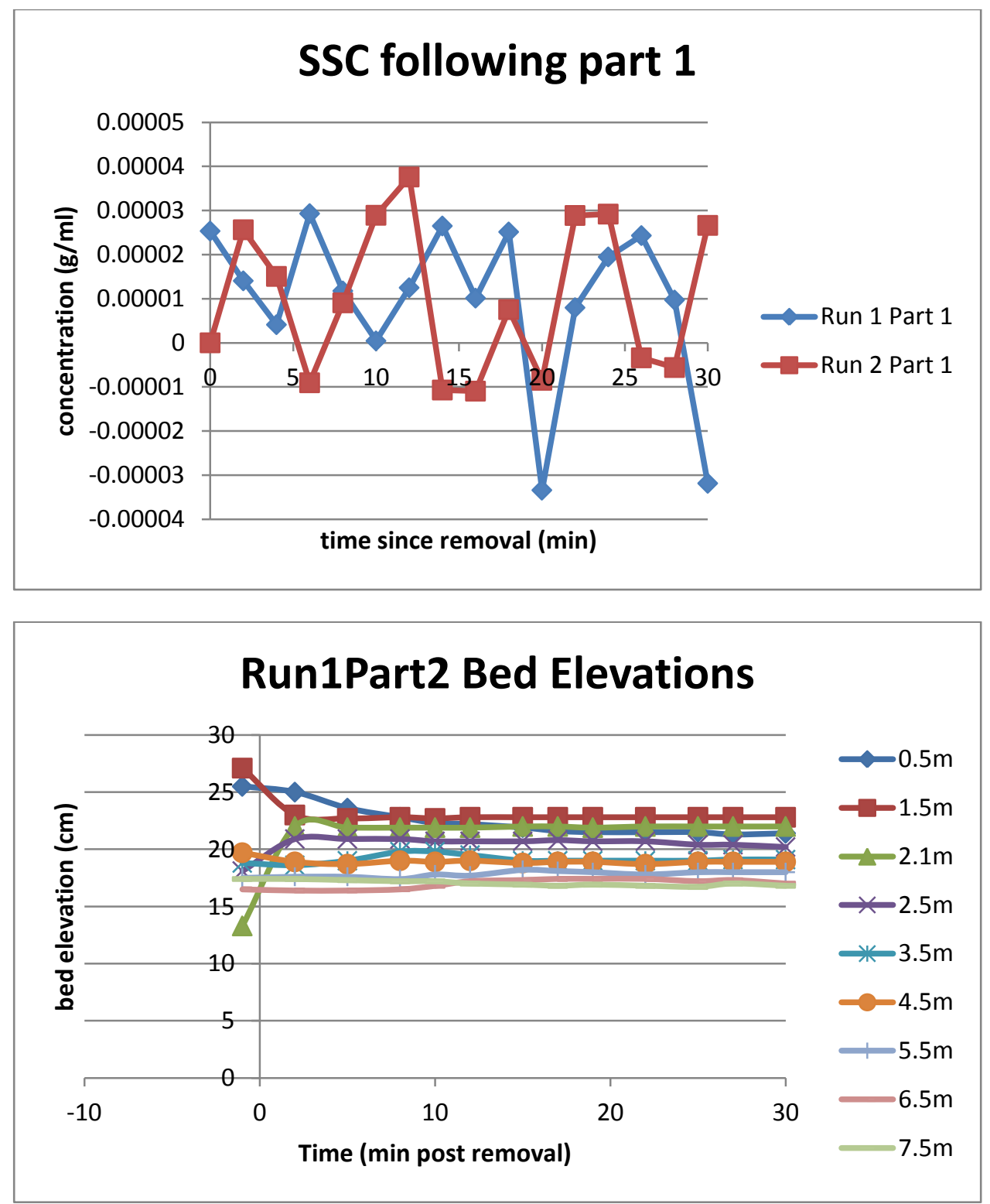


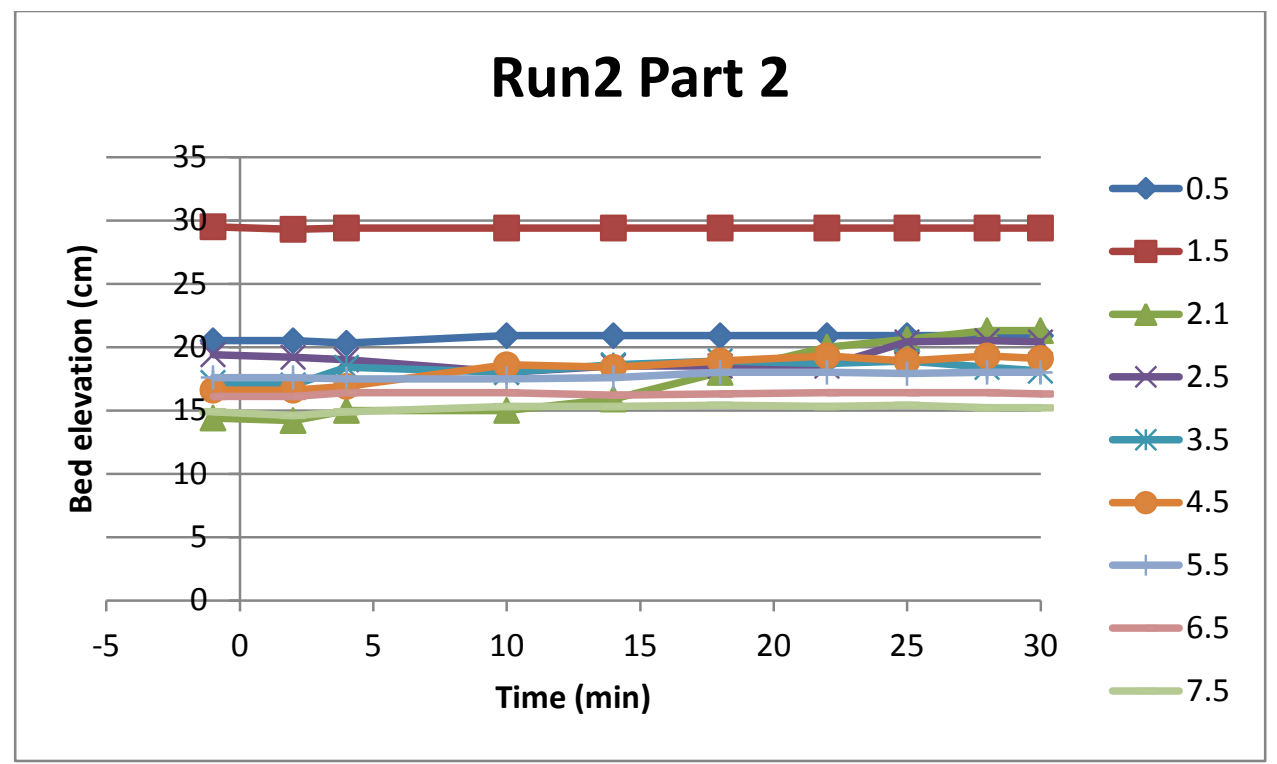

Deposition at $2.1 \mathrm{~m}$ in both Run 1 and Run 2 following the removal of Part 2.



Following the first 2 minutes, both Runs 1 and 2 had similar amounts of suspended concentration for the remainder of the run following the removal of Part 2. 

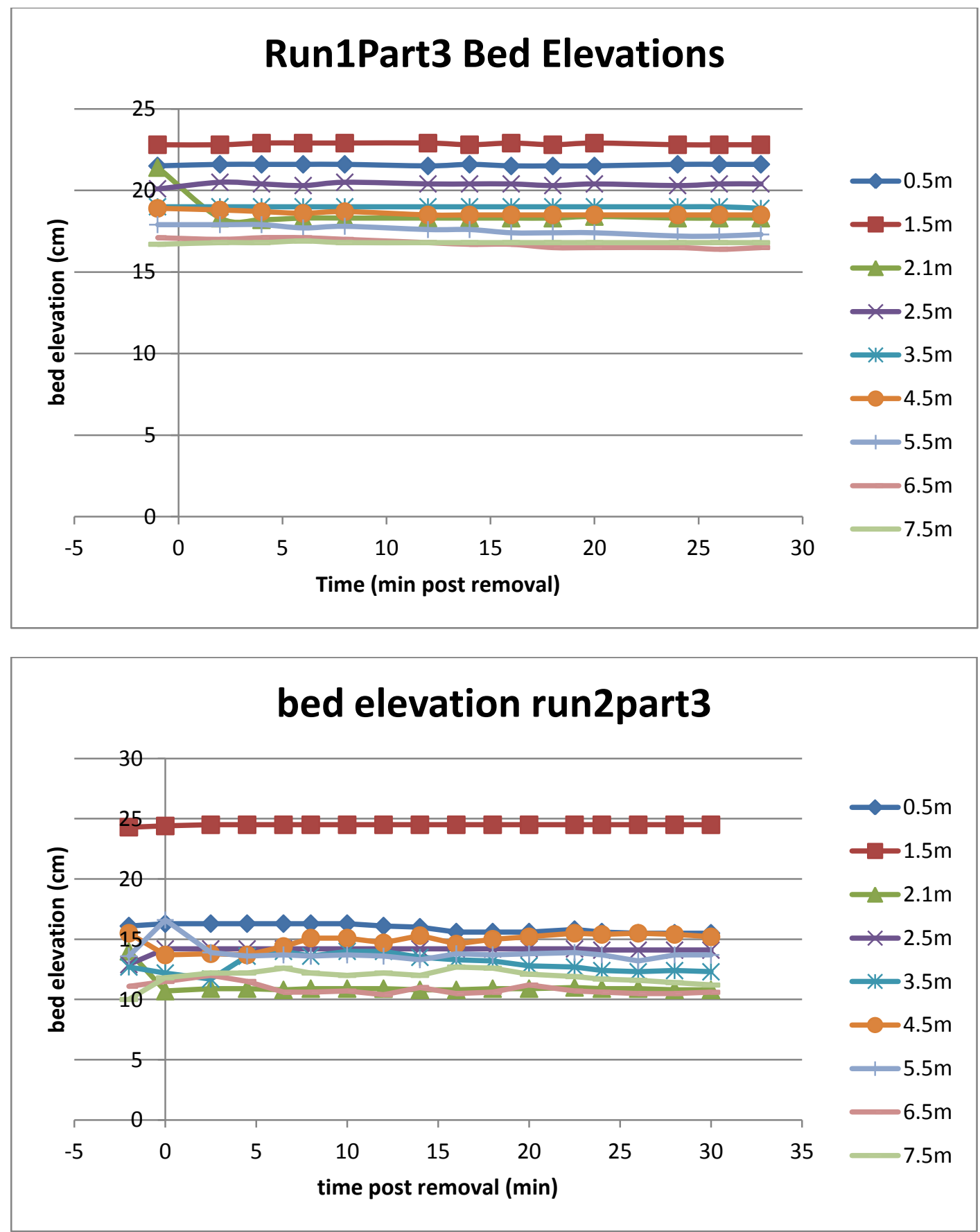

Minimal changes to the downstream bed following the removal of Part 3 in both runs. 


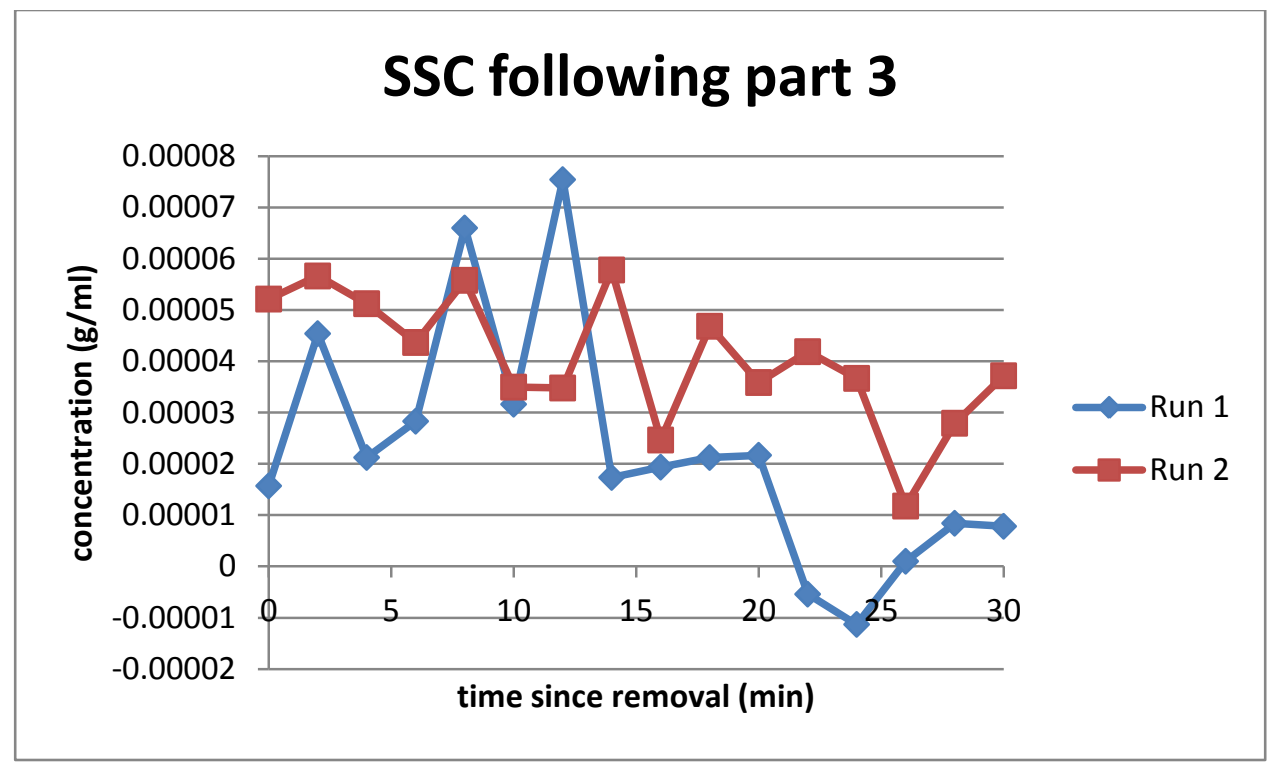

Both Runs 1 and 2 had a decreasing amount of suspended sediment concentration as the time since removal increased following the removal of Part 3.

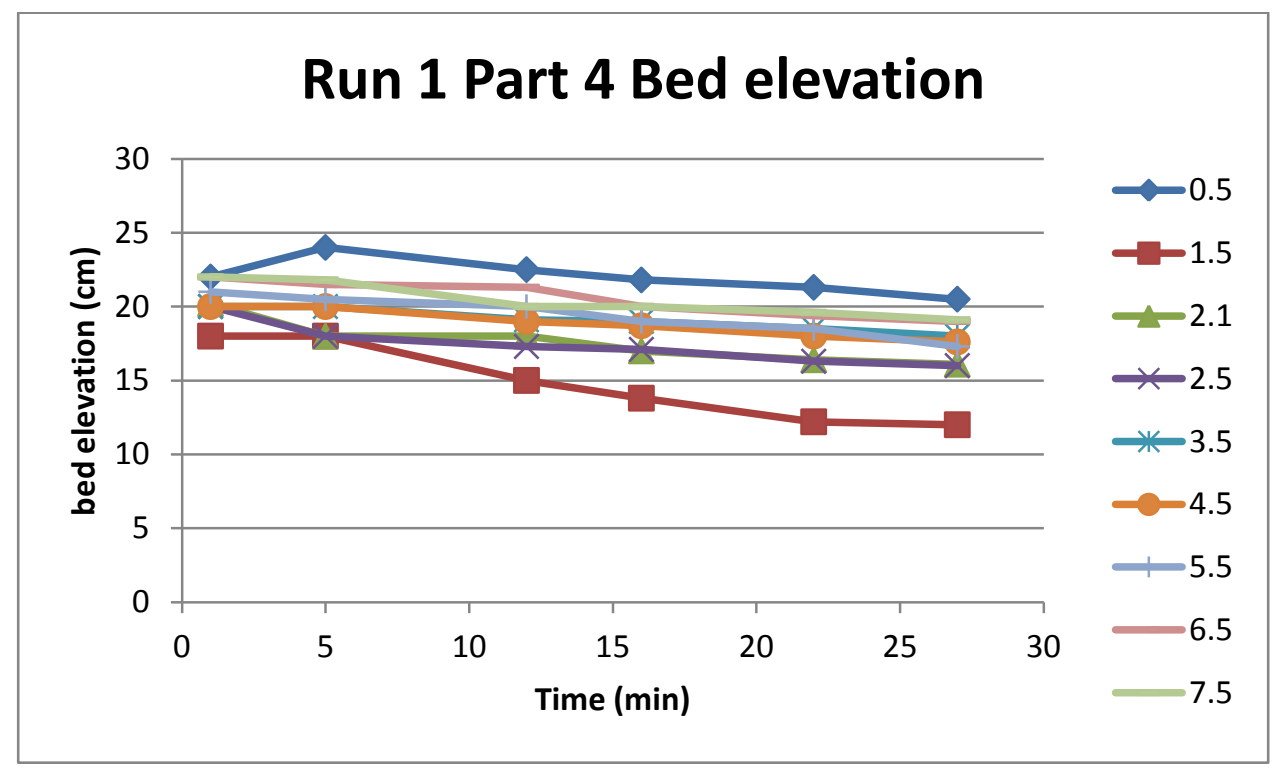



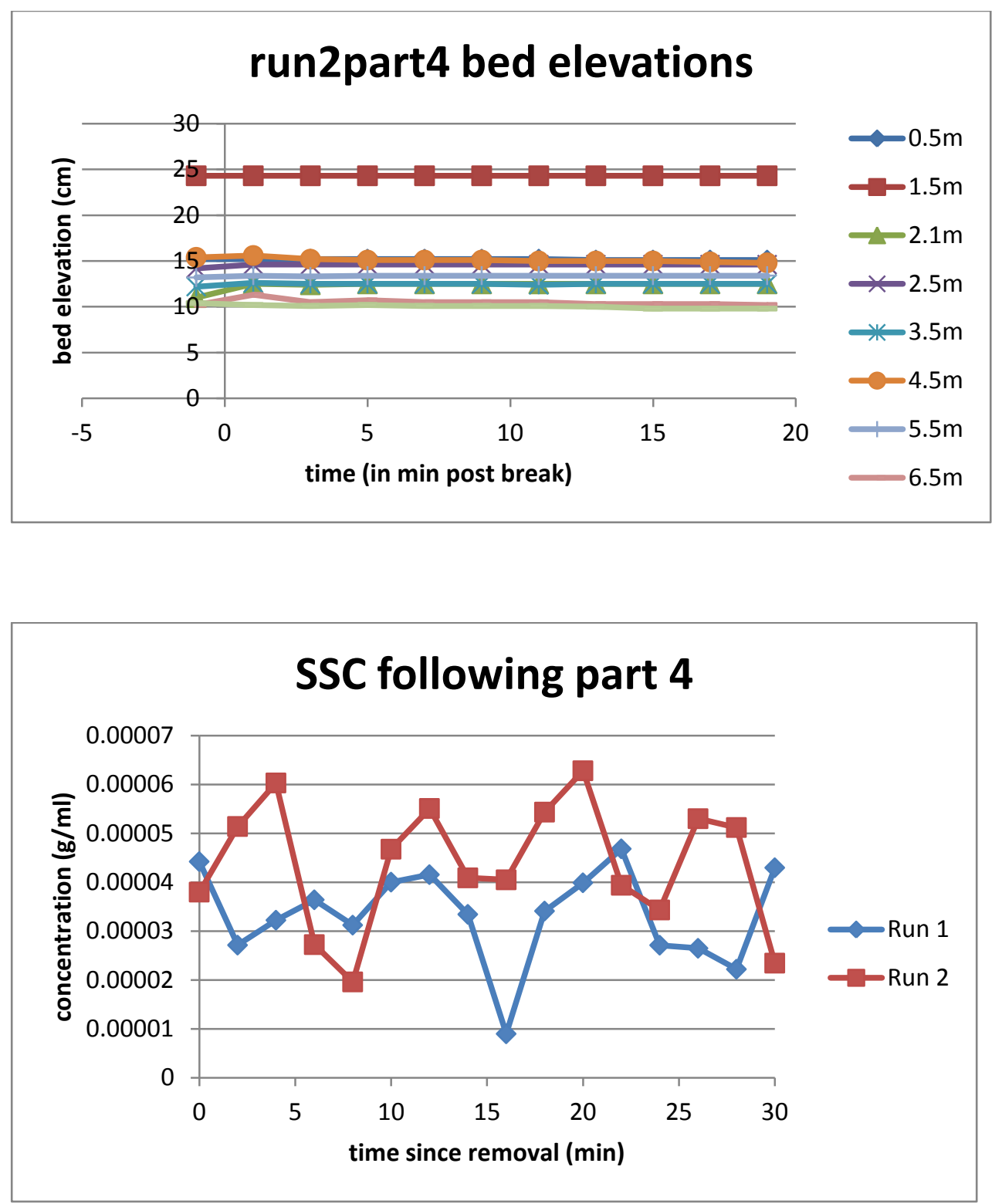


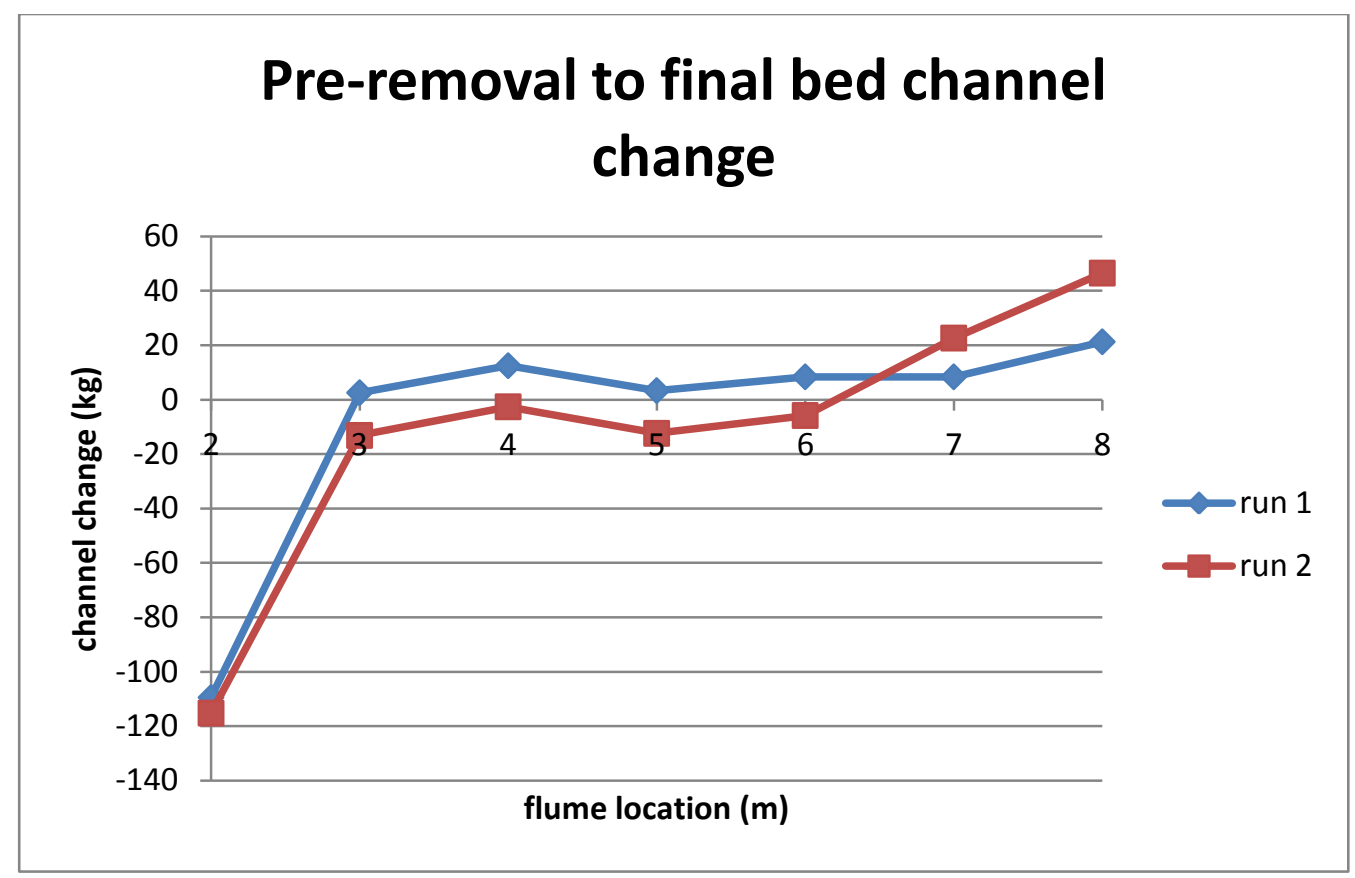

One of the most important parameters that I investigated was the change in channel bed over each run. The differencing in the rasters resulted in very similar amounts of change from the pre-removal to final beds in both Runs 1 and 2. 